Shih Yung Chin

\title{
SIMULAÇÃO DO PROCESSO DE RETIRADA DE ITENS EM CDP: UM ESTUDO DE CASO EM EMPRESA DO RAMO AUTOMOTIVO.
}

Dissertação apresentada à Escola de Engenharia de São Carlos da Universidade de São Paulo, como parte dos requisitos para obtenção do título de Mestre em Engenharia Mecânica.

Orientador: Prof. Dr. Arthur José Vieira Porto

São Carlos - SP

2005 


\section{DEDICATÓRIA}

Confia no Senhor e faze o bem; assim habitarás na terra, e te alimentarás em segurança. Deleita-te também no Senhor, e Ele te concederá o que deseja o teu coração. Entrega o teu caminho ao Senhor; confia Nele, e Ele tudo fará. (Salmos 37:3 5).

Ao Deus Triúno,

minha fonte de vida $\mathrm{e}$ esperança.

Aos meus pais, Fu e Li Chuan, minha melhor escola.

Aos irmãos, Hong e Yuan, por tudo que passamos juntos. 


\section{AGRADECIMENTOS}

Ao meu orientador, Professor Titular Arthur José Vieira Porto, pela sua confiança, amizade, dedicada orientação durante a elaboração deste trabalho.

À minha família, pelo seu apoio, carinho e esperança depositados em mim em todos os momentos.

Aos Professores da banca examinadora, Eduardo Vila Gonçalves Filho e Silvio Pires, pelas sugestões que contribuíram para a melhoria do trabalho.

Aos amigos Alessandro Silva, Luís Araújo, Elmer, Julio, Mathias e dentre outros pelas suas inestimáveis amizades em todos os momentos.

À igreja evangélica projeto raízes de São Carlos por me acolher em momentos difíceis.

Aos amigos José Hamilton, Mamoru, Ana Paula, Denise, Ricardo, Merylin, Daniel Maeda, Silmara, Beth, João Gilberto, Mariella, Ana Rita, Heleno, Heráclito, Hilano, pela grande amizade, incentivo e ajuda.

À Coordenação de Aperfeiçoamento de Pessoal de Nível Superior - CNPq, pela bolsa de estudo concedida.

À empresa, onde foi realizado o estudo, por fornecer informações que contribuíram para o desenvolvimento deste trabalho.

À todos os colegas, professores e funcionários do Departamento de Engenharia Mecânica da EESC/USP, pelas suas colaborações. 
SUMÁRIO

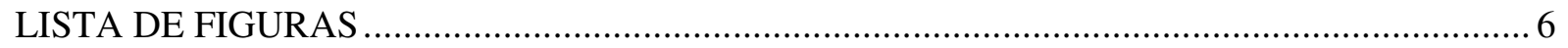

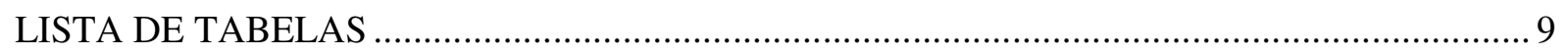

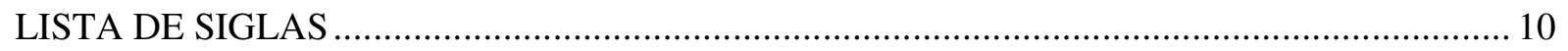

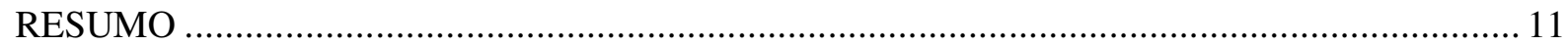

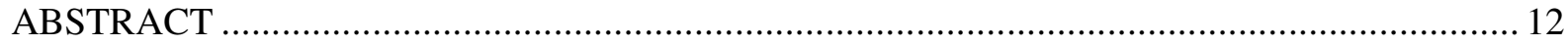

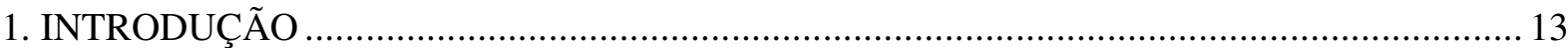

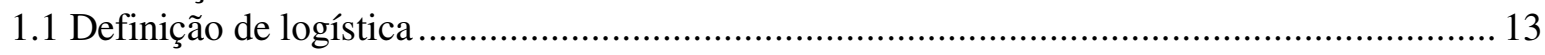

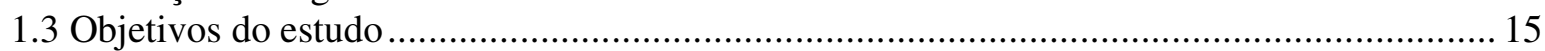

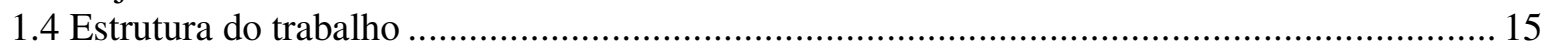

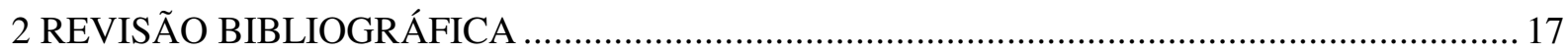

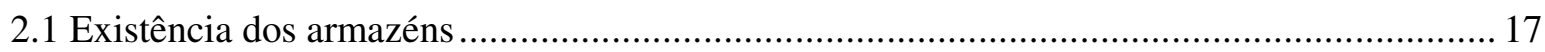

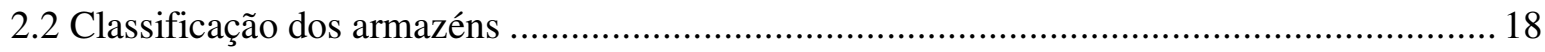

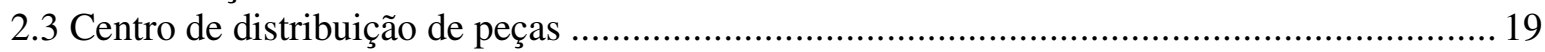

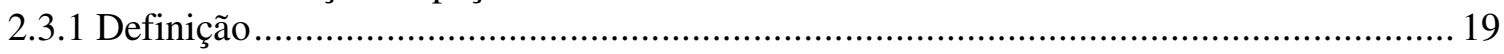

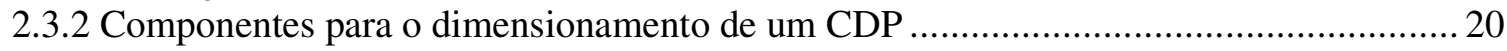

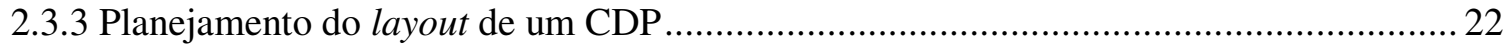

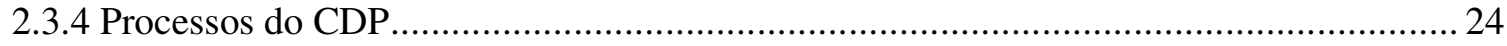

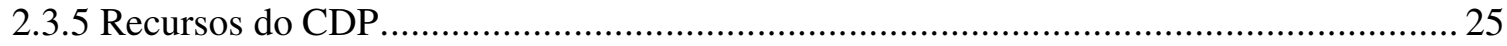

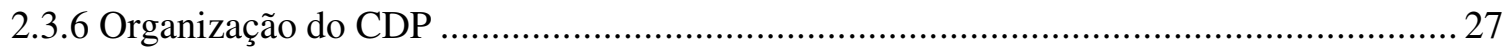

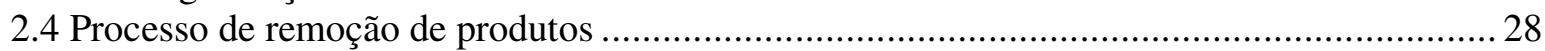

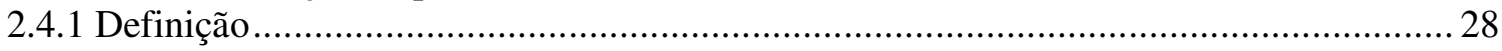

2.4.2 Impacto exercido pela competitividade no processo ............................................. 30

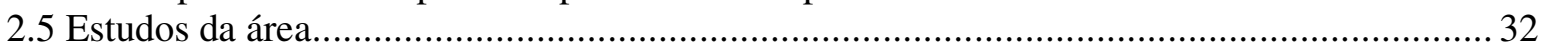

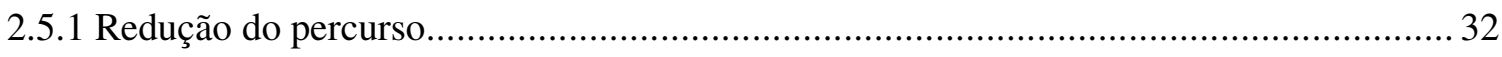

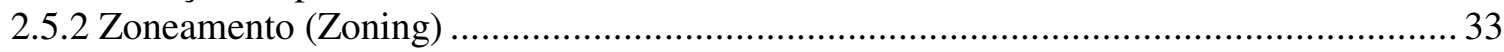

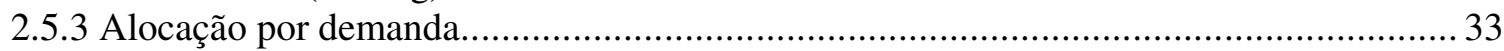

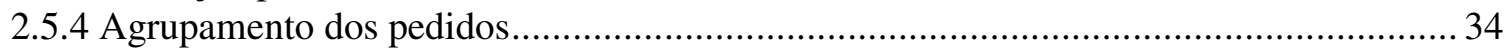

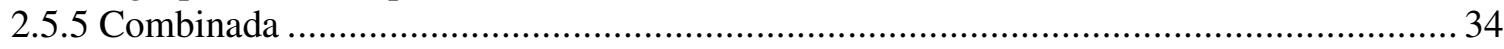

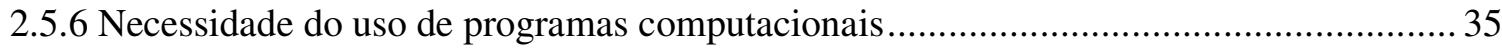

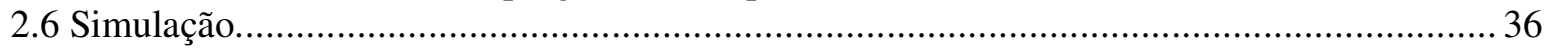

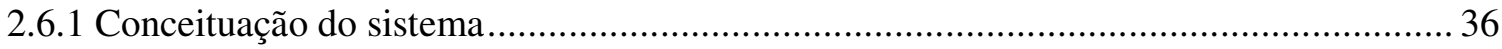

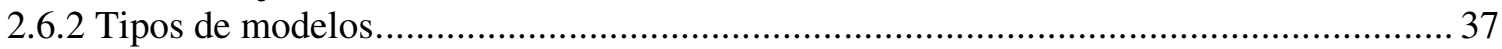

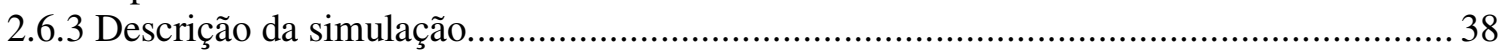

2.6.4 Descrição das etapas da simulação...................................................................... 40

2.6.5 Motivações para o uso da simulação neste trabalho.................................................. 41

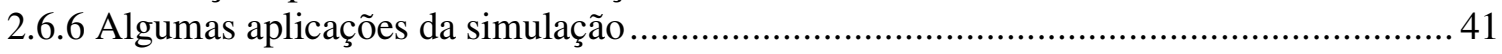

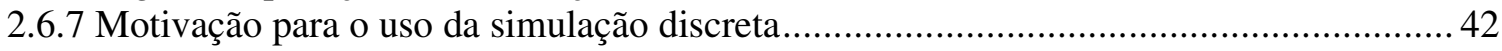

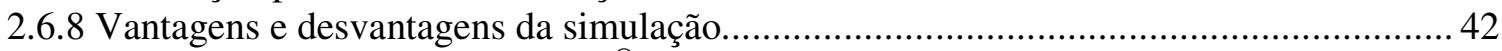

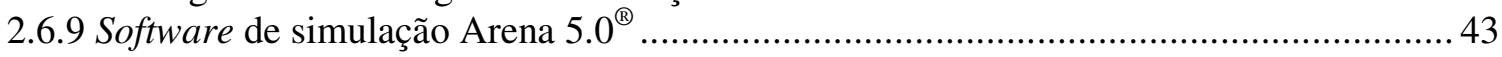

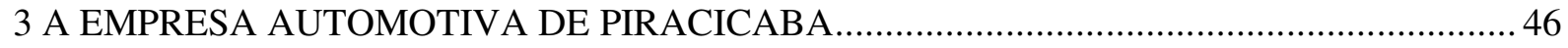

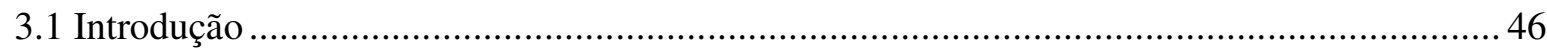

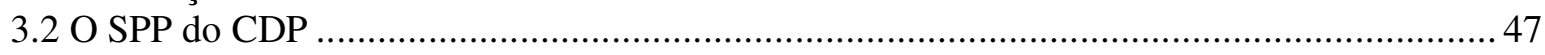

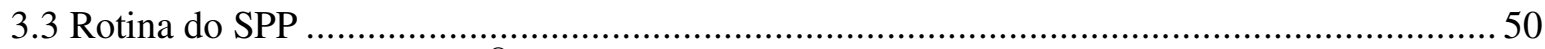

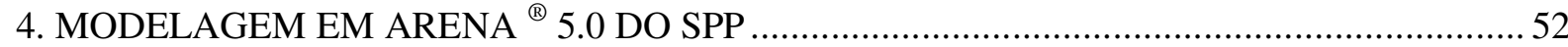

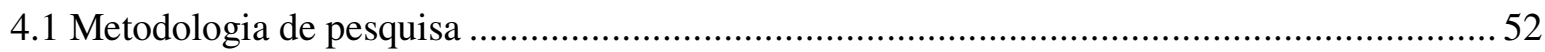

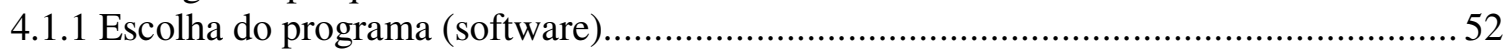

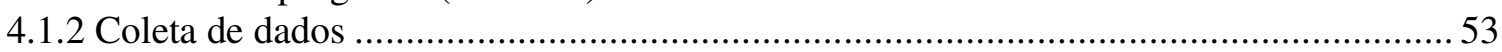

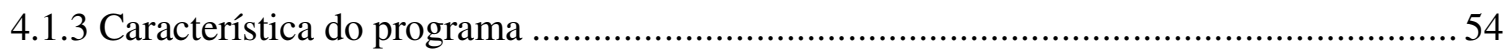

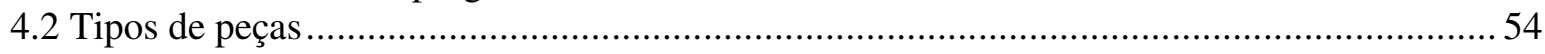

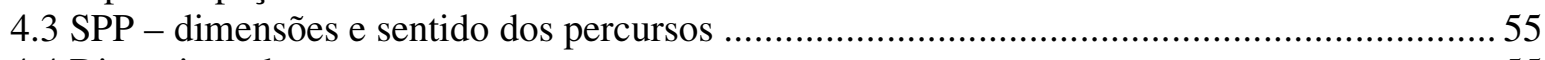

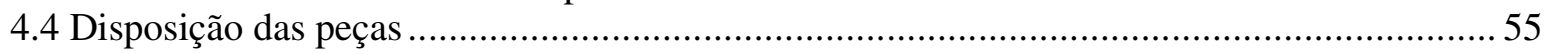


4.5 Modelagem do percurso - localização das seções dos corredores...........................................57

4.6 Modelagem do número total de itens do pedido …………...............................................5

4.7 Modelagem do número de itens do pedido por tipo $\mathrm{ABC}$.................................................5 59

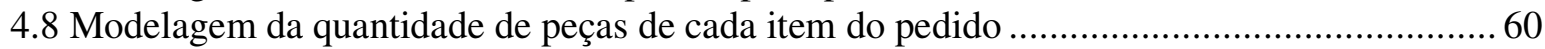

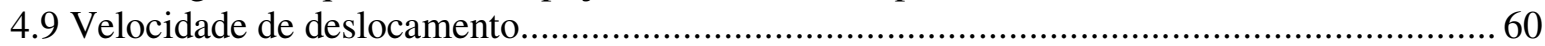

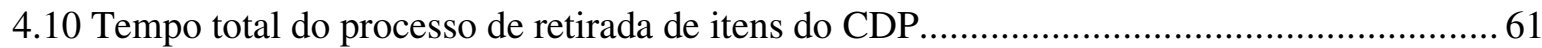

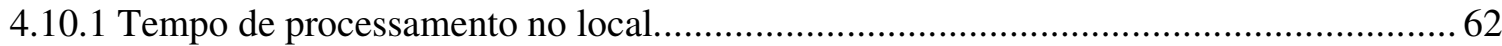

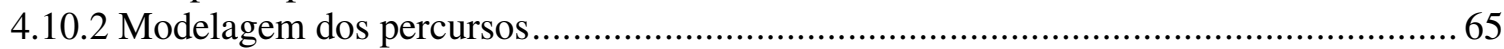

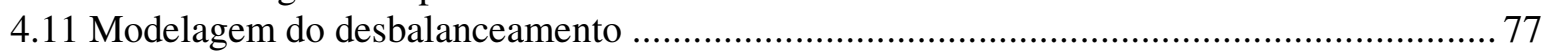

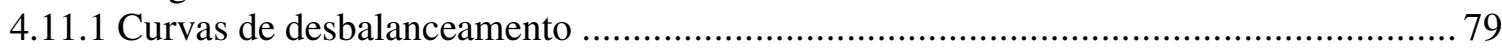

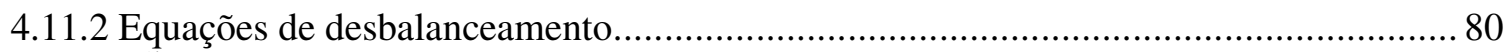

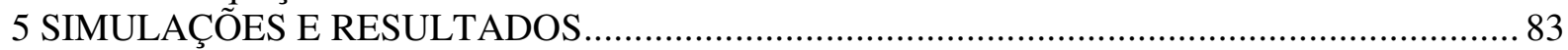

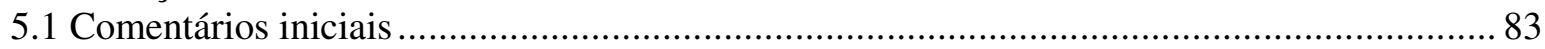

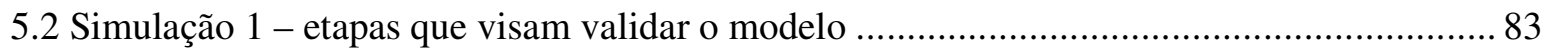

5.2.1 Simulação com 1 funcionário e todos os itens do pedido................................................. 83

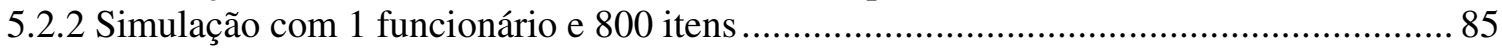

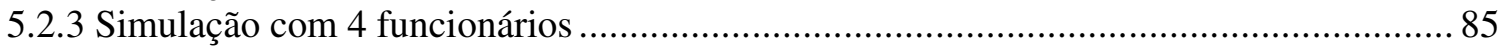

5.3 Simulação 2 - avaliação de cenários .................................................................................. 88

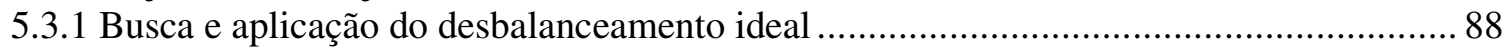

5.3.2 Simulação com 3 funcionários e desbalanceamento de 20\% …………………………..... 89

5.3.3 Simulação com alteração da velocidade de deslocamento ............................................... 90

5.3.4 Simulação alteração da carga máxima do transportador ................................................. 94

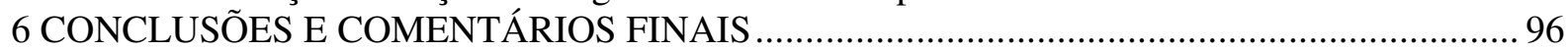

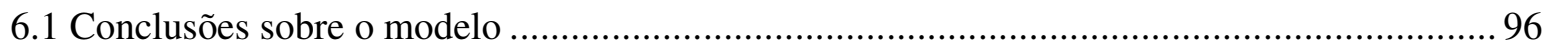

6.2 Sugestões para futuros desenvolvimentos .................................................................... 97

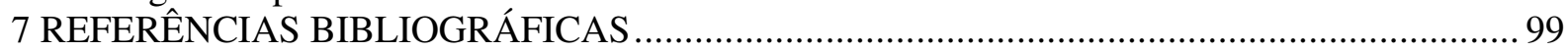

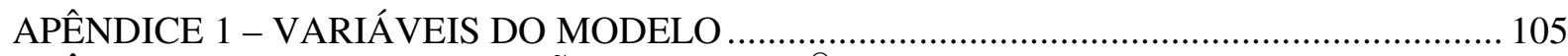

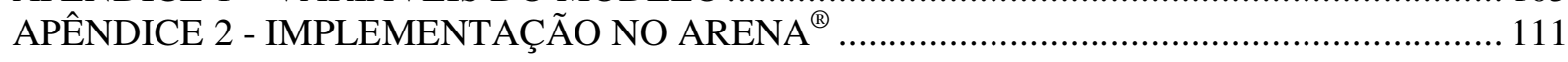

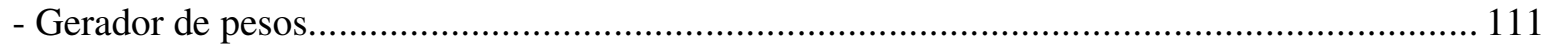

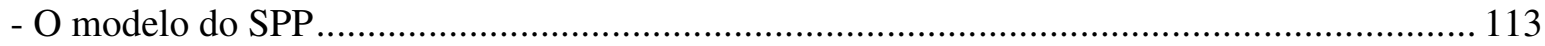

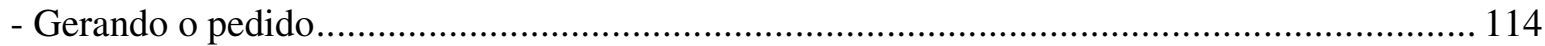

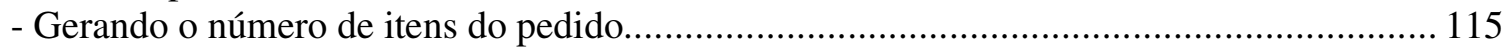

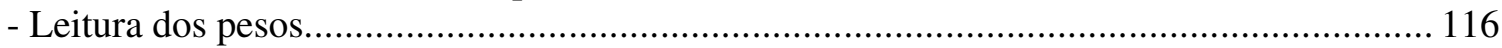

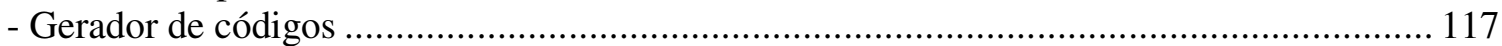

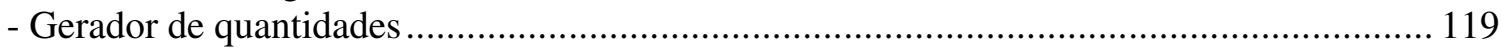

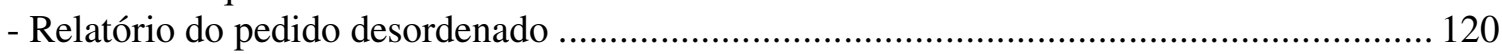

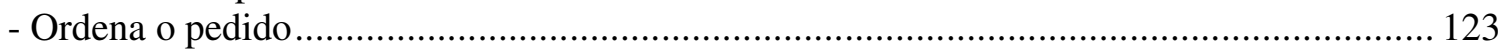

- Relatório do pedido ordenado..................................................................................... 124

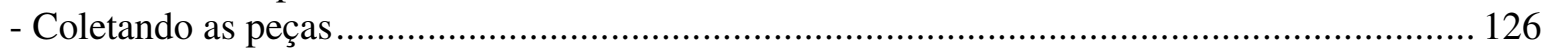

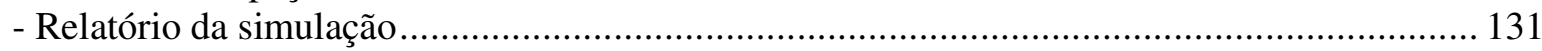

- Coletando as informações ........................................................................................ 131

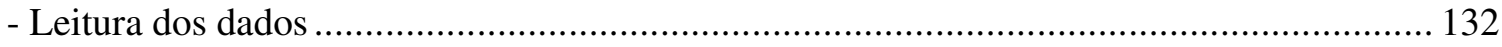

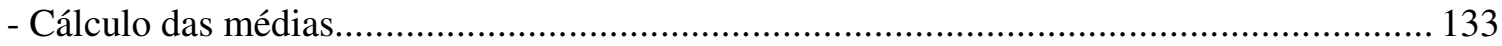

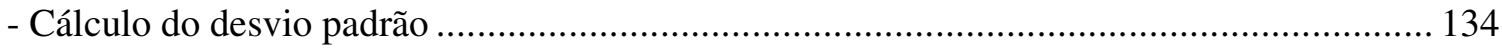

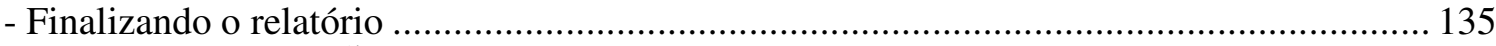

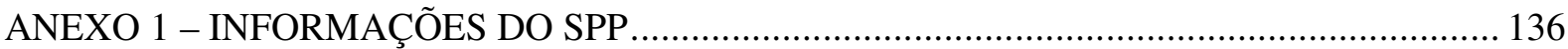

ANEXO 2 - METHODS-TIME MEASUREMENT (MTM) …………….............................. 137 


\section{LISTA DE FIGURAS}

FIGURA 01 - ILUSTRA O CDP DENTRO DO CONTEXTO LOGÍSTICO ............................. 19

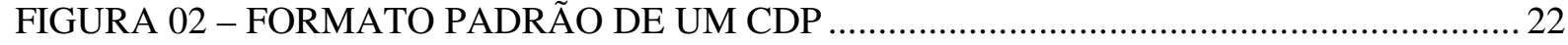
FIGURA 03 - ESQUEMA DO CDP (ADAPTADO DE ROODBERGEN \& DE KOSTER, 2001).

FIGURA 04 - SISTEMA INFLUENCIADA PELO MEIO EXTERNO …................................. 36

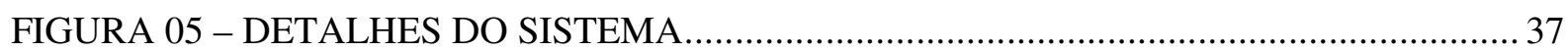

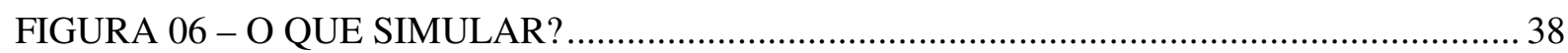

FIGURA 07 - PROPOSTA DE SISTEMATIZAÇÃO DOS ESTUDOS DE SIMULAÇÃO .......... 39

FIGURA 08 -TEMPLATE, MÓDULOS DO TEMPLATE E ÁREA DE TRABALHO NO ARENA

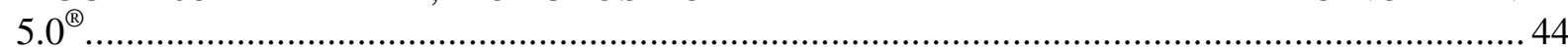

FIGURA 09 - ESQUEMA DO MODELO QUE ANALISA CURRÍCULOS (FONTE: PARAGON,

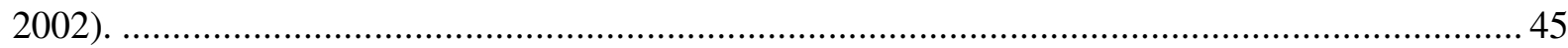

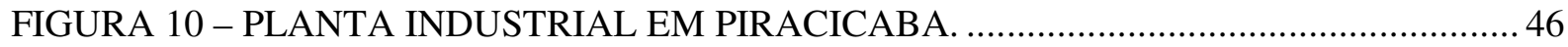

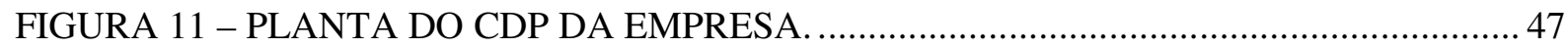

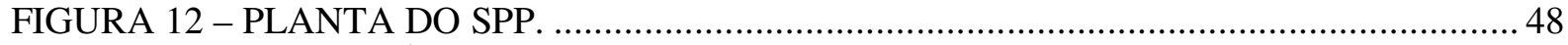

FIGURA 13 - DIMENSÕES DAS PRATELEIRAS E CORREDORES DO CDP. .................... 48

FIGURA 14 - EXEMPLO DE PRIMEIRA ETIQUETA (CAPA) .......................................... 50

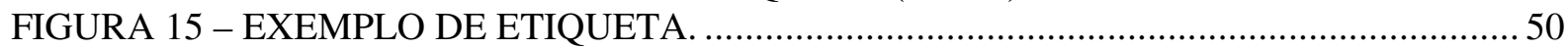

FIGURA 16 - SENTIDO DE MOVIMENTAÇÃO NOS CORREDORES................................... 55

FIGURA 17 - DEFINIÇÃO DAS DIMENSÕES DO SETOR DA PRATELEIRA E DAS

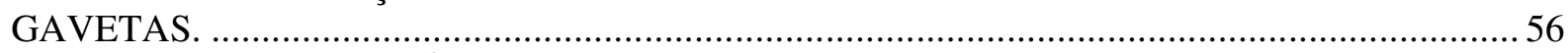

FIGURA 18 - DISPOSIÇÃO DAS PEÇAS A, B E C NO SPP. ........................................... 57

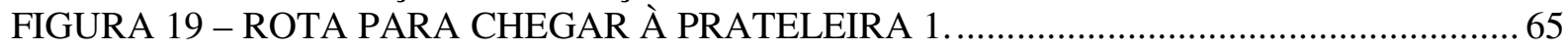

FIGURA 20 - ROTAS CHEGANDO A DIVERSAS PRATELEIRAS ..................................... 66

FIGURA 21 - LÓGICA PARA O CÁLCULO DA DISTÂNCIA ENTRE O EMPACOTAMENTO

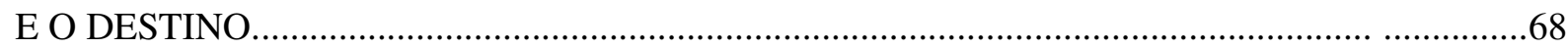

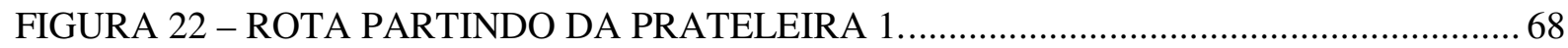

FIGURA 23 - ROTAS PARTINDO DE DIFERENTES PRATELEIRAS. ...............................69

FIGURA 24 - LÓGICA PARA O CÁLCULO DA DISTÂNCIA ENTRE UMA PRATELEIRA E

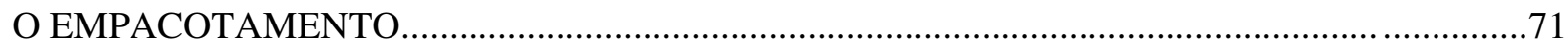

FIGURA 25 - ROTAS ENTRE DIFERENTES PRATELEIRAS. …...................................... 73

FIGURA 26 - LÓGICA PARA CÁLCULO DA DISTÂNCIA ENTRE ITENS . .......................... 77

FIGURA 27 - EQUAÇÕES PARA DESBALANCEAMENTO............................................ 79

FIGURA 28 - CÁLCULO DO ITEM FINAL DE CADA FUNCIONÁRIO_............................... 82

FIGURA 29 - RESULTADOS DA PRIMEIRA SIMULAÇÃO............................................... 84

FIGURA 30 - COMPOSIÇÃO DO TEMPO TOTAL PARA 1 FUNCIONÁRIO......................... 84

FIGURA 31 - RESULTADOS DA SEGUNDA SIMULAÇÃO.............................................. 85

FIGURA 32 - COMPOSIÇÃO DO TEMPO TOTAL PARA 1 FUNCIONÁRIO E 800 ITENS.... 85

FIGURA 33 - TEMPO TOTAL MÉDIO DE 4 FUNCIONÁRIOS COM DIVISÃO

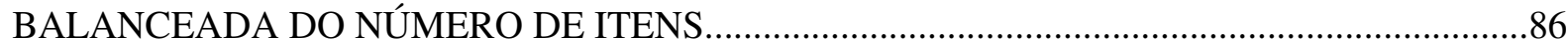

FIGURA 34 - COMPOSIÇÃO DO TEMPO TOTAL PARA 4 FUNCIONÁRIOS. ......................87

FIGURA 35 - TEMPOS TOTAIS MÉDIOS POR FUNCIONÁRIO COM DIVERSOS

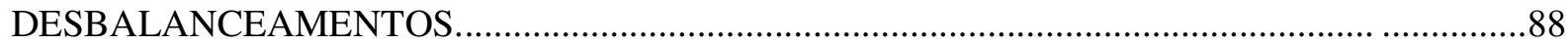

FIGURA 36 - TEMPO TOTAL MÉDIO PARA 3 FUNCIONÁRIOS......................................... 90

FIGURA 37 - COMPARAÇÃO DOS TEMPOS DOS FUNCIONÁRIOS COM ALTERAÇÃO DA

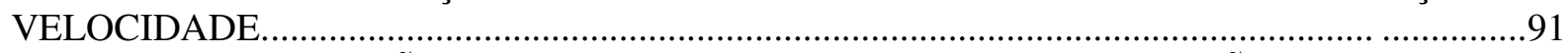

FIGURA 38 - VARIAÇÃO DO TEMPO DE DESLOCAMENTO EM FUNÇÃO DA

VELOCIDADE. 
FIGURA 39 - TEMPOS DE IDENTIFICAÇÃO DO LOCAL (DESBALANCEAMENTO DE

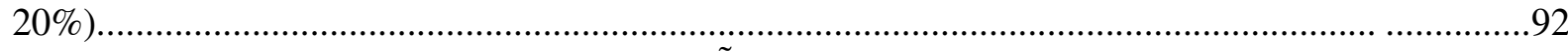
FIGURA 40 - TEMPOS DE IDENTIFICAÇÃO DO ITEM (DESBALANCEAMENTO DE

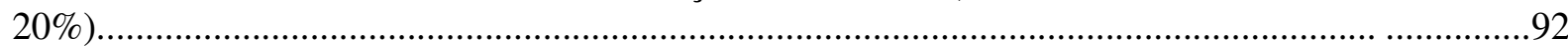
FIGURA 41 - TEMPOS DE COLETA (DESBALANCEAMENTO DE 20\%) .......................... 92 FIGURA 42 - TEMPO TOTAL MÉDIO DE 5 FUNCIONÁRIOS COM VELOCIDADE

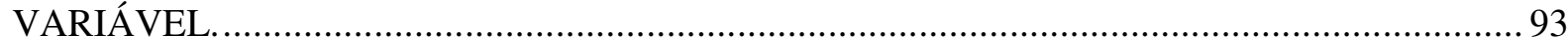
FIGURA 43 - TEMPO TOTAL MÉDIO DE 4 FUNCIONÁRIOS COM VELOCIDADE DE 1m/s.

FIGURA 44 - INFLUÊNCIA DA CARGA MÁXIMA ADMISSÍVEL NO TRANSPORTADOR.95 FIGURA 45 - MODELO GERADOR DE PESOS .......................................................... 111

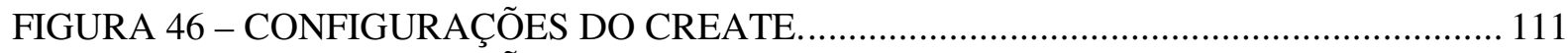

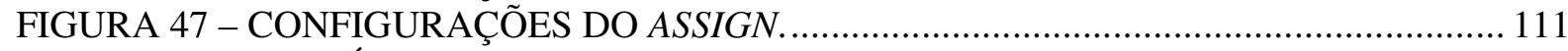

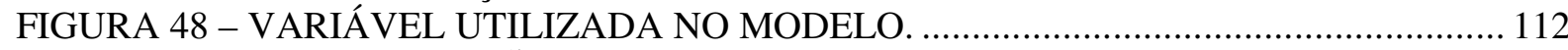

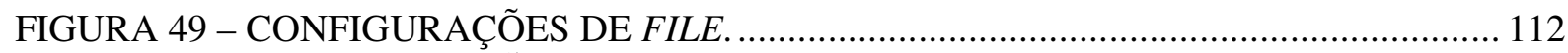

FIGURA 50 - CONFIGURAÇÕES DE READWRITE ................................................... 112

FIGURA 51 - EXEMPLO DOS PESOS GERADOS PELO MODELO PARA O ARQUIVO

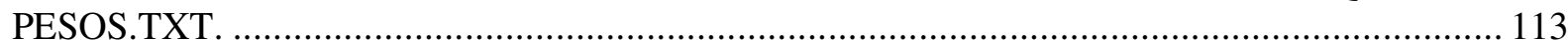

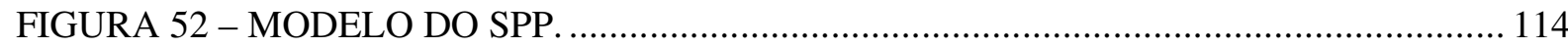

FIGURA 53 - INTERFACE VBA PARA CONFIGURAÇÃO DA SIMULAÇÃO. ................... 114

FIGURA 54 - SUBMODELO GERA AS QUANTIDADES DO PEDIDO.............................. 115

FIGURA 55 - CONFIGURAÇÃO DO DECIDE NÚMERO DE ITENS ALEATÓRIO? ............ 115 FIGURA 56 - CONFIG DO GERA QUANTIDADE DE ITENS DO PEDIDO E NÚM FIXO DE

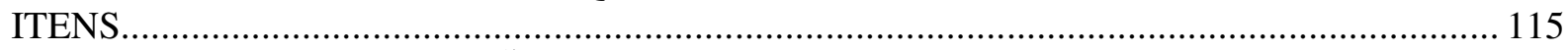

FIGURA 57 - CONFIGURAÇÃO DO DEFINE QUANTIDADE DE ITENS A, B E C. ............ 116

FIGURA 58 - SUBMODELO LEITURA DOS PESOS . ................................................... 116

FIGURA 59 - CONFIGURAÇÃO DO BLOCO READWRITE E DO BLOCO FILE................ 116

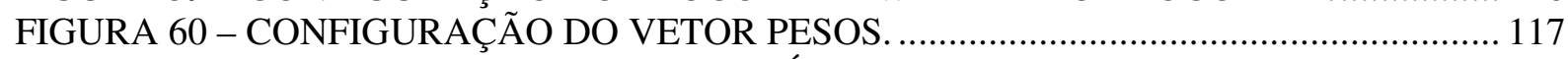

FIGURA 61 - SUBMODELO GERADOR DE CÓDIGOS.................................................. 117

FIGURA 62 - CONFIGURAÇÕES DO ASSIGN - INICIALIZA VARIÁVEIS........................... 118

FIGURA 63 - CONFIGURAÇÕES DO ASSIGN - INICIALIZA VARIÁVEIS.......................... 118

FIGURA 64 - CONFIGURAÇÃO DOS ASSIGN'S PARA CADA ETAPA................................ 118

FIGURA 65 - CONFIGURAÇÃO DO ASSIGN - GERA CÓDIGO. ........................................ 119

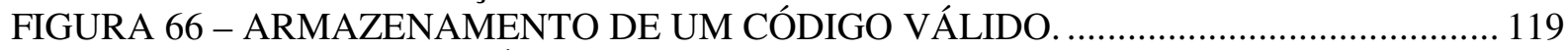

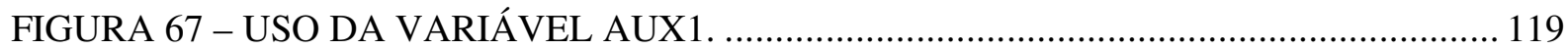

FIGURA 68 - SUBMODELO GERADOR DE QUANTIDADES. ......................................... 120

FIGURA 69 - CONFIGURAÇÃO DO ASSIGN - PEGA O PESO. ........................................ 120

FIGURA 70 - CONFIGURAÇÃO DO VETOR PEDIDO. ..................................................... 120

FIGURA 71 - SUBMODELO RELATÓRIO DO PEDIDO DESORDENADO. ........................ 121

FIGURA 72 - CONFIGURAÇÃO DO ASSIGN - RECEBE REPLICAÇÃO............................ 121

FIGURA 73 - CONFIGURAÇÃO DO READWRITE - IMPRIME CABEÇALHO................... 122

FIGURA 74 - EXEMPLO DO RELATÓRIO DE PEDIDO DESORDENADO. ........................ 122

FIGURA 75 - CONFIGURAÇÃO DO READWRITE - IMPRIME DADOS ........................... 123

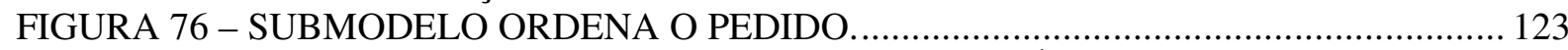

FIGURA 77 - CONFIGURAÇÃO DO ASSIGN - INICIA VARIÁVEIS. .................................. 124

FIGURA 78 - CONFIGURAÇÃO DO ASSIGN - PEGA VALORES DO VETOR..................... 124

FIGURA 79 - CONFIGURAÇÃO DO DECIDE - ORDEM ERRADA? .................................. 124

FIGURA 80 - CONFIGURAÇÃO DO ASSIGN - TROCA..................................................... 124

FIGURA 81 - SUBMODELO RELATÓRIO DO PEDIDO ORDENADO ............................... 125

FIGURA 82 - EXEMPLO DO RELATÓRIO DE PEDIDO ORDENADO. ................................ 126

FIGURA 83 - CONFIGURAÇÃO DO READWRITE - IMPRIME DADOS............................ 126

FIGURA 84 - CONFIGURAÇÃO DO ASSIGN - ZERA O CONTADOR ............................... 126 
FIGURA 85 - SUBMODELO COLETA DAS PEÇAS........................................................ 127

FIGURA 86 - CONFIGURAÇÃO DO ASSIGN - ITENS POR FUNCIONÁRIO

BALANCEADOS.

FIGURA 87 - CONFIGURAÇÃO DO ASSIGN - ITENS POR FUNCIONÁRIO

DESBALANCEADOS.

FIGURA 88 - SUBMODELO TEMPO PARA DESLOCAR.

129

FIGURA 89 - SUBMODELO TEMPO PARA DESLOCAMENTO ........................................ 129

FIGURA 90 - SUBMODELO ESPAÇO DO EMPACOTAMENTO ....................................... 129

FIGURA 91 - CONFIGURAÇÃO DOS BLOCOS ASSIGN DO SUBMODELO ESPAÇO DO

EMPACOTAMENTO.

130

FIGURA 92 - SUBMODELO ESPAÇO DO ITEM ANTERIOR. ......................................... 130

FIGURA 93 - CONFIGURAÇÃO DO ASSIGN - CALCULA Perini e PerFin. ........................... 130

FIGURA 94 - CONFIGURAÇÃO DOS $A S S I G N ' S$ PARA PRATELEIRA PAR E IMPAR........ 131

FIGURA 95 - SUBMODELO RELATÓRIO DA SIMULAÇÃO. ....................................... 131

FIGURA 96 - EXEMPLO DO RELATÓRIO FINAL ........................................................ 132

FIGURA 97 - SUBMODELO ESTATÍSTICAS. .............................................................. 132

FIGURA 98 - SUBMODELO CÁLCULO DAS ESTATÍSTICAS. ....................................... 132

FIGURA 99 - SUBMODELO LEITURA DOS DADOS. .................................................... 132

FIGURA 100 - CONFIGURAÇÃO DO DECIDE - TODAS AS ESTATÍSTICAS?.................. 133

FIGURA 101 - SUBMODELO CÁLCULO DAS MÉDIAS................................................... 134

FIGURA 102 - CONFIGURAÇÃO DO ASSIGN - CALCULA A MÉDIA. ............................ 134

FIGURA 103 - SUBMODELO DESVIO PADRÃO........................................................... 134

FIGURA 104 - CONFIGURAÇÃO DO ASSIGN - DA MATRIZ PARA VARIÁVEL E

SOMATÓRIO.............................................................................................................. 134

FIGURA 105 - CONFIGURAÇÃO DO ASSIGN - CALCULA O DESVIO PADRÃO.............. 135

FIGURA 106 - SUBMODELO RELATÓRIO DA ESTATÍSTICA........................................... 135

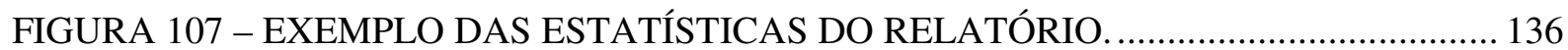




\section{LISTA DE TABELAS}

TABELA 01 - DESCREVE AS PARTES DE “O QUE ENVOLVE PARA SIMULAR?” ............ 39 TABELA 02 - DISTRIBUIÇÃO DOS ITENS NA CLASSIFICAÇÃO POR FREQÜÊNCIA DE VENDA.

TABELA 03 - DISTRIBUIÇÃO DOS ITENS POR PEDIDO. ................................................. 49

TABELA 04 - NÚMERO DE ITENS REAIS DA PRATELEIRA DOS TIPOS A, B E C............54

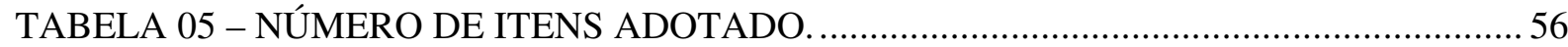

TABELA 06 - NÚMERO DE ITENS ABC DE UM PEDIDO.................................................. 58

TABELA 07 - DIVISÃO PERCENTUAL DO PEDIDO (APROXIMAÇÕES PARA A

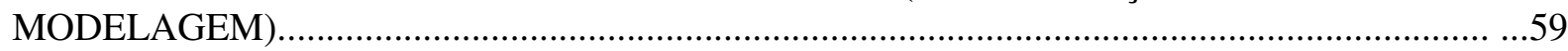

TABELA 08 - DISTRIBUIÇÃO DA QUANTIDADE DE PEÇAS EM FUNÇÃO DE SUAS

MASSAS.

TABELA 09 - RELAÇÃO DAS MASSAS COM SEUS RESPECTIVOS FATORES (FONTE:

ADAPTADO DE MAYNARD, 1970).

TABELA 10 - DISTÂNCIAS DO EMPACOTAMENTO PARA CADA PRATELEIRA...............66

TABELA 11 - RELAÇÃO DAS DISTÂNCIAS COM OS PRIMEIROS 4 VALORES, QUE SÃO

2,$0 ; 9,0 ; 38,5$ E 21,5 .

TABELA 12 - DISTÂNCIAS, EM METROS, DE CADA PRATELEIRA ATÉ O

EMPACOTAMENTO...

TABELA 13 - RELAÇÃO DAS DISTÂNCIAS COM OS PRIMEIROS 4 VALORES QUE SÃO

21,$5 ; 4,5 ; 24,0$ E 41,0 .

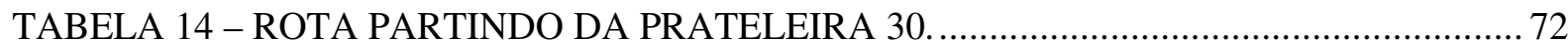

TABELA 15 - ROTAS PARTINDO DA PRATELEIRA 29 ….......................................... 72

TABELA 16 - ROTA PARTINDO DA PRATELEIRA 28 …................................................ 72

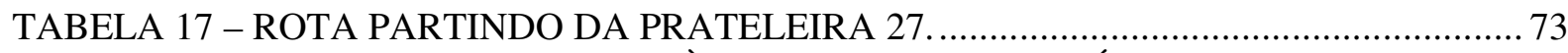

TABELA 18a - ROTAS COM DESTINO ÀS PRATELEIRAS 1 ATÉ $10 . \ldots \ldots \ldots \ldots \ldots \ldots \ldots \ldots \ldots \ldots . . . . . . . . . . . . . . . . . . . .74$

TABELA 18b - ROTAS COM DESTINO ÀS PRATELEIRAS 11 ATÉ 20............................. 75

TABELA 18c - ROTAS COM DESTINO ÀS PRATELEIRAS 21 ATÉ 30............................... 76

TABELA 19 - EXEMPLO DE DESBALANCEAMENTO DO NÚMERO DE ITENS DA LC....78

TABELA 20 - EQUAÇÕES DE DESBALANCEAMENTO. .................................................... 80

TABELA 21 - EXEMPLO DE ITENS ACUMULADOS POR 5 FUNCIONÁRIOS. ...................81

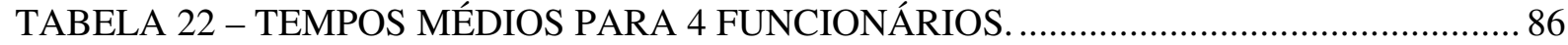

TABELA 23 - NÚMEROS DE TRANSPORTADORES UTILIZADOS .................................. 94

TABELA 24 - DADOS PROCESSADOS PARA O CÁLCULO DAS ESTATÍSTICAS............ 133

TABELA 25 - DADOS DO TEMPO DE “ALCANÇAR” (FONTE: MAYNARD, 1970)........... 137

TABELA 26 - DADOS DO TEMPO DE “MOVER” (FONTE: MAYNARD, 1970)................. 137

TABELA 27 - DADOS DO TEMPO DE “GIRAR E APLICAR PRESSÃO” (FONTE:

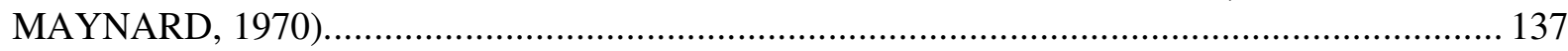

TABELA 28 - DADOS DO TEMPO DE “AGARRAR” (FONTE: MAYNARD, 1970)............ 138

TABELA 29 - DADOS DO TEMPO DE "POSICIONAR” (FONTE: MAYNARD, 1970)......... 138

TABELA 30 - DADOS PARA O CÁLCULO DO TEMPO DE “SOLTAR” (FONTE:

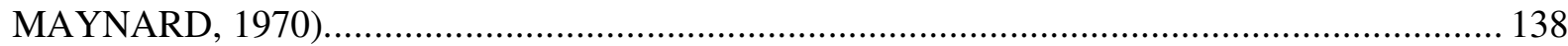

TABELA 31 - DADOS PARA O CÁLCULO DO TEMPO DE “DESENGATAR” (FONTE:

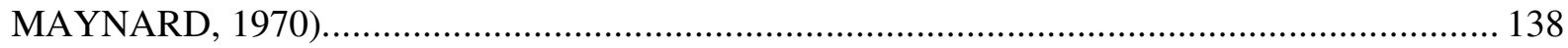

TABELA 32 - TEMPO PARA MOVER E FOCALIZAR OS OLHOS (FONTE: MAYNARD, 1970). 


\section{LISTA DE SIGLAS}

CDP - Centro de Distribuição de Peças

CPO - Cube per Order Index

F - Funcionário Atual

LC - Lista de Coleta

$\mathrm{N}$ - Número de Itens Anterior

NF - Número de Funcionários

NIP - Número de Itens do Pedido

PD - Percentual de Desbalanceamento

PerFin - Percurso Final

Perlni - Percurso Inicial

SPP - Setor de Peças Pequenas

TMU - Time Measurement Unity

USP - Universidade de São Paulo 


\section{RESUMO}

SHIH, Y. C. (2005). Simulação do processo de retirada de itens em CDP: um estudo de caso em empresa do ramo automotivo. São Carlos, 2005. Dissertação (Mestrado) Escola de Engenharia de São Carlos, Universidade de São Paulo.

Este trabalho cria um modelo, em simulação a eventos discretos, utilizando o software ARENA $5.0^{\circledR}$, do Centro de Distribuição de Peças de uma empresa do ramo automotivo, para geração de informações relacionadas ao deslocamento dos funcionários nos corredores. Existem diversas variáveis que estão diretamente relacionadas à movimentação no processo de retirada de itens, tais como capacidade e velocidade do transportador manual, influência do peso dos itens na coleta, dentre outras, que dificultam o processo de tomada de decisão. As técnicas propostas na bibliografia apresentam dificuldades em fornecer soluções já que não são capazes de trabalhar simultaneamente com estas variáveis, apresentando, assim, resultados discrepantes com a realidade. A simulação permite lidar com tais variáveis e fornecer resultados que servirão de suporte aos Decisores para a tomada de decisão e assim gerenciar melhor os funcionários para completar a coleta de itens dos pedidos sem atrasos.

Palavras-chave: processo de retirada de itens, modelagem em simulação discreta e gerenciamento. 


\section{ABSTRACT}

SHIH, Y. C. (2005). Simulation of items retrieving process in PDC: a case study in automotive company. Dissertação. São Carlos, 2005 (Mestrado) - Escola de Engenharia de São Carlos, Universidade de São Paulo.

This work builds a model, by the discrete event simulation, using the software ARENA $5.0^{\circledR}$, of a Parts Distribution Centre of an automotive company, to generate information related to employees routing in aisles. There are several variables related to the movement in the retrieving process, such as capacity and velocity of the manual trolley, influence of the mass of items in the collecting process, among others, which make the decision process difficult. The techniques found in the literature demonstrate certain difficulties in providing solutions because they are not capable of dealing with those variables simultaneously, presenting, consequently, discrepancy results to the reality. The simulation permits to deal with those variables simultaneously and proving results to support managers in decisions and, therefore, to improve employees management in order to finalize the collecting of items without delay.

Key-words: retrieving process, discrete simulation modeling, management. 


\section{INTRODUÇÃO}

\subsection{Definição de logística}

Ao longo da história da civilização humana, as pessoas buscam, por meio de guerras, expandir seus territórios, satisfazer seus interesses econômicos, dentre outros. As guerras têm impulsionado as pessoas a estudarem a melhor forma de suprir armas às tropas, caso contrário haveria grande possibilidade de serem destruídas pelas forças do oponente. Trata-se de uma ciência que visa estudar e propor alternativas que tornassem viáveis a disponibilidade de armas em diversos lugares a custo e tempo reduzidos. Esta ciência foi denominada logística.

A logística, pela definição de Ferreira (1988), é parte da arte da guerra que trata do planejamento da realização de:

- Projeto e desenvolvimento, obtenção, armazenamento, transporte, distribuição, reparação, manutenção e evacuação de material (para fins operativos ou administrativos);

- Recrutamento, incorporação, instrução e adestramento, designação, transporte, bem-estar, evacuação, hospitalização e desligamento de pessoal;

- Aquisição ou construção, reparação, manutenção e operação de instalações e acessórios destinados a ajudar o desempenho de qualquer função militar;

- Contrato ou prestação de serviços.

Magee (1977) comenta que a palavra logística é de origem francesa. Era um termo militar que significava a arte de transportar, abastecer e alojar as tropas. Tomou, depois, um significado mais amplo, tanto para uso militar como industrial: a arte de administrar o fluxo de materiais e produtos, da fonte para o cliente.

Segundo Sturion (2000), a logística tem sua origem nas forças armadas, e se relaciona com a aquisição e fornecimento de todos os produtos e materiais necessários para cumprir uma missão. Está agora sendo utilizada por empresas para satisfazer as necessidades de um grande número de clientes amplamente dispersos, tanto dentro das fronteiras nacionais quanto em ambientes internacionais.

Conforme o Conselho de Administração Logística (CLM - Council of Logistics Management), que é uma organização profissional de gestores de logística, professores e práticos, formada em 1962, a logística no mundo empresarial consiste em dispor a mercadoria (produto) ou o serviço certo, no lugar certo, no tempo certo e nas condições desejadas.

As atividades logísticas em um contexto empresarial incluem transporte, manutenção dos inventários, processamento de pedidos, armazenamento e manuseio de 
materiais. Estas atividades fornecem uma ponte entre os produtores de mercadorias e os mercados consumidores, os quais estão separados pela distância. Portanto, todos devem se interagir para que as atividades logísticas ocorram (LIU, 1999).

Magee (1977) descreve as atividades da logística com mais detalhes. Para este autor, estas atividades são designadas por:

a) Distribuição - refere-se à combinação de atividades e instituições ligadas à propaganda, venda e transferência física de produtos ou serviços;

b) Logística - refere-se à arte de administrar o fluxo de materiais e produtos, da fonte ao usuário. O sistema logístico inclui o fluxo de materiais desde a aquisição da matéria-prima até a entrega dos produtos acabados aos usuários finais;

c) Distribuição física - refere-se à parte de um sistema logístico que diz respeito à movimentação externa dos produtos, do vendedor ao cliente ou consumidor;

d) Suprimento físico - refere-se à parte de um sistema logístico no tocante à movimentação interna de materiais ou produtos, das fontes ao comprador;

e) Planejamento e controle da produção - diz respeito ao fluxo de materiais, desde o recebimento da matéria-prima, passando pelas etapas de fabricação e processamento, até o estoque de produtos acabados.

\subsection{0 reflexo da competitividade em logística}

Em um mercado globalizado, onde as empresas competem pelo preço, pela qualidade e confiabilidade de seus produtos e serviços, dentre outros, os empresários têm se preocupado bastante em estudar formas para ganhar vantagens sobre os seus concorrentes e para conquistar novos clientes ou mesmo para manter os já existentes. Enfim, são questões vitais que devem ser respondidas por estes empresários para manterem as suas empresas vivas neste mercado competitivo.

Ultimamente, as empresas estão encontrando clientes extremamente exigentes, e para atendê-los melhor, muitas delas estão passando por transformações para que possam ser competitivas (FAWCETT \& COOPER, 1998).

Diversas são as formas de se lidar com a exigência dos clientes. Para Gunasekaran et al. (2001), a exigência pode ser entendida em "como satisfazer o cliente?". Alguns tópicos quanto à satisfação do cliente são definidos por estes autores como flexibilidade, tempo de espera para os clientes receberem os produtos ou serviços e, por fim, serviços extras pós-venda ou pós entrega dos produtos. 
A exigência dos clientes define o que se chama de fatores competitivos, e estes geram os objetivos de desempenho. São estes objetivos de desempenho que as empresas devem trabalhar com seriedade para que os fatores competitivos possam ser atingidos. Para Slack et al. (1999), todas as partes de qualquer empresa têm os seus próprios papéis a desempenharem para se chegar ao sucesso. Isto implica que as atividades da logística também devem se preocupar quanto à questão do sucesso.

A atividade Distribuição, a qual faz parte do conjunto de atividades da logística, é composta de sub-atividades, sendo uma delas a Transferência Física dos Produtos, que por sua vez também é dividida em sub-atividades: armazenamento, manutenção de estoque, retirada (ou coleta) e despacho das peças. Estas sub-atividades não mais acrescentam valor ao produto, que já está terminado. Portanto as atividades de Distribuição e Distribuição Física necessitam de um planejamento especial pois geram custos diretamente vinculados ao manuseio das peças, que consumirão parte do lucro agregado com a venda da peça, pois o preço desta foi definido no ato da venda, atividade que antecede a estas duas (PETERSEN \& AASE, 2003 e TOMPKINS et al., 1996). O estudo de Coyle et al. (1996) afirma que o custo do processo de retirada de peças demanda cerca de 50 a $70 \%$ do custo total de todas as sub-atividades.

\subsection{Objetivos do estudo}

O objetivo deste trabalho é modelar, em simulação discreta utilizando o software ARENA $5.0^{\circledR}$, o processo de retirada de peças para obtenção de informações que sirvam de auxílio em tomadas de decisão visando reduzir o seu custo, baseado no gerenciamento dos recursos relacionados ao tempo do processo. Justifica-se este objetivo pela importância que é os Decisores terem previamente acesso a informações importantes sobre os possíveis recursos envolvidos antes da chegada de qualquer pedido, pois, se assim não for, o Decisor não poderá se prevenir de uma série de problemas que venham a acontecer podendo acarretar atraso na consolidação do pedido e, conseqüentemente, o aumento dos custos.

\subsection{Estrutura do trabalho}

Este trabalho é dividido em 6 capítulos, mais as referências bibliográficas, anexos e apêndices. 
O capítulo 2 apresenta a revisão bibliográfica da logística e onde os armazéns se enquadrariam neste contexto logístico, além de esclarecer a importância e a necessidade de se criar os armazéns. Além disso, define com exatidão os processos dos armazéns, as políticas existentes e os recursos utilizados em cada processo. Em especial, o processo de retirada de itens será exposto com mais detalhes porque é o de maior custo para os armazéns e, por isso, procura-se identificar os problemas apresentados pelos autores da área de armazenamento e as suas propostas para solucioná-los.

No capítulo 3 é apresentada uma breve descrição da empresa, onde será realizado o estudo de caso, o seu histórico, os setores envolvidos no armazenamento de peças e principalmente a sua forma de trabalho, o que engloba turnos de trabalho, tipos de talões gerados pelo computador para os funcionários realizarem a coleta, dentre outros.

Depois de detalhada a empresa, o capítulo 4 irá tratar da modelagem do processo de retirada de itens no software ARENA $5.0^{\circledR}$, com as simplificações adotadas, e os motivos que levaram a esta simplificação. Inicia-se este capítulo com a descrição da metodologia de pesquisa, apresentando-se os materiais e métodos utilizados para a coleta de dados. Será apresentada, em detalhes, cada etapa do processo de retirada de itens, o qual envolve desde a geração do pedido até a geração de resultados pelo modelo, tais como os recursos utilizados e o tempo despendido por cada funcionário. Ainda neste capítulo, propõe-se uma nova técnica de divisão do número de itens do pedido que busca reduzir o tempo de retirada de itens de cada funcionário e também um algoritmo que permita estimar o deslocamento dos funcionários.

O capítulo 5 apresenta os resultados e alguns comentários sobre algumas das decisões que os planejadores poderiam tomar para evitar alguns problemas que possam levar ao atraso na consolidação dos pedidos.

O capítulo 6 apresenta as conclusões e alguns problemas encontrados no trabalho.

Os apêndices e os anexos vêm em seguida, finalizando assim este trabalho. 


\section{REVISÃO BIBLIOGRÁFICA}

O presente capítulo irá esclarecer a necessidade de se criar os armazéns, bem como onde estão inseridos em um contexto logístico. As classificações dos armazéns, os seus recursos, processos e políticas de gerenciamento envolvidos em cada processo são apresentados. Em especial, será detalhado o processo de retirada onde serão descritos as suas características e os tempos constituintes, indicando a motivação para o seu estudo por meio da simulação discreta.

\subsection{Existência dos armazéns}

Novaes \& Alvarenga (1994) afirmam que ao longo do processo logístico existem diversos fluxos de mercadorias. Nas interfaces desse processo, isto é, nos pontos de transição de um fluxo para outro, entre manufatura e transferência, ou entre transferência e distribuição física, surge a necessidade de se manter os produtos estocados por um certo período de tempo. Esse tempo de permanência pode ser muito curto, necessário apenas para se fazer a triagem da mercadoria recém-chegada e reembarcá-la, como também pode ser relativamente longo.

Não importa o produto está sendo armazenado como estoque, ou onde ele está posicionado na operação; o estoque existirá porque existe uma diferença de ritmo ou de taxa entre fornecimento e demanda. Se o fornecimento de qualquer produto ocorresse exatamente quando fosse demandado, o produto nunca seria estocado (SLACK et al. 1999).

Segundo Ballou (2001), a estocagem é necessária porque geralmente é impossível ou impraticável fornecer produção instantânea e cumprir prazos de entrega aos clientes. Ele funciona como um "pulmão" entre a oferta e a demanda, de forma que a disponibilidade de produtos necessários aos clientes pode ser mantida, enquanto fornece flexibilidade à produção e à logística para buscar métodos mais eficientes de manufatura e distribuição de produtos.

Para Tompkins et al. (1996), existem diversos tipos de armazéns e, portanto, dependendo onde estes estão localizados no contexto logístico, pode ter diferentes missões. Em geral, os propósitos são:

a) Permitir o equilíbrio da diferença entre a quantidade produzida com a demandada. 
Para este propósito, os armazéns são comumente alocados próximos aos pontos de manufatura.

b) Encontrar uma localização mais adequada entre a manufatura e o consumo.

c) Encontrar alternativas de se construir armazéns próximos aos clientes para atendê-los em menor tempo.

Segundo Harmon (1994), nesta era de tecnologia de comunicações e informática espaciais, a transferência excessivamente lenta dos dados de reposição de estoques e da demanda do ponto de vendas, através das redes de distribuição, até o fornecedor do produto, e adiante até os fornecedores de componentes e materiais é extremamente arcaica, exceto para um punhado de empresas de ponta. Em muitas etapas da logística, as empresas transmitem apenas informações sobre o pedido para os seus fornecedores. Estes, na falta dos dados de previsão e posição dos estoques de seus clientes, precisam trabalhar na penumbra, prevendo por si próprios a demanda do cliente ou tentando reagir a ela com sistemas de controle de estoques de ponto de pedido.

\subsection{Classificação dos armazéns}

Segundo Moura (1989), existem duas distinções para os armazéns. A primeira distinção está relacionada aos armazéns com as necessidades do ciclo de produção, tais como o estocamento de matérias-primas e componentes. Pode-se citar, como exemplo, o armazenamento de matérias-primas, produtos adquiridos de terceiros, materiais semiacabadas, materiais em processo, produtos acabados, peças sobressalentes, manutenção, suprimentos diversos, sucatas, cavacos, retalhos, ferramentas e material de embalagem.

A segunda refere-se ao ciclo de distribuição, ou seja, com a armazenagem de produtos destinados à venda tais como armazém central (Centros de Distribuição), armazéns secundários (regionais) descentralizados, almoxarifados (seccionais) e armazenagem de produtos de reposição no local de uso. Em termos de tipos de materiais armazenados nesta segunda distinção, existem duas categorias. A primeira categoria seriam os materiais não elaborados, semi-elaborados (que passam ao processo de produção), consumíveis (ou seja, todos os suprimentos que, ainda que não passem a compor diretamente o produto acabado, são indispensáveis para a realização do ciclo de produção). Na segunda categoria mencionada, pode-se incluir todos os produtos acabados. O conceito de "produto acabado" é relativo, pois depende do tipo de indústria. 


\subsection{Centro de distribuição de peças}

\subsubsection{Definição}

O Centro de Distribuição de Peças (CDP) é definido como um espaço físico responsável pela armazenagem de uma variedade de produtos de um fornecedor ou da própria fábrica (onde o produto foi produzido) e liberar os produtos para seus clientes (MULCAHY, 1994). Portanto, o CDP é um tipo de armazém.

Frazelle (2002) compreende CDP como sendo um local onde se armazena produtos de diversos fabricantes por um determinado período até que estes mesmos sejam liberados para os armazéns de cada cliente. A figura 01 esquematiza o posicionamento do CDP em relação aos fabricantes e cliente.

Gurgel (1996) afirma que as expedições das fábricas tendem a evoluir para CDP, expedindo mercadorias provenientes de várias fábricas de uma corporação, produtos comprados de terceiros e mesmo mercadorias importadas. Os CDP's devem ficar em áreas de fácil acesso, tanto para as carretas dos caminhões provenientes das fábricas, como para os caminhões de distribuição urbana. Sua localização e seu tamanho dependerão da área atingida pelo centro, da população concentrada na área e do poder aquisitivo desta população.

O objetivo da administração dos CDP's será sempre duplo e antagônico, como elevar a qualidade dos serviços prestados aos clientes e simultaneamente reduzir os custos desta operação de distribuição.

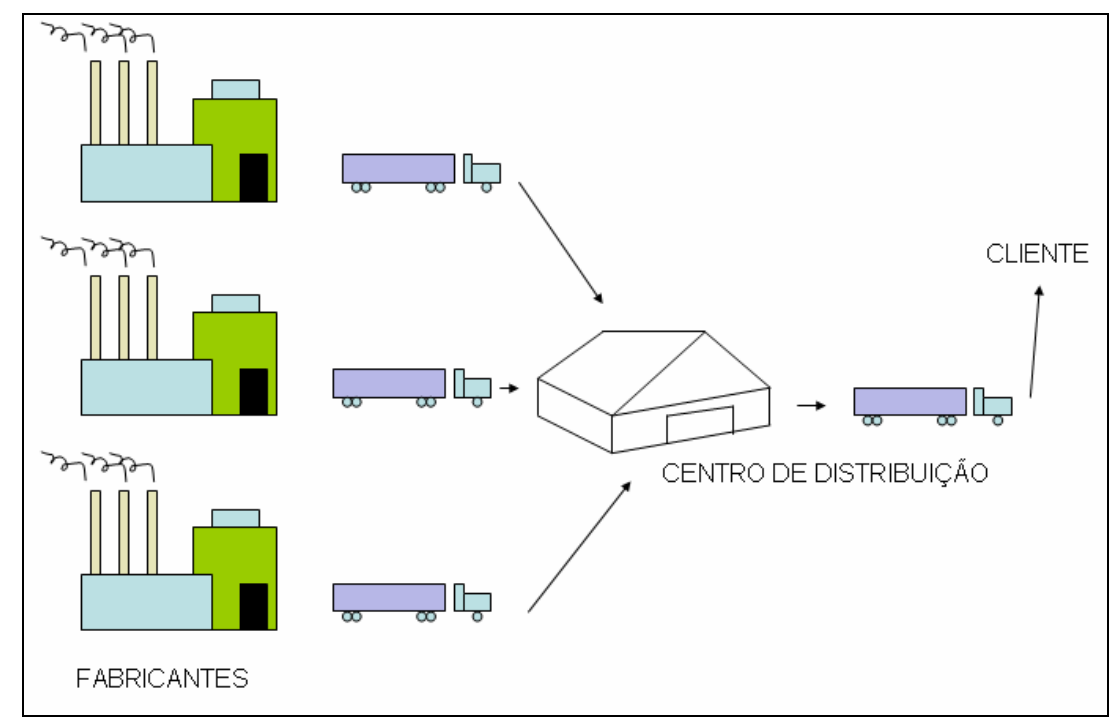

FIGURA 01 - ILUSTRA O CDP DENTRO DO CONTEXTO LOGÍSTICO (ADAPTADO DE BALLOU, 2001). 


\subsubsection{Componentes para o dimensionamento de um CDP}

Para se definir os componentes do dimensionamento de um CDP, Novaes \& Alvarenga (1994) afirmam que:

- Como o CDP funciona como um pulmão entre a demanda e a oferta de produtos, é necessário conhecer o estoque máximo, porque desta forma é que terá uma boa estimativa do espaço necessário para armazenar os produtos;

- Em seguida, é preciso definir o tipo de movimentação, pois este tópico condiciona os espaços livres (corredores), a forma de armazenagem, a altura das pilhas, dentre outros;

- É necessário definir o arranjo físico (ou layout) da área de armazenagem: forma e tipo de células (gavetas, prateleiras, etc), sua distribuição espacial, corredores, acessos, etc.

- E por fim, distribuir o espaço disponível para armazenar as diferentes categorias de produto, seguindo, para isso, um critério racional de forma a reduzir ao máximo o esforço de movimentação.

Harmon (1994) entende estes componentes como sendo uma conseqüência dos fatores-chave da armazenagem:

1) Os novos armazéns precisam ser projetados de uma forma modular melhorada, para futuras expansões, caso seja razoavelmente possível a previsão do aumento dos produtos e linhas de produtos. Entretanto, espaço extra para uma eventualidade não fará sentido na nova era de drásticas reduções de estoques na maioria das empresas de ponta. Assim, os módulos pré-planejados dos futuros armazéns deverão ser acrescentados somente quando necessários e prejudicando ao mínimo a lógica e o fluxo dos módulos anteriormente construídos.

2) A maioria dos armazéns funciona mais efetivamente com uma mescla de automação de alta tecnologia, semi-automação, automação de baixo custo e armazenagem manual, para as faixas de itens de alta, média e baixa demanda e os vários tamanhos e formatos de containers correspondentes. Portanto, os melhores planosmestres de armazenagem basear-se-ão na combinação mais lógica das famílias de produtos estocados com as diferentes alternativas de armazenagem, transporte e equipamentos de movimentação. O armazém típico constará de mais de uma família de produtos com características afins e, portanto, com vários tipos de equipamentos. 
3) A utilização inteligente e eficiente do espaço do armazém é vital para a maximização do uso do capital em conjunto com a minimização das despesas operacionais e da folha de pagamentos. Espaços de armazenagem que correspondam precisamente ao tamanho dos containers cheios a eles destinados diminuem 0 desperdício de espaço em 50\%, se comparados com containers ocupando metade do espaço ou cheios até a metade. Ambas as situações ocorrem em grande parte dos armazéns, o que indica grande potencial de melhoria. Os containers são caixas grandes, geralmente de metal, e são encontrados com bastante freqüência em portos marítimos.

4) Uma meta de reorganização deve ser o estabelecimento ou a melhoria de zonas por grau de atividade. Um armazém, ao localizar os produtos de maior movimentação em uma determinada área e equipá-la para o processamento de grande volume, consegue aumentar sensivelmente a produtividade da armazenagem.

5) Sempre que possível, os planos de longo prazo devem incluir a redução dos estoques nos armazéns ao mínimo, em conjunto com a manutenção ou melhoria do atendimento aos clientes. Isso será conseguido pela melhoria contínua, com o passar do tempo, mediante programas da empresa e dos fornecedores, que reduzam substancialmente o tempo de reabastecimento e aumentem a freqüência de entregas de armazéns menores.

6) Os armazéns projetados para receber, expedir e apanhar pedidos $24 \mathrm{~h}$ por dia, aproveitarão melhor o investimento em prédios e equipamentos. Em contraposição, os armazéns projetados para funcionar durante apenas um turno apresentam grande desvantagem competitiva.

7) Espaço de armazenagem extra, prevendo um eventual crescimento futuro de longo prazo e picos sazonais, geralmente aumenta a capacidade do armazém acima de sua necessidade normal, sobretudo nos primeiros anos.

8) O fluxo em linha reta através de um armazém é, quase sempre, uma alternativa de layout insatisfatória. O layout mais efetivo normalmente teria entrada e saída nas mesmas docas, com os itens de maior volume mais próximos do ponto de recebimento e remessa.

9) Tamanhos de corredores drasticamente reduzidos são métodos para a redução do movimento e o aumento da densidade de armazenagem.

10) Muitos armazéns possuem imensos espaços ociosos nas áreas de recebimento, embalagem e expedição. Alguns chegam a desperdiçar o espaço elevado em áreas de armazenagem. Os melhores armazéns aproveitarão cada centímetro cúbico de espaço para armazenagem vertical ou com escritórios elevados. 
A figura 02 ilustra a vista superior de um armazém padrão. Neste armazém podese notar que os locais de armazenamento (representados por quadrados) estão dispostos um ao lado do outro, constituindo assim uma prateleira. Estes locais de armazenamento são regiões das prateleiras responsáveis pelo armazenamento temporário das peças até que algum pedido o solicite. Pode-se notar que as prateleiras são separadas por corredores. Dependendo da largura dos corredores, é possível até mesmo a passagem de empilhadeiras para o transporte de produtos. As empilhadeiras, que fazem parte do recurso dos armazéns, serão descritas com mais detalhes no item 2.3.5.

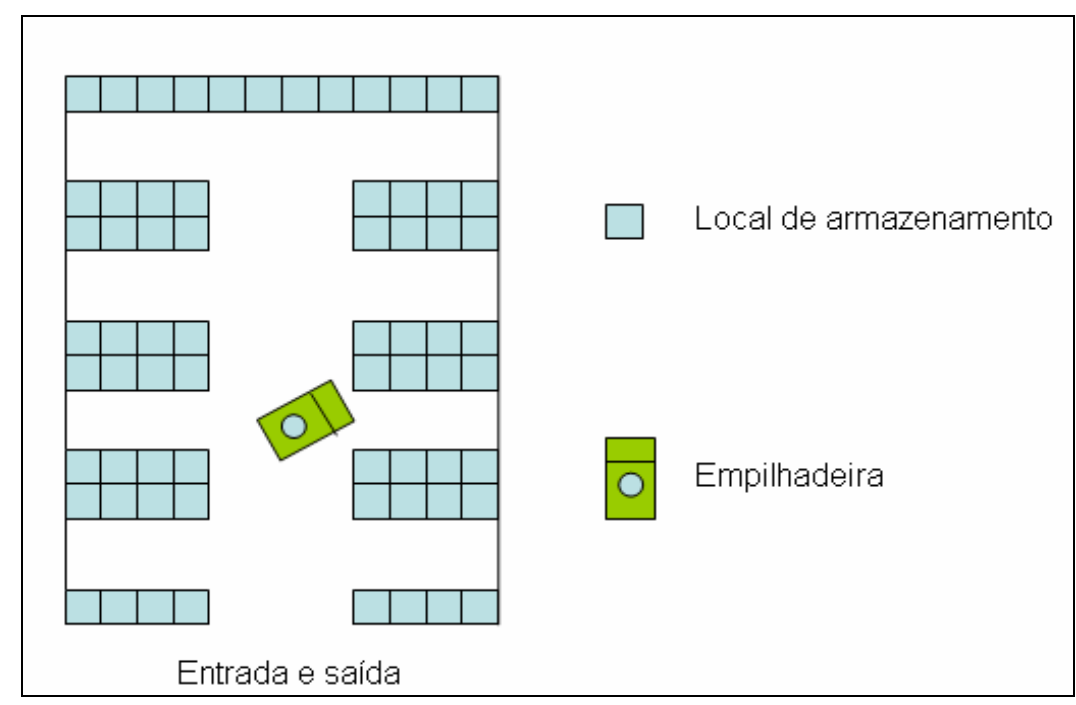

FIGURA 02 - FORMATO PADRÃO DE UM CDP (ADAPTADO DE ASKIN \& STANDRIDGE, 1993).

\subsubsection{Planejamento do layout de um CDP}

Tompkins et al. (1996) afirmam que estudar a relação entre popularidade, similaridade, tamanho e características dos produtos permitem maximizar o desempenho de um CDP. Ainda segundo os autores, esta maximização também pode ser obtida estudando-se a forma com que os produtos ocupam as prateleiras.

Popularidade: Slack et al. (1999) comentam que existem 3 classificações de produtos, dadas por A, B e C conforme o valor do investimento. Produtos classe A são aqueles $20 \%$ de produtos de alto valor que representam cerca de $80 \%$ do valor total do estoque. Os de classe B são aqueles de valor médio, usualmente os seguintes $30 \%$ dos produtos que representam cerca de $10 \%$ do valor total. E por fim, os de classe C são aqueles itens de baixo valor que, apesar de compreender cerca de $50 \%$ do total de tipos 
de produtos estocados, representam provavelmente somente cerca de $10 \%$ do valor total de produtos estocados.

Para Corrêa (1979), quando existe uma alta diversidade de artigos (ou produtos), pode-se trabalhar com um método de controle chamado $A, B$, e $C$ (equivalente ao método chamado em inglês management by exception), largamente utilizado na indústria. Consiste, basicamente, em separar e classificar em três grupos todos os artigos do estoque. O grupo A seria que dentre os $75 \%$ do que são consumidos ou vendidos dos produtos, os de maior venda correspondem aos 10\% de artigos do armazém. Segundo Petersen (1999), os artigos mais demandados ou de elevado grau de circulação são encontrados nas regiões mais próximas às saídas dos armazéns, porque dessa forma pode-se obter grandes reduções de percursos dos funcionários.

Portanto, Materiais de elevado consumo são armazenados próximos às saídas dos CDP's, porque a circulação tanto de funcionários quanto de transportadores são bastante elevados nesta região e portanto alocando-se os materiais próximos às saídas permitem reduzir a distância de percurso já que o empacotamento, na maioria dos casos, ficam próximos desta região de saída.

Similaridade: O segundo princípio para o layout do CDP refere-se à similaridade do produto armazenado, ou seja, os produtos que são recebidos e distribuídos conjuntamente devem ser armazenados próximos uns dos outros;

Volume e peso: Artigos de pequeno porte ocupando espaço de artigos de grande porte podem estar gerando perda de espaço de armazenamento. Porém, na prática, quando aplicados os 2 princípios acima pode não ser possível separar por tamanho, e por isso deve-se ajustar as alturas das prateleiras. Para Bowersox \& Closs (1986), o volume do local de armazenamento deve acompanhar o volume dos produtos. Produtos pesados devem estar armazenados em prateleiras (próximas ao chão) para minimizar o esforço físico dos funcionários.

Características: As características dos produtos armazenados também são importantes porque alguns deles podem possuir algum odor que pode contaminar outros produtos. O material que compõe o produto também pode ser fundamental para se decidir em qual parte e em qual prateleira deve-se armazenar o produto para que não deforme ou quebre a embalagem do produto.

Utilização do espaço: E por último, deve-se maximizar o uso do espaço quando são considerados todos os princípios. Esta maximização pode ser alcançada através de: 1) Conservação do espaço - Redução do espaço tridimensional não aproveitado do local de armazenamento da prateleira; 2) Limitações de espaço - Conhecer as limitações de 
espaço do local de armazenamento para que facilite a remoção dos produtos das prateleiras. Além disso, conhecendo o peso dos produtos, pode-se estabelecer quantos "andares" de prateleiras que o sistema de armazenamento poderá suportar. Este tópico diz respeito às limitações de espaço e este pode ser fundamental para a tomada de decisões, como por exemplo, se é possível ou não o uso de empilhadeiras para armazenar ou remover os itens; 3) Acessibilidade - Deve-se planejar quantos corredores deverá ter o CDP para que o acesso aos itens das prateleiras seja facilitado.

Askin \& Standridge (1993) afirmam que muitas pessoas consideram os armazéns como sendo apenas um local físico para armazenar produtos. Para estes dois autores, dentro dos armazéns existe uma variedade de instalações e atividades que exigem manipulação de informações e principalmente de materiais.

Mais recentemente, armazéns têm sido caracterizados sob três categorias: processos, recursos e organização. As combinações destas englobam os tipos de recursos, decisões, dentre outros, para a realização de atividades. É importante, portanto, compreender estas características, pois consegue-se visualizar tudo o que está envolvido para a realização de determinadas atividades (ROUWENHORST et al., 2000).

\subsubsection{Processos do CDP}

Para que o CDP seja capaz de armazenar os produtos dos fornecedores por um certo período de tempo e depois entregá-los aos clientes, é necessário um conjunto de atividades atuando nele. Segundo Moura (1997), estas atividades são:

- Recebimento - Conjunto de atividades que são responsáveis por permitir a entrada física de materiais e executar a conferência em termos de quantidade e qualidade;

- Endereçamento para o estoque ou alocação - Ato de transportar e de colocar o material no local onde será armazenado;

- Armazenagem - É o local físico onde os produtos permanecem armazenados por um certo tempo até que uma determinada demanda faça com que eles sejam retirados do local de armazenamento. Este local deve estar de acordo com o formato e quantidade dos produtos para que haja armazenamento adequado;

- Remoção do estoque - Consiste em retirar o produto do local armazenado para atender às demandas;

- Separação e acumulação dos produtos - O primeiro (separação) retira todas as mercadorias de todos os pedidos simultaneamente do armazém para depois separá-los 
por pedido. Caso exista algum destes pedidos ainda não atendidos, existe a necessidade de esperar a próxima remoção para completá-lo, que seria a acumulação dos produtos;

- Embalagem e expedição - Ambos devem efetuar as seguintes atividades:

a) Checar se os pedidos foram atendidos ou completados;

b) Empacotar as mercadorias adequadamente;

c) Preparar os documentos, como a fatura, o endereço do local de destino, dentre outros;

d) Definir o peso e a quantidade, pois o caminhão pode não ter capacidade suficiente para levar consigo as mercadorias;

Podem existir outras atividades, que podem variar de empresa para empresa.

\subsubsection{Recursos do CDP}

Frazelle (1992) identificou alguns dos principais recursos dos CDP's:

a) Unidades de armazenamento: Estas unidades podem ser representadas por caixas, pallets, dentre outras. Para Ballou (2001), a economia do manuseio de materiais é diretamente proporcional ao tamanho da carga manuseada. Isto é, com o aumento do tamanho da carga, um número menor de viagens será requerido para estocar determinada quantidade de mercadorias e, portanto, maior será a economia. Dessa forma, para alcançar uma elevada eficiência no manuseio de materiais, trabalha-se com a unitização da carga. A unitização pode ser feita por paletes ou containers. Esta unitização, segundo Frazelle (1992), também pode ser representada por caixas de papelão. Um palete (ou skid), por exemplo, é uma plataforma portátil com diversas dimensões disponíveis no mercado, feita geralmente de madeira ou papelão corrugado, no qual os bens são empilhados para o transporte e a armazenagem. Os containers também podem ser considerados como unitização de carga.

b) Sistema de armazenamento: Refere-se às condições físicas que o meio oferece para armazenar um produto. Como exemplo, pode-se citar as prateleiras. Ballou (2001) afirma que os dispositivos de armazenagem promovem a utilização plena do espaço e melhoram a eficiência do manuseio de produtos. Ainda segundo o autor, o dispositivo mais importante é o rack. Os racks são prateleiras, geralmente de metal ou de madeira, sobre as quais as mercadorias são colocadas. As prateleiras proporcionam empilhamento do piso ao teto, e as mercadorias sobre as prateleiras inferiores estão tão acessíveis quanto aquelas armazenadas nas prateleiras superiores, embora os itens com giro 
elevado devam ser colocados perto do piso para reduzir o tempo de serviço total. Estas prateleiras devem estar aptas a armazenar produtos de diferentes tamanhos. Outro dispositivo de armazenagem disponível inclui prateleiras fechadas, estofamento horizontal e vertical, escaninhos e estruturas em perfil $U$. Todos estes equipamentos ajudam a ordenação da armazenagem e o manuseio de produtos de formas irregulares;

c) Remoção da mercadoria: Esta atividade pode ser realizada manualmente ou até mesmo com auxílio de algum tipo de equipamento (mecanizado ou automático). Os equipamentos de manuseio de materiais operados manualmente, tais como transportadores manuais de duas rodas e transportadores plataforma de quatro rodas, fornecem alguma vantagem mecânica na movimentação dos produtos e requerem somente um investimento modesto. Esses equipamentos podem ser usados para um grande número de produtos e sob uma ampla variedade de circunstâncias. Entre os equipamentos mecânicos mais conhecidos estão os guindastes, caminhões industriais, elevadores e guinchos. Entretanto, o equipamento mais comumente encontrado na indústria é a empilhadeira e suas variações. A empilhadeira é geralmente apenas uma parte do sistema de manuseio de materiais. É combinado com o carregamento paletizado e às vezes com as prateleiras. O equipamento mecanizado permite o empilhamento elevado de carga e o movimento de cargas de tamanho substancial. Com equipamento de manuseio controlado por computador, códigos de barra e tecnologia de leitura ótica, alguns sistemas de manuseio de materiais que foram desenvolvidos chegam perto da automatização completa. Tais sistemas são chamados de sistemas automatizados de armazenamento e recuperação (AS/RS).

d) Equipamentos eletrônicos para a remoção da mercadoria: São equipamentos de apoio de modo a agilizar esta atividade. Como exemplo, pode-se citar os leitores de código de barras;

e) Sistema computacional: Auxilia no gerenciamento do armazém. Este é responsável, por exemplo, pela atualização dos estoques a medida em que as peças são retiradas. Dessa forma os Decisores podem ter noção real de quanto, quando e em que quantidade serão necessários para requisitar peças dos fornecedores para fins de reposição;

f) E por fim, os funcionários. Existem diversas tarefas a serem feitas pelos funcionários. Estes são responsáveis em retirar as peças das prateleiras, depositar as peças coletadas aos setores de embalagem, manipular os transportadores nos corredores, dentre outras. 


\subsubsection{Organização do CDP}

Inclui todo o planejamento e controle aplicados aos processos do armazém. Os processos seguintes ilustram com clareza o planejamento e controle necessários para que as operações ocorram. Reuwenhorst et al. (2000) afirmam que em cada processo do CDP existem políticas para coordená-lo.

a) Fluxo do processo: Para permitir que exista fluxo de produtos nos armazéns, deve-se, por exemplo, decidir se os produtos (os que chegam dos fornecedores) devem ou não ser separados em uma determinada área do armazém. Esta separação, dependendo da área do armazém, pode aumentar o fluxo do produto em certas partes do processo;

b) Processo de recebimento: Neste processo, estuda-se formas mais adequadas para o recebimento dos produtos. Neste momento, deve-se estudar qual a melhor política. Por exemplo, qual o melhor transportador a ser usado? Em qual área do armazém os produtos devem estar provisoriamente armazenados para que o armazenamento seja mais adequado em termos de temperatura e percurso até as prateleiras;

c) Endereçamento para o estoque ou alocação: Esta etapa consiste em alocar os produtos nas prateleiras. No entanto, é importante que se defina qual política adotar. Os produtos podem, como uma das políticas, serem agrupados entre si de modo que o percurso do funcionário seja reduzido;

d) Processo de armazenamento: Dentre os principais, pode-se citar a forma com que as prateleiras devem estar divididas (se é por demanda do produto ou por família, por exemplo);

e) Remoção do estoque: Em vez de remover diretamente o produto, estuda-se alguma estratégia como, por exemplo, o agrupamento de pedidos que implique em redução do percurso;

f) Separação e acumulação: Depois que os produtos são retirados, deve-se analisar se os produtos já devem estar separados por cliente no transportador ou podem ser misturados para serem separados posteriormente;

g) Embalagem e expedição: Deve-se decidir qual tipo de embalagem usar e as estratégias de manipulação destas embalagens. E também estudar o melhor transportador que consiga lidar adequadamente com estas embalagens. Em expedição, deve-se definir estrategicamente o período em que os caminhões devem ser liberados para atender aos clientes. Além disso, é importante conhecer o período em que as docas estão livres para permitir este processo. 
h) Por fim, mesmo que não seja um processo, deve-se salientar a importância da existência de alguma estratégia para lidar com funcionários e equipamentos. Portanto, deve-se conhecer o desempenho de cada funcionário para alocá-lo em atividades nas quais ele possa alcançar seu melhor desempenho. Além disso, deve-se analisar se os equipamentos permitem agilizar os processos citados anteriormente.

\subsection{Processo de remoção de produtos}

\subsubsection{Definição}

O processo de remoção ou retirada de produtos é uma das atividades mais importantes dos CDP's, pois é nesta etapa que os produtos são removidos das prateleiras pelos funcionários para atender aos pedidos.

Segundo Rosenwein (1996), existem algumas terminologias comumente utilizadas por diversos autores que realizaram estudos deste processo. Para este autor, o produto (ou a mercadoria) passa a ser tratado como sendo item. Cada item está alocado em determinadas regiões do CDP, denominadas de locais de armazenamento. A linha de um item (line item) refere-se à exigência do cliente por um item em uma quantidade específica. O pedido é simplesmente um conjunto de line items. E, portanto, um pedido pode conter diversos itens de quantidades distintas entre eles. Remoção de itens do pedido é o ato dos funcionários (coletadores) percorrerem os corredores do CDP e coletarem os itens dos locais armazenados. Este percurso pode ser denominado por roteamento ou viagem.

Alguns termos bastante usados na bibliografia podem ser vistos na figura 03. Os números desta figura, representados por li, com i variando de 1 até 22, representam os diferentes tipos de itens que estão em diferentes locais do CDP. 


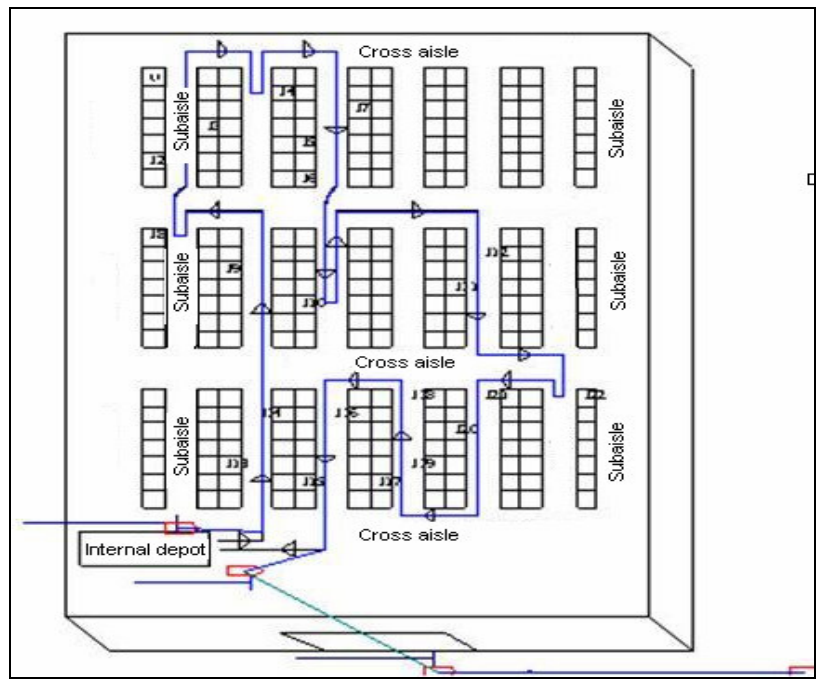

FIGURA 03 - ESQUEMA DO CDP (ADAPTADO DE ROODBERGEN \& DE KOSTER, 2001).

Nota: Itens li, $\mathrm{i}=1, . .22$

A figura 03 apresenta um percurso, os quais os coletadores partem do depósito interno e circula os corredores até atingir os locais de armazenamento. O depósito interno tem a finalidade de armazenar temporariamente as peças coletadas. Além disso, é um local onde as listas de coleta são geradas. No entanto, nem todos os CDP possuem este depósito.

Existem 2 corredores importantes: O corredor vertical e corredor horizontal. $\mathrm{O}$ corredor vertical é um corredor onde os coletadores permanecem estacionados para a realização da retirada de itens. No entanto, em muitos estudos de caso, é importante ilustrar em que local do corredor vertical o coletador deve alcançar, e por este motivo, os principais autores da bibliografia denominam de subcorredor (ou subaisle), que é o corredor que divide as prateleiras. Portanto, um corredor vertical é dividido em diversos subaisles. Os corredores que cruzam as prateleiras, perpendicularmente, são denominados de cross aisles. Geralmente as larguras dos cross aisles são maiores que a dos subaisles, e, portanto é de se esperar que mais de um único funcionário circule em cross aisles. Porém dependendo do CDP, as larguras dos subaisles também podem permitir a circulação de mais de um funcionário.

Neste percurso, é comum que os funcionários utilizem transportadores manuais (ou carrinhos), ou trolley (em inglês) para auxiliá-los neste processo, permitindo-lhes que os itens coletados sejam previamente guardados nestes transportadores para futuramente serem contabilizados e despachados aos clientes. Estes transportadores permitem aos coletadores removerem maior quantidade de itens por viagem. Segundo Hall (1993), este 
processo consiste em remover itens das prateleiras. Os itens a serem removidos estão registrados em listas de coleta (LC), onde nelas constam os locais de cada tipo de item (pontos de coleta), a quantidade e a seqüência de coleta. O funcionário, ao receber estas listas, percorre os corredores do CDP, removendo e transportando os itens das prateleiras para o setor de empacotamento e, em seguida, tais itens são distribuídos aos clientes.

Tompkins et al. (1996) identificaram alguns componentes do processo de retirada de itens extremamente importantes que podem aumentar a sua eficiência. Dentre os componentes, pode-se citar:

- Viagem para ou entre os pontos de coleta;

- Extração ou remoção de itens dos locais de armazenamento;

- Movimentação do corpo, mãos e braços para alcançar o item;

- Transição dos documentos, onde estão contidas as informações dos itens;

- Ordenação dos itens;

- Empacotamento;

- Localização dos pontos de coleta.

Para estes autores, é possível que a viagem e a extração sejam combinadas para se ganhar tempo. Existem carrosséis, por exemplo, que permitem transportar os itens dos pontos de coleta e extrair novos itens simultaneamente. Os carrosséis são sistemas automatizados de transporte de itens.

Também é possível fazer com que, durante a viagem do transportador, haja uma organização dos documentos para decidir qual será o próximo item a ser coletado.

No momento da coleta, pode-se separar os itens por pedido para ganhar tempo. Esta separação, muitas vezes, é feita porque nos transportadores existem orifícios, os quais permitem a separação dos itens. Fazendo-se isso, pode-se ganhar tempo.

Quando a quantidade de itens solicitados no pedido é pequena, é possível coletar, separar e também empacotar ao mesmo tempo. Isto faz com que se ganhe tempo até chegar ao setor de empacotamento.

\subsubsection{Impacto exercido pela competitividade no processo}

Para Chiavenato (1990), armazenar ou estocar é guardar algo para utilização futura. Se a utilização for muito remota no tempo, sua guarda se torna prolongada: ocupa espaço alugado ou comprado, requer pessoal, significa capital empatado, precisa ser segurado contra incêndio ou roubo, etc. Em outras palavras, ter estoque é ter despesas de estocagem. Porém, se a utilização for imediata, provavelmente não haja tempo para 
estocar, o que pode acarretar paralisação em processo de produção, caso ocorra qualquer atraso no fornecimento.

A competitividade entre empresas para a conquista do mercado tem forçado diversos setores das empresas a buscarem soluções para a redução dos seus custos. De fato, as empresas são dinâmicas e constantemente sofrem modificações internas para acompanhar a competitividade. Qualquer modificação errônea pode trazer elevados prejuízos financeiros.

As atividades dos sistemas de armazenamento são responsáveis pelo recebimento dos pedidos e envio de produtos aos clientes (PETERSEN \& AASE, 2003). Por fazerem parte da empresa, estes também sofrem competitividade dos concorrentes na disputa pelo atendimento aos clientes e, por isso, é fundamental que haja constantes melhorias nestes sistemas (GUNASEKARAN et al., 1999).

Segundo Daniels et al. (1998) e Makris \& Giakoumakis (2003), o custo total dos CDP's é influenciado principalmente por uma das suas atividades, denominada de processo de retirada de itens. A razão disso é que consome cerca de $60 \%$ de mão de obra (DALY, 1993).

Qualquer solução que vise aumentar a eficiência desse processo tem importante papel na redução desses custos (MALTON, 1991) e, para que isso aconteça, Frazelle (1989) afirma que se deve preocupar com a minimização do tempo de retirada de itens.

A forma como as empresas reagem a estas pressões define o que se chama de objetivos de desempenho. São estes objetivos de desempenho que as empresas devem trabalhar com seriedade para que possa permanecer competitiva no mercado (SHIH et al. 2004). E por isso, é importante também que o sistema de armazenamento esteja preparado para as variações de demanda para que o cliente não seja prejudicado em não poder receber o seu produto a tempo. A seguir são apresentados os principais objetivos de desempenho de Slack et al. (1999), aplicados em um CDP.

- Qualidade: $O$ ato de realizar corretamente as atividades proporciona qualidade. Em um CDP, por exemplo, quando os coletadores esquecem de levar alguma lista de coleta podem gerar um tempo extra só para percorrer os corredores;

- Rapidez: O ato de realizar as atividades com rapidez. Como exemplo, em um CDP, o objetivo de desempenho relacionado ao período de tempo em que o cliente solicita um produto até recebê-lo é denominado rapidez;

- Confiabilidade: Realizar as atividades em tempo. É a capacidade que tem o CDP de entregar as peças em período estipulado no contrato, por exemplo; 
- Flexibilidade: É a capacidade que tem uma empresa de mudar as suas operações.

Dessa forma, uma empresa com vantagem em flexibilidade apresenta boa capacidade de lidar com um grande número de pedidos sem ter problemas com a base de dados do sistema computacional e nem confusão dos coletadores em retirar esta grande variedade de itens.

- Custo: O próprio nome sugere fazer as coisas baratas para ganhar vantagem em custo. Como exemplo, quanto menor o percurso realizado pelos coletadores, menor o custo dos funcionários.

\subsection{Estudos da área}

A seguir, serão levantados alguns dos principais trabalhos da área de armazenamento. Basicamente todos dão enfoque às formas de se reduzir o custo do processo de remoção de itens. Roodbergen \& De Koster (2001) citam que existem alguns métodos, apresentados nas seções 2.5.1 até 2.5.5, para se alcançar à minimização do tempo do processo de retirada de itens, sendo que estes métodos podem ser estudados individualmente ou de forma combinada entre eles. Dentro de cada seção, são apresentados trabalhos de diversos autores que aplicam ou buscam alcançar tais métodos.

\subsubsection{Redução do percurso}

Consiste em determinar a rota entre os itens que leva à menor distância percorrida. Hall (1993) criou uma heurística para um CDP com dois cross aisles, enquanto Ratliff \& Rosenthal (1983) desenvolveram um eficiente algoritmo. Alguns pesquisadores trabalham com a variação das larguras dos corredores. Por exemplo, Goetschalckx \& Ratliff (1988a, 1988b) focam subaisles largos enquanto Rana (1990) propõe um algoritmo para subaisles estreitos. Roodbergen \& De Koster (2001) estudaram o impacto dos cross aisles centrais sobre o percurso. Ainda com relação ao cross aisle, Vaughan \& Petersen (1999) avaliam até que ponto é viável o seu uso para se obter aumento da eficiência dos CDP's. Caron et al. (2000) avaliaram os diferentes percursos quando existem diferentes posicionamentos das prateleiras, número de corredores e principalmente o número de pontos de coleta nos quais o transportador deve parar durante a realização da coleta. Bozer et al. (1990) também propõem novos métodos de percursos, mas os locais onde os itens estão armazenados são restritos. 
No entanto, a maioria dos trabalhos citados acima se embasou em algumas políticas de roteamento, que podem ser vistas com bastante detalhe em Goetschalckx \& Ratliff (1988). Dentre as políticas, pode-se citar:

Traversal policy - o funcionário, responsável pela coleta, entra por uma das extremidades do subaisle e sai por outra extremidade. Pode existir tanto um ponto quanto vários pontos de coleta. Esta técnica pode ser vista em Goetschalckx \& Ratliff (1988).

Return policy - o funcionário entra por uma das extremidades do subaisle e sai pelo mesmo que entrou. Esta técnica pode ser vista em Goetschalckx \& Ratliff (1988).

Largest gap return policy - o funcionário percorre uma determinada parte do subaisle, até onde está o ponto de coleta, e sai pelo mesmo por onde entrou. Este é na realidade um intermediário entre as duas políticas citadas anteriormente (traversal e return). A aplicação desta técnica pode também ser vista em Hall (1993).

\subsubsection{Zoneamento (Zoning)}

O CDP é dividido em zonas e em cada uma delas há um funcionário que fica responsável pela coleta dos itens. Zoneamento refere-se a atribuir separadores individuais de pedidos para atender apenas um número limitado de itens de estoque em vez de sua roteirização através de todo o estoque. Para este tópico não existe um estudo específico, porém este método é utilizado em conjunto com os demais. Um dos trabalhos que pode ser citado é o de Kallina \& Lynn (1976), que lida simultaneamente com o zoneamento e o método de alocação por demanda, que está descrito no tópico seguinte.

\subsubsection{Alocação por demanda}

Itens com demandas semelhantes são armazenados próximos uns dos outros. Van den Berg et al. (1998) propõem uma função matemática que minimize o número de funcionários. Em particular, estudam a reposição dos itens no CDP. Heskett (1963) já retratava a importância de se criar algum método que pudesse resolver os problemas de alocação de itens para que se pudesse reduzir os custos dos funcionários. Este autor propôs o índice Cube-Per-Order (CPO) e fez algumas aplicações. CPO é a razão do espaço requerido para a armazenagem dos itens sobre a freqüência de pedidos dos itens. Isto significa que um item com baixo CPO deve ser armazenado próximo às regiões de saída. Este critério é, em essência, um método heurístico que compara os resultados de aplicação do critério em cada caso prático das diferentes formas de alocação, para se verificar com quais destes consegue-se obter maior redução de percurso. Em 1976, 
autores como Kallina \& Lynn ilustraram um exemplo prático de alocação de itens segundo o critério CPO para minimizar o custo dos funcionários e descreveram passos para se implementar o critério em um programa computacional. Kallyna (1976) fez um estudo e mostrou que os resultados do método de CPO são considerados como soluções ótimas. Litvak \& Adan (2002) buscam obter a maior redução do tempo de percurso dos funcionários estudando as diferentes formas de alocação de itens. Jarvis \& McDowell (1991) desenvolvem um modelo estocástico para definir o local de alocação do item visando a minimização do tempo gasto de percurso de remoção de itens.

\subsubsection{Agrupamento dos pedidos}

Os itens dos pedidos de vários clientes são agrupados em uma única lista de coleta para serem coletados simultaneamente nas prateleiras, como em Liu (1999) e Gibson \& Sharp (1992). Rosenwein (1996) propõe uma heurística que define, iterativamente, um agrupamento entre pedidos que resulte no menor percurso. O trabalho de Lin \& Lu (1999) aborda duas estratégias. A primeira diz respeito a situações em que o funcionário inicia o processo de retirada de itens sem agrupar pedido e, neste caso, trabalha com pedido unitário. A segunda estratégia considera agrupamento de pedidos. A partir disso, é avaliado o tempo do processo e verifica-se que, dependendo do número de itens e quantidade de peças de cada item, pode-se obter a minimização do tempo do processo em ambos os casos.

\subsubsection{Combinada}

Petersen \& Aase (2003) abordam a combinação das estratégias de coleta, armazenamento e roteamento dos funcionários para verificar em quais níveis de cada estratégia é que se consegue alcançar uma maior redução do tempo total.

Vários autores desenvolveram modelos de percursos nos CDP's para obterem o comprimento de viagem variando os esquemas de rotas e de políticas de armazenagem para um determinado número ou número médio de pontos de coleta. Pode-se citar os trabalhos de Kunder \& Gudehus (1975) e Caron et al. (1998).

Existem trabalhos que também tratam simultaneamente de alocação e retirada de itens visando reduzir o tempo de ciclo, como é descrito em Kim et al. (2003). Este trabalho apresenta um algoritmo de reposição de itens e avalia a percepção do cliente em termos de ganhos de tempo. 
Brynzér \& Johnsson (1996) apresentaram os fatores que afetam o desempenho de retirada de itens, incluindo o agrupamento de pedidos, a seqüência com que os itens são removidos, os locais onde estão armazenados os itens, a divisão do armazém em regiões ou zonas, layout do armazém (que envolve, por exemplo, o posicionamento das prateleiras, a largura dos corredores, dentre outros), a forma com que a coleta é realizada (se é por equipamentos de coleta ou manualmente).

As técnicas apresentadas no trabalho de Lin \& Lu (1999) também podem ser consideradas como a combinação dos métodos. Este trabalho busca alcançar um alto desempenho no processo de retirada de itens utilizando as estratégias de agrupamento e zoneamento.

\subsubsection{Necessidade do uso de programas computacionais}

Ezziane (2000) e Chaudhuri \& Dayal (1997) comentam a importância de se usar programas computacionais em qualquer parte da empresa, para que esta se torne competitiva no mercado. Atualmente, muitos CDP's utilizam programas computacionais para auxiliar os funcionários nos processos de retirada de itens, tais como: organização dos pedidos, geração de informações que dizem respeito à seção do corredor (ou pontos de coleta) onde está localizado o item, organização das LC's numa seqüência para a minimização de percursos dos funcionários nos corredores, dentre outros importantes aspectos. Vaughan \& Petersen (1999) comentam que programas computacionais dos sistemas de armazenamento são capazes de converter os pedidos dos clientes em LC, onde constam o tipo, quantidade e localização dos itens. Dessa forma, estes sistemas permitem aos Decisores uma melhor coordenação das atividades (VAN DEN BERG, 1996).

Os programas computacionais atualmente utilizados só permitem gerar informações quando um pedido real chega ao sistema, tornando a empresa vulnerável a reclamações por não estar preparada para situações adversas. Tais reclamações são provindas de clientes que não conseguem receber os produtos no prazo determinado. Um bom gerenciamento só acontece quando se tem informações prévias para a prevenção de futuros problemas. Assim, faz-se necessária uma ferramenta capaz de executar ensaios de modo a fornecer rapidamente informações sobre o sistema estudado.

As ferramentas da simulação computacional têm como uma das principais características a criação de modelos que representem os sistemas reais. Banks et al. 
(1984) comentam que a simulação permite interações internas dos modelos que tornam possível a compreensão o sistema real.

Sendo assim, a simulação apresenta-se como uma das importantes ferramentas a ser explorada em análises de sistemas, uma vez que consegue lidar com diversas variáveis simultaneamente (MARíN et al.,1998).

Dessa forma, no tópico 2.6 será detalhada a simulação e seus principais conceitos, o que inclui modelagem e algumas aplicações nos sistemas de manufatura. Também será comentada, com mais detalhes, a motivação do seu uso neste trabalho.

\subsection{Simulação}

\subsubsection{Conceituação do sistema}

No mundo existem constantes interações de materiais, pessoas, meio ambiente, dentre outras. Estas interações podem resultar em diversos comportamentos. Uma fábrica, por exemplo, devido às constantes interações entre os recursos disponíveis e de pessoas, gera peças. Este conjunto de interações constitue o que se chama de sistema. A figura 04 ilustra um diagrama de sistema, de acordo com Pritsker (1995).

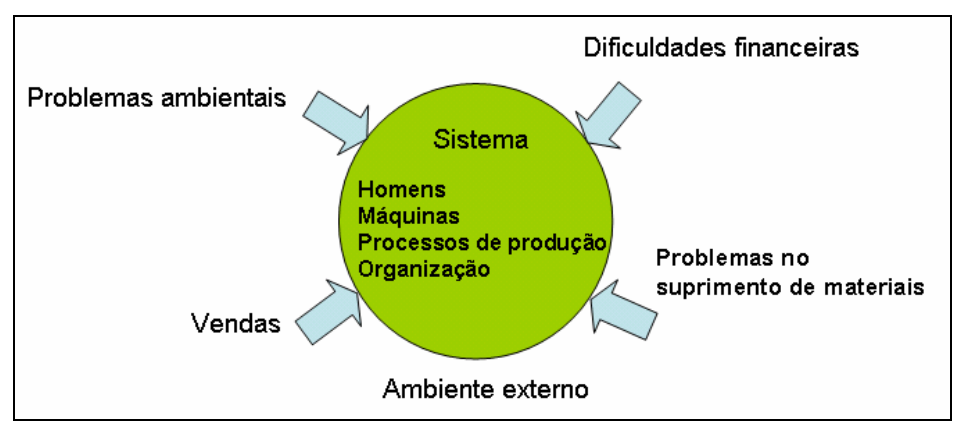

FIGURA 04 - SISTEMA INFLUENCIADA PELO MEIO EXTERNO (FONTE: PRITSKER, 1995).

Em geral não é importante, ou não é possível, se levantar todos os dados do sistema, e por isso, são criados modelos para substituir estes sistemas. Assim, estes modelos podem ser chamados de simplificação dos sistemas. Os modelos são criados quando existe a necessidade de se compreender algum tipo de comportamento do sistema real (GORDON, 1969).

Banks et al. (1984) e Banks (1998) ressaltam que, para entender e analisar um sistema, alguns dos principais termos do modelo precisam estar definidos:

- Entidade: Objeto de interesse do sistema; 
- Atributo: Propriedade de uma entidade;

- Atividade: Tarefa sendo feita pela entidade fixa ou recurso num período de tempo;

- Recurso: É uma entidade fixa que executa uma determinada atividade para a entidade dinâmica;

- Estado: Variáveis necessárias para descrever o sistema num instante qualquer;

- Evento: Ocorrências que poderão alterar o estado do sistema;

- Endógeno: Relativo a atividades e eventos que ocorrem dentro do sistema;

- Exógeno: Relativo a atividades e eventos no meio que afetam o sistema.

A figura 05 ilustra com detalhes a interação de uma parte destes termos em um sistema.

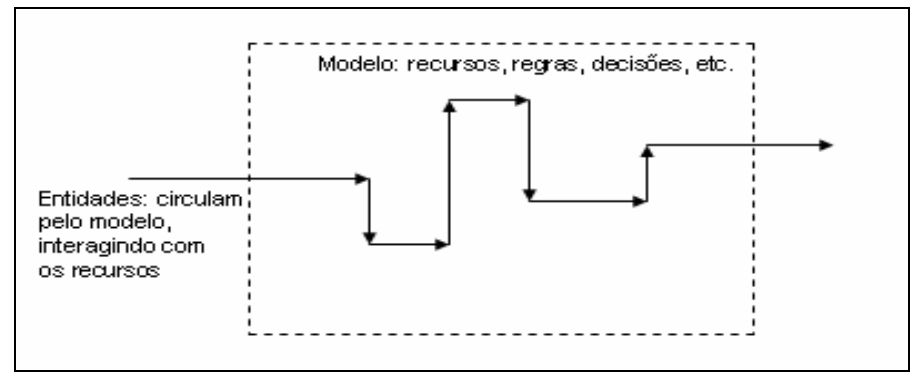

FIGURA 05 - DETALHES DO SISTEMA (FONTE: PARAGON, 2002).

\subsubsection{Tipos de modelos}

Banks et al. (1984) descrevem que os modelos podem ser classificados como matemáticos ou físicos. O modelo matemático utiliza notações e equações matemáticas para representar um sistema. Os modelos de simulação, por fazerem parte do grupo de modelos matemáticos, podem ser classificados como: estáticos ou dinâmicos, determinísticos ou estocásticos, e discretos ou contínuos.

Modelo estático: Representa o sistema num instante de tempo apenas. Não é levado em consideração a variável tempo no modelo;

Modelo dinâmico: Diferente do estático, este representa a variação do sistema com o tempo.

Modelo determinístico: Quando não existem variáveis aleatórias de entrada no modelo.

Modelo estocástico: Quando existe uma ou mais variáveis aleatórias de entrada no modelo. 
Modelo discreto: Considera o comportamento das variáveis de estado variando conforme períodos de tempos separados adequadamente, diferentes do instantâneo.

Modelo contínuo: Considera o comportamento instantâneo da variável de estado em relação a cada fração de tempo.

\subsubsection{Descrição da simulação}

A simulação utiliza modelos que podem ser manipulados e testados para examinar o comportamento dinâmico do sistema (BENNETT, 1995).

Os programas computacionais, como os softwares de simulação, trabalham com modelos e, uma vez implementados e executados nestes softwares, é possível verificar o comportamento do modelo no decorrer do tempo. Para Pritsker (1995), a simulação computacional é um processo que envolve desde a criação, teste e verificação de comportamento dos modelos de um sistema real no computador.

A simulação computacional tem como uma das principais características a criação de modelos que representam os sistemas reais. Banks et al. (1984) e Law \& Kelton (1991) comentam que a aplicação das ferramentas, oferecidas pelos softwares, nos modelos permitem melhor interações internas e com isso é possível compreender o sistema real.

Além de abordar esta questão, estas ferramentas permitem aos indivíduos adquirirem um pensamento sistêmico, podendo assim contextualizar melhor o problema e auxiliar a responder as questões chaves. Para melhor esclarecimento, Kellner et al. (1999) propuseram um esquema para a criação dos modelos (ver figura 06). A Tabela 01 detalha cada componente da figura 06.

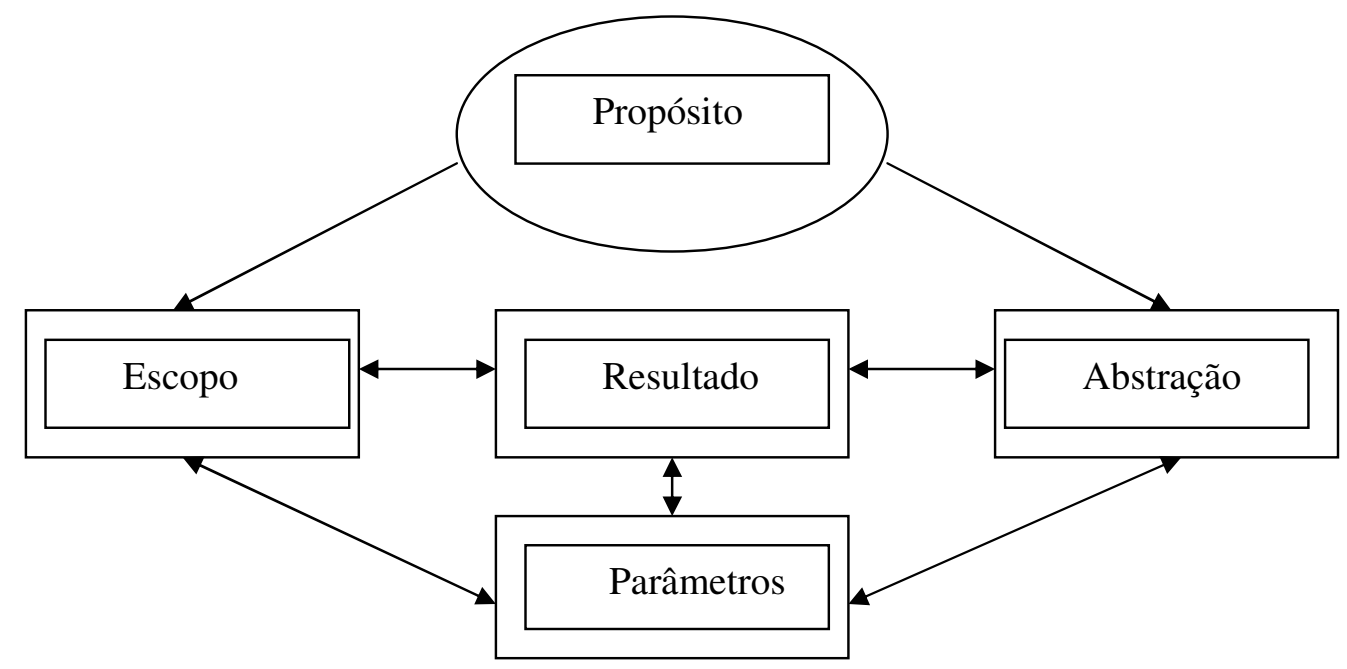

FIGURA 06 - O QUE SIMULAR? (FONTE: KELLNER et al., 1999). 
TABELA 01 - DESCREVE AS PARTES DE "O QUE ENVOLVE PARA SIMULAR?"

\begin{tabular}{|l|l|}
\hline $\begin{array}{l}\text { Partes envolvidas } \\
\text { para decidir “o } \\
\text { que simular?” }\end{array}$ & Descrição \\
\hline Resultado & São informações que se deseja obter no final da simulação. É o propósito do trabalho. \\
\hline Parâmetros & São as variáveis que irão influenciar no modelo. \\
\hline Abstração & $\begin{array}{l}\text { Os modelos devem mostrar claramente o comportamento dos elementos, o } \\
\text { relacionamento entre eles, dentre outros. }\end{array}$ \\
\hline Propósito & $\begin{array}{l}\text { Existem 6 propósitos: Gerenciamento estratégico, planejamento, gerenciamento de } \\
\text { controle e operações, melhoria, compreensão e aprendizagem. }\end{array}$ \\
\hline Escopo & É a orientação do modelo para não se perder o enfoque do problema. \\
\hline
\end{tabular}

Porém estas partes são, na realidade, uma simplificação da proposta de sistematização de estudos de simulação elaborada por Lobão \& Porto (1997). Esta proposta pode ser vista em diversas etapas, como ilustrado na figura 07.

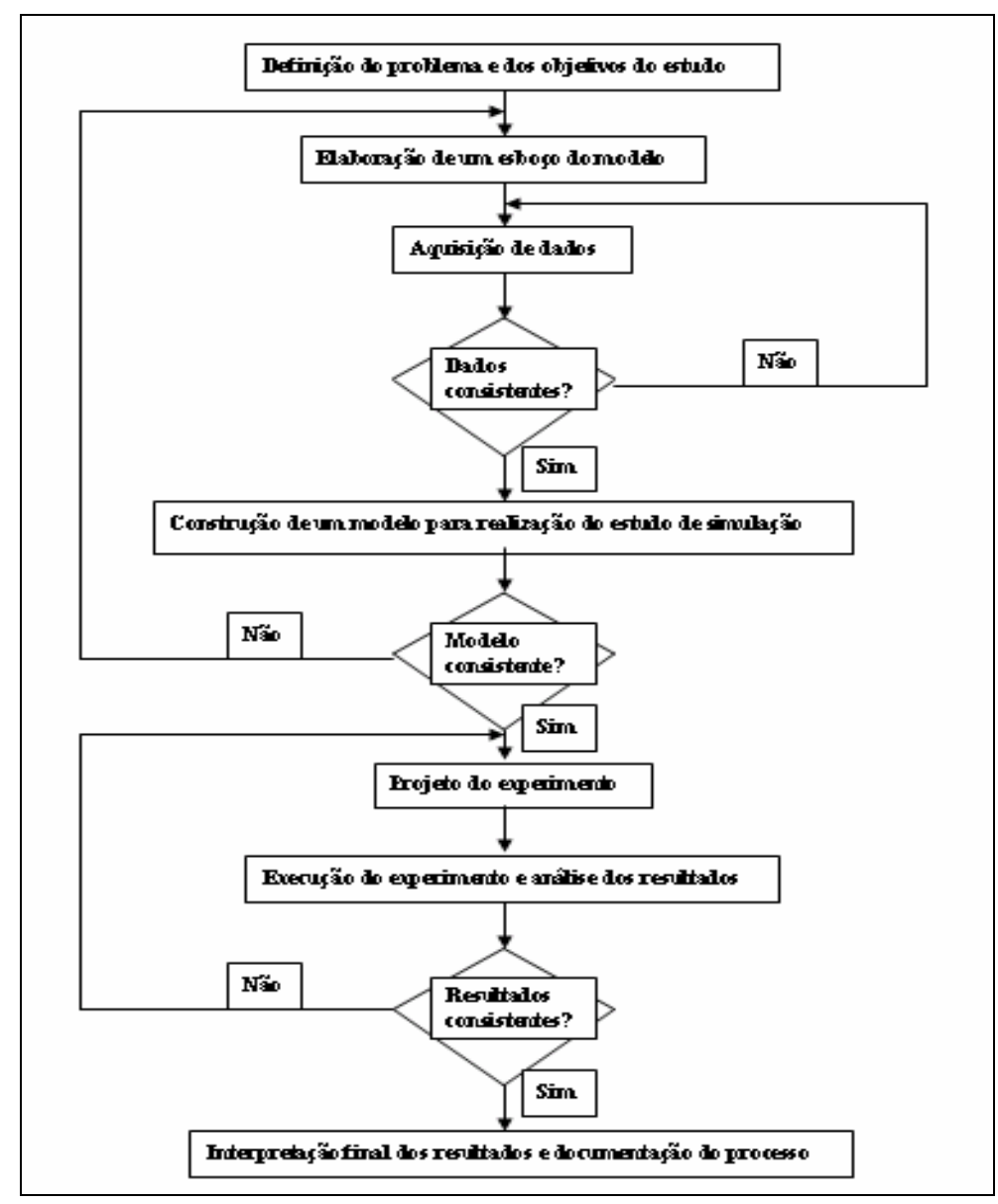

FIGURA 07 - PROPOSTA DE SISTEMATIZAÇÃO DOS ESTUDOS DE SIMULAÇÃO (FONTE: LOBÃO \& PORTO, 1997). 


\subsubsection{Descrição das etapas da simulação}

Pritsker (1995) afirma que os passos para a realização de um bom estudo de simulação são constituídos pelas seguintes etapas:

1) Deve-se identificar os objetivos, definir o sistema que será modelado e especificar os medidores. É nesta etapa que se define o propósito do uso da simulação, o que se espera obter no final para a tomada de decisão, dentre outros pontos importantes.

2) Inicia-se o processo de criação ou construção prévia do modelo. O modelo do sistema consiste na descrição da parte estática e dinâmica. Em estática são definidos os elementos do sistema e as características dos modelos. Já em dinâmica define-se a interação de elementos do modelo ao longo do tempo.

A modelagem do sistema determina o tipo de dado de entrada no modelo. Alguns tipos de dados já podem estar disponíveis ou não, enquanto outros podem requerer bastante tempo e elevado custo para aquisição.

Após a criação dos modelos, estes são adaptados para um programa computacional para que a simulação possa acontecer.

3) A verificação do modelo consiste em fazer ajustes do modelo no programa. Este serve basicamente para evitar discrepâncias entre o modelo e do criado em computador.

4) Inicia-se a validação do modelo. É nesta etapa que os dados de saída do modelo são comparados ao do sistema real para verificar se este modelo representa adequadamente o sistema estudado.

5) Planejamentos estratégico e tático consistem em definir procedimentos para a manipulação dos dados de entrada. Ou seja, é nesta etapa os dados de entrada serão definidos para que se consiga obter os dados desejados para decisão.

6) Análise dos resultados gerados pelo modelo de simulação. Existem programas computacionais que permitem aos usuários realizarem animações. Desta forma, o resultado da simulação não se trata meramente de dados, mas também a interface de animação que permite melhor visualização do sistema. Além disso, permitem aos usuários trabalharem com a estatística dos resultados, fornecendo resultados dentro de um intervalo de confiança.

7) E por fim, pode-se tomar decisões e implementar mudanças no sistema baseados em dados obtidos do modelo. O sucesso de implementação depende do grau de interação do modelador com os indivíduos que trabalham no sistema durante toda a etapa porque, desta forma, pode-se conhecer com mais detalhes os problemas 
enfrentados. Todos os detalhes do sistema, os dados de entrada e os de saída devem estar documentados adequadamente para futuras análises ou consultas de informações.

Comumente inicia-se a construção "errônea" do modelo e este necessita de alterações para que se aproxime cada vez mais ao sistema real. Pode-se notar, com muita freqüência, constantes reformulações dos objetivos e principalmente reconstrução dos modelos.

\subsubsection{Motivações para o uso da simulação neste trabalho}

A motivação do uso da simulação neste trabalho é que, ao criar e executar os modelos, os Decisores terão informações antes de se tomar qualquer tipo de decisão errônea que possa resultar em excessos de custos (KELTON et al., 1998). Miller (2000) afirma que a simulação pode ser utilizada para criar e testar diferentes cenários para a melhor compreensão do sistema real.

Os métodos de resolução de problemas apresentados na bibliografia pelos autores podem não ser as mais adequadas e isto se deve ao fato de que os estudos se tornam cada vez mais complexos à medida que mais restrições ou fatores são impostos ao problema, os quais, por sua vez, são impostos pelas pressões provindas da competitividade, e por isso os empresários têm dificuldades em aplicar tais métodos para a obtenção de soluções. Geralmente os empresários necessitam rapidamente de informações não para obter a solução diante de um sistema dinâmico, mas informações que sirvam de suporte para a tomada de decisão.

Carson (2003) comenta que qualquer alteração dos fatores pode tornar o estudo do sistema bastante complicado e por isso a simulação passa a ser útil nestes casos.

Por estas razões, é importante que as técnicas de simulação sejam utilizadas para se gerar informações antes que qualquer decisão seja tomada no sistema real (ÜLGEN \& GUNAL, 1998). Naylor et al. (1971) já alertavam da existência de processos extremamente caros para a obtenção dos dados e, por isso, a simulação passa a ser uma alternativa. Além disso, os autores também afirmam que os modelos de simulação podem lidar simultaneamente com diversos parâmetros.

\subsubsection{Algumas aplicações da simulação}

Os estudos de simulação são utilizados em diversos ramos da ciência. Alfieri \& Brandimarte (1997) ilustram a importância de se utilizar os modelos de simulação em 
estudo da cadeia de suprimento, podendo integrar os meios de transporte, a quantidade demandada do item, entre outros.

Modelos de simulação foram criados e utilizados por Jansen et al. (2001) em cadeia de suprimentos, para integrar centros de distribuição, fazendo reduções dos períodos de entregas de produtos aos clientes, aumentando a freqüência das entregas, entre outras.

Garcia et al. (1999) descreveram um estudo de simulação para uma companhia de jornal, cuja finalidade foi melhorar o tempo de entrega para o produto. Os resultados mostraram uma melhoria de $13 \%$ no tempo de entrega para impressão de jornal e tarefas de armazenagem.

Shih et al. (2004) construíram um modelo de simulação de um armazém de 3 cross-aisles e, juntamente com a ferramenta de planejamento de experimentos, puderam concluir que a melhoria de eficiência dos recursos nem sempre implica em melhoria do sistema todo.

Yamada (2004) propõe a especificação e a criação de experimentos, modelos e interfaces padrões para o apoio ao processo de planejamento da produção de um sistema produtivo sucroalcooleiro, via simulação.

\subsubsection{Motivação para o uso da simulação discreta}

Taha (1988) e Banks et al. (1984) comentam que em simulação discreta, as alterações do comportamento do sistema não ocorrem de maneira contínua. Neste tipo de simulação, deseja-se avaliar o comportamento do sistema segundo um determinado tipo de evento que chega ao sistema em instantes de tempo (discretamente) e não o comportamento em todos os instantes de tempo (continuamente).

A razão de se utilizar a simulação discreta em vez da contínua se deve ao fato de que as variáveis dos modelos de simulação contínua são representadas por equações e estas equações, muitas vezes, se tornam complicadas (GORDON, 1969). Já os modelos de simulação discreta utilizam distribuições estatísticas das variáveis (mais simples em termos de manipulação dos dados).

\subsubsection{Vantagens e desvantagens da simulação}

Pedgen et al. (1995) apresentam uma série de vantagens e desvantagens referentes ao uso da simulação. Algumas das vantagens são: 
1) Novas políticas, procedimentos operacionais, regras de decisão, fluxo de informações, e procedimentos organizacionais podem ser adotados e estudados sem interromper o sistema;

2) Testar novos equipamentos, sistemas de transportes mesmo sem serem adquiridos fisicamente e até mesmo avaliar novos arranjos físicos sem alterar o arranjo atual;

3) Identificar os gargalos existentes no sistema;

4) Obtenção dos dados em menor espaço de tempo em comparação ao sistema real;

Algumas das desvantagens, pode-se citar:

1) Para se criar os modelos exige-se treinamento;

2) Os resultados da simulação podem ser difíceis de serem interpretados;

3) O processo de modelagem e de análise de dados podem requer bastante tempo;

Devido às desvantagens apresentadas, Banks et al. (1984) propõem uma série de alternativas ou soluções que poderiam resolver os problemas das desvantagens de se utilizar a simulação.

1) Fabricantes de softwares de simulação têm se preocupado em desenvolver pacotes computacionais que permitam aos usuários inserirem os dados de forma mais didática para a execução do modelo.

2) Muitos fabricantes de programas de simulação têm desenvolvido ferramentas que permitam ao programa analisar mais adequadamente os dados de saída.

3) O desenvolvimento de hardwares permitiu aos programas desempenharem com mais agilidade a simulação.

\subsubsection{Software de simulação Arena $5.0^{\circ}$}

Banks et al. (1984) afirmam que o software de simulação ARENA ${ }^{\circledR}$, um dos disponíveis no mercado atual, trabalha com módulos. Estes módulos, uma vez interligados entre si na região denominada área de trabalho, permitem que as entidades percorram estes elementos (que são os módulos) a partir de um determinado evento.

A figura 08 ilustra os templates, módulos e área de trabalho do software ARENA ${ }^{\circledR}$ de versão 5.0 . 


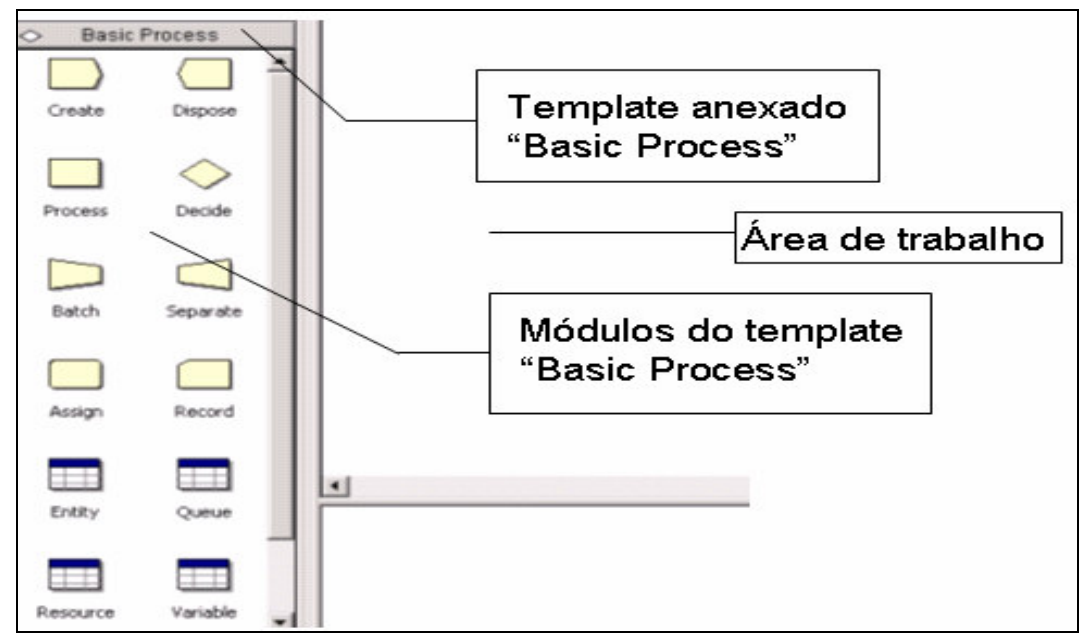

FIGURA 08 -TEMPLATE, MÓDULOS DO TEMPLATE E ÁREA DE TRABALHO NO ARENA $5.0^{\circledR}$.

A modelagem no Arena $5.0^{\circledR}$ é feita por meio da descrição do fluxograma da entidade ao longo do sistema. Isso facilita a visualização e a compreensão do modelo ao longo do seu desenvolvimento. Cada módulo possui um conjunto específico de parâmetros que podem ser configurados de acordo com as especificações do modelo. Este tipo de interface permite que o programador desenvolva um modelo sem a necessidade de conhecer a linguagem de programação SIMAN que o Arena ${ }^{\circledR}$ utiliza para a construção e execução dos modelos.

A figura 09 ilustra a construção de um modelo em Arena $5.0^{\circledR}$ de um sistema que avalia os currículos de candidatos para uma vaga de trabalho. O módulo initiate de nome "Chegam os currículos" ativa o modelo com a emissão de uma entidade denominada currículo. Dentro deste módulo, existem opções que definem a taxa de chegada dos currículos. Em seguida, as entidades passam por um outro módulo, process, de nome "Secretária lê os currículos". Nesta etapa, as entidades exigem do sistema um recurso para a realização da leitura dos currículos, que é a própria secretária. Geralmente os recursos são modelados usando-se o módulo process. E assim sucessivamente. 


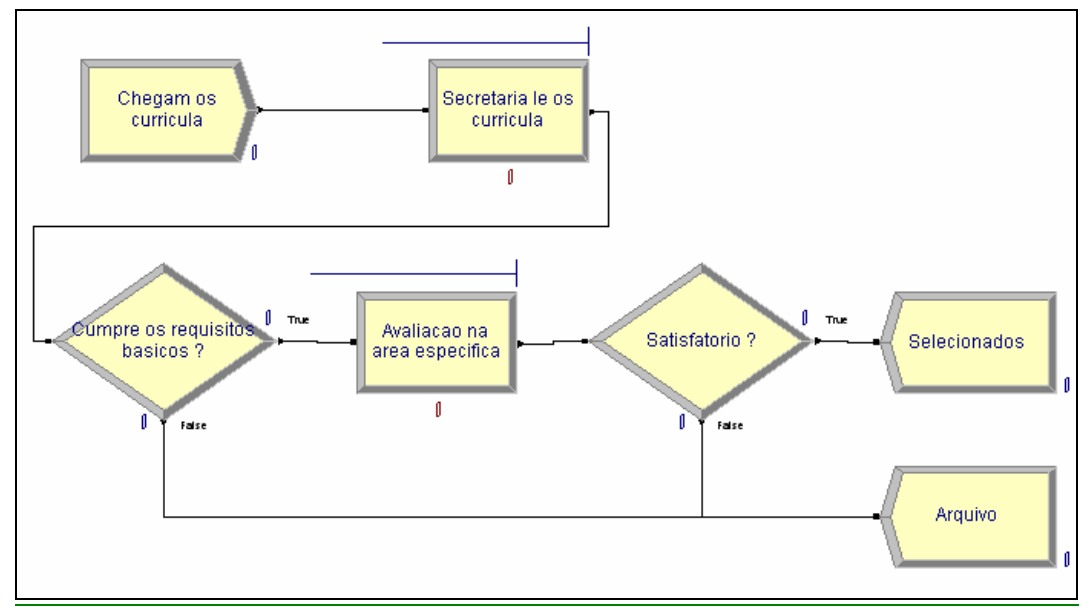

FIGURA 09 - ESQUEMA DO MODELO QUE ANALISA CURRÍCULOS (FONTE:

PARAGON, 2002). 


\section{A EMPRESA AUTOMOTIVA DE PIRACICABA}

\subsection{Introdução}

Em 1976, na cidade de Piracicaba, foi inaugurada uma planta industrial com área de $165.000 \mathrm{~m}^{2}$, como mostra a figura 10. Atualmente esta planta conta com o CDP Centro de Distribuição de Peças.

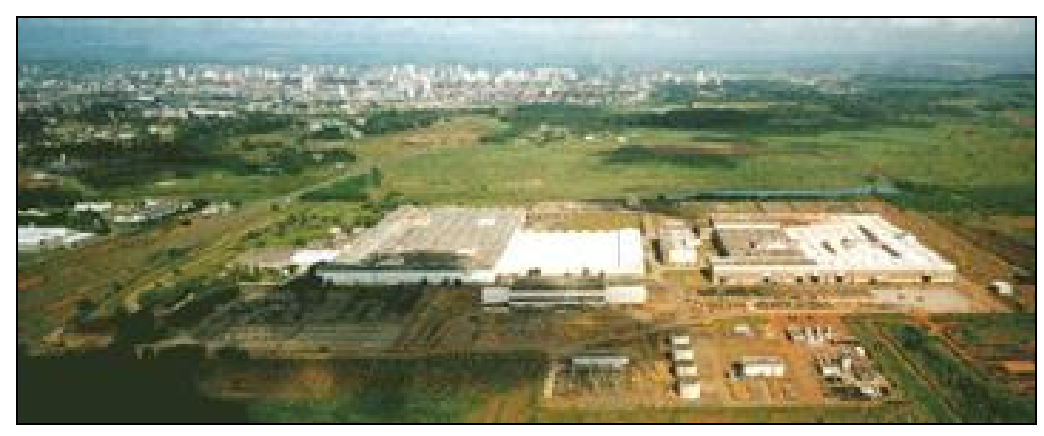

FIGURA 10 - PLANTA INDUSTRIAL EM PIRACICABA.

O CDP de Piracicaba atende atualmente até $90 \%$ dos itens solicitados. Para a reposição de estoque, este CDP conta com três tipos de fornecedores: peças provenientes da própria planta industrial, dos fornecedores nacionais (mais de 140) e de uma fornecedora estrangeira para as peças importadas.

A Divisão de Operações de Peças tem 47 empregados no CDP trabalhando em três turnos e cobrindo as 24 horas do dia, sendo que 13 destes trabalham diretamente com o setor de coleta e outros 10 aprendizes deficientes físicos cuidam da embalagem das peças pequenas.

A figura 11 mostra uma planta do CDP de Piracicaba. Nela pode-se verificar o posicionamento do Setor de Peças Pequenas, representado por SPP, que é o alvo deste trabalho de simulação. Este setor depende basicamente de 2 áreas para funcionar. $A$ área localizada abaixo do SPP é o local onde chegam as peças para reabastecimento ou reposição do CDP, enquanto a outra, localizada na parte esquerda do SPP é o setor de empacotamento dos itens.

A armazenagem é fundamentada em métodos estatísticos. Por exemplo, para realizar a estimativa de armazenagem, são coletados os dados do número de peças (daquelas mais vendidas nos últimos 12 meses). Mas também existe o chamado estoque de proteção: toda vez que uma máquina nova está sendo lançada no Brasil ou em determinada região, o revendedor estoca peças daquele novo modelo. 


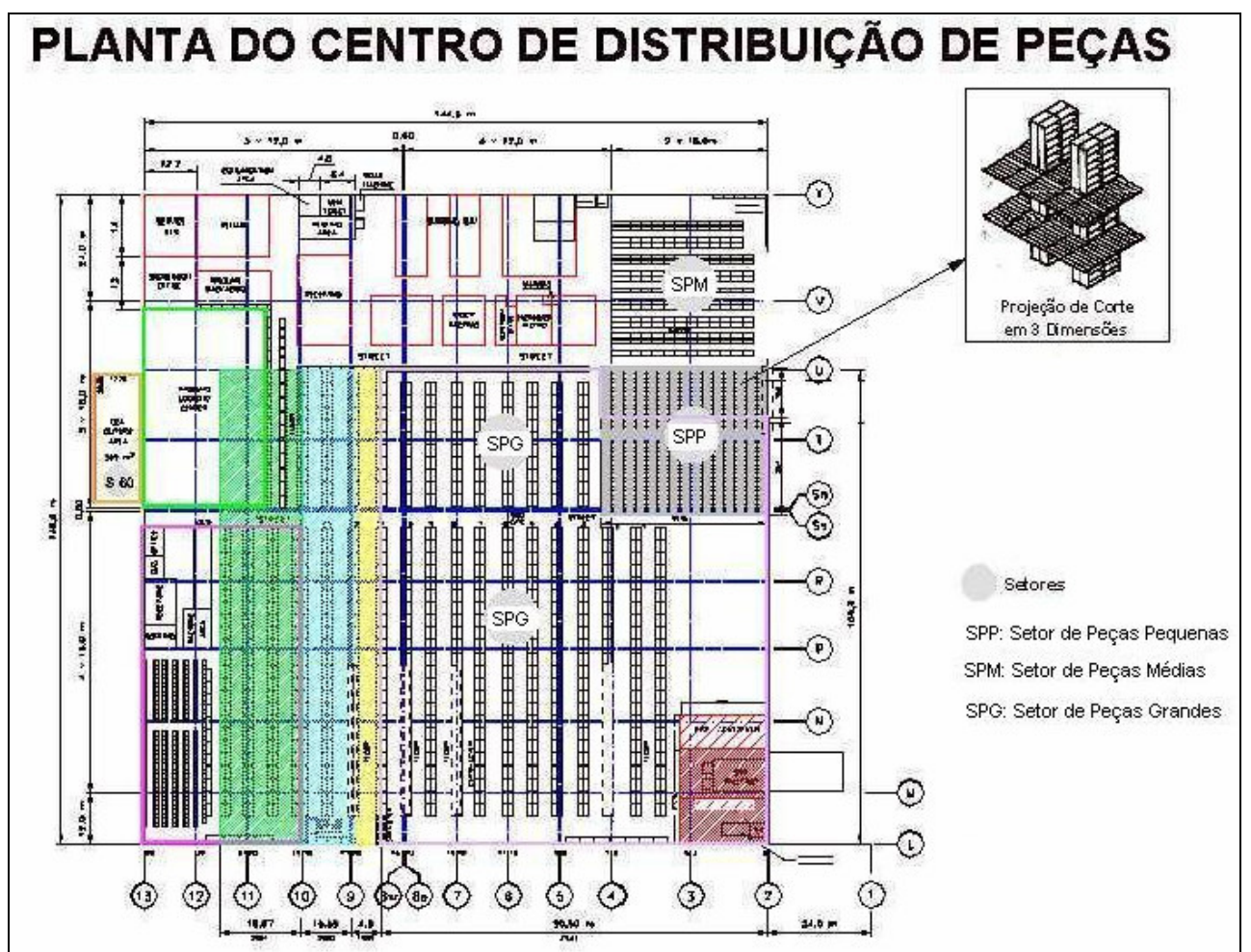

FIGURA 11 - PLANTA DO CDP DA EMPRESA.

\subsection{O SPP do CDP}

O SPP, como mostra o detalhe da figura 12, possui 3 andares (térreo e mais dois pisos). Cada andar possui pouco mais de 2 metros de altura, permitindo o acesso à parte superior das prateleiras sem a necessidade de nenhum equipamento auxiliar.

As suas dimensões externas são: 39 metros de largura por 37 metros de comprimento, e cada andar possui 30 prateleiras, divididas em 15 corredores verticais, como mostra a figura 13. 


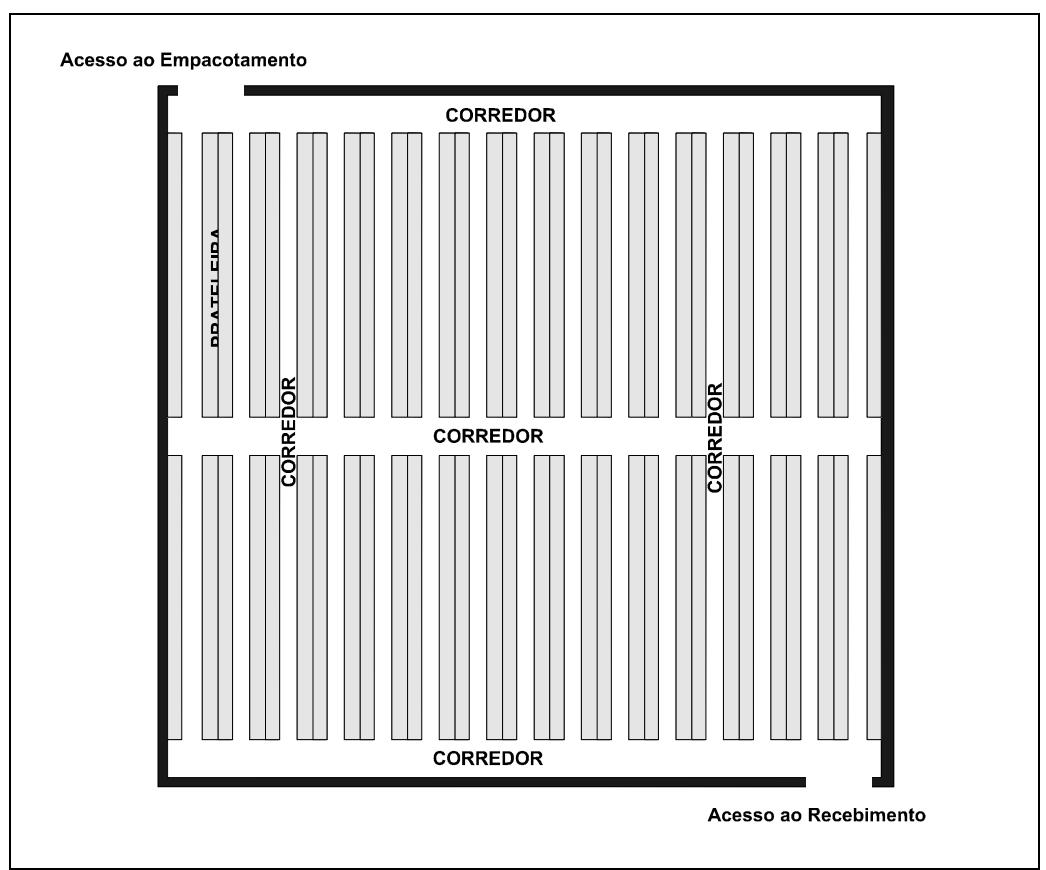

FIGURA 12 - PLANTA DO SPP.

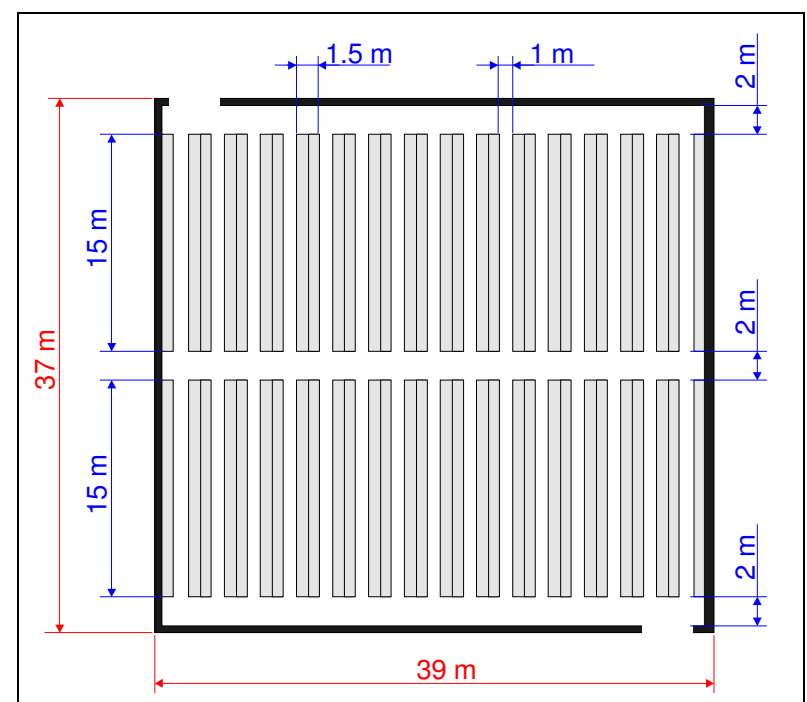

FIGURA 13 - DIMENSÕES DAS PRATELEIRAS E CORREDORES DO CDP.

No SPP são armazenados cerca de 80.000 itens diferentes. Os itens são classificados segundo sua freqüência de venda. Os produtos mais vendidos são definidos como tipo $\mathrm{A}$ e os menos vendidos são tipo $\mathrm{E}$. A tabela 02 apresenta a distribuição de itens conforme a classificação por freqüência de venda.

Os dados históricos de um semestre revelam uma média de 3.205 itens por pedido, sendo que, em média, são recebidos 3 pedidos por dia com uma distribuição entre tipos $A$ 
até $E$ conforme ilustrado na tabela 03. Deve ficar claro que o "número de itens" e "quantidade de peças" são denominações distintas. Assim, cada item do pedido pode possuir uma quantidade diferente de peças. Por exemplo, o cliente pode solicitar 25 peças de um item e 2 peças de outro.

TABELA 02 - DISTRIBUIÇÃO DOS ITENS NA CLASSIFICAÇÃO POR FREQÜÊNCIA DE VENDA.

\begin{tabular}{|c|c|}
\hline Item tipo & Número de itens \\
\hline A & 1.522 \\
\hline B & 3.120 \\
\hline C & 25.413 \\
\hline D & 21.846 \\
\hline E & 25.311 \\
\hline Total & 77.212 \\
\hline
\end{tabular}

TABELA 03 - DISTRIBUIÇÃO DOS ITENS POR PEDIDO.

\begin{tabular}{|c|c|c|}
\hline Item tipo & Número de itens & Percentual do Pedido \\
\hline A & 1.033 & $32,23 \%$ \\
\hline B & 733 & $22,87 \%$ \\
\hline C & 1.141 & $35,60 \%$ \\
\hline D & 199 & $6,21 \%$ \\
\hline E & 99 & $3,09 \%$ \\
\hline Total & 3.205 & $100 \%$ \\
\hline
\end{tabular}

Cada pedido diário é constituído por 3 nomenclaturas de itens:

- Emergência - são os que devem ser enviados com maior urgência e são constituídos, em média, de 891 itens;

- Reposição de mercado - também aparecem com maior freqüência e constituídos por cerca de 2.169 itens;

- Exportação - totalizam cerca de 145 itens.

Somando-se todas as 3 nomenclaturas, totalizam cerca de 3.205 itens por pedido. 


\subsection{Rotina do SPP}

$\mathrm{Na}$ parte da manhã, os funcionários executam a reposição de itens do setor de recebimento para as prateleiras. Neste mesmo período, o programa computacional recebe os pedidos dos clientes. No período da tarde, os pedidos são convertidos em talões (o mesmo que LC) e entregues aos funcionários. Os talões apresentam, em suas capas, algumas informações básicas como data, hora, responsável, cliente e número total de etiquetas que compõem o talão. Um exemplo da primeira etiqueta, denominada de capa, pode ser observada na figura 14.

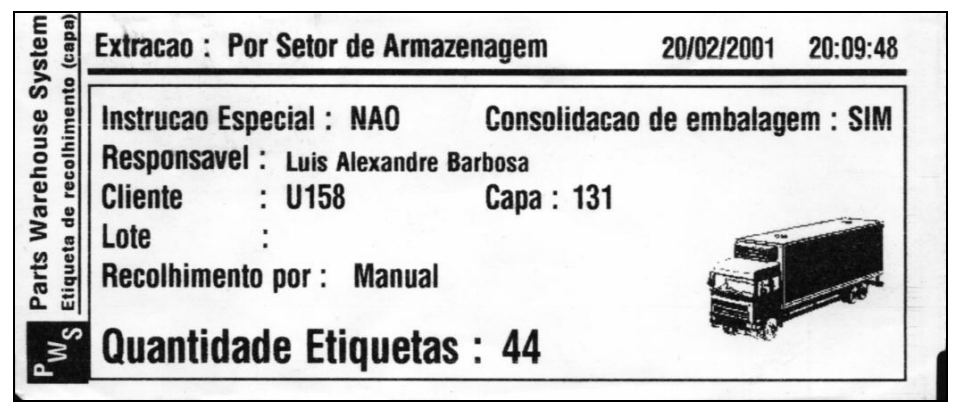

FIGURA 14 - EXEMPLO DE PRIMEIRA ETIQUETA (CAPA).

Cada talão traz vários dados da peça a ser recolhida, tais como: local ou seção, quantidade, número, nome e seqüência. A figura 15, como exemplo, apresenta a primeira etiqueta, sendo que antes desta vem a capa 131. As etiquetas são automaticamente impressas na ordem de local (endereço) para facilitar a seqüência de coleta.

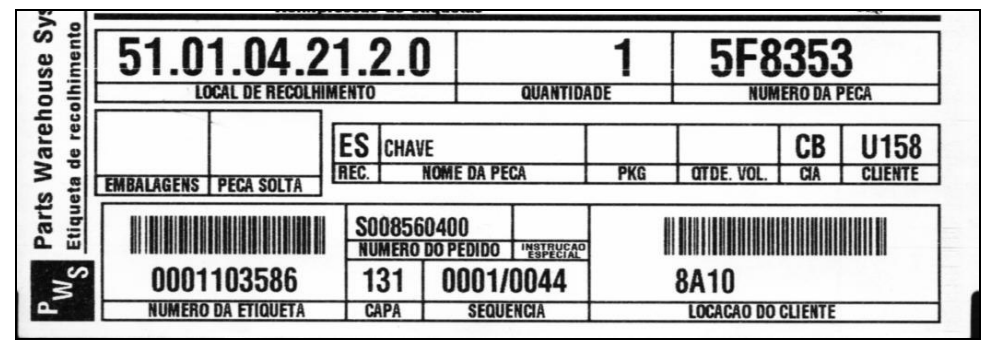

FIGURA 15 - EXEMPLO DE ETIQUETA.

O funcionário recebe o talão, pega um transportador (de capacidade de até $120 \mathrm{~kg}$ ) e segue em direção ao SPP. Seguindo a seqüência dos talões elaborada pelo sistema, o funcionário desloca-se até a seção do corredor, onde faz a identificação da peça. Sendo positiva a identificação, o funcionário recolhe da prateleira a quantidade de peças definidas para o item e as coloca no transportador. O funcionário tem em mãos um 
equipamento que executa a leitura do código de barras. Neste equipamento indica a peça e a quantidade recolhida para que seja descontada do estoque e adicionada ao pedido do cliente. Assim, na medida em que a coleta é realizada, os itens são depositados neste transportador até atingir sua capacidade. Em seguida, este é levado ao setor de empacotamento. No setor de empacotamento, os itens são descarregados do transportador e empacotados para despacho aos clientes. Este despacho acontece no período noturno. 


\section{MODELAGEM EM ARENA ${ }^{\circledR} 5.0$ DO SPP}

\subsection{Metodologia de pesquisa}

A etapa inicial de modelagem é obter, por meio da simulação, a média de tempo gasto pelos funcionários para coletar as peças de um pedido. Para isso, é importante descrever a metodologia de pesquisa utilizada, o que engloba materiais e métodos utilizados para a modelagem do SPP. Segundo Cervo \& Bervian (1996) para se conduzir uma pesquisa, deve-se levantar os instrumentos, aparelhos, materiais diversos ou documentos.

\subsubsection{Escolha do programa (software)}

A simulação, considerada como ferramenta de apoio à decisão, trabalha com modelos computacionais para a execução de seus modelos. Dessa forma, é natural que seja requisitado computadores e programas computacionais. Em outras áreas da ciência que não utilizam este tipo de ferramenta, é comum a requisição de equipamentos especiais para se coletar dados, por exemplo.

No laboratório de simulação discreta da USP - São Carlos estão disponíveis diversos equipamentos (no que se refere a computadores) e softwares, tais como Automod, Promodel e ARENA ${ }^{\circledR}$ 5.0. Os dois primeiros dão prioridade à animação gráfica, permitindo assim ao usuário do software visualizar a empresa executando, virtualmente, as suas tarefas. Estes têm uma melhor interface para com os usuários leigos nestes tipos de programa. A coleta de dados do modelo, portanto, acontece após a execução desta animação. Quanto ao terceiro programa, apesar de poder trabalhar com a animação, pode-se também coletar os dados a partir da execução do fluxograma, como descrito no capítulo 2.

O software escolhido para o desenvolvimento do trabalho foi ARENA ${ }^{\circledR}$ 5.0. porque no caso do CDP em estudo, as peças solicitadas nos talões são extremamente variadas, ou seja, as posições que os funcionários devem alcançar nas prateleiras são distintas. A animação, portanto, seria complicada de ser desenvolvida porque neste programa cada percurso, para se alcançar uma única peça, é modelado por uma única linha. Devido à alta variabilidade de peças, seria necessário modelar inúmeras linhas. Além deste aspecto de animação, este software permite o uso de linguagem básica de programação. Esta programação torna o modelo mais enxuto. No caso das inúmeras linhas, por 
exemplo, o uso de condições do tipo "if" da linguagem básica de programação permite "varrer" todas as prateleiras.

\subsubsection{Coleta de dados}

O Professor Arthur José Vieira Porto do depto. de Eng. Mecânica da Escola de Engenharia de São Carlos-USP, orientador do projeto, forneceu a planta do CDP, figura 11, para a discussão inicial da forma de como é a realização do trabalho desta empresa. Não foi realizada nenhuma visita técnica durante o mestrado, por inviabilidade econômica e por falta de disponibilidade de tempo do Professor, no entanto, o estudo é válido porque ele fez muitas visitas antes de se iniciar este trabalho e tem profundos conhecimentos dela.

As etiquetas, como apresentadas nas figuras 14 e 15, também foram fornecidas pelo Professor e foi discutida a forma de movimentação dos funcionários nos corredores em função das ordens das etiquetas, ou seja, as etiquetas definiam a movimentação seqüencial dos funcionários nos corredores. Com isso, foi possível visualizar como deveria ser o início da modelagem. Além das etiquetas, o anexo 1 foi enviado por um dos funcionários da empresa ao Professor. Nele estão contidas as informações sobre o pedido, tipos de itens existentes no CDP, dentre outras, solidificando-se assim a idéia de funcionamento de um CDP.

Além disso, este trabalho sucede ao trabalho de Colmanetti (2001). Este autor trabalhou com o mesmo Setor, porém o seu enfoque era estudar a viabilidade de se substituir a coleta de itens realizada manualmente, com auxílio de transportadores manuais, pela correia transportadora. Os detalhes do seu trabalho não são importantes de serem relatados, pois as etapas são simplesmente similares à este. As etapas iniciais da modelagem e a coleta de dados também podem ser encontradas, na íntegra, no CD-ROM do Laboratório de Simulação da Escola de Engenharia de São Carlos-USP.

Muitos dados de parâmetros foram, então, aproveitados deste trabalho tais como o tempo de coleta, velocidade do transportador, dentre outros. Alguns dados já estavam apresentados em distribuição estatística, outros foram necessários atribuir distribuições em sua amostra (dados históricos já coletados) de um período de observação. Este período de observação variava de um parâmetro ao outro, porque uns foram coletados em períodos de 1 mês, outros de 1 semana. Em decorrência da possibilidade do período de observação ser curto para certos parâmetros, pode não ser suficiente para se estimar a população já que estatisticamente é necessário ter amostras maiores do que 30 . A 
razão de se trabalhar com certos tipos de distribuições estatísticas pode ser vista, com mais detalhes, a partir da seção 4.2 .

\subsubsection{Característica do programa}

O software ARENA ${ }^{\circledR} 5.0$ trabalha com distribuições estatísticas, além de equações matemáticas. Nota-se, como já dito na seção 4.1.2, que a maioria de seus dados já eram dados em distribuição. Desta forma, utilizou-se a distribuição fornecida considerando-se que seus dados são fiéis à realidade. Os que não eram dados em distribuição, procurouse, com embasamento teórico, comentar a motivação do uso daquele tipo de distribuição. Os tópicos a seguir mostram as etapas iniciais da modelagem.

\subsection{Tipos de peças}

Como citado no capítulo 3, o SPP é composto de três andares e trabalha com as peças divididas em $A, B, C, D$ e $E$.

O modelo proposto considera apenas peças tipo $A, B$ e $C$, visto que são responsáveis por $90,7 \%$ da quantidade total dos pedidos típicos. No capítulo 3 foi comentado que o CDP atende a cerca de $90 \%$ do total de itens solicitados. Se considerarmos esta porcentagem, o valor de $90 \%$ de 3.205 itens equivale a cerca de 2.900 e este valor representa aproximadamente o mesmo valor da soma do número total de itens do pedido dos tipos A, B e C.

Considera-se também um único andar, porque as demais são idênticas a esta. A tabela 04 ilustra o número de itens se considerarmos apenas os tipos $\mathrm{A}, \mathrm{B}$ e $\mathrm{C}$.

TABELA 04 - NÚMERO DE ITENS REAIS DA PRATELEIRA DOS TIPOS A, B E C.

\begin{tabular}{|c|c|}
\hline Tipo de item & $\begin{array}{c}\text { Número de } \\
\text { itens }\end{array}$ \\
\hline A & 1.522 \\
\hline B & 3.120 \\
\hline C & 25.413 \\
\hline Total & 30.055 \\
\hline
\end{tabular}




\subsection{SPP - dimensões e sentido dos percursos}

A figura 16 apresenta a forma de movimentação dos funcionários pelos corredores. Os números próximos às setas representam a numeração das prateleiras. Nos corredores horizontais, também chamados de cross-aisles, os funcionários podem andar em ambos os sentidos, como mostram as setas avermelhadas. Já os percursos nos corredores verticais, ou subaisles, são em sentido único e marcados com setas em negrito.

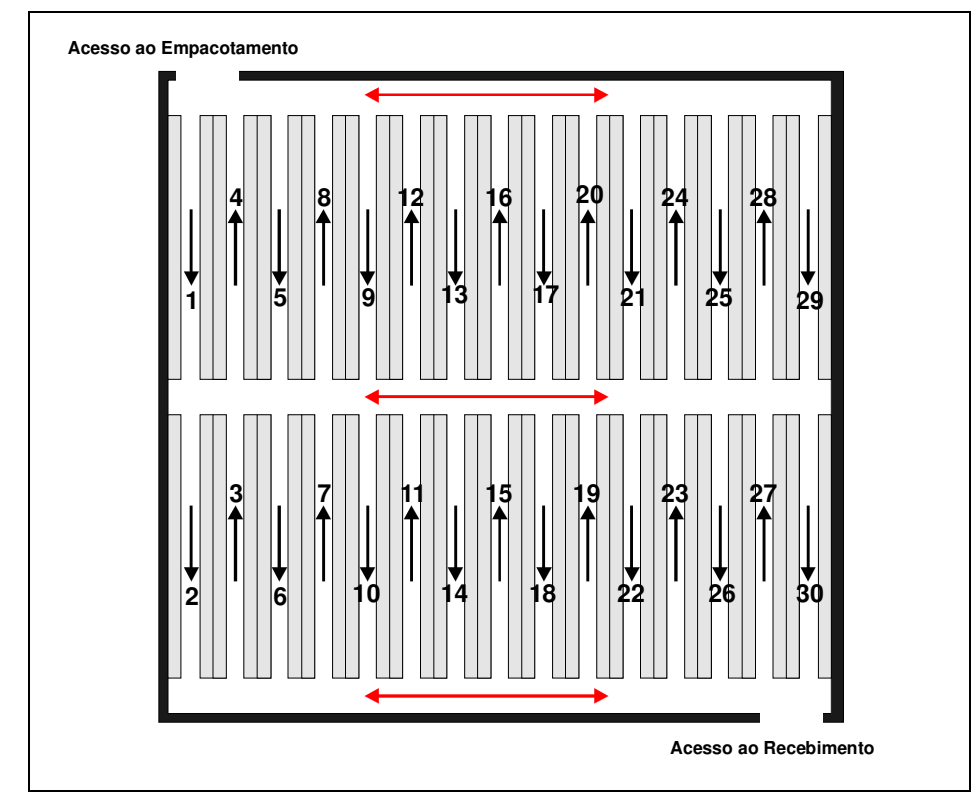

FIGURA 16 - SENTIDO DE MOVIMENTAÇÃO NOS CORREDORES.

Nos subaisles, devido às suas dimensões, é possível a circulação de apenas um único funcionário (incluindo o transportador) por vez. Sendo assim, os sentidos devem ser seguidos pelos funcionários com rigor. Por exemplo: em um certo pedido, é necessário recolher uma peça no início da prateleira 1 e outra no final da prateleira 4 (ver figura 16). Apesar da proximidade dos dois locais de coleta, é obrigatório que o funcionário realize o percurso de todo o subaisle da prateleira 1 e em seguida o da prateleira 4 para que obedeça os sentidos de movimentação.

\subsection{Disposição das peças}

A densidade de itens dispostas em um depósito é altamente variável. Essa variabilidade aumenta sensivelmente o nível de detalhe do modelo, tornando-o muito complexo, porém, com a incerteza de se obter um incremento relevante na precisão dos resultados. Devido a isso, foi adotada uma padronização na densidade de itens. $O$ 
número total de itens foi aproximado para 30.000. Como o CDP possui 30 prateleiras, tem-se uma densidade de 1.000 itens por prateleira, sendo 500 itens no lado direito e 500 no lado esquerdo. $O$ número de itens $A B C$ foi arredondado de modo que ocupassem prateleiras inteiras (tabela 05).

TABELA 05 - NÚMERO DE ITENS ADOTADO.

\begin{tabular}{|c|c|c|}
\hline & \multicolumn{2}{|c|}{ Adotado } \\
\hline Tipo de item & Quantidade & Percentual \\
\hline A & 2.000 & $6,67 \%$ \\
\hline B & 4.000 & $13,33 \%$ \\
\hline C & 24.000 & $80,00 \%$ \\
\hline Total & 30.000 & $100,00 \%$ \\
\hline
\end{tabular}

Para permitir um cálculo aproximado da posição de um item no corredor, definiu-se que cada prateleira será dividida em 10 setores ou seções e o número de gavetas de cada seção é 50 . Em cada seção existem 2 subseções, afinal os funcionários têm de selecionar qual das 2 prateleiras (esquerda ou direita) daquele subaisle se encontra o item e, portanto, existem 25 gavetas de cada lado. Cada gaveta possui 2 espaços para o armazenamento de 2 tipos de itens (ver figura 17). Na extremidade da gaveta estão fixados 2 etiquetas, onde estão registrados os nomes das peças com seus respectivos códigos. Assim, a seqüência de localização de um item é a seguinte: seção, subseção e gaveta e espaço dentro da gaveta.
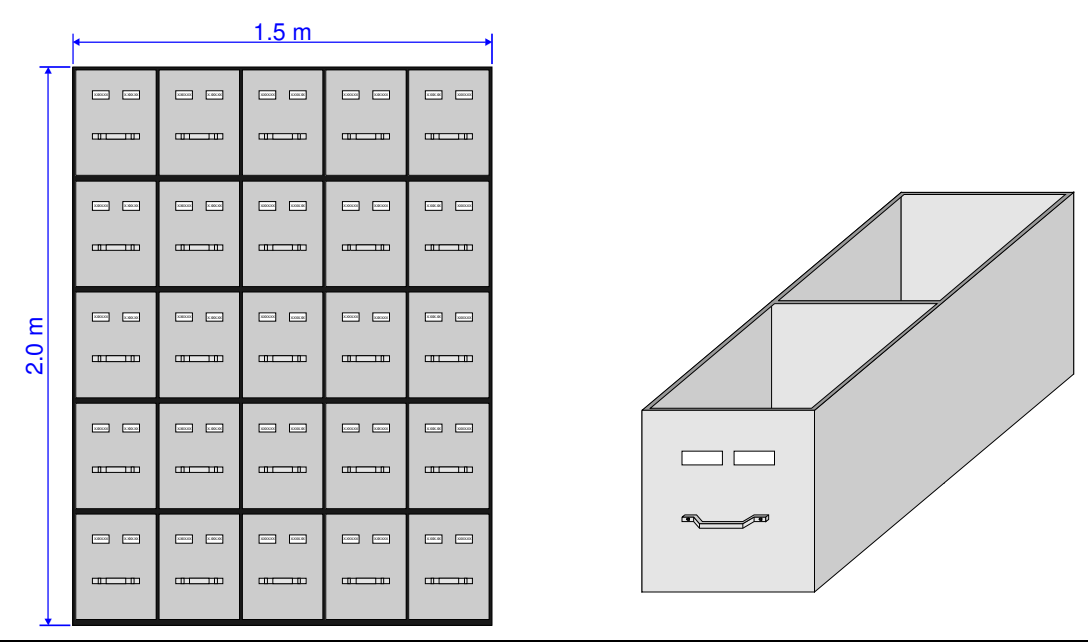

FIGURA 17 - DEFINIÇÃO DAS DIMENSÕES DO SETOR DA PRATELEIRA E DAS GAVETAS. 
Com estas definições é possível armazenar todas as 30.000 variedades de itens. $\mathrm{E}$, portanto, com estas informações, o CDP pode ser dividido conforme a sua rotatividade, como ilustrado na figura 18. Nas prateleiras indicadas em cor vermelha estão os itens de elevada rotatividade, chamados de itens tipo A. Para as de cor amarela, têm-se os itens tipo B e por fim, os itens C, que ocupam a maior parte do CDP, são indicados pela cor verde. As peças com maior freqüência de venda estão mais próximas do setor de empacotamento.

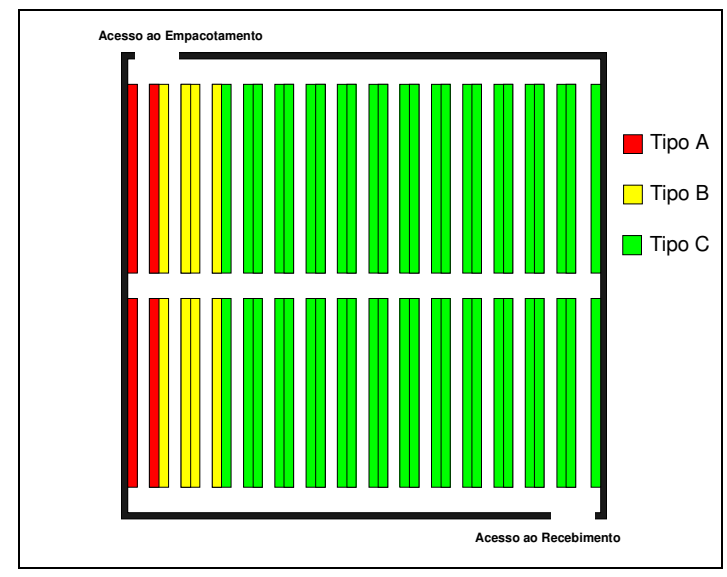

FIGURA 18 - DISPOSIÇÃO DAS PEÇAS A, B E C NO SPP.

\subsection{Modelagem do percurso - localização das seções dos corredores}

O trabalho de Brynzér \& Johansson (1996) descreve que, para coletar as peças, os funcionários, munidos de transportadores, caminham de seção em seção até coletarem todos os itens solicitados na LC. É importante que a localização da seção, onde está armazenado um determinado tipo de item, seja conhecida pois, dessa forma, é possível determinar o percurso dos funcionários nos corredores.

Os itens requisitados nos pedidos dos clientes são recebidos e convertidos em códigos de formato numérico (de 1 a 30.000) no período da manhã. Assim, dado o código do item (de 1 a 30.000 ), é possível calcular a prateleira (de 1 a 30) e a seção do subaisle (de 1 a 10). As equações (1) e (2) permitem este cálculo. A localização do item depende apenas do seu código.

$$
\text { Prateleira }=1+\operatorname{In}\left(\frac{\text { Codigo-1 }}{1000}\right) \text {, em que: }
$$

Prateleira: número da prateleira do item requisitado

Int: função que retorna a parte inteira do número

Código: código do item requisitado 


$$
\text { Seção=1+Int }\left(\frac{\text { Codigo-1 }}{1000}-\operatorname{Int}\left(\frac{\text { Codigo-1 }}{1000}\right) * 10\right) \text {, em que: }
$$

Seção: localização do item no subaisle

Int: função que retorna a parte inteira do número

Código: código do item requisitado

\subsection{Modelagem do número total de itens do pedido}

Quando se trabalha com modelos de simulação, o ideal é utilizar dados reais. Porém, em muitos casos, estes dados são difíceis de serem obtidos. A estatística permite conhecer as informações da população a partir da amostra. Assim, o uso de aproximações ou dados estatísticos permite representar os dados reais. Banks (1998) comenta que é necessário conhecer as distribuições estatísticas dos dados antes de inseri-los no modelo de simulação.

Os dados da tabela 06 representa a média de um pedido em período de 7 dias. Os valores percentuais podem então ser obtidos:

TABELA 06 - NÚMERO DE ITENS ABC DE UM PEDIDO.

\begin{tabular}{|c|c|c|}
\hline Item tipo & Número de itens & Percentual do pedido \\
\hline A & 1.033 & $35,54 \%$ \\
\hline B & 733 & $25,21 \%$ \\
\hline C & 1.141 & $39,25 \%$ \\
\hline Total & 2.907 & $100,00 \%$ \\
\hline
\end{tabular}

No entanto, existem diversos tipos de distribuições, tais como uniforme, normal e exponencial. Law \& Kelton (1991) afirmam que a distribuição triangular pode ser utilizada quando existem poucos dados disponíveis. Uma boa estimativa das informações da população só acontece a partir de uma amostra de tamanho 30, o que equivale a 30 dias.

O número de itens solicitado em um pedido será modelado segundo a distribuição triangular (TRIA) com valores 2.200, 2.500 e 3.000 (devido aos 90\% de 3205 itens). Além disso, os dados históricos revelam que muito dificilmente os pedidos possuem menos de 2.200 ou mais de 3.000 itens. Como a distribuição triangular gera números reais, utiliza-se 
uma função que retorna apenas a parte inteira (AINT) do número gerado, como apresentado na equação (3), pois o número de itens deve ser um valor inteiro.

Número de itens = AINT(TRIA(2.200, 2.500, 3.000))

Em que:

Número de itens: número de itens de um pedido escolhido aleatoriamente pelo modelo

AINT: retorna apenas o valor inteiro de um número real

TRIA: distribuição triangular

\subsection{Modelagem do número de itens do pedido por tipo $\mathrm{ABC}$}

Após definir o número total de itens de um único pedido, o modelo definirá a porcentagem de cada um dos tipos A, B e C no pedido. Para a simulação, adotam-se algumas aproximações que representem melhor esta variabilidade para o modelo. Estas aproximações, baseadas em uma distribuição uniforme (UNIF), podem ser vistas na tabela 07. A escolha da distribuição uniforme se deve ao fato de que em Arena 5.0, esta distribuição era a única que produzia resultados igualmente distribuídos na faixa de 0,3 a 0,4 . As demais produziam resultados altamente concentrados em 0,3 e em 0,4. A partir destas informações, os itens tipo A, B e C podem ser obtidos a partir das equações 4, 5 e 6.

TABELA 07 - DIVISÃO PERCENTUAL DO PEDIDO (APROXIMAÇÕES PARA A MODELAGEM).

\begin{tabular}{|c|c|}
\hline Item tipo & Percentual do pedido \\
\hline A & 30 à $40 \%$ \\
\hline B & 20 à $30 \%$ \\
\hline C & 30 à $50 \%$ \\
\hline
\end{tabular}

Itens_A $=$ AINT(UNIF $(0,3$ a 0,4) * Número de itens)

Itens_B $=$ AINT(UNIF( 0,2 a 0,3) * Número de itens)

Itens_C $=$ Número de itens - Itens_A - Itens_B

Em que:

Itens_A: número de itens tipo A

Itens_B: número de itens tipo $B$

Itens $\mathrm{C}$ : número de itens tipo $\mathrm{C}$ 
AINT: retorna apenas a parte inteira

UNIF: distribuição uniforme

Número de itens: número total de itens escolhido aleatoriamente pelo modelo

\subsection{Modelagem da quantidade de peças de cada item do pedido}

O número de peças de cada item do pedido é muito variável. Na prática, peças pesadas (tendendo a $20 \mathrm{~kg}$ ) não são solicitadas em grandes quantidades. Para resolver este problema e aproximar a simulação da realidade, foram adotadas quatro distribuições diferentes conforme a faixa de massa do item solicitado (tabela 08). Uma dessas distribuições é exponencial (EXPO). Pelo mesmo motivo, o uso da exponencial para peças até $1 \mathrm{~kg}$ foi preferível em vez da uniforme, porque é a única que pode representar um alto valor de quantidade de peças.

\section{TABELA 08 - DISTRIBUIÇÃO DA QUANTIDADE DE PEÇAS EM FUNÇÃO DE SUAS MASSAS.}

\begin{tabular}{|l|c|}
\hline \multicolumn{1}{|c|}{ Massa de cada peça } & $\begin{array}{c}\text { Quantidade de peças do } \\
\text { item }\end{array}$ \\
\hline Até $1 \mathrm{~kg}$ & $\operatorname{AINT}(\mathrm{EXPO}(7))+1$ \\
\hline De 1 até $5 \mathrm{~kg}$ & $\operatorname{AINT}(\operatorname{UNIF}(1 ; 8))$ \\
\hline De 5 até $10 \mathrm{~kg}$ & $\operatorname{AINT}(\operatorname{UNIF}(1 ; 4))$ \\
\hline De 10 até $20 \mathrm{~kg}$ & $\operatorname{AINT}(\operatorname{UNIF}(1 ; 3))$ \\
\hline
\end{tabular}

\subsection{Velocidade de deslocamento}

O tempo de deslocamento depende da distância a ser percorrida e da velocidade com que o funcionário se desloca. Esta distância, por sua vez, depende das posições das seções onde os itens se encontram, como visto nas equações 1 e 2.

O modelo proposto irá considerar a velocidade de carregamento nulo como sendo a seguinte distribuição triangular de mínimo 0,75 , moda 1,00 e máximo 1,20, em metros por segundo.

Sabe-se que quanto maior a massa depositada no transportador, maior o tempo consumido no deslocamento e, de acordo com Maynard (1970), a velocidade do transportador é obtida multiplicando-se a velocidade de carregamento nulo por um fator, 
que será denominado, neste trabalho, de Fator_V. A equação matemática para se calcular o fator de redução de velocidade pode ser vista na equação 7. Até o momento, não existe na bibliografia autores que equacionaram o impacto sobre o Fator_V.

$$
\text { Fator_V }=0,75+0,25\left(\frac{120-C \arg a[k g]}{120}\right)
$$

Em que:

Carga[kg]: é a somatória de todos os pesos das peças no transportador

Fator_V: é o fator de redução de velocidade do transportador exercido pelo peso das peças

De (7), pode-se verificar que, quando a carga estiver em $0 \mathrm{~kg}$, ou seja, o transportador estiver vazio, tem-se Fator_V $=1,00$ e quando a carga estiver em $120 \mathrm{~kg}$ (transportador na capacidade máxima) tem-se Fator_V=0,75. Experimentos poderiam determinar de forma mais precisa a variação da velocidade em função da carga. Logo, a velocidade de deslocamento será representada pela equação 8:

$$
\text { Velocidade de Deslocamento }[\mathrm{m} / \mathrm{s}]=\operatorname{DisTri}(0,75 ; 1,00 ; 1,20) * \text { Fator_V }
$$

Em que:

Fator_V: é o fator de redução de velocidade do transportador exercido pelo peso das peças

Velocidade de Deslocamento[m/s]: é a velocidade do carrinho

O valor de $120 \mathrm{~kg}$ de carga máxima no transportador é o valor atualmente suportado pelos transportadores existentes no CDP. Além disso, será implementado no modelo opções de escolha com outros valores de cargas máximas dos transportadores para tornar flexível a análise da influência da carga do transportador no tempo.

\subsection{Tempo total do processo de retirada de itens do CDP}

Frazelle (1989) cita dois dos principais componentes do tempo total do processo de retirada de itens do CDP:

a) Tempo de deslocamento - Este é o tempo despendido para percurso nos corredores até atingir a seção onde se encontra o item desejado;

b) Tempo de processamento no local ou subseção - É o tempo que o funcionário gasta para procurar a subseção mais o tempo gasto para identificar a gaveta, o que inclui também o espaço dentro da gaveta e coletar ou remover os itens da prateleira para o transportador. Estes tempos estão detalhados a seguir. 


\subsubsection{Tempo de processamento no local}

Para aproximar a simulação da realidade, foram adicionadas duas distribuições triangulares. Uma representa o tempo gasto para identificar a subseção, onde se encontra o item, conforme a equação (9). A outra se refere ao tempo que se leva para identificar a peça no local de recolhimento e, neste caso, o funcionário deve comparar o código descrito na LC com o código na gaveta ou prateleira. Este valor pode ser visto na equação (10). As distribuições foram definidas em conjunto com funcionários responsáveis pela coleta, dadas em segundos [s].

Tempo de Identificação do Local $[s]=\operatorname{TRIA}(1,5 ; 2,5 ; 4,0)$

Em que:

Tempo de Identificação do Local: é o tempo gasto na subseção para localizar a gaveta

TRIA: distribuição triangular

Tempo de Identificação da Peça $[s]=$ TRIA $(1,0 ; 1,5 ; 3,0)$

Em que:

Tempo de Identificação da Peça: é o tempo gasto para localizar o espaço da gaveta onde se encontra a peça

TRIA: distribuição triangular

O tempo de coleta das peças varia em função de dois fatores.

Maynard (1970) afirma que existem basicamente 3 grupos de movimentos das mãos para se coletar uma única peça. $O$ primeiro grupo consiste em alcançar a peça. $O$ segundo grupo de movimento consiste em movê-la e por último, consiste em girar a mão, aplicar pressão, agarrar, posicionar, desengatar e soltar a peça. Além destes movimentos, existem os tempos provenientes da movimentação e focalização dos olhos. $O$ terceiro grupo é o mais complexo, porém neste trabalho muitos são desconsiderados porque a maioria destes lida com o formato físico das peças que não são enfoques do trabalho.

A partir dos dados fornecidos (ver em anexo 2 as tabelas 25 a 32 de MAYNARD, 1970, com TMU valendo 0,036s), o tempo de coleta de uma única peça passa a ser uma distribuição triangular de mínimo 1,00, moda 1,50 e máximo 1,70, em segundos. Neste trabalho, o tempo de coleta de uma única peça será definido como uma distribuição 
triangular de mínimo 1,0, moda 3,0 e máximo 4,0, em segundos, porque além do tempo dos componentes, existe também o tempo para abrir e fechar as gavetas.

Ainda segundo o autor, existe um fator, gerado pelo peso (em $\mathrm{kg}$ ) dos itens, que pode afetar os tempos de coleta. Quanto maior a massa, maior é o tempo despendido para este item (ver tabela 09). Em particular, neste trabalho será considerado o recolhimento de apenas uma única peça de cada vez.

\section{TABELA 09 - RELAÇÃO DAS MASSAS COM SEUS RESPECTIVOS FATORES} (FONTE: ADAPTADO DE MAYNARD, 1970).

\section{Peso em lb}

$2,5 \mathrm{lb}$

$7,5 \mathrm{lb}$

12,5lb

17,5lb

22,5lb

27,5lb

$32,5 \mathrm{lb}$

$37,5 \mathrm{lb}$

42,5lb

47,5lb
Peso em kg

$1,134 \mathrm{~kg}$

$3,5 \mathrm{~kg}$

$5,67 \mathrm{~kg}$

$7,94 \mathrm{~kg}$

$10 \mathrm{~kg}$

$12,47 \mathrm{~kg}$

$14,74 \mathrm{~kg}$

$17 \mathrm{~kg}$

$19,28 \mathrm{~kg}$

$21,55 \mathrm{~kg}$

\section{Fator_P}

1

1,06

1,11

1,17

1,22

1,28

1,33

1,39

1,44

1,50

A partir da tabela 09, pode-se obter uma equação geral para o valor do Fator_P (representada pela equação 11) que será multiplicada ao tempo de coleta. Esta equação é obtida a partir da interpolação dos valores desta tabela.

$$
\begin{aligned}
& \begin{array}{lll}
1,134 \mathrm{~kg} & 1 \\
\text { Peso } & \longleftrightarrow \text { Fator_P } \\
14,74 \mathrm{~kg} & 1,33
\end{array} \\
& \left(\frac{1,134-\text { Peso }}{1,134-14,741}\right)=\left(\frac{1-\text { Fator_P }_{-}}{1-1,33}\right) \rightarrow(1,134-\text { Peso }) *(-0,33)=(-13,607) *\left(1-\text { Fator_P }_{-}\right) \rightarrow \\
& -0,374+0,33^{*} \text { Peso }=-13,607+13,607^{*} \text { Fator_P } \rightarrow \\
& 13,607^{\star} \text { Fator_P }=0,33^{\star} \text { Peso }+13,233 \rightarrow
\end{aligned}
$$


Em que:

Peso: é o peso individual da peça na mão do coletador

Fator_P: é o fator de redução de peso da peça na movimentação da mão

Porém, destes 3 grupos de movimentos da mão, apenas um grupo lida com o peso das peças, que é a movimentação da mão com o item. Portanto, a equação 11 não deve ser multiplicada diretamente no tempo de coleta, a não ser que exista uma adaptação. Para adaptá-lo, utilizaremos a terça parte (por ser de 3 grupos de movimentos) dos valores deste fator para multiplicar o tempo de coleta, resultando na equação (12):

$$
\text { Fator_P=0,0081*Peso+0,324 }
$$

Em que:

Peso: é o peso individual da peça na mão do coletador

Fator_P: é o fator de redução de peso individual da peça na movimentação da mão

Um segundo fator que pode afetar os tempos de coleta é a quantidade de peças a serem recolhidas. Quanto mais peças do item a serem coletadas, mais tempo será gasto. Dessa forma, na equação (13) tem-se o tempo de coleta.

Tempo de Coleta $[\mathrm{s}]=\mathrm{TRIA}(1,3,4) *$ Quantidade_de_Peças * Fator_P

Em que:

TRIA: é a distribuição triangular do tempo

Quantidade de Peças: quantidade de peças coletadas

Fator_P: é o fator de redução de peso individual da peça na movimentação da mão

Outro fator que poderia influenciar este tempo seria a posição do item em termos de altura na prateleira. Peças na parte central são manipuladas mais rapidamente do que as peças mais altas ou mais baixas, mas este fator não será considerado no modelo.

\subsubsection{Pesos das peças no estoque}

Para o cálculo da equação (12), é necessário conhecer o peso de cada peça em estoque. Como esses valores reais não estão disponíveis, foi criada uma base de dados com pesos aleatórios, variando entre 0,1 e $20 \mathrm{~kg}$. Os pesos são criados por um modelo no software Arena $5.0^{\circledR}$ desenvolvido especificamente para esta tarefa, e os valores gerados pelo modelo serão armazenados em um arquivo. Este procedimento tem as seguintes vantagens:

- Reduz a quantidade de entidades do modelo que irá simular o tempo de coleta; 
- Impossibilita que a cada replicação as peças tenham seus pesos alterados (não condizendo assim com a realidade), afinal o peso da peça é uma identidade única e não pode alterar de uma replicação a outra;

- Possibilita que, no futuro, valores reais dos pesos sejam usados na simulação.

\subsubsection{Modelagem dos percursos}

Independentemente de se conhecer o número de viagens necessárias para os funcionários recolherem todas as peças de um pedido, pode-se dizer que existem três movimentações distintas em cada viagem, que serão comentadas a seguir. Conhecendose os percursos, pode-se obter o tempo de deslocamento.

\subsubsection{Rotas do empacotamento para as prateleiras (com transportador vazio)}

Este tipo de movimentação depende da localização da prateleira de destino, que será chamado de primeiro componente, e da seção onde o item está localizado, que será chamado de segundo componente.

A figura 19 mostra a rota que vai do setor de empacotamento para a prateleira 1. Cada seta em azul, que é o primeiro componente, tem 1 metro de comprimento e o segundo componente, representado pela seta em vermelho, é variável (PerFin).

Note que a distância é fixa para cada rota às prateleiras, com exceção da parte final que depende da seção onde o item está localizado. Esta parte do percurso será denominada PerFin (Percurso Final) e pode ser calculada pela equação (14).

PerFin $[\mathrm{m}]=$ Secao Destino $* 1,5$

Em que:

PerFin[m]: é o percurso no subaisle para se atingir a seção desejada

Secao Destino: identifica a seção do subaisle

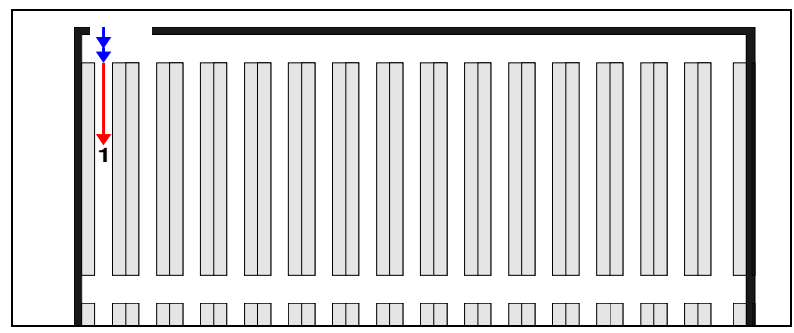

FIGURA 19 - ROTA PARA CHEGAR À PRATELEIRA 1. 
Da mesma forma, a figura 20 apresenta as rotas que chegam até as prateleiras 2 , 8, 11, 18, 21, 23 e 30. Além disso, mostra outros trajetos onde as grandes setas em preto que atravessam toda a prateleira medem 15 metros (comprimento do subaisle) e setas horizontais em verde que medem 2,5 metros (do centro de um subaisle ao centro do outro). Se o item está localizado em alguma seção da segunda prateleira, o primeiro componente do percurso é composto por quatro setas azuis e uma seta preta, totalizando 19 metros.

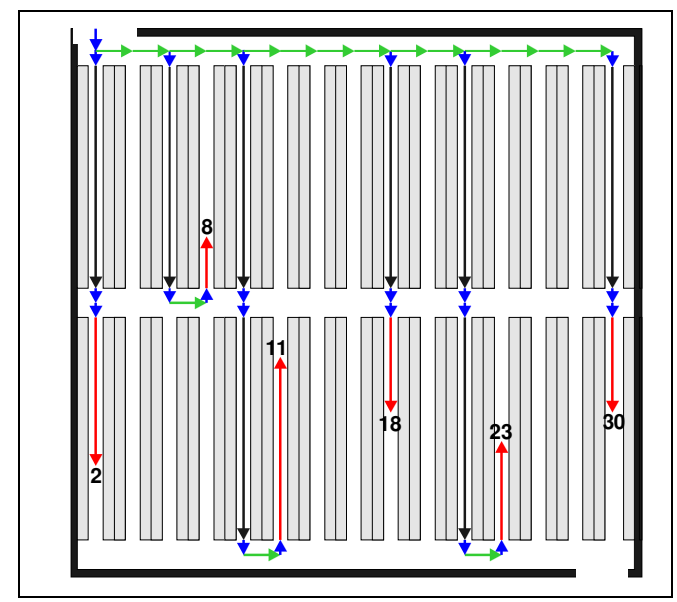

FIGURA 20 - ROTAS CHEGANDO A DIVERSAS PRATELEIRAS.

De maneira genérica, os valores dos deslocamentos nos corredores do setor de empacotamento até as seções dos corredores podem ser vistos na tabela 10.

TABELA 10 - DISTÂNCIAS DO EMPACOTAMENTO PARA CADA PRATELEIRA.

\begin{tabular}{|c|c|}
\hline Prateleira & Distância \\
\hline 01 & 02,0+PerFin \\
\hline 02 & $19,0+$ PerFin \\
\hline 03 & $38,5+$ PerFin \\
\hline 04 & $21,5+$ PerFin \\
\hline 05 & $07,0+$ PerFin \\
\hline 06 & $24,0+$ PerFin \\
\hline 07 & $43,5+$ PerFin \\
\hline 08 & $26,5+$ PerFin \\
\hline 09 & $12,0+$ PerFin \\
\hline 10 & $29,0+$ PerFin \\
\hline
\end{tabular}

\begin{tabular}{|c|c|}
\hline Prateleira & Distância \\
\hline 11 & $48,5+$ PerFin \\
\hline 12 & $31,5+$ PerFin \\
\hline 13 & $17,0+$ PerFin \\
\hline 14 & $34,0+$ PerFin \\
\hline 15 & $53,5+$ PerFin \\
\hline 16 & $36,5+$ PerFin \\
\hline 17 & $22,0+$ PerFin \\
\hline 18 & $39,0+$ PerFin \\
\hline 19 & $58,5+$ PerFin \\
\hline 20 & $41,5+$ PerFin \\
\hline
\end{tabular}

\begin{tabular}{|c|c|}
\hline Prateleira & Distância \\
\hline 21 & $27,0+$ PerFin \\
\hline 22 & $44,0+$ PerFin \\
\hline 23 & $63,5+$ PerFin \\
\hline 24 & $46,5+$ PerFin \\
\hline 25 & $32,0+$ PerFin \\
\hline 26 & $49,0+$ PerFin \\
\hline 27 & $68,5+$ PerFin \\
\hline 28 & $51,5+$ PerFin \\
\hline 29 & $37,0+$ PerFin \\
\hline 30 & $54,0+$ PerFin \\
\hline
\end{tabular}


Analisando a tabela 10, nota-se que apenas os 4 primeiros valores são básicos, dados por 2, 19, 38,5 e 21,5. As demais distâncias do primeiro componente podem ser obtidas somando-se os 4 valores básicos com múltiplos de 5 . A tabela 11 apresenta esta relação sem a parcela PerFin para tornar a visualização mais simples.

TABELA 11 - RELAÇÃO DAS DISTÂNCIAS COM OS PRIMEIROS 4 VALORES, QUE SÃO 2,0; 9,0; 38,5 E 21,5.

\begin{tabular}{|c|c|r|}
\hline Prateleira & Distância & \multicolumn{1}{c|}{ Relação } \\
\hline $\mathbf{0 1}$ & 2,0 & $2,0+0{ }^{*} 5$ \\
\hline $\mathbf{0 2}$ & 19,0 & $19,0+0{ }^{*} 5$ \\
\hline $\mathbf{0 3}$ & 38,5 & $38,5+0{ }^{*} 5$ \\
\hline $\mathbf{0 4}$ & 21,5 & $21,5+0{ }^{*} 5$ \\
\hline $\mathbf{0 5}$ & 7,0 & $2,0+1^{*} 5$ \\
\hline $\mathbf{0 6}$ & 24,0 & $19,0+{ }^{*} 5$ \\
\hline $\mathbf{0 7}$ & 43,5 & $38,5+1^{*} 5$ \\
\hline $\mathbf{0 8}$ & 26,5 & $21,5+1{ }^{*} 5$ \\
\hline $\mathbf{0 9}$ & 12,0 & $2,0+2{ }^{*} 5$ \\
\hline $\mathbf{1 0}$ & 29,0 & $19,0+2{ }^{*} 5$ \\
\hline $\mathbf{1 1}$ & 48,5 & $38,5+2{ }^{*} 5$ \\
\hline $\mathbf{1 2}$ & 31,5 & $21,5+2{ }^{*} 5$ \\
\hline $\mathbf{1 3}$ & 17,0 & $2,0+3{ }^{*} 5$ \\
\hline $\mathbf{1 4}$ & 34,0 & $19,0+3{ }^{*} 5$ \\
\hline $\mathbf{1 5}$ & 53,5 & $38,5+3{ }^{*} 5$ \\
\hline
\end{tabular}

\begin{tabular}{|c|c|r|}
\hline Prateleira & Distância & \multicolumn{1}{c|}{ Relação } \\
\hline $\mathbf{1 6}$ & 36,5 & $21,5+3^{*} 5$ \\
\hline $\mathbf{1 7}$ & 22,0 & $2,0+4^{*} 5$ \\
\hline $\mathbf{1 8}$ & 39,0 & $19,0+4^{*} 5$ \\
\hline $\mathbf{1 9}$ & 58,5 & $38,5+4^{*} 5$ \\
\hline $\mathbf{2 0}$ & 41,5 & $21,5+4^{*} 5$ \\
\hline $\mathbf{2 1}$ & 27,0 & $2,0+5^{*} 5$ \\
\hline $\mathbf{2 2}$ & 44,0 & $19,0+5^{*} 5$ \\
\hline $\mathbf{2 3}$ & 63,5 & $38,5+5^{*} 5$ \\
\hline $\mathbf{2 4}$ & 46,5 & $21,5+5^{*} 5$ \\
\hline $\mathbf{2 5}$ & 32,0 & $2,0+6{ }^{*} 5$ \\
\hline $\mathbf{2 6}$ & 49,0 & $19,0+6^{*} 5$ \\
\hline $\mathbf{2 7}$ & 68,5 & $38,5+6{ }^{*} 5$ \\
\hline $\mathbf{2 8}$ & 51,5 & $21,5+6{ }^{*} 5$ \\
\hline $\mathbf{2 9}$ & 37,0 & $2,0+7^{*} 5$ \\
\hline $\mathbf{3 0}$ & 54,0 & $19,0+7^{*} 5$ \\
\hline
\end{tabular}

Os quatro valores iniciais podem ser armazenados em um vetor, e pode-se utilizar uma lógica para selecionar o valor correto e somá-lo ao múltiplo de 5 . A figura 19 apresenta a lógica elaborada. 


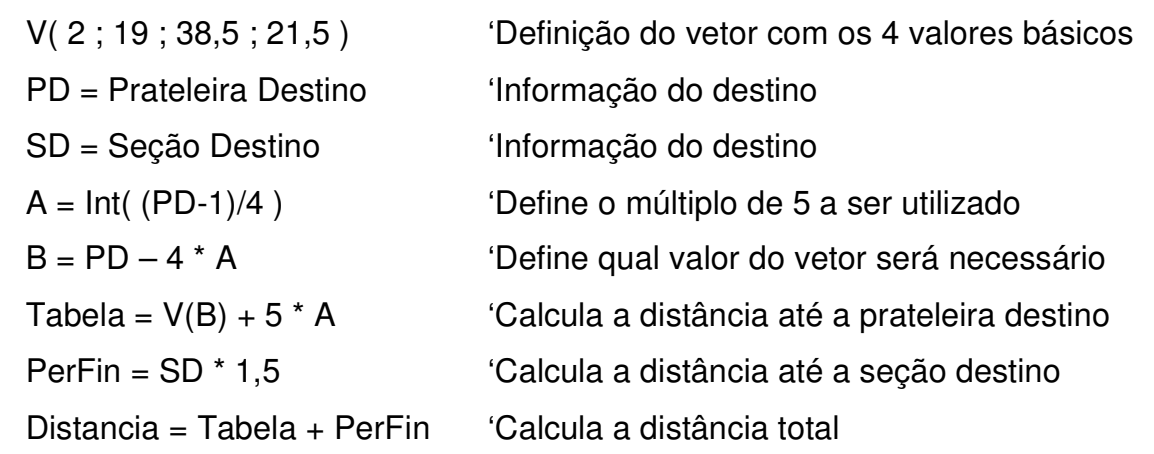

\section{FIGURA 21 - LÓGICA PARA O CÁLCULO DA DISTÂNCIA ENTRE O EMPACOTAMENTO E O DESTINO.}

\subsubsection{Rotas das prateleiras para o empacotamento (com transportador cheio)}

Após completar a carga de um transportador ou de recolher o último item da LC, o funcionário deve mover-se da prateleira até o setor de empacotamento.

Para cada prateleira, há uma rota de retorno específica que tem o primeiro componente da distância de valor fixa. Apenas uma parte desta distância (segundo componente) é variável e depende da seção onde iniciará o retorno. Esta parte do percurso será denominada Perlni (Percurso Inicial), e pode ser calculada conforme a equação (15).

$$
\operatorname{PerIni}[\mathrm{m}]=(10-\text { Secao }) * 1,5
$$

Em que:

Perlni[m]: é o percurso que parte da seção ao cross aisle

Secao: é a seção do subaisle onde foi realizada a última coleta

A figura 22 apresenta a rota da prateleira 1 para o setor de empacotamento. 0 trecho em vermelho é a variável Perlni. Cada seta em azul tem 1 metro, em verde 2,5 metros e em preto 15 metros.

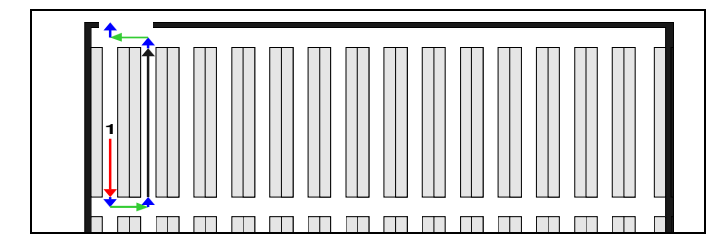

FIGURA 22 - ROTA PARTINDO DA PRATELEIRA 1. 
Da mesma forma, a figura 23 apresenta as rotas que partem das prateleiras 2, 8, $11,18,21,23$ e 30.

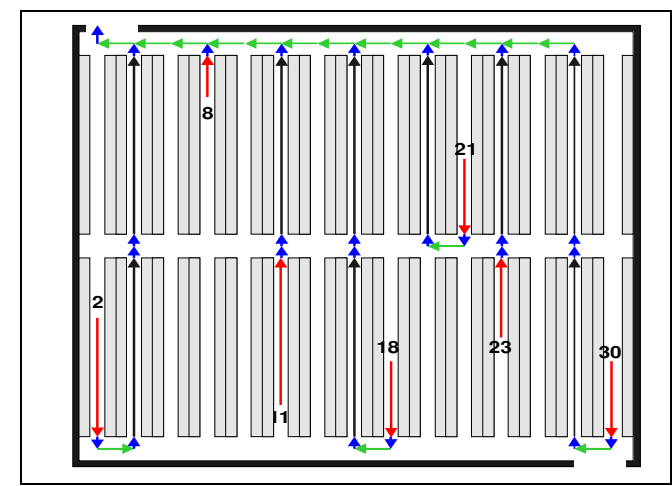

FIGURA 23 - ROTAS PARTINDO DE DIFERENTES PRATELEIRAS.

A tabela 12 mostra os valores dos percursos que os funcionários devem realizar das seções até o setor de empacotamento. Percebe-se que os valores desta tabela são somas da equação 15, representada na figura 23 pela seta de tamanho variável que se iniciam no meio das prateleiras, com as dimensões das setas em preto $(15 \mathrm{~m})$, em verde $(2,5 \mathrm{~m})$ e em azul $(1 \mathrm{~m})$.

TABELA 12 - DISTÂNCIAS , EM METROS, DE CADA PRATELEIRA ATÉ O EMPACOTAMENTO.

\begin{tabular}{|c|c|}
\hline Prateleira & Distância \\
\hline 01 & Perini $+24,0$ \\
\hline 02 & Perini $+41,0$ \\
\hline 03 & Perini $+21,5$ \\
\hline 04 & Perlni $+4,5$ \\
\hline 05 & Perlni $+24,0$ \\
\hline 06 & Perlni $+41,0$ \\
\hline 07 & Perlni $+26,5$ \\
\hline 08 & Perlni $+9,5$ \\
\hline 09 & Perlni $+29,0$ \\
\hline 10 & Perlni $+46,0$ \\
\hline
\end{tabular}

\begin{tabular}{|c|c|}
\hline Prateleira & Distância \\
\hline 11 & Perlni $+31,5$ \\
\hline 12 & Perlni $+14,5$ \\
\hline 13 & Perlni $+34,0$ \\
\hline 14 & Perlni $+51,0$ \\
\hline 15 & Perlni $+36,5$ \\
\hline 16 & Perlni $+19,5$ \\
\hline 17 & Perlni $+39,0$ \\
\hline 18 & Perlni $+56,0$ \\
\hline 19 & Perlni $+41,5$ \\
\hline 20 & Perlni $+24,5$ \\
\hline
\end{tabular}

\begin{tabular}{|c|c|}
\hline Prateleira & Distância \\
\hline 21 & Perlni $+44,0$ \\
\hline 22 & Perlni $+61,0$ \\
\hline 23 & Perlni $+46,5$ \\
\hline 24 & Perlni $+29,5$ \\
\hline 25 & Perlni $+49,0$ \\
\hline 26 & Perlni $+66,0$ \\
\hline 27 & Perlni $+51,5$ \\
\hline 28 & Perlni $+34,5$ \\
\hline 29 & Perlni $+54,0$ \\
\hline 30 & Perlni $+71,0$ \\
\hline
\end{tabular}

Analogamente à tabela 10, na tabela 12 também existe uma regra de formação com 4 valores básicos e os demais relacionados a estes por múltiplos de 5, que podem ser vistos na tabela 13. Porém, esta regra de formação só é valida a partir da terceira prateleira. A razão disso é que da terceira prateleira em diante, os funcionários retornam 
ao setor de empacotamento caminhando nos subaisles anteriores, e nas prateleiras 1 e 2 este fato já não ocorre, porque o retorno dos funcionários só pode ser realizado no subaisle posterior.

A tabela 13 apresenta esta relação, sem apresentar a parcela Perlni para tornar a visualização mais simples.

TABELA 13 - RELAÇÃO DAS DISTÂNCIAS COM OS PRIMEIROS 4 VALORES QUE SÃO 21,5; 4,5; 24,0 E 41,0.

\begin{tabular}{|c|c|r|}
\hline Prateleira & Distância & \multicolumn{1}{c|}{ Relação } \\
\hline $\mathbf{0 1}$ & 24,0 & \\
\hline $\mathbf{0 2}$ & 41,0 & \\
\hline $\mathbf{0 3}$ & 21,5 & $21,5+0{ }^{*} 5$ \\
\hline $\mathbf{0 4}$ & 4,5 & $4,5+0{ }^{*} 5$ \\
\hline $\mathbf{0 5}$ & 24,0 & $24,0+0^{*} 5$ \\
\hline $\mathbf{0 6}$ & 41,0 & $41,0+0{ }^{*} 5$ \\
\hline $\mathbf{0 7}$ & 26,5 & $21,5+1^{*} 5$ \\
\hline $\mathbf{0 8}$ & 9,5 & $4,5+1^{*} 5$ \\
\hline $\mathbf{0 9}$ & 29,0 & $24,0+1{ }^{*} 5$ \\
\hline $\mathbf{1 0}$ & 46,0 & $41,0+1^{*} 5$ \\
\hline $\mathbf{1 1}$ & 31,5 & $21,5+2{ }^{*} 5$ \\
\hline $\mathbf{1 2}$ & 14,5 & $4,5+2{ }^{*} 5$ \\
\hline $\mathbf{1 3}$ & 34,0 & $24,0+2{ }^{*} 5$ \\
\hline $\mathbf{1 4}$ & 51,0 & $41,0+2{ }^{*} 5$ \\
\hline $\mathbf{1 5}$ & 36,5 & $21,5+3^{*} 5$ \\
\hline
\end{tabular}

\begin{tabular}{|c|c|r|}
\hline Prateleira & Distância & \multicolumn{1}{c|}{ Relação } \\
\hline $\mathbf{1 6}$ & 19,5 & $4,5+3^{*} 5$ \\
\hline $\mathbf{1 7}$ & 39,0 & $24,0+3^{*} 5$ \\
\hline $\mathbf{1 8}$ & 56,0 & $41,0+3^{*} 5$ \\
\hline $\mathbf{1 9}$ & 41,5 & $21,5+4^{*} 5$ \\
\hline $\mathbf{2 0}$ & 24,5 & $4,5+4^{*} 5$ \\
\hline $\mathbf{2 1}$ & 44,0 & $24,0+4^{*} 5$ \\
\hline $\mathbf{2 2}$ & 61,0 & $41,0+4^{*} 5$ \\
\hline $\mathbf{2 3}$ & 46,5 & $21,5+5^{*} 5$ \\
\hline $\mathbf{2 4}$ & 29,5 & $4,5+5^{*} 5$ \\
\hline $\mathbf{2 5}$ & 49,0 & $24,0+5^{*} 5$ \\
\hline $\mathbf{2 6}$ & 66,0 & $41,0+5^{*} 5$ \\
\hline $\mathbf{2 7}$ & 51,5 & $21,5+6{ }^{*} 5$ \\
\hline $\mathbf{2 8}$ & 34,5 & $4,5+6{ }^{*} 5$ \\
\hline $\mathbf{2 9}$ & 54,0 & $24,0+6{ }^{*} 5$ \\
\hline $\mathbf{3 0}$ & 71,0 & $41,0+6{ }^{*} 5$ \\
\hline
\end{tabular}

Os quatro valores iniciais podem ser armazenados em um vetor, e pode-se utilizar uma lógica para selecionar o valor correto e somá-lo ao múltiplo de 5 . A figura 24 apresenta a lógica elaborada. 


\begin{tabular}{|cl|}
\hline $\begin{array}{c}\mathrm{V}(21,5 ; 4,5 ; 24 ; 41) \\
\text { Se Prateleira Origem }=1 \text { então Tabela }=24\end{array}$ & 'Vetor com os 4 valores básicos \\
Se Prateleira Origem $=2$ então Tabela $=41$ & 'Definição direta do valor \\
Se Prateleira Origem $>3$ então & 'Definição direta do valor \\
$\mathrm{A}=\operatorname{lnt}($ (Prateleira Origem -3$) / 4)$ & 'Múltiplo de 5 a ser utilizado \\
$\mathrm{B}=$ Prateleira Origem $-2-4{ }^{*} \mathrm{~A}$ & 'Define um dos valores do vetor \\
Tabela $=\mathrm{V}(\mathrm{B})+{ }^{*} \mathrm{~A}$ & 'Valor da tabela 13 \\
Fim-se & 'Distância até a seção destino \\
Perlni $=(10-$ Seção Origem $){ }^{*} 1,5$ & 'Calcula a distância total \\
Distancia $=$ Perlni + Tabela & \\
\hline
\end{tabular}

\section{FIGURA 24 - LÓGICA PARA O CÁLCULO DA DISTÂNCIA ENTRE UMA PRATELEIRA E O EMPACOTAMENTO.}

\subsubsection{Rotas entre prateleiras}

Para calcular o tempo de deslocamento entre as seções dos corredores, é necessário calcular a distância entre estes itens. Há duas situações distintas. Na primeira situação, o item seguinte da LC está localizado na mesma prateleira do item atual. A distância pode ser calculada pela equação (16).

$$
\text { Distância }[\mathrm{m}]=(\text { Seção Destino }- \text { Seção }) * 1,5
$$

Em que:

Distância[m]: é a distância a ser percorrida entre as seções da mesma prateleira ou não

Seção Destino: é a seção a ser atingida pelo coletador

Seção: é a seção onde foi realizada a última coleta

Na segunda situação, o próximo item está localizado em uma outra prateleira. Esta situação envolve três componentes:

- o deslocamento para ir até o final da prateleira atual (Perlni);

- o deslocamento da prateleira atual até a prateleira de destino; e

- o deslocamento até a seção de destino (PerFin).

Para uma fácil compreensão da lógica, as rotas serão apresentadas da última para a primeira prateleira. As primeiras rotas serão mostradas em detalhes.

A prateleira 30 , por ser a última, não possui rotas que a levem para prateleiras seguintes. Sendo assim, o cálculo do percurso é apresentado na tabela 14. Esta 
apresenta a distância a ser percorrida, em metros, para sair da seção atual e chegar à seção destino da mesma prateleira (é a própria equação 16).

TABELA 14 - ROTA PARTINDO DA PRATELEIRA 30.

\begin{tabular}{|c|c|}
\hline \multicolumn{2}{|c|}{ Prateleira 30 } \\
\hline Prateleira Destino & Distância [m] \\
\hline 30 & $(\text { Seção Destino - Seção })^{*}$ 1,5 \\
\hline
\end{tabular}

Estando na prateleira 29, é possível que a seção destino seja da própria prateleira, e o seu cálculo é mostrado em (16). Mas se a seção destino estiver na prateleira 30, será necessário avançar as seções restantes da prateleira 29, mais o espaço de 2 metros entre as duas prateleiras (o qual corresponde com a largura do cross aisle) e por fim mais as primeiras seções da prateleira 30. A tabela 15 apresenta a distâncias de cada rota.

TABELA 15 - ROTAS PARTINDO DA PRATELEIRA 29.

\begin{tabular}{|c|c|}
\hline \multicolumn{2}{|c|}{ Prateleira 29 } \\
\hline Prateleira Destino & Distância [m] \\
\hline 29 & ${\text { (Seção Destino }- \text { Seção })^{*} 1,5}^{\text {Perlni }+2+\text { PerFin }}$ \\
\hline 30 & Pen \\
\hline
\end{tabular}

Da prateleira 28 são possíveis três rotas de destino: para a própria prateleira 28 , para a prateleira 29 e para a prateleira 30. As rotas estão apresentadas na tabela 16.

TABELA 16 - ROTA PARTINDO DA PRATELEIRA 28.

\begin{tabular}{|c|c|}
\hline \multicolumn{2}{|c|}{ Prateleira 28 } \\
\hline Prateleira Destino & Distância [m] \\
\hline 28 & ${\text { (Seção Destino }- \text { Seção) }{ }^{*} 1,5} 1,5$ Perlni $+4,5+$ PerFin \\
\hline 30 & Perlni $+21,5+$ PerFin \\
\hline
\end{tabular}

A tabela 17 mostra as quatro possíveis rotas partindo da prateleira 27. Já é possível notar que as prateleiras iniciais possuem diversas possibilidades de destino. A prateleira 1 possui 30 destinos, a prateleira 2 possui 29 , a prateleira 3 possui 28 e assim 
por diante. E com isso, nota-se que as prateleiras iniciais têm mais possibilidades de destino do que as prateleiras finais.

TABELA 17 - ROTA PARTINDO DA PRATELEIRA 27.

\begin{tabular}{|c|c|}
\hline \multicolumn{2}{|c|}{ Prateleira 27 } \\
\hline Prateleira Destino & Distância [m] \\
\hline 27 & (Seção Destino - Seção) $^{*} 1,5$ \\
\hline 28 & Perlni $+2+$ PerFin \\
\hline 29 & Perlni $+21,5+$ PerFin \\
\hline 30 & Perlni $+4,5+$ PerFin \\
\hline
\end{tabular}

A figura 25 mostra cinco rotas entre prateleiras. A primeira parte da prateleira 2 e vai até a prateleira 4 . Outra rota mostra o caminho percorrido entre a prateleira 4 e a prateleira 11. Também é mostrada a distância percorrida entre a prateleira 5 e 8 . A rota seguinte parte da prateleira 17 e vai para a 18. A última movimentação é da prateleira 21 para 27.

Cada uma destas rotas mostra seu início (Perlni) e seu final (PerFin) em vermelho. Esses valores dependem da seção de origem e da seção de destino. A distância entre prateleiras é composta de partes de 1 metro (em azul), 2,5 metros (em verde) e 15 metros (em preto).

As tabelas 18a, 18b e 18c seguintes mostram todas as possibilidades de rotas entre prateleiras. Elas não apresentam os termos Perlni e PerFin para simplificar a visualização dos valores.

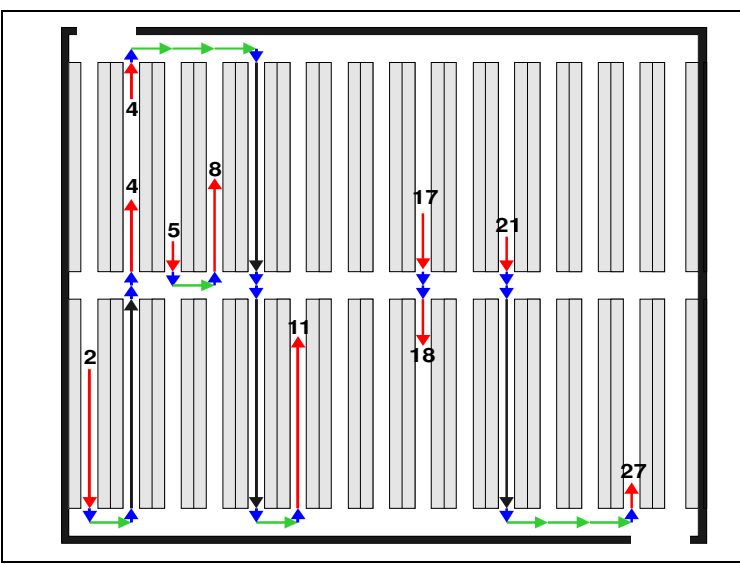

FIGURA 25 - ROTAS ENTRE DIFERENTES PRATELEIRAS. 
TABELA 18a - ROTAS COM DESTINO ÀS PRATELEIRAS 1 ATÉ 10.

\begin{tabular}{|c|c|c|c|c|c|c|c|c|c|c|}
\hline \multirow{2}{*}{ 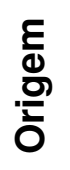 } & \multicolumn{10}{|c|}{ Prateleira de Destino } \\
\hline & 01 & 02 & 03 & 04 & 05 & 06 & 07 & 08 & 09 & 10 \\
\hline 01 & - & 2 & 21,5 & 4,5 & 24 & 7 & 26,5 & 9,5 & 29 & 12 \\
\hline 02 & - & - & 4,5 & 21,5 & 41 & 24 & 9,5 & 26,5 & 46 & 29 \\
\hline 03 & - & - & - & 2 & 21,5 & 4,5 & 24 & 7 & 26,5 & 9,5 \\
\hline 04 & - & - & - & - & 4,5 & 21,5 & 41 & 24 & 9,5 & 26,5 \\
\hline 05 & - & - & - & - & - & 2 & 21,5 & 4,5 & 24 & 7 \\
\hline 06 & - & - & - & - & - & - & 4,5 & 21,5 & 41 & 24 \\
\hline 07 & - & - & - & - & - & - & - & 2 & 21,5 & 4,5 \\
\hline 08 & - & - & - & - & - & - & - & - & 4,5 & 21,5 \\
\hline 09 & - & - & - & - & - & - & - & - & - & 2 \\
\hline 10 & - & - & - & - & - & - & - & - & - & - \\
\hline
\end{tabular}


TABELA 18b - ROTAS COM DESTINO ÀS PRATELEIRAS 11 ATÉ 20.

\begin{tabular}{|c|c|c|c|c|c|c|c|c|c|c|}
\hline \multirow{2}{*}{$\begin{array}{c}\text { 号 } \\
\text { 岕 }\end{array}$} & \multicolumn{10}{|c|}{ Prateleira de Destino } \\
\cline { 2 - 12 } & $\mathbf{1 1}$ & $\mathbf{1 2}$ & $\mathbf{1 3}$ & $\mathbf{1 4}$ & $\mathbf{1 5}$ & $\mathbf{1 6}$ & $\mathbf{1 7}$ & $\mathbf{1 8}$ & $\mathbf{1 9}$ & $\mathbf{2 0}$ \\
\hline $\mathbf{0 1}$ & 31,5 & 14,5 & 34 & 17 & 36,5 & 19,5 & 39 & 22 & 41,5 & 24,5 \\
\hline $\mathbf{0 2}$ & 14,5 & 31,5 & 51 & 34 & 19,5 & 36,5 & 56 & 39 & 24,5 & 41,5 \\
\hline $\mathbf{0 3}$ & 29 & 12 & 31,5 & 14,5 & 34 & 17 & 36,5 & 19,5 & 39 & 22 \\
\hline $\mathbf{0 4}$ & 46 & 29 & 14,5 & 31,5 & 51 & 34 & 19,5 & 36,5 & 56 & 39 \\
\hline $\mathbf{0 5}$ & 26,5 & 9,5 & 29 & 12 & 31,5 & 14,5 & 34 & 17 & 36,5 & 19,5 \\
\hline $\mathbf{0 6}$ & 9,5 & 26,5 & 46 & 29 & 14,5 & 31,5 & 51 & 34 & 19,5 & 36,5 \\
\hline $\mathbf{0 7}$ & 24 & 7 & 26,5 & 9,5 & 29 & 12 & 31,5 & 14,5 & 34 & 17 \\
\hline $\mathbf{0 8}$ & 41 & 24 & 9,5 & 26,5 & 46 & 29 & 14,5 & 31,5 & 51 & 34 \\
\hline $\mathbf{0 9}$ & 21,5 & 4,5 & 24 & 7 & 26,5 & 9,5 & 29 & 12 & 31,5 & 14,5 \\
\hline $\mathbf{1 0}$ & 4,5 & 21,5 & 41 & 24 & 9,5 & 26,5 & 46 & 29 & 14,5 & 31,5 \\
\hline $\mathbf{1 1}$ & - & 2 & 21,5 & 4,5 & 24 & 7 & 26,5 & 9,5 & 29 & 12 \\
\hline $\mathbf{1 2}$ & - & - & 4,5 & 21,5 & 41 & 24 & 9,5 & 26,5 & 46 & 29 \\
\hline $\mathbf{1 3}$ & - & - & - & 2 & 21,5 & 4,5 & 24 & 7 & 26,5 & 9,5 \\
\hline $\mathbf{1 4}$ & - & - & - & - & 4,5 & 21,5 & 41 & 24 & 9,5 & 26,5 \\
\hline $\mathbf{1 5}$ & - & - & - & - & - & 2 & 21,5 & 4,5 & 24 & 7 \\
\hline $\mathbf{1 6}$ & - & - & - & - & - & - & 4,5 & 21,5 & 41 & 24 \\
\hline $\mathbf{1 7}$ & - & - & - & - & - & - & - & 2 & 21,5 & 4,5 \\
\hline $\mathbf{1 8}$ & - & - & - & - & - & - & - & - & 4,5 & 21,5 \\
\hline $\mathbf{1 9}$ & - & - & - & - & - & - & - & - & - & 2 \\
\hline $\mathbf{2 0}$ & - & - & - & - & - & - & - & - & - & - \\
\hline
\end{tabular}


TABELA 18C - ROTAS COM DESTINO ÀS PRATELEIRAS 21 ATÉ 30.

\begin{tabular}{|c|c|c|c|c|c|c|c|c|c|c|}
\hline \multirow{2}{*}{ 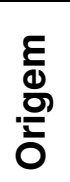 } & \multicolumn{10}{|c|}{ Prateleira de Destino } \\
\hline & 21 & 22 & 23 & 24 & 25 & 26 & 27 & 28 & 29 & 30 \\
\hline 01 & 44 & 27 & 46,5 & 29,5 & 49 & 32 & 51,5 & 34,5 & 54 & 37 \\
\hline 02 & 61 & 44 & 29,5 & 46,5 & 66 & 49 & 34,5 & 51,5 & 71 & 54 \\
\hline 03 & 41,5 & 24,5 & 44 & 27 & 46,5 & 29,5 & 49 & 32 & 51,5 & 34,5 \\
\hline 04 & 24,5 & 41,5 & 61 & 44 & 29,5 & 46,5 & 66 & 49 & 34,5 & 51,5 \\
\hline 05 & 39 & 22 & 41,5 & 24,5 & 44 & 27 & 46,5 & 29,5 & 49 & 32 \\
\hline 06 & 56 & 39 & 24,5 & 41,5 & 61 & 44 & 29,5 & 46,5 & 66 & 49 \\
\hline 07 & 36,5 & 19,5 & 39 & 22 & 41,5 & 24,5 & 44 & 27 & 46,5 & 29,5 \\
\hline 08 & 19,5 & 36,5 & 56 & 39 & 24,5 & 41,5 & 61 & 44 & 29,5 & 46,5 \\
\hline 09 & 34 & 17 & 36,5 & 19,5 & 39 & 22 & 41,5 & 24,5 & 44 & 27 \\
\hline 10 & 51 & 34 & 19,5 & 36,5 & 56 & 39 & 24,5 & 41,5 & 61 & 44 \\
\hline 11 & 31,5 & 14,5 & 34 & 17 & 36,5 & 19,5 & 39 & 22 & 41,5 & 24,5 \\
\hline 12 & 14,5 & 31,5 & 51 & 34 & 19,5 & 36,5 & 56 & 39 & 24,5 & 41,5 \\
\hline 13 & 29 & 12 & 31,5 & 14,5 & 34 & 17 & 36,5 & 19,5 & 39 & 22 \\
\hline 14 & 46 & 29 & 14,5 & 31,5 & 51 & 34 & 19,5 & 36,5 & 56 & 39 \\
\hline 15 & 26,5 & 9,5 & 29 & 12 & 31,5 & 14,5 & 34 & 17 & 36,5 & 19,5 \\
\hline 16 & 9,5 & 26,5 & 46 & 29 & 14,5 & 31,5 & 51 & 34 & 19,5 & 36,5 \\
\hline 17 & 24 & 7 & 26,5 & 9,5 & 29 & 12 & 31,5 & 14,5 & 34 & 17 \\
\hline 18 & 41 & 24 & 9,5 & 26,5 & 46 & 29 & 14,5 & 31,5 & 51 & 34 \\
\hline 19 & 21,5 & 4,5 & 24 & 7 & 26,5 & 9.5 & 29 & 12 & 31,5 & 14,5 \\
\hline 20 & 4,5 & 21,5 & 41 & 24 & 9,5 & 26.5 & 46 & 29 & 14,5 & 31,5 \\
\hline 21 & - & 2 & 21,5 & 4.5 & 24 & 7 & 26,5 & 9,5 & 29 & 12 \\
\hline 22 & - & - & 4,5 & 21,5 & 41 & 24 & 9,5 & 26,5 & 46 & 29 \\
\hline 23 & - & - & - & 2 & 21,5 & 4.5 & 24 & 7 & 26,5 & 9,5 \\
\hline 24 & - & - & - & - & 4,5 & 21.5 & 41 & 24 & 9,5 & 26,5 \\
\hline 25 & - & - & - & - & - & 2 & 21,5 & 4,5 & 24 & 7 \\
\hline 26 & - & - & - & - & - & - & 4,5 & 21,5 & 41 & 24 \\
\hline 27 & - & - & - & - & - & - & - & 2 & 21,5 & 4,5 \\
\hline 28 & - & - & - & - & - & - & - & - & 4,5 & 21,5 \\
\hline 29 & - & - & - & - & - & - & - & - & - & 2 \\
\hline
\end{tabular}




\begin{tabular}{|l|l|l|l|l|l|l|l|l|l|l|}
\hline 30 & - & - & - & - & - & - & - & - & - & - \\
\hline
\end{tabular}

Também neste caso é possível notar regras de formação dos valores. São importantes os 4 primeiros valores da linha 1 até a prateleira de destino 05, da tabela 18a, (que se repetem nas demais linhas ímpares) e os 4 primeiros valores da linha 2 até a prateleira de destino 06 (que se repetem para as outras linhas pares). Em uma mesma linha há a relação com múltiplos de 5 , de forma similar à analisada nos itens anteriores. Os valores das tabelas 18 também seguem um padrão de 4 números básicos. Porém, dependendo da prateleira de origem ser par ou ímpar, os 4 números básicos de cada grupo de prateleira destino (par ou ímpar) se tornam distintos. Existem, portanto, 8 números básicos dados por:

Prateleira de origem ímpar: 2 21,5 4,5 e 24

Prateleira de origem par: 4,5 21,5 41 e 24.

A figura 26 apresenta uma lógica que permite obter de forma simplificada os valores contidos nas tabelas 18. Foram definidos dois vetores, por serem de dois grupos, para armazenar os valores básicos e são usadas quatro informações: prateleira de origem (PO), seção de origem (SO), prateleira destino (PD) e seção destino (SD).

\begin{tabular}{|ll|}
\hline Impar( $2 ; 21,5 ; 4,5 ; 24)$ & 'Definição o vetor Impar \\
Par $(4,5 ; 21,5 ; 41 ; 24)$ & 'Definição o vetor Impar \\
Se PO=PD então & 'Se é na mesma prateleira, então... \\
Distância $=(\mathrm{SD}-\mathrm{SO}){ }^{*} 1,5$ & 'Cálculo da equação 16 \\
Senão & \\
Perlni=(10-SO $)^{\star} 1,5$ & 'Cálculo do Percurso Inicial \\
PerFin= SD*1,5 & 'Cálculo do Percurso Final \\
$\mathrm{B}=$ Int $((\mathrm{PD}-\mathrm{PO}-1) / 4)$ & 'Define qual o múltiplo de 5 \\
$\mathrm{~A}=(\mathrm{PD}-\mathrm{PO})-4{ }^{*} \mathrm{~B}$ & 'Seleciona um dos 4 valores base \\
$\mathrm{Se}(\mathrm{PO} / 2)-\operatorname{Int}(\mathrm{PO} / 2)=0$ então & 'Se a prateleira de origem é par, então... \\
Tabela=Par(A)+5* B & 'Cálculo do valor da Tabela 18 \\
Senão & \\
Tabela=Impar(A)+5 B & 'Cálculo do valor da Tabela 18 \\
Fim-Se & \\
Distancia=Perlni+Tabela+PerFin & 'Cálculo final da distância entre itens \\
Fim-Se & \\
\hline
\end{tabular}

FIGURA 26 - LÓGICA PARA CÁLCULO DA DISTÂNCIA ENTRE ITENS.

\subsection{Modelagem do desbalanceamento}

O funcionário que é responsável por recolher as peças das prateleiras iniciais irá se deslocar menos do que o funcionário que irá recolher as peças do final. A principal razão 
é que as prateleiras das peças iniciais estão próximas da porta de acesso do setor de empacotamento, enquanto que os itens finais estão distantes dessa porta. $O$ resultado disso é que a parte inicial do pedido será recolhida em menos tempo do que a parte final.

Isto leva à necessidade de desbalancear o número de itens da LC entre os funcionários. O primeiro funcionário receberia mais itens e o último menos. A tabela 19 exemplifica este raciocínio com uma LC dividida entre 5 funcionários. No caso da divisão balanceada, cada funcionário deverá recolher 100 itens, gerando, portanto deslocamentos desiguais entre os funcionários.

Para desbalancear esta lista, será adotada uma variação linear entre o primeiro e o último. Uma parcela dos itens que seriam coletados pelo último funcionário será adicionada ao primeiro. O mesmo procedimento é aplicado aos demais funcionários proporcionalmente.

Portanto, o desbalanceamento consiste em alocar uma parte dos itens da LC dos últimos funcionários (os que percorrem as prateleiras finais) aos funcionários iniciais, resultando em coletas desiguais do número de itens de forma a equilibrar os seus tempos de retirada de itens.

TABELA 19 - EXEMPLO DE DESBALANCEAMENTO DO NÚMERO DE ITENS DA LC.

\begin{tabular}{|c|c|c|c|}
\hline Funcionário & Itens balanceados & $\begin{array}{c}\text { Itens } \\
\text { desbalanceados em } \\
\mathbf{5 0 \%}\end{array}$ & Variação \\
\hline 1 & 100 & 150 & $100+50 \%$ de 100 \\
\hline 2 & 100 & 125 & $100+25 \%$ de 100 \\
\hline 3 & 100 & 100 & $100+0 \%$ de 100 \\
\hline 4 & 100 & 75 & $100-25 \%$ de 100 \\
\hline 5 & 100 & 50 & $100-50 \%$ de 100 \\
\hline
\end{tabular}

O desbalanceamento de $50 \%$ indica que o primeiro funcionário recebe $50 \%$ a mais de itens enquanto o último recebe $50 \%$ menos. Os funcionários intermediários trocam percentuais proporcionais. Para introduzir este procedimento no modelo computacional é necessário definir uma forma de variar o percentual adotado entre os funcionários. Adotou-se um Fator que varia linearmente de -1 a 1 e que é multiplicado pelo percentual de desbalanceamento desejado. Para 5 funcionários têm-se: Fator $=1$ para 0 primeiro funcionário, Fator $=0,5$ para o segundo, Fator $=0$ para o terceiro, Fator $=-0,5$ para 0 quarto e Fator $=-1$ para o quinto. É importante notar que, quando o número de 
funcionários é ímpar, o funcionário central não sofre nenhuma alteração, pois o Fator que multiplica o percentual de desbalanceamento fica nulo.

O número de itens desbalanceados da Tabela 19 pode ser calculado a partir da equação 17.

Itens_Desbalanceados $=$ Itens_Balanceados $*(1+$ Fator $*$ Percentual_de_Desbalanceamento $)$

Em que:

Itens Desbalanceados: é o número de itens a serem recebidos por cada funcionário após o desbalanceamento

Fator: é a normalização da porcentagem de desbalanceamento

Percentual de Desbalanceamento: percentual do número de itens que será transferido do último funcionário ao primeiro

\subsubsection{Curvas de desbalanceamento}

Para modelar esse desbalanceamento, é necessário definir uma equação linear que varie de 1 até -1 do primeiro ao último funcionário. A figura 27 apresenta um gráfico contendo as 7 equações lineares plotadas. Ao definir-se o número de funcionários, está sendo escolhida uma das retas do gráfico. No caso da tabela 19, com 5 funcionários, a reta a ser usada para obter os valores dos Fatores é a central.

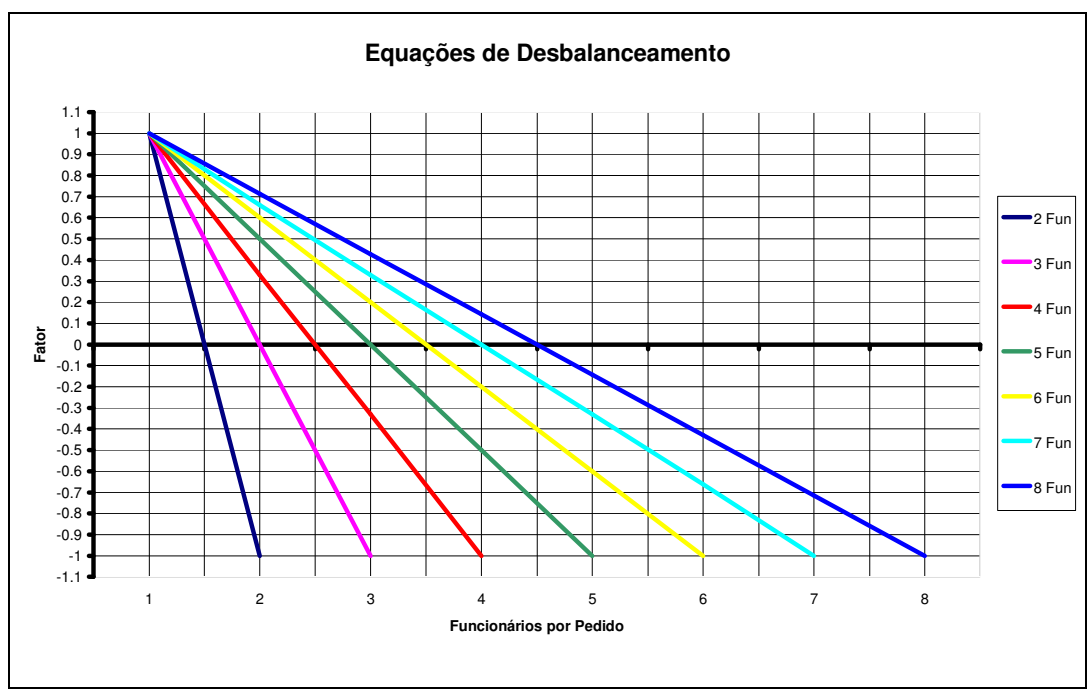

FIGURA 27 - EQUAÇÕES PARA DESBALANCEAMENTO. 


\subsubsection{Equações de desbalanceamento}

Ao invés de implementar as 7 equações de desbalanceamento, pode-se buscar uma equação genérica para o cálculo dos fatores de acordo com o número de funcionários.

A tabela 20 apresenta todas as 7 equações, na forma $Y=a^{*} X+b$ para permitir uma comparação e buscar uma regra de formação em comum, onde $Y$ é $O$ fator de desbalanceamento e $\mathrm{X}$ o número do funcionário.

TABELA 20 - EQUAÇÕES DE DESBALANCEAMENTO.

\begin{tabular}{|c|l|}
\hline Número de Funcionários & Equação \\
\hline 2 & $Y=-2^{\star} X+3$ \\
\hline 3 & $Y=-1^{\star} X+2$ \\
\hline 4 & $Y=-0,667^{\star} X+1,667$ \\
\hline 5 & $Y=-0,5^{\star} X+1,5$ \\
\hline 6 & $Y=-0,4^{\star} X+1,4$ \\
\hline 7 & $Y=-0,333^{\star} X+1,333$ \\
\hline 8 & $Y=-0,2857^{\star} X+1,2857$ \\
\hline
\end{tabular}

Observando a tabela 20, nota-se que todas equações mantém a mesma relação entre os coeficientes a e b, já que $Y=a X+b$. Esta relação é definida pela equação (18).

$$
\mathrm{a}=-\mathrm{b}+1
$$

Em que:

a: coeficiente de $X$

b: coeficiente da constante

É necessário então relacionar o coeficiente b com o número de funcionários. Esta relação é apresentada pela equação (19).

$$
\mathrm{b}=1+\frac{2}{\text { Número_de_Funcionários }-1}
$$

Em que:

B: coeficiente da constante

Número de Funcionários: é o número total de funcionários que receberão as LC's 
A equação (20) apresenta o cálculo dos itens desbalanceados, que leva em consideração todas as variáveis. Para simplificar a notação, foram adotados os seguintes padrões:

Itens_desbalanceados $=$ Arredondamento $\left(\frac{N I P}{N F}+(a * F+b) * \frac{N I P}{N F} * P D\right)$

Em que:

NIP: número de itens do pedido

NF: número de funcionários

F: funcionário atual

PD: percentual de desbalanceamento

a: coeficiente de $X$ (coordenada $X$ da figura 27 )

b: coeficiente da constante da equação originada pelas curvas da figura 27

Itens desbalanceados: é o número de itens recebido pelo funcionário de número $\mathrm{F}$

Pode-se agora verificar a funcionalidade do cálculo, comparando a equação 20 com a tabela 19 que dividiu 500 itens para 5 funcionários com $50 \%$ de desbalanceamento. Mas, antes deve-se usar a equação (19) para se obter os valores das incógnitas a e b. Para este caso têm-se os seguintes valores:

$$
a=-0,5 \quad \mathrm{~b}=1,5 \quad \mathrm{NI}=500 \quad \mathrm{NF}=5 \quad \mathrm{PD}=0,5
$$

Porém, no modelo desenvolvido onde se lida com a ordenação e divisão de código dos itens, é necessário que os códigos sejam acumulativos, como ilustrados na tabela 21. Isto acontece porque deve-se somar os itens já colhidos com os que serão coletados pelo funcionário atual, ou seja, o funcionário 2 irá coletar até o item de código 275 do pedido, pois o primeiro coletou até o item 150 e ele tem de coletar 125 itens, considerando-se que no pedido existam 500 itens (de código 1 a 500 sem faltar um código sequer).

TABELA 21 - EXEMPLO DE ITENS ACUMULADOS POR 5 FUNCIONÁRIOS.

\begin{tabular}{|c|c|c|c|}
\hline Funcionário & $\begin{array}{c}\text { Itens } \\
\text { balanceados }\end{array}$ & $\begin{array}{c}\text { Itens desbalanceados } \\
\text { em } \mathbf{5 0 \%}\end{array}$ & $\begin{array}{c}\text { Itens desbalanceados } \\
\text { acumulados }\end{array}$ \\
\hline 1 & 100 & 150 & 150 \\
\hline 2 & 100 & 125 & 275 \\
\hline 3 & 100 & 100 & 375 \\
\hline 4 & 100 & 75 & 450 \\
\hline 5 & 100 & 50 & 500 \\
\hline
\end{tabular}


A figura 28 mostra a lógica utilizada para permitir obter os itens desbalanceados acumulados.

\begin{tabular}{|c|c|}
\hline$b=1+2 /(N F-1)$ & 'Cálculo do coeficiente b \\
\hline$a=-b+1$ & 'Cálculo do coeficiente a \\
\hline$S I A=0$ & 'Inicializa o Somatório de Itens Anteriores \\
\hline$N I A=0$ & 'Inicializa o Número de Itens Anteriores \\
\hline \multicolumn{2}{|l|}{ Para F de 1 até NF faça } \\
\hline \multicolumn{2}{|c|}{ Itens_do_Funcionário=Arredondamento $\left(\left(a^{*} F+b\right)^{\star} N I P / N F^{\star} P D\right)$} \\
\hline$S I A=S I A+N I A$ & 'Atualiza o Somatório de Itens Anteriores \\
\hline \multicolumn{2}{|c|}{ ItemFinal $=\left(\mathrm{NIP} / \mathrm{NF}{ }^{*} \mathrm{~F}\right)+$ Itens_do_Funcionário $+\mathrm{SIA} \quad$ 'Valor Desejado } \\
\hline \multicolumn{2}{|l|}{ NIA = Itens_do_Funcionário } \\
\hline Fim - Para & \\
\hline
\end{tabular}

FIGURA 28 - CÁLCULO DO ITEM FINAL DE CADA FUNCIONÁRIO. 


\section{SIMULAÇÕES E RESULTADOS}

\subsection{Comentários iniciais}

A abordagem inicial é verificar se realmente o modelo proposto é condizente com o sistema real em estudo. Caso contrário, se algum novo cenário fosse proposto ou então alguma técnica fosse criada sobre este modelo, não poderia ser aplicada ao sistema real.

Em seguida, o trabalho busca identificar se de fato o tempo de deslocamento é maior que as demais componentes do tempo do processo. Caso contrário, não seria importante propor algum tipo de melhoria no deslocamento, visando a redução do seu tempo, sendo que a maior composição está em outro componente.

No decorrer do trabalho para a obtenção dos resultados, surgiu a idéia de se criar o desbalanceamento do número de itens da lista de coleta entre os funcionários. Além de se desbalancear a lista de coleta, são criados diversos cenários para verificar se é possível reduzir ainda mais o tempo total deste processo.

\subsection{Simulação 1 - etapas que visam validar o modelo}

\subsubsection{Simulação com 1 funcionário e todos os itens do pedido}

A figura 29 mostra os resultados obtidos com a simulação do tempo gasto para completar um pedido com apenas um funcionário, em 30 replicações. As configurações são:

- quantidade variável de itens

- 1 funcionário

- carga máxima de $120 \mathrm{~kg}$

- velocidade variável

Cabe lembrar que um pedido é composto por aproximadamente 2.900 itens e o programa irá usar um valor aleatório que esteja entre 2.200, 2.500 e 3.000. 


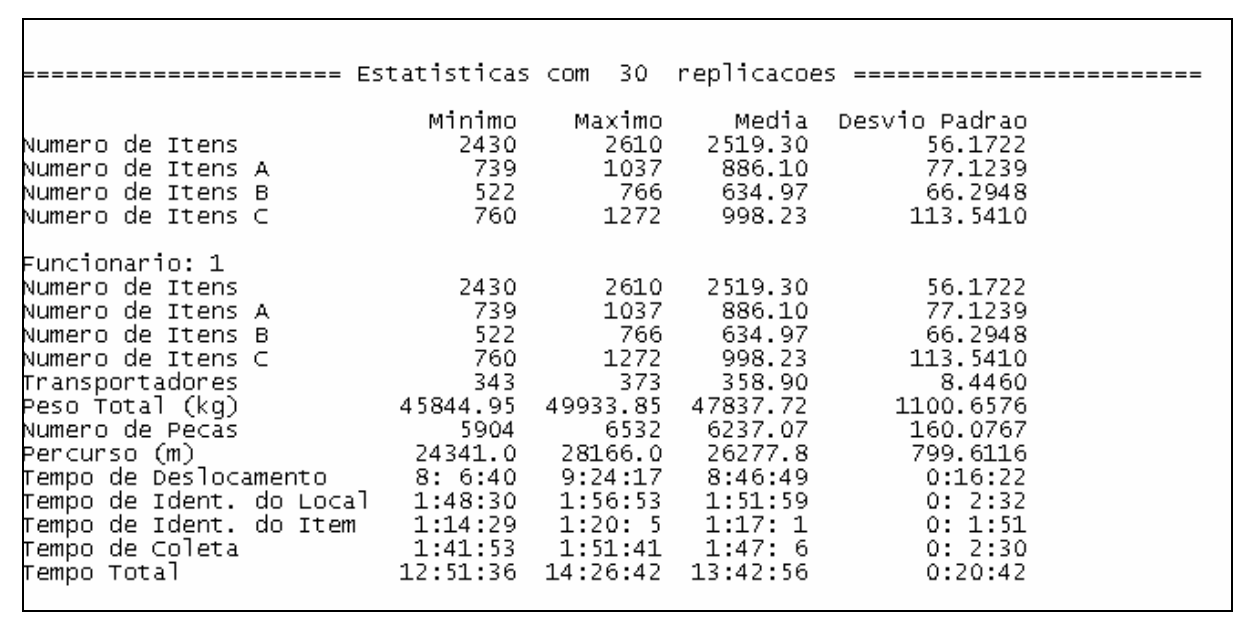

\section{FIGURA 29 - RESULTADOS DA PRIMEIRA SIMULAÇÃO.}

Os resultados chamam a atenção porque, em média, um funcionário gasta 13 horas e 42 minutos para coletar 2.519 itens, percorrendo 26,3 km e utilizando 359 transportadores manuais.

Para possibilitar futuras comparações, foi elaborado o gráfico com os componentes do tempo do processo, conforme apresentado na figura 30. Nota-se, que a maior parcela de tempo é gasta com a atividade de deslocamento.

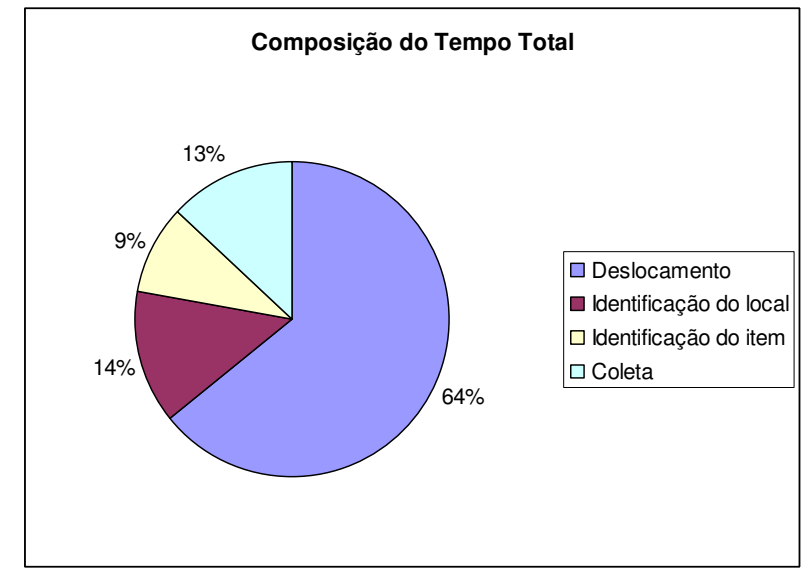

FIGURA 30 - COMPOSIÇÃO DO TEMPO TOTAL PARA 1 FUNCIONÁRIO.

Com base nesta simulação imaginou-se que, para trabalhar dentro das 4 horas da parte da tarde, um funcionário coletaria cerca de 800 itens. O raciocínio foi o seguinte: (13 horas e 42 minutos) / 4 horas $\approx 3$, e sendo assim, 2.519 itens / $3 \approx 800$ itens. Isso gerou a próxima simulação. 


\subsubsection{Simulação com 1 funcionário e 800 itens}

A figura 31 mostra os resultados obtidos em 30 replicações. As configurações são: quantidade de itens fixa em 800 itens, 1 funcionário, carga máxima de $120 \mathrm{~kg}$ e velocidade variável.

O tempo total médio foi de 4 horas e 26 minutos, um pouco acima das 4 horas esperadas. Isto leva à decisão de se utilizar até 2 funcionários para coletarem 800 itens.

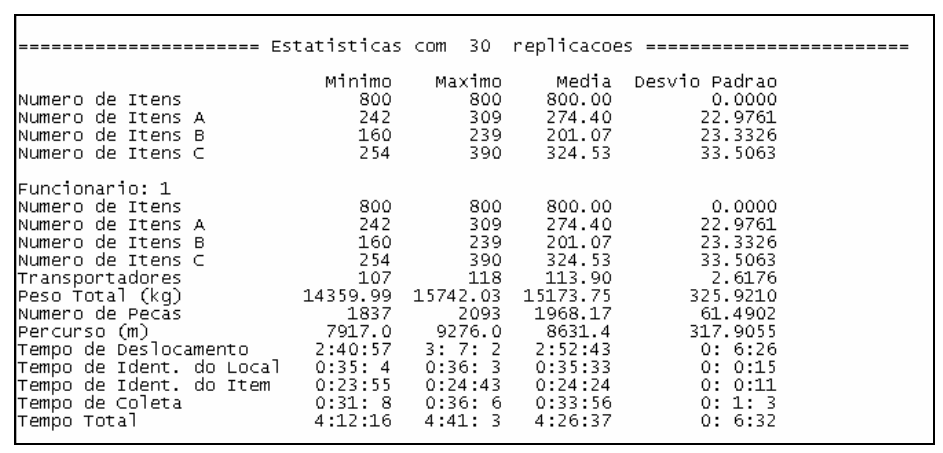

\section{FIGURA 31 - RESULTADOS DA SEGUNDA SIMULAÇÃO.}

A figura 32 apresenta um gráfico com os componentes do tempo deste processo. A divisão dos tempos praticamente mantém a mesma relação que na simulação 1.

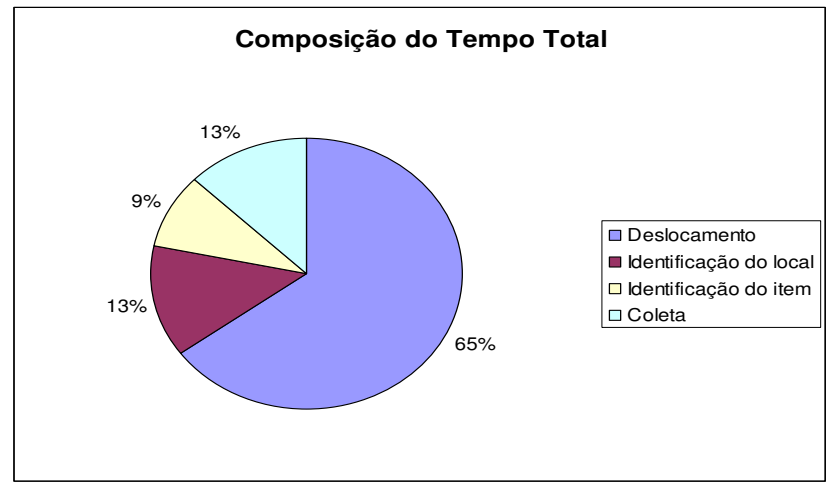

FIGURA 32 - COMPOSIÇÃO DO TEMPO TOTAL PARA 1 FUNCIONÁRIO E 800 ITENS.

\subsubsection{Simulação com 4 funcionários}

As configurações para esta simulação são:

- quantidade variável de itens

- 4 funcionários 
- divisão balanceada ( $\approx 2.500$ itens divididos igualmente para 4 funcionários)

- carga máxima de $120 \mathrm{~kg}$

- velocidade variável.

A figura 33 mostra um gráfico com os tempos totais médios de cada funcionário, baseados nos resultados obtidos em 30 replicações.

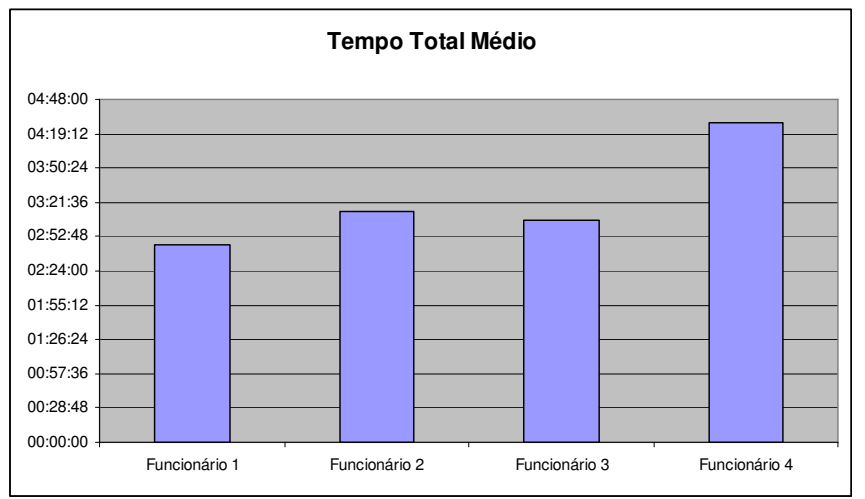

FIGURA 33 - TEMPO TOTAL MÉDIO DE 4 FUNCIONÁRIOS COM DIVISÃO BALANCEADA DO NÚMERO DE ITENS.

Como era esperado, apesar de cada funcionário coletar o mesmo número de itens, há uma diferença de quase 2 horas entre o tempo do primeiro e do último funcionário.

A tabela 22 exibe os tempos médios de cada funcionário. Por esta tabela, os tempos de identificação do local são muito próximos. O mesmo acontece com os tempos de identificação dos itens e tempos de coleta. A figura 34 mostra um gráfico montado com os dados da tabela 22 .

TABELA 22 - TEMPOS MÉDIOS PARA 4 FUNCIONÁRIOS.

\begin{tabular}{|l|c|c|c|c|}
\hline & Funcionário 1 & Funcionário 2 & Funcionário 3 & Funcionário 4 \\
\hline Deslocamento & $01: 32: 42$ & $02: 01: 00$ & $01: 53: 13$ & $03: 15: 06$ \\
\hline Ident. do Local & $00: 27: 20$ & $00: 27: 26$ & $00: 27: 33$ & $00: 27: 24$ \\
\hline Ident. do Item & $00: 18: 46$ & $00: 18: 49$ & $00: 18: 51$ & $00: 19: 05$ \\
\hline Coleta & $00: 26: 50$ & $00: 26: 23$ & $00: 26: 32$ & $00: 26: 22$ \\
\hline Total & $02: 45: 39$ & $03: 13: 40$ & $03: 06: 10$ & $04: 27: 58$ \\
\hline
\end{tabular}




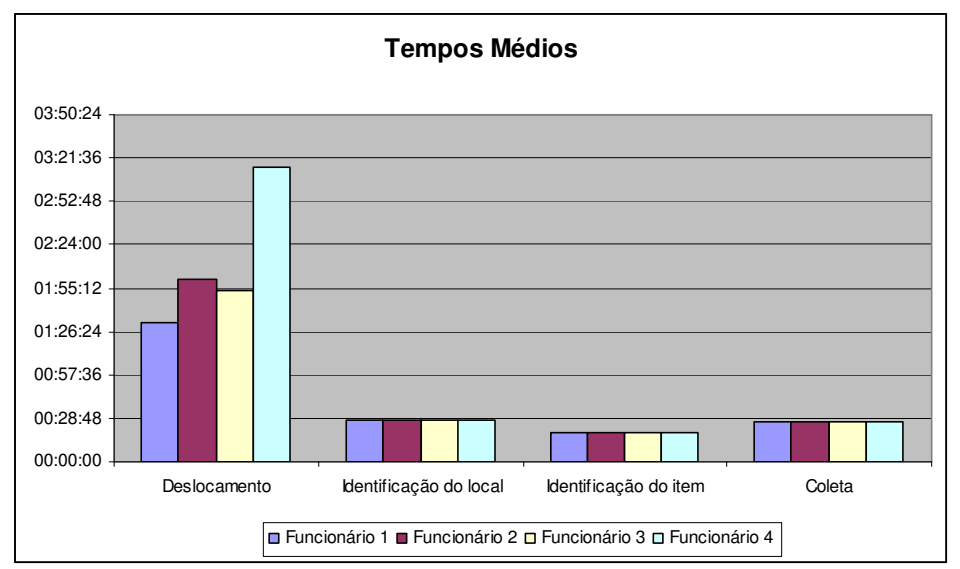

FIGURA 34 - COMPOSIÇÃO DO TEMPO TOTAL PARA 4 FUNCIONÁRIOS.

O aumento gradativo do número de funcionários reduz o tempo total médio do processo de retirada de itens. O tempo médio do funcionário 4 é $26 \mathrm{~min}$. superior ao período da tarde.

Se houverem mais funcionários, este processo terminaria antes do período de 4 horas de coleta e passariam a estar na condição de ociosidade, a não ser que os mesmos funcionários possam executar outras atividades neste período. $\mathrm{O}$ aumento do número de funcionários faz reduzir o tempo total deste processo, porém deve-se tomar precauções quanto ao custo envolvido. Afinal, o propósito deste trabalho é exatamente reduzir o custo proveniente do tempo total médio e, o aumento de funcionários pode gerar custos relativamente altos. Por outro lado, poucos funcionários não serão capazes de consolidar os pedidos solicitados no dia, como é o caso de 1 único funcionário ou até mesmo de 2 funcionários participando da coleta.

Pode-se notar que o modelo estudado produz resultados bastante semelhantes ao do sistema real. O resultado do modelo mostra que são necessários aproximadamente de 4 funcionários no processo por pedido. Como são 3 pedidos diários, são necessários 12 funcionários, condizendo aproximadamente ao sistema real que necessita de 13 funcionários só no processo de coleta. Dessa forma, pode-se afirmar que o modelo está preparado para estudo de cenários.

Pela figura 34 é possível concluir que a diferença nos tempos é proveniente da diferença das distâncias a serem percorridas entre o setor de empacotamento e as prateleiras. Dessa forma, no tópico 5.3 é apresentada a aplicação da técnica de desbalanceamento do número de itens das LC para minimizar esta diferença. 


\subsection{Simulação 2 - avaliação de cenários}

\subsubsection{Busca e aplicação do desbalanceamento ideal}

Com a implementação no modelo da possibilidade de desbalancear o número de itens por funcionário, é possível executá-lo com diversos valores em simulação. A figura 35 mostra os resultados obtidos com diversos níveis de desbalanceamento, para 4 funcionários atuando no processo.

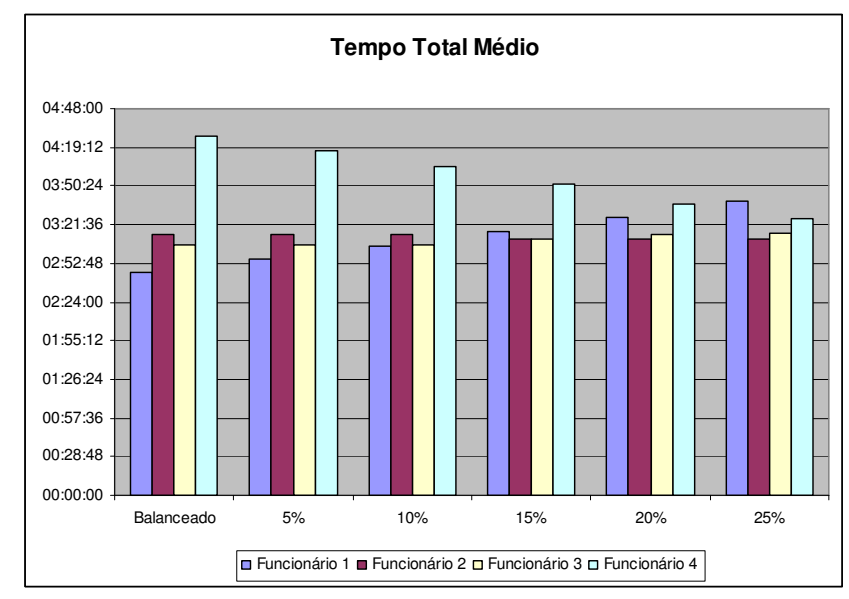

FIGURA 35 - TEMPOS TOTAIS MÉDIOS POR FUNCIONÁRIO COM DIVERSOS DESBALANCEAMENTOS.

Os resultados da figura 35 indicam que o desbalanceamento de $20 \%$ é o que melhor permitiu equilibrar o tempo total de retirada de itens de todos os funcionários. Conforme já explicado, a coleta de um pedido só é completada quando todos os funcionários encerram a coleta de suas partes da LC. Assim, na situação balanceada (tópico 5.2.3) a coleta é encerrada às 4 horas, 27 minutos e 58 segundos, que é o tempo gasto pelo funcionário 4 . Portanto, ele ultrapassa o período de 4 horas do expediente da tarde. Além disso, verifica-se que há diferença em torno de 2 horas entre os tempos dos funcionários.

Com o desbalanceamento de $20 \%$, a coleta encerra-se quando o funcionário 4 termina a sua parte da LC com 3 horas, 35 minutos e 31 segundos. Comparando-se estas duas situações, verifica-se uma redução de $19,57 \%$ no tempo de finalização do pedido.

Nota-se também que o efeito de um alto valor de desbalanceamento resulta em efeitos opostos comparados ao da LC balanceada, ou seja, o tempo despendido pelos 
funcionários que realizam as coletas das peças nos corredores finais do CDP praticamente é transferido aos que realizam as coletas nos corredores iniciais.

Vale ressaltar que, em todos os valores dos desbalanceamentos analisados, incluindo a LC balanceada, as desigualdades dos tempos totais médios entre os funcionários se referem aos corredores percorridos e não às diferenças do número de itens.

O desbalanceamento da LC deve ser analisado com atenção, pois valores inadequados podem acarretar em aumento no tempo total médio de certos funcionários.

O desbalanceamento de $20 \%$, que obteve bons resultados no CDP estudado, ainda não é considerado ideal, porque os tempos totais médios, poderiam estar mais próximos. Porém, dificilmente estes tempos irão coincidir, pois dependem de diversas variáveis, tais como: divisão do pedido realizada pelo computador, capacidade do transportador, disposição e formato dos corredores, velocidade de deslocamento e até mesmo da experiência dos funcionários.

A execução e análise de simulações em torno de $20 \%$ poderão definir um valor de desbalanceamento que aproxime ainda mais os tempos médios de coleta para o CDP em estudo. Além disso, podem ser propostas novas formas de desbalanceamento, diferentes da linear analisada neste trabalho.

Os resultados indicaram, portanto, que cerca de 4 funcionários com um desbalanceamento de $20 \%$ da lista de coleta conseguem retirar 2.500 itens da prateleira.

Desta forma, são necessários cerca de 12 funcionários para coletarem todos os 3 pedidos do dia, que totalizam 7.500 itens.

\subsubsection{Simulação com 3 funcionários e desbalanceamento de $20 \%$}

Considera-se, a seguir, um outro experimento com 3 funcionários e um desbalanceamento de 20\%. Deve-se analisar se, com esta decisão, os tempos totais de cada funcionário não excedem o período de 4 horas, afinal, com 4 funcionários, existe um tempo ocioso que poderia ser minimizado caso um funcionário fosse removido do serviço e portanto os dados da figura 36, que apresenta os resultados desta simulação, deverão ser comparados ao da figura 35. 


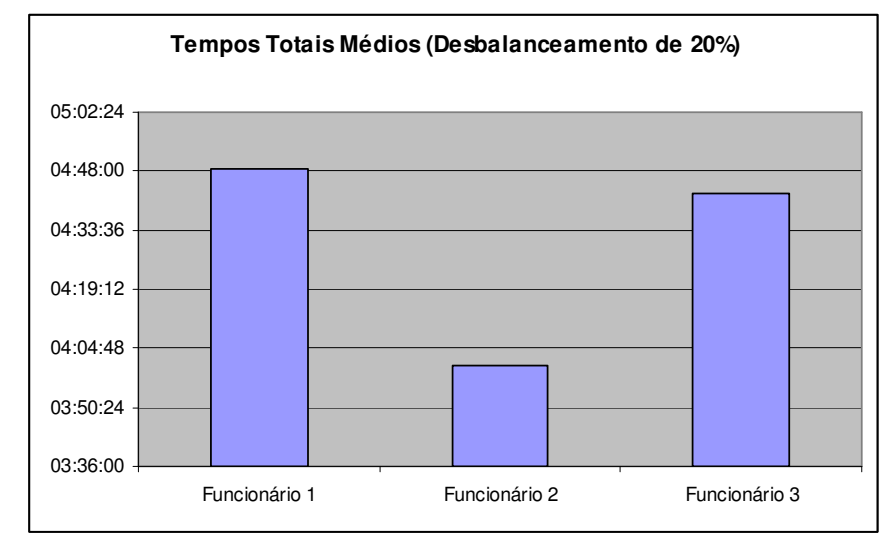

\section{FIGURA 36 - TEMPO TOTAL MÉDIO PARA 3 FUNCIONÁRIOS.}

Nas simulações, realizadas nos tópicos 5.3.1 e 5.3.2, foram utilizadas as seguintes configurações: número variável de itens, 30 replicações, velocidade variável, carga máxima de $120 \mathrm{~kg}$. Os resultados da figura 36 indicam que o CDP deve utilizar 4 funcionários e com as listas de coleta desbalanceadas em $20 \%$, já que se fosse com apenas 3 funcionários ultrapassariam o período de 4 horas de serviço.

\subsubsection{Simulação com alteração da velocidade de deslocamento}

A velocidade assumida nas simulações anteriores, medida diretamente do transportador é gerada por uma distribuição triangular de $(0,75 ; 1,00 ; 1,20)$, em metros por segundo, multiplicada pelo fator_V, por causa da influência da carga do transportador.

Neste tópico, a velocidade será mantida constante, em vez de uma distribuição triangular, devido aos transportadores existentes no mercado como os elétricos e autoguiados (AGV's), supondo-se, nestes casos, que os transportadores, mesmo com o aumento da carga, conseguem atingir e manter constante a sua velocidade máxima. As simulações seguintes buscam comparar o ganho de tempo quando a velocidade máxima é fixa, ou seja, quando não sofre influência da carga (Fator_ $V=1$ ). As velocidades máximas assumidas para o modelo são $1 \mathrm{~m} / \mathrm{s}$ e $1,5 \mathrm{~m} / \mathrm{s}$.

A figura 37 mostra o resultado obtido para 30 replicações, com 4 funcionários, carga máxima de $120 \mathrm{~kg}$ e desbalanceamento de $20 \%$. Além de uma redução no tempo por causa das velocidades de 1 e 1,5m/s, é possível perceber uma menor flutuação entre os tempos dos funcionários a medida em que a velocidade é aumentada, como é o caso da velocidade do transportador de $1,5 \mathrm{~m} / \mathrm{s}$. As diferenças de tempo entre os funcionários chegam a ser de apenas $20 \mathrm{~min}$. (que é a diferença entre o funcionário 1 e funcionário 3 ). 


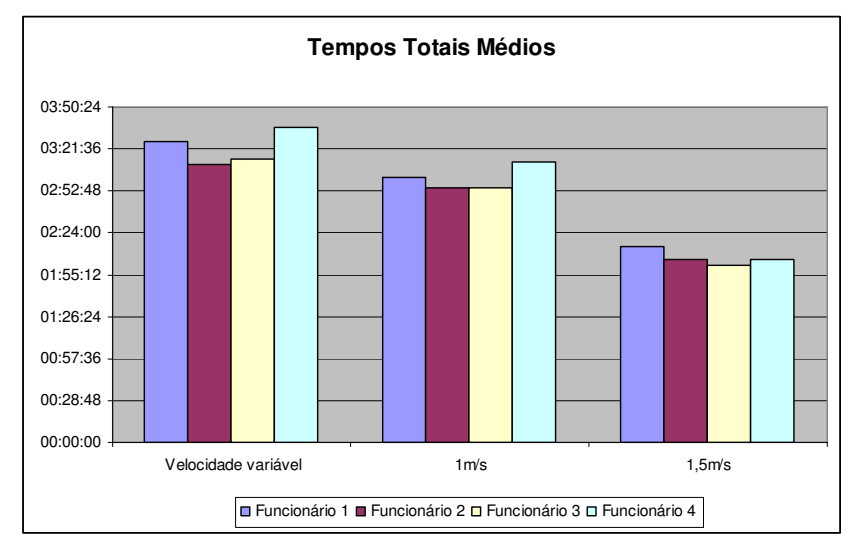

FIGURA 37 - COMPARAÇÃO DOS TEMPOS DOS FUNCIONÁRIOS COM ALTERAÇÃO DA VELOCIDADE.

De fato, o aumento da velocidade do transportador reduz ainda mais o tempo total médio do processo de retirada de itens. A figura 38 ilustra com mais detalhes de onde a redução está sendo proveniente, afinal a velocidade afeta apenas o tempo de deslocamento e não nos tempos de identificação do local ou subseção, item e coleta.

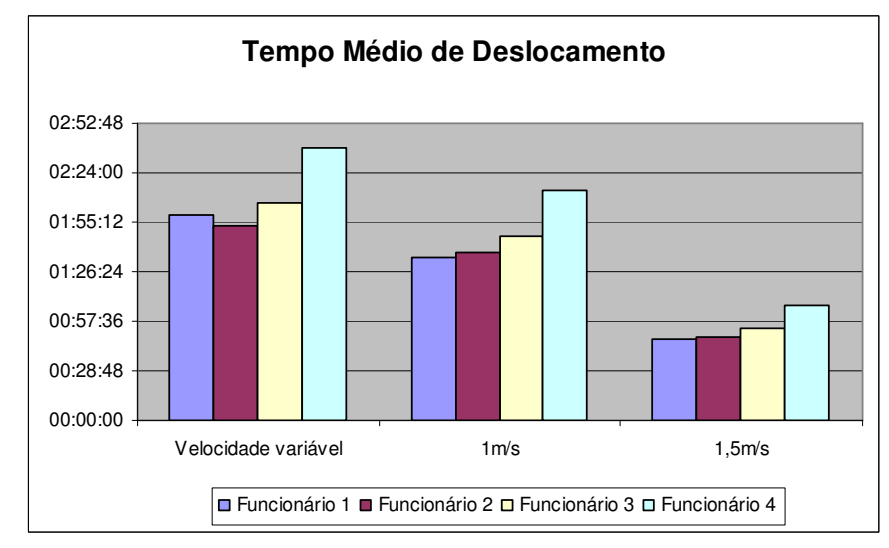

\section{FIGURA 38 - VARIAÇÃO DO TEMPO DE DESLOCAMENTO EM FUNÇÃO DA VELOCIDADE.}

Os demais componentes do tempo total não são influenciados pela velocidade e sim pelo desbalanceamento, como mostram as figuras 39,40 e 41 . 


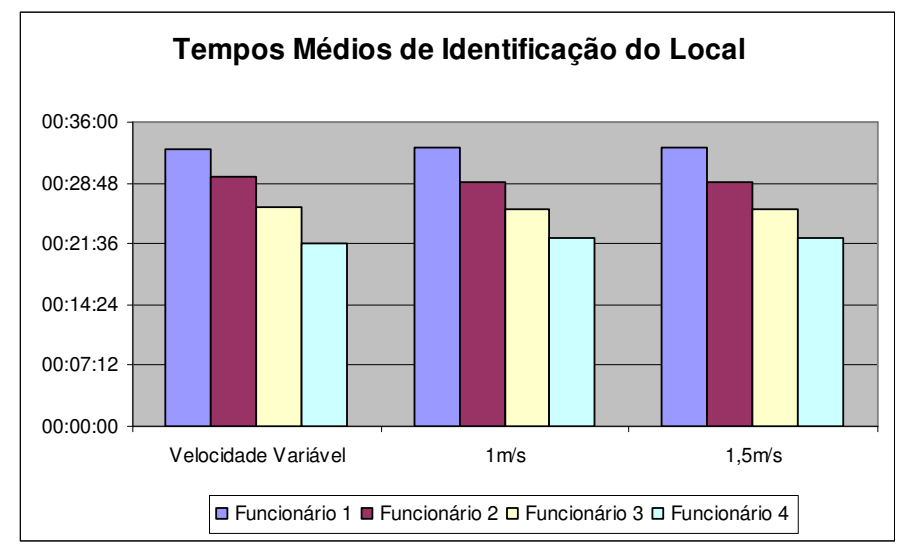

FIGURA 39 - TEMPOS DE IDENTIFICAÇÃO DO LOCAL (DESBALANCEAMENTO DE $20 \%$ ).

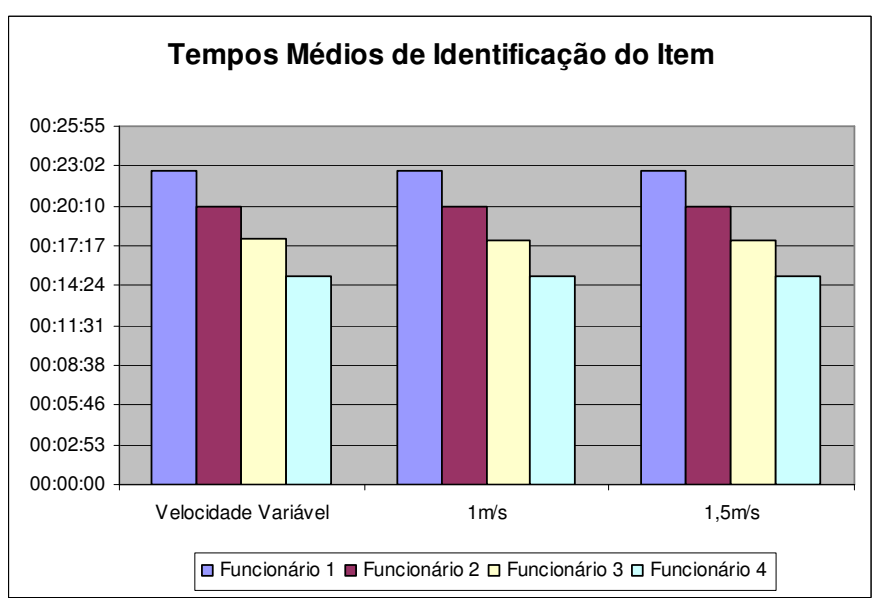

FIGURA 40 - TEMPOS DE IDENTIFICAÇÃO DO ITEM (DESBALANCEAMENTO DE $20 \%$ ).

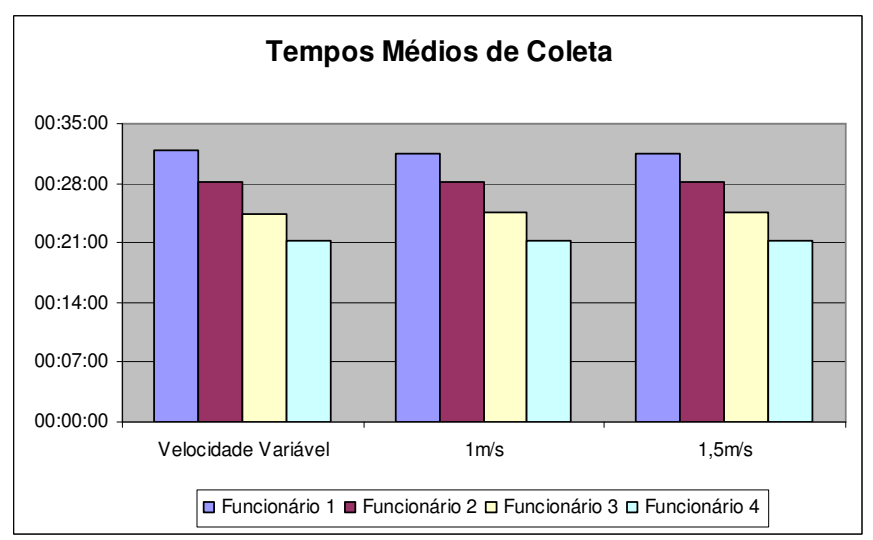

FIGURA 41 - TEMPOS DE COLETA (DESBALANCEAMENTO DE 20\%). 
Com a figuras 37, ocorre uma dúvida na definição sobre se contratar mais funcionários ou se trocar os transportadores por outros de maior velocidade. Para isso, são comparados os resultados das seguintes simulações anteriores: 5 funcionários com velocidade variável do transportador (ver figura 42), e 4 funcionários com transportador de velocidade de $1 \mathrm{~m} / \mathrm{s}$ (ver figura 43).

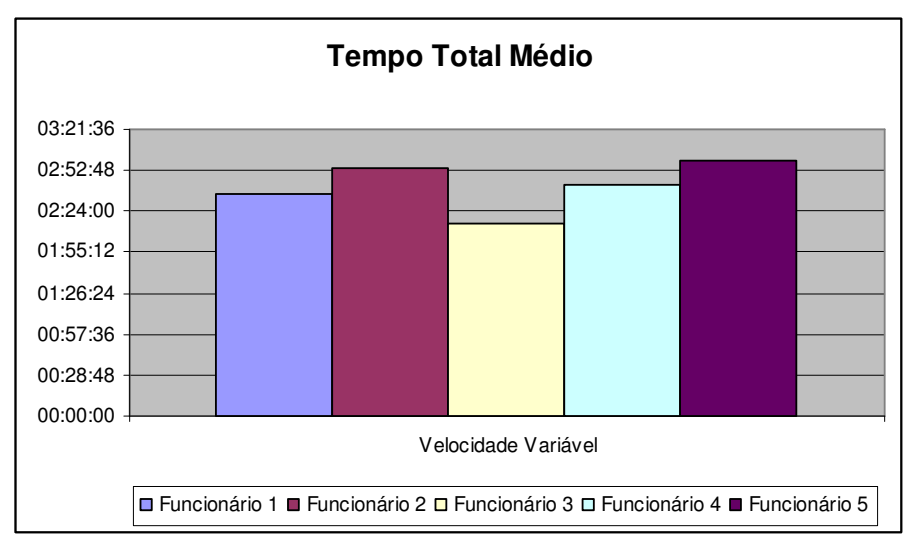

FIGURA 42 - TEMPO TOTAL MÉDIO DE 5 FUNCIONÁRIOS COM VELOCIDADE VARIÁVEL.

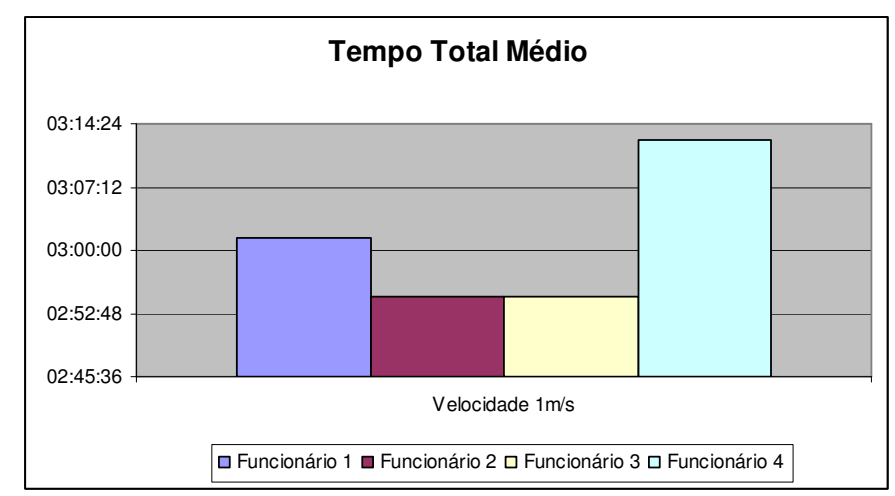

\section{FIGURA 43 - TEMPO TOTAL MÉDIO DE 4 FUNCIONÁRIOS COM VELOCIDADE DE} $1 \mathrm{~m} / \mathrm{s}$.

É necessário avaliar os custos de aquisição, recarga das baterias, manutenção e treinamento, para concluir se a aquisição de transportadores motorizados é mais vantajosa. 


\subsubsection{Simulação alteração da carga máxima do transportador}

Outra possibilidade estudada foi a alteração da carga máxima suportada pelo transportador. As simulações anteriores usaram sempre o limite de $120 \mathrm{~kg}$, que é a carga admissível pelos transportadores disponíveis atualmente na empresa. A carga máxima reduz diretamente o número de transportadores usados, o que significa menos viagens entre as prateleiras e o setor de empacotamento. O numerador e denominador da equação 7 de valor $120 \mathrm{~kg}$ passam a variar conforme a carga máxima admissível do transportador em estudo.

A tabela 23 compara o número de transportadores usados, em média, por cada funcionário, considerando um desbalanceamento de 20\% (30 replicações para cada carga máxima), para cargas máximas de $120 \mathrm{~kg}, 150 \mathrm{~kg}$ e $200 \mathrm{~kg}$.

TABELA 23 - NÚMEROS DE TRANSPORTADORES UTILIZADOS.

\begin{tabular}{|l|c|c|c|}
\hline & 120kg & 150kg & 200kg \\
\hline Funcionário 1 & 102,67 & 84,67 & 65,00 \\
\hline Funcionário 2 & 94,67 & 76,33 & 59,67 \\
\hline Funcionário 3 & 84,33 & 68,33 & 52,67 \\
\hline Funcionário 4 & 72,33 & 59,67 & 46,00 \\
\hline
\end{tabular}

A figura 44 compara os tempos totais médios de 4 funcionários (com desbalanceamento de 20\%) para as três cargas máximas distintas e de velocidade variável. A simulação poderia ter sido realizada para velocidades maiores como 1,5 m/s, mas não é necessária porque existe uma tendência para a redução gradativa do tempo total médio.

Alguns fatores de decisão que, sob a visão dos empresários podem melhorar o sistema, porém acabam gerando resultados inesperados. A princípio, quanto maior a carga admissível do transportador, mais dificuldade o funcionário teria de manipulação e, conseqüentemente, maior seria o tempo total médio, porém, houve redução deste tempo. A razão disso é que, por admitir maior carga, menos viagens foram necessárias para efetuar a coleta. 


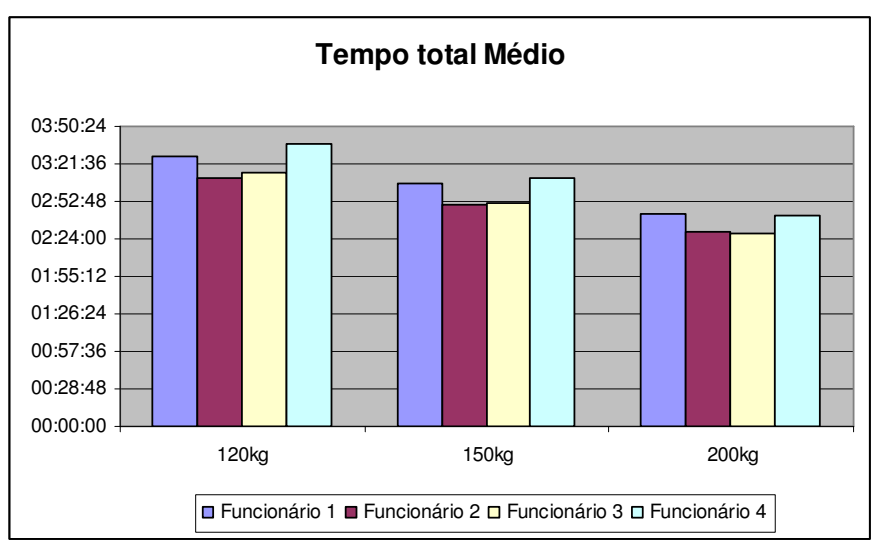

FIGURA 44 - INFLUÊNCIA DA CARGA MÁXIMA ADMISSÍVEL NO TRANSPORTADOR.

Todos os resultados apresentados nos tópicos 5.3 .3 e 5.3.4 geram dúvidas de decisão. A escolha do melhor procedimento de operação deste processo para se obter a maior redução do tempo total médio surge da combinação dos 3 fatores estudados. Em outras palavras, pode-se até trabalhar com 4 funcionários, capacidade e velocidade do transportador de $200 \mathrm{~kg}$ e $1,5 \mathrm{~m} / \mathrm{s}$ respectivamente para reduzir ainda mais o tempo total médio, porém este procedimento geraria custos excessivos em curto prazo para se adquirir novos transportadores. Se o enfoque é muito grande em reduzir ainda mais o tempo total médio a curto prazo, sendo que o período máximo de coleta é de 4 horas, parece ser mais conveniente aumentar o número de funcionários. 


\section{CONCLUSÕES E COMENTÁRIOS FINAIS}

Neste capítulo apresenta-se as conclusões, alguns problemas estudados no trabalho, assim como sugestões para trabalhos futuros.

\subsection{Conclusões sobre o modelo}

Pode-se afirmar que os objetivos inicialmente traçados para este trabalho foram plenamente atingidos. O processo de retirada de itens do CDP foi totalmente modelado. A execução da simulação 1 do tópico 5.2 mostrou que o modelo desenvolvido representa adequadamente o sistema real. O conjunto dos resultados das diversas simulações efetuadas gerou, de fato, análises e conclusões que fornecem informações importantes de apoio à tomada de decisão a respeito dos diversos parâmetros que afetam o processo de retirada de itens. Com isso, alguns comentários são relatados a seguir.

As informações geradas pela execução das simulações permitem que os Decisores conheçam antecipadamente as informações referentes aos deslocamentos dos funcionários nos corredores do CDP e, desta forma, possam estimar os recursos necessários, tais como o número de transportadores e número de funcionários necessários para que os pedidos sejam consolidados dentro de um período de tempo estabelecido de serviço, evitando-se assim, atrasos na consolidação.

É importante que se utilizem ferramentas de simulação para avaliar situações ou cenários em sistemas de manufatura, principalmente nos CDP's porque, desta forma, os empresários podem visualizar ou ter boas noções, a partir das informações obtidas no modelo, de como se comportará o sistema real antes de se tomar qualquer tipo de decisão que possa futuramente prejudicá-lo.

Vale lembrar que o papel da simulação não é obter a solução, como deduzir o nível ótimo de operação, mas sim fornecer informações que servirão de suporte para os gerenciadores tomarem suas decisões em sistemas que mudam de comportamento constantemente.

E possível afirmar que o tempo de deslocamento, pelas pressuposições adotadas neste trabalho, é o que compõe a maior parte do tempo total do processo de retirada de itens e, portanto, deve-se estudar novos métodos para minimizar este tempo. É importante também manter a continuidade aos estudos em todas as etapas deste processo, pois a melhoria de apenas uma etapa (em deslocamento) pode não trazer 
melhorias ao processo todo, afinal existem diversos componentes do tempo deste processo.

Estas inúmeras informações geradas pelo modelo acabam indicando a importância de se trabalhar, em paralelo, o uso de planejamento de experimentos para se avaliar os resultados, a fim de concluir qual é o maior impactante que gera maiores ganhos para o sistema.

\subsection{Sugestões para futuros desenvolvimentos}

Foi necessário estimar alguns dados devido à impossibilidade de se obter os valores reais. É importante, portanto, obter dados, no sistema real, relativos a algumas variáveis, e executar o modelo com tais dados para o aprimoramento dos resultados obtidos com os dados estimados. As variáveis são:

Número de itens por pedido: apesar de se ter a média do número de itens do pedido do semestre, é importante que se conheça a distribuição estatística adequada. Provavelmente haverá uma distribuição diferente para cada um dos clientes.

Velocidade de Deslocamento: deve-se determinar a distribuição estatística mais adequada que represente a velocidade de deslocamento do funcionário.

Fator V: deve-se obter a influência da carga no transportador sobre a velocidade de deslocamento do funcionário.

Tempo de identificação do local, de identificação do item e de coleta: deve-se determinar a distribuição estatística mais adequada a partir de um maior número de amostras de tempo.

Setor de empacotamento: como não há dados geométricos deste local, não foi possível modelá-lo e, dessa forma, este trabalho não levou em consideração as distâncias percorridas. Sabe-se apenas que existem áreas específicas para depositar as peças de cada cliente. Sabendo qual o cliente, será possível determinar a rota do funcionário com maior exatidão e, conseqüentemente, calcular o tempo gasto nesta parte do deslocamento.

Transportadores: não havia informações sobre os procedimentos dos funcionários após encher um transportador. Poderiam ocorrer duas situações:

1 - o funcionário deixa o transportador cheio no local reservado para um dos clientes, encaminha-se seguidamente para o local onde ficam estacionados os transportadores vazios e encaminha-se para a seção, dando continuidade à coleta. 
2 - o funcionário poder utilizar o mesmo transportador (o cheio), em que ele próprio retira as peças do transportador, deixando-as em um local reservado para cada cliente e retorna ao SPP.

Animação: é importante escolher e implementar uma forma de animação que permita aos Decisores acompanharem o deslocamento do funcionário entre as seções e prateleiras do setor. 


\section{REFERÊNCIAS BIBLIOGRÁFICAS}

ALFIERI, A.; BRANDIMARTE, P. (1997). Object-oriented modeling and simulation of integrated production/distribution systems. Computer Integrated Manufacturing Systems, v. 10, n.4, p.261-266.

ASKIN, R. G.; STANDRIDGE, C. R. (1993). Modeling and analysis of manufacturing systems, John Wiley \& Sons, New York, Cap. 10, p. 327, 1993.

BALLOU, R. H. (2001). Gerenciamento da cadeia de suprimentos: planejamento, organização e logística empresarial, $4^{\text {th }}$ ed. Editora Bookman, Porto Alegre.

BANKS, J. (1998). Handbook of simulation: principles, methodology, advances, applications, and practice, John Wiley \& Sons, New York.

BANKS, J. et al. (1984). Discrete-event system simulation, $2^{\text {nd }}$ ed. Prentice-Hall, New Jersey.

BENNETT, B. S. (1995). Simulation fundamentals, Prentice-Hall, London, Cap. 1, p. 2.

BOWERSOX, D. J.; CLOSS, D. J. (1986). Logistical management: the integrated supply chain process, $3^{\text {rd }}$ ed. Mc Graw-Hill, New York, Cap. 13, p. 398.

BOZER, Y. A. SCHORN, E.; SHARP, G. P. (1990). Geometric approaches to solve the chebyshev traveling salesman problem. IIE Transactions, v. 22, p. 239-254.

BRYNZÉR, H.; JOHANSSON, M. I. (1996). Storage location assignment: using the product structure to reduce order picking times. International Journal of Production Economics, v. 46-47, p. 595-603.

CARON, F. et al. (1998). Routing policies and COI-based storage policies in picker-to-part systems. International Journal of Production Research, v. 36, n.3, p.713-732.

CARON, F. et al. (2000). Layout design in manual picking systems: a simulation approach. Integrated Manufacturing Systems, v. 11, n.2, p.94-104.

CARSON, J. S. (2003). Introduction to modeling and simulation. Proceedings of the 2003 Winter Simulation Conference, S. Chick, P. J. Sánchez, D. Ferrin, D. J. Morrice, eds.

CERVO, A. L.; BERVIAN, P. A. (1996). Metodologia científica, $4^{\text {th }}$ ed. Editora Makron Books, São Paulo, Cap. 4, p. 68.

CHAUDHURI, S.; DAYAL, U. (1997). Data warehousing and OLAP for decision support. SIGMOD Record, (ACM Special Interest Group on Management of Data), v. 26, n. 2, 507508.

CHIAVENATO, I. (1990). Iniciação ao planejamento e controle da produção. Editora McGRAW-HILL, São Paulo, Cap. 6, p. 99. 
CORRÊA, J. (1979). Gerência econômica de estoques e compras, $5^{\text {th }}$ ed. Editora da Fundação Getúlio Vargas, Cap. 3, p. 35.

COLMANETTI, M. S. (2001). Modelagem de sistemas manufatura orientada pelo custeio das atividades e processos. São Carlos. Dissertação (Mestrado) - Escola de Engenharia de São Carlos, Universidade de São Paulo.

COYLE, J. J. et al. (1996). The management of business logistics. $6^{\text {th }}$ ed. West publishing, St. Paul.

DALY, F. (1993). Use common sense to reduce the picking path. Plant Engineering and Maintenance, v. 16, n.4, p.13.

DANIELS, R. L.; RUMMEL, J. L.; SCHANTZ, R. (1998). A model for warehouse order picking. European Journal of Operational Research, v. 105, p. 1-17.

EZZIANE, Z. (2000). Evaluating customer service performance in warehousing environments. Logistics Information Management, v. 13, n. 2, p. 90-94.

FAWCETT, S. E.; COOPER, M. B. (1998). Logistics performance measurement and customer success. International Marketing Management, v. 27, p.341-357.

FERREIRA, A. B. H. (1988). Dicionário aurélio básico da língua portuguesa. Editora Nova Fronteira. Rio de Janeiro, p. 399.

FRAZELLE, E. H. (1989). Stock location assignment and order picking productivity. PhD Thesis.

FRAZELLE, E. H. (1992). Material handling systems and terminology. Lionheart, Atlanta. FRAZELLE, E. H. (2002). World class warehousing and material handling, Mc Graw-Hill. New York, Cap. 1, p. 3.

GARCIA, M. L. et al. (1999). A simulation of the product distribution in the newspaper industry. Winter Simulation Conference Proceedings, p. 1268-1271.

GIBSON, D. R.; SHARP, G. P. (1992). Order batching procedures. European Journal of Operational Research, v. 58, p.57-67.

GOETSCHALCKX, M.; RATLIFF, H. D. (1988a). An efficient algorithm to cluster order picking items in a wide aisle. Engineering Costs and Production Economics, v. 13, p. 263271.

GOETSCHALCKX, M.; RATLIFF, H. D. (1988b). Order picking in an aisle. IIE Transactions, v. 20, n.1.

GORDON, G. (1969). System simulation. $2^{\text {nd }}$ ed. Prentice-Hall, New Jersey.

GUNASEKARAN, A. et al. (1999). Improving the effectiveness of warehousing operations: a case study. Industrial Management \& Data Systems, v. 99, n. 8, p. 328-339. 
GUNASEKARAN, A. et al. (2001). Performance measures and metrics in a supply chain environment. International Journal of Operations \& Production Management, v. 21, n. 1-2, p. 71-87.

GURGEL, F. A. (1996). Administração dos fluxos de materiais e de produtos, Editora Atlas, São Paulo, Cap. 12, p. 98.

HALL, R. W. (1993). Distance approximations for routing manual pickers in a warehouse. IIE Transactions, v. 25, n.4.

HARMON, R. L. (1994). Reinventando a distribuição: logística de distribuição classe mundial, Editora Campus, Rio de Janeiro.

HESKETT, J. L. (1963). Cube-per-order index - a key to warehouse stock location. Transportation and Distribution Management, v.3, p. 27-31.

JANSEN, D. R. et al. (2001). Simulation model of multi-compartment distribution in the catering supply chain. European Journal of Operational Research. Vol. 133, n.1, p.210224.

JARVIS, J. M.; MCDOWELL, E. D. (1991). Optimal product layout in an order picking warehouse. IIE Transactions, v. 23, n.1, p.93-102.

KALLINA, C. (1976). Optimality of the cube-per-order index rule for stock location in a distribution warehouse. American Can Company.

KALLINA, C.; LYNN, J. (1976). Application of the cube-per-order index rule for stock location in a distribution warehouse. Interfaces, v. 7, n. 1.

KELLNER, M. I. et al. (1999). Software process simulation modeling: why? what? how?. The Journal of Systems and Software, v. 46, n.2-3, p.91-105.

KELTON, W. D. et al. (1998). Simulation with arena. WCB/McGraw-Hill, New York, Cap. 1, p. 13.

KIM, B. I.; et al. (2003). Realization of a short cycle time in warehouse replenishment and order picking. International Journal of Production Research, v. 41, n. 2, p. 349-364.

KUNDER, R; GUDEHUS, T. (1975). Mittlere wegzeiten beim eindimensionalen kommissionarem. Zeitschrift fur Operazions Research, v. 19, p. B53-B72.

LAW, A.M.; KELTON, W.D. (1991). Simulation modeling and analysis. $2^{\text {nd }}$ ed. McGrawHill, New York.

LITVAK, N.; ADAN, I. (2002). On a class of order pick strategies in paternosters. Operations Research Letters, v. 30, n.6, p.377-386.

LIN, C. H.; LU, I. Y. (1999). The procedure of determining the order picking strategies in distribution center. International Journal of Production Economics, n. 60-61, p. 301-307. 
LIU, C. M. (1999). Clustering techniques for stock location and order-picking in a distribution center. Computers \& Operations Research, v. 26, n.10-11, p.989-1002.

LOBÃO, E. DE C.; PORTO, A. J. V. (1997). Proposta para sistematização de estudos de simulação. (CD ROM) In. ENCONTRO NACIONAL DE ENGENHARIA DE PRODUÇÃO, 17., Gramado, RS. Anais. Out.

MAGEE, J. F. (1977). Logística Industrial: Análise e administração dos sistemas de suprimento e distribuição. Editora Pioneira, São Paulo, 351 p.

MAKRIS, P. A.; GIAKOUMAKIS, I. G. (2003). K-interchange heuristic as an optimization procedure for material handling applications. Applied Mathematical Modelling, v. 27, p.345-358.

MALTON, I. (1991). Efficient order picking: the need for it and possible solutions. Proceedings of the $11^{\text {th }}$ International Conference on Automation in Warehousing, p. 97109, 1991.

MARÍN, R. M. et al. (1998). Design and simulation of an industrial automated overhead warehouse. Integrated Manufacturing Systems, v. 9, n. 5, p. 308-313.

MAYNARD, H. B. (1970). Manual de engenharia de produção: padrões de tempos elementares pré-determinados. Editora Edgard Blücher, São Paulo.

MILLER, S. (2000). Introduction to manufacturing simulation. Proceedings of the 2000 Winter Simulation Conference, J. A. Joines, R. R. Barton, K. Kang, and P. A. Fishwick, ed. MOURA, R. A. (1989). Logística: suprimentos, armazenagem e distribuição física. Editora IMAM, São Paulo, Cap. 1, p. 3.

MOURA, R. A. (1997). Armazenagem e distribuição física. Editora IMAM, São Paulo, Cap. 1, p. 9.

MULCAHY, D. E. (1994). Warehouse distribution \& operations handbook. Editora Mc Graw-Hill, New York, Cap. 1, p. 1.2.

NAYLOR, T. H. et al. (1971). Técnicas de simulação em computadores. Editora Vozes, São Paulo.

NOVAES, A. G. N.; ALVARENGA, A. C. (1994). Logística aplicada: suprimento e distribuição física. Editora Pioneira, São Paulo.

PARAGON (2002). Introdução à simulação com ARENA 5.0. Rockwell software, São Paulo, Cap. 1, p. 31.

PEDGEN, C. D. et al. (1995). Introduction to simulation using SIMAM. $2^{\text {nd }}$ ed., Mc GrawHill, New York. 
PETERSEN, C. G.; AASE, G. (2003). A Comparison of picking, storage, and routing policies in manual order picking. International Journal of Production Economics. Article in press.

PETERSEN, C. G. (1999). The impact of routing and storage policies on warehouse efficiency. International Journal of Operations \& Production Management, v. 19, n. 10, p. 1053-1064.

PRITSKER, A. A. B. (1995). Introduction to simulation and SLAM II. $4^{\text {th }}$ ed. John Wiley \& Sons, New York.

RANA, K. (1990). Order picking in narrow-aisle warehouses. International Journal of Physical Distribution and Logistics Management, v. 20, n. 2.

RATLIFF, H. D.; ROSENTHAL, A. S. (1983). Order-picking in a rectangular warehouse: a solvable case of traveling salesman problem. Operations Research, v. 31, n. 3, p. 507521.

ROODBERGEN, K. J.; DE KOSTER, R. (2001). Routing order pickers in a warehouse with a middle aisle. European Journal of Operational Research, v. 133, n. 1, p. 32-43.

ROSENWEIN, M. B. (1996). A comparison of heuristics for the problem of batching orders for warehouse selection. International Journal of Production Research, v. 34, n.3, p.657664.

ROUWENHORST, B.; REUTER, B.; STOCKRAHM, V.; VAN HOUTUM, G. J.; MANTEL, R. J. \& ZIJM, W. H. M. (2000). Warehouse design and control: framework and literature review. European Journal of Operational Research, v. 122, p. 515-533.

SHIH, Y. C. et al. (2004). Análise do impacto das atividades críticas na eficiência e efetividade dos sistemas de armazenamento utilizando planejamento de experimentos. CONGRESSO SOCIETY AUTOMOTIVE ENGINEERING, São Paulo. Nov.

SLACK, N.et al. (1999). Administração da produção. Edição Compacta, Editora Atlas, São Paulo, Cap. 2, p. 56-57.

STURION, M. C. (2000). Modelagem de simulação dos processos de administração de material como potencializador do aumento de valor agregado em serviços logísticos. São Carlos. 18 p. Dissertação (Mestrado) - Escola de Engenharia de São Carlos, Universidade de São Paulo.

TAHA, H. A. (1988). Simulation modeling and simnet, Prentice Hall, New Jersey, Cap. 1, p. 5.

TOMPKINS, J. A. et al. (1996). Facilities planning. $2^{\text {nd }}$ ed. John Wiley \& Sons, New York, Cap. 9, p. 391. 
ÜLGEN, O.; GUNAL, A. (1998). Simulation of manufacturing and material handling systems: Handbook of Simulation. Jerry Banks ed. John Wiley \& Sons, New York, p. 547570.

VAN DEN BERG, J. P. (1996). Planning and control of warehousing systems. The Netherlands. Ph.D. Thesis - Fac. Mech. Engrg., Enschede, University of Twente.

VAN DEN BERG, J. P. et al. (1998). Forward-reserve allocation in a warehouse with unitload replenishments. European Journal of Operational Research, v. 111, p. 98-113.

VAUGHAN, T. S.; PETERSEN, C. G. (1999). The effect of warehouse cross aisles on order picking efficiency. International Journal of Production Research, v. 37, n. 4, p. 881897.

YAMADA, M. C. (2004). Especificação de experimentos, modelos e interfaces padrões para o apoio ao processo de planejamento da produção de um sistema produtivo sucroalcooleiro, via simulação. São Carlos. 174p. Tese (Doutorado) - Escola de Engenharia de São Carlos, Universidade de São Paulo. 


\section{APÊNDICE 1 - VARIÁVEIS DO MODELO}

Este apêndice tem por finalidade descrever a função de cada variável utilizada no modelo para permitir uma compreensão mais rápida de seu funcionamento. A listagem está em ordem alfabética.

\begin{tabular}{|c|c|}
\hline Nome da Variável & Descrição \\
\hline Aux1 & Variável utilizada em diversas etapas do modelo. \\
\hline Aux2 & Variável utilizada em diversas etapas do modelo. \\
\hline Aux3 & $\begin{array}{l}\text { Utilizada na ordenação do pedido e na leitura do arquivo } \\
\text { Dados.txt. }\end{array}$ \\
\hline Aux4 & Utilizada somente na ordenação do pedido. \\
\hline Carga Maxima & $\begin{array}{l}\text { Recebe seu valor a partir da interface VBA. Define qual a } \\
\text { capacidade, em } \mathrm{kg} \text {, do transportador de peças utilizado na } \\
\text { coleta. }\end{array}$ \\
\hline Carro & $\begin{array}{l}\text { Armazena o número total de transportadores utilizados pelo } \\
\text { funcionário para realizar a sua coleta. }\end{array}$ \\
\hline Codigo & $\begin{array}{l}\text { Recebe o código do item. É utilizada na geração dos códigos, } \\
\text { no relatório e na coleta de peças (pois a partir do código é } \\
\text { possível determinar a prateleira e seção onde se encontra o } \\
\text { item). }\end{array}$ \\
\hline Coeficiente A & $\begin{array}{l}\text { Esta variável é usada apenas para o cálculo do } \\
\text { desbalanceamento. Recebe o valor do coeficiente A da } \\
\text { equação da reta de desbalanceamento. }\end{array}$ \\
\hline Coeficiente B & $\begin{array}{l}\text { Esta variável é usada apenas para o cálculo do } \\
\text { desbalanceamento. Recebe o valor do coeficiente B da } \\
\text { equação da reta de desbalanceamento. }\end{array}$ \\
\hline Contador & Utilizada em diversas partes do modelo. \\
\hline Contador2 & $\begin{array}{l}\text { Utilizada em diversas partes do modelo e quando Contador já } \\
\text { está em uso. }\end{array}$ \\
\hline Dados $(200,108)$ & $\begin{array}{l}\text { Recebe os valores do arquivo Dados.txt ao final da última } \\
\text { replicação para permitir o cálculo das estatísticas (mínimo, } \\
\text { máximo, média e desvio padrão). Cada linha recebe os } \\
\text { dados de uma replicação. O número de colunas utilizadas em } \\
\text { uma simulação depende do número de funcionários } \\
\text { selecionados. Definindo apenas } 1 \text { funcionário serão utilizadas } \\
17 \text { das } 108 \text { colunas. Selecionando } 8 \text { funcionários todas as } \\
108 \text { colunas serão usadas. }\end{array}$ \\
\hline Desvio(1, 108) & $\begin{array}{l}\text { Armazena o resultado do cálculo do desvio padrão de cada } \\
\text { variável. O número de colunas utilizadas em uma simulação } \\
\text { depende do número de funcionários selecionados. Definindo } \\
\text { apenas } 1 \text { funcionário serão utilizadas } 17 \text { das } 108 \text { colunas. } \\
\text { Selecionando } 8 \text { funcionários todas as } 108 \text { colunas serão } \\
\text { usadas. }\end{array}$ \\
\hline Espaco & $\begin{array}{l}\text { Utilizada em três locais, mas com a mesma finalidade: } \\
\text { permitir o cálculo do tempo de deslocamento. Recebe o } \\
\text { espaço percorrido entre itens (submodelo Espaço do Item } \\
\text { Anterior), do empacotamento para um item (submodelo } \\
\text { Espaço do Empacotamento) e de uma prateleira para o } \\
\text { empacotamento (submodelo Tempo para Deslocar). }\end{array}$ \\
\hline Etapa & $\begin{array}{l}\text { A geração dos códigos dos itens do pedido é realizada em } \\
\text { três etapas. Na primeira são gerados os códigos das peças } \\
\text { tipo A. Na segunda gera-se os itens B e finalmente, na } \\
\text { terceira etapa são gerados os itens do tipo C. Esta variável }\end{array}$ \\
\hline
\end{tabular}




\begin{tabular}{|c|c|}
\hline & $\begin{array}{l}\text { permite que sejam selecionados os valores corretos para } \\
\text { cada etapa. }\end{array}$ \\
\hline Fator B & $\begin{array}{l}\text { Variável usada no cálculo do desbalanceamento de itens por } \\
\text { funcionário. }\end{array}$ \\
\hline Fator B Anterior & $\begin{array}{l}\text { Variável usada no cálculo do desbalanceamento de itens por } \\
\text { funcionário. }\end{array}$ \\
\hline Fator_P & $\begin{array}{l}\text { O valor desta variável influencia no tempo de coleta de } \\
\text { peças. Se as peças são leves este fator diminuirá o tempo } \\
\text { definido por uma distribuição triangular. Quanto mais pesada } \\
\text { a peça em coleta, maior o valor deste fator e, } \\
\text { conseqüentemente, maior o tempo de coleta. }\end{array}$ \\
\hline Fator_V & $\begin{array}{l}\text { Utilizada quando o usuário define que a velocidade de } \\
\text { deslocamento será variável. Inicialmente a velocidade é } \\
\text { obtida de uma distribuição triangular e, em seguida, é } \\
\text { multiplicada por este fator. Quanto maior o peso adicionado } \\
\text { ao transportador de peças, maior é a influência do fator no } \\
\text { sentido de diminuir a velocidade de deslocamento. }\end{array}$ \\
\hline Fim & $\begin{array}{l}\text { Utilizada na geração dos códigos dos itens. Recebe um valor } \\
\text { diferente para cada uma das três etapas. Indica quando a } \\
\text { etapa deve se encerrar. }\end{array}$ \\
\hline Funcionario & $\begin{array}{l}\text { Armazena qual o funcionário que está em processo de coleta } \\
\text { de peças. Funciona como um contador. }\end{array}$ \\
\hline Funcionarios & $\begin{array}{l}\text { Número total de funcionários que realizarão a coleta de } \\
\text { peças de um pedido. Recebe o seu valor a partir da interface } \\
\text { VBA e pode variar entre } 1 \text { e } 8 \text {. }\end{array}$ \\
\hline Hdesvio & $\begin{array}{l}\text { Horas do valor do desvio padrão. Usado nas estatísticas do } \\
\text { relatório. }\end{array}$ \\
\hline Hmaximo & Horas do valor máximo. Usado nas estatísticas do relatório. \\
\hline Hmedia & Horas do valor médio. Usado nas estatísticas do relatório. \\
\hline Hminimo & Horas do valor mínimo. Usado nas estatísticas do relatório. \\
\hline $\operatorname{Impar}(4,1)$ & Utilizada para o cálculo do espaço entre uma seção e outra. \\
\hline Itens & $\begin{array}{l}\text { Número total de itens do pedido. Seu valor depende da } \\
\text { escolha que o usuário realizar na interface VBA. Se for } \\
\text { determinada uma geração aleatória, recebe o valor vindo de } \\
\text { uma distribuição triangular. Se for determinado um valor fixo } \\
\text { receberá o valor especificado pelo usuário, por meio da } \\
\text { variável Número de ltens. }\end{array}$ \\
\hline Itens Balanceados & $\begin{array}{l}\text { Indica o desejo do usuário em relação ao balanceamento de } \\
\text { itens por funcionário. Seu valor é definido na interface VBA. } \\
\text { Se o usuário define que a divisão de itens será balanceada o } \\
\text { seu valor será } 1 \text {. No caso contrário receberá o valor } 0 \text {. }\end{array}$ \\
\hline Itens do Funcionario & $\begin{array}{l}\text { Número total de itens coletados pelo funcionário para constar } \\
\text { no relatório final. }\end{array}$ \\
\hline Itens_A & Número total de itens do tipo A que compõem o pedido. \\
\hline Itens_A do Funcionario & $\begin{array}{l}\text { Número total de itens do tipo } \mathrm{A} \text { coletados pelo funcionário } \\
\text { para constar no relatório final. }\end{array}$ \\
\hline Itens_B & Número total de itens do tipo B que compõem o pedido. \\
\hline Itens_B do Funcionario & $\begin{array}{l}\text { Número total de itens do tipo } \mathrm{B} \text { coletados pelo funcionário } \\
\text { para constar no relatório final. }\end{array}$ \\
\hline Itens_C & Número total de itens do tipo $\mathrm{C}$ que compõem o pedido. \\
\hline
\end{tabular}




\begin{tabular}{|c|c|}
\hline Itens_C do Funcionario & $\begin{array}{l}\text { Número total de itens do tipo } \mathrm{C} \text { coletados pelo funcionário } \\
\text { para constar no relatório final. }\end{array}$ \\
\hline Limite & $\begin{array}{l}\text { Utilizada na geração dos códigos dos itens. Recebe um valor } \\
\text { diferente para cada uma das três etapas. Apresenta o limite } \\
\text { do valor do código a ser gerado em cada etapa. }\end{array}$ \\
\hline Maximo $(1,108)$ & $\begin{array}{l}\text { Armazena o maior valor de cada coluna da matriz } \\
\text { Dados(200, 108). O número de colunas utilizadas em uma } \\
\text { simulação depende do número de funcionários selecionados. } \\
\text { Definindo apenas } 1 \text { funcionário serão utilizadas } 17 \text { das } 108 \\
\text { colunas. Selecionando } 8 \text { funcionários todas as } 108 \text { colunas } \\
\text { serão usadas. }\end{array}$ \\
\hline Mdesvio & $\begin{array}{l}\text { Minutos do valor do desvio padrão. Usado nas estatísticas do } \\
\text { relatório. }\end{array}$ \\
\hline Media(1, 108) & $\begin{array}{l}\text { Armazena a média dos valores de cada coluna da matriz } \\
\text { Dados(200, 108). O número de colunas utilizadas em uma } \\
\text { simulação depende do número de funcionários selecionados. } \\
\text { Definindo apenas } 1 \text { funcionário serão utilizadas } 17 \text { das } 108 \\
\text { colunas. Selecionando } 8 \text { funcionários todas as } 108 \text { colunas } \\
\text { serão usadas. }\end{array}$ \\
\hline Minimo $(1,108)$ & $\begin{array}{l}\text { Armazena o menor valor de cada coluna da matriz } \\
\text { Dados(200, 108). O número de colunas utilizadas em uma } \\
\text { simulação depende do número de funcionários selecionados. } \\
\text { Definindo apenas } 1 \text { funcionário serão utilizadas } 17 \text { das } 108 \\
\text { colunas. Selecionando } 8 \text { funcionários todas as } 108 \text { colunas } \\
\text { serão usadas. }\end{array}$ \\
\hline Mmaximo & Minutos do valor máximo. Usado nas estatísticas do relatório. \\
\hline Mmedia & Minutos do valor médio. Usado nas estatísticas do relatório. \\
\hline Mminimo & Minutos do valor mínimo. Usado nas estatísticas do relatório. \\
\hline Numero de Estatisticas & $\begin{array}{l}\text { Utilizada para o cálculo das estatísticas. Depende do número } \\
\text { de funcionários escolhidos pelo usuário. Escolhendo apenas } \\
1 \text { funcionário esta variável receberá o valor } 17 \text {. Escolhendo } 8 \\
\text { funcionário seu valor será } 108 \text {. }\end{array}$ \\
\hline Numero de Itens & $\begin{array}{l}\text { Utilizada quando o usuário define que o pedido terá um } \\
\text { número fixo de itens. Seu valor é proveniente da interface } \\
\text { VBA e é transferida para a variável Itens no início do modelo. }\end{array}$ \\
\hline $\operatorname{Par}(4,1)$ & Utilizada para o cálculo do espaço entre uma seção e outra. \\
\hline Pecas & $\begin{array}{l}\text { Armazena o número total de peças coletadas pelo } \\
\text { funcionário. }\end{array}$ \\
\hline Pedido $(1.850,2)$ & $\begin{array}{l}\text { Na primeira coluna são armazenados os códigos dos itens do } \\
\text { pedido (número inteiro entre } 1 \text { e } 30.000 \text { ). A segunda coluna } \\
\text { possui a quantidade solicitada de cada item (número inteiro } \\
\text { entre } 1 \text { e } 50 \text { ). }\end{array}$ \\
\hline Percurso Total & $\begin{array}{l}\text { Utilizada no relatório, armazena o total de deslocamentos } \\
\text { realizados pelo funcionário. }\end{array}$ \\
\hline PerFin & $\begin{array}{l}\text { Armazena a distância que deve ser percorrida entre o início } \\
\text { de uma prateleira até a seção destino (é o percurso final de } \\
\text { um deslocamento, seja ele originado de um item anterior ou } \\
\text { do setor de empacotamento). }\end{array}$ \\
\hline Perlni & $\begin{array}{l}\text { Armazena a distância que deve ser percorrida entre a seção } \\
\text { atual e o final da prateleira atual (é o percurso inicial de um } \\
\text { deslocamento, seja ele para ir até o próximo item ou para o } \\
\text { setor de empacotamento). }\end{array}$ \\
\hline Peso no Carro & Responsável por armazenar o somatório dos pesos das \\
\hline
\end{tabular}




\begin{tabular}{|c|c|}
\hline & $\begin{array}{l}\text { peças coletadas. Torna possível determinar o momento de se } \\
\text { deslocar para o setor de empacotamento quando comparado } \\
\text { com o valor da variável Carga Máxima que é definido pelo } \\
\text { usuário na interface VBA. }\end{array}$ \\
\hline Peso Total & Recebe o peso total das peças coletadas pelo funcionário. \\
\hline Pesos $(30.000,1)$ & $\begin{array}{l}\text { Armazena } 0 \text { peso de cada um dos } 30.000 \text { itens } \\
\text { armazenados. Varia entre } 0,1 \mathrm{e} 20 \text {. }\end{array}$ \\
\hline Prateleira & Define a prateleira atual onde se está coletando. \\
\hline Prateleira Destino & $\begin{array}{l}\text { Define a prateleira para a qual o funcionário deverá se } \\
\text { deslocar para realizar a coleta do próximo item. }\end{array}$ \\
\hline Primeiro Item & $\begin{array}{l}\text { Armazena } 0 \text { código do primeiro item coletado pelo } \\
\text { funcionário. }\end{array}$ \\
\hline Quantidade Variável & $\begin{array}{l}\text { Indica o desejo do usuário em relação à quantidade de itens } \\
\text { do pedido. Seu valor é definido na interface VBA. Se o } \\
\text { usuário define que o número de itens é constante esta } \\
\text { variável receberá o valor } 0 \text {. No caso contrário receberá o } \\
\text { valor } 1 .\end{array}$ \\
\hline Replicacao & Recebe o valor da variável Siman NREP. \\
\hline Replicacoes & Recebe o valor da variável Siman MREP. \\
\hline Rota & $\begin{array}{l}\text { Utilizada para conter o espaço percorrido (entre itens, entre } \\
\text { prateleira e setor de armazenamento ou entre o setor de } \\
\text { armazenamento e prateleira). }\end{array}$ \\
\hline Sdesvio & $\begin{array}{l}\text { Segundos do valor do desvio padrão. Usado nas estatísticas } \\
\text { do relatório. }\end{array}$ \\
\hline Secao & Define a seção onde está sendo realizada a coleta. \\
\hline Secao Destino & $\begin{array}{l}\text { Define a seção para a qual o funcionário deverá se deslocar } \\
\text { para realizar a coleta do próximo item. }\end{array}$ \\
\hline Smaximo & $\begin{array}{l}\text { Segundos do valor máximo. Usado nas estatísticas do } \\
\text { relatório. }\end{array}$ \\
\hline Smedia & $\begin{array}{l}\text { Segundos do valor médio. Usado nas estatísticas do } \\
\text { relatório. }\end{array}$ \\
\hline Sminimo & $\begin{array}{l}\text { Segundos do valor mínimo. Usado nas estatísticas do } \\
\text { relatório. }\end{array}$ \\
\hline Somatorio $(1,108)$ & $\begin{array}{l}\text { Armazena a soma dos valores de cada coluna da matriz } \\
\text { Dados(200, 108). O número de colunas utilizadas em uma } \\
\text { simulação depende do número de funcionários selecionados. } \\
\text { Definindo apenas } 1 \text { funcionário serão utilizadas } 17 \text { das } 108 \\
\text { colunas. Selecionando } 8 \text { funcionários todas as } 108 \text { colunas } \\
\text { serão usadas. }\end{array}$ \\
\hline Somatorio de Fator B & $\begin{array}{l}\text { Variável usada no cálculo do desbalanceamento de itens por } \\
\text { funcionário. }\end{array}$ \\
\hline SomatorioQuadrado $(1,108)$ & $\begin{array}{l}\text { Armazena o resultado do somatório dos quadrados das } \\
\text { diferenças entre cada valor de Dados }(200,108) \text { e Media( } 1 \text {, } \\
\text { 108), ou seja, } \sum(\mathrm{x}-\overline{\mathrm{x}})^{2} \text {. O número de colunas utilizadas } \\
\text { em uma simulação depende do número de funcionários } \\
\text { selecionados. Definindo apenas } 1 \text { funcionário serão utilizadas } \\
17 \text { das } 108 \text { colunas. Selecionando } 8 \text { funcionários todas as } \\
108 \text { colunas serão usadas. }\end{array}$ \\
\hline TCh & Armazena as horas do Tempo de Coleta. \\
\hline TClh & Armazena as horas do Tempo de Confirmação do Item. \\
\hline
\end{tabular}




\begin{tabular}{|c|c|}
\hline TClm & Armazena os minutos do Tempo de Confirmação do Item. \\
\hline TCls & Armazena os segundos do Tempo de Confirmação do Item. \\
\hline TCLh & Armazena as horas do Tempo de Confirmação do Local. \\
\hline TCLm & Armazena os minutos do Tempo de Confirmação do Local. \\
\hline TCLS & Armazena os segundos do Tempo de Confirmação do Local. \\
\hline $\mathrm{TCm}$ & Armazena os minutos do Tempo de Coleta. \\
\hline TCs & Armazena os segundos do Tempo de Coleta. \\
\hline TDh & Armazena as horas do Tempo de Deslocamento. \\
\hline TDm & Armazena os minutos do Tempo de Deslocamento. \\
\hline TDs & Armazena os segundos do Tempo de Deslocamento. \\
\hline Tempo & $\begin{array}{l}\text { Utilizado em diversas partes para conter o tempo gasto } \\
\text { naquela tarefa (deslocamento, identificação do local, } \\
\text { identificação do item ou coleta). Em seguida é adicionada à } \\
\text { variável específica para totalização. }\end{array}$ \\
\hline Tempo de Coleta & $\begin{array}{l}\text { Tempo de coleta total gasto pelo funcionário, na forma } \\
\text { décima. }\end{array}$ \\
\hline Tempo de Confirmacao do Item & $\begin{array}{l}\text { Tempo de confirmação do item total gasto pelo funcionário, } \\
\text { na forma decimal. }\end{array}$ \\
\hline Tempo de Confirmacao do Local & $\begin{array}{l}\text { Tempo de confirmação do local total gasto pelo funcionário, } \\
\text { na forma decimal. }\end{array}$ \\
\hline Tempo de Deslocamento & $\begin{array}{l}\text { Tempo de deslocamento gasto total pelo funcionário, na } \\
\text { forma decimal. }\end{array}$ \\
\hline Tempo Total & $\begin{array}{l}\text { Valor de tempo total que o funcionário utilizou para realizar a } \\
\text { coleta. É o somatório das quatro variáveis: Tempo de Coleta, } \\
\text { Tempo de Confirmação do Local, Tempo de Confirmação do } \\
\text { ltem e Tempo de Deslocamento. }\end{array}$ \\
\hline Total de Itens do Funcionario & Armazeno o número de itens que o funcionário coletou. \\
\hline Trocou & $\begin{array}{l}\text { Utilizada na ordenação dos itens do pedido. A variável é } \\
\text { iniciada com valor zero a cada início de análise do vetor } \\
\text { Pedido. Caso ocorra uma troca de posição entre itens que } \\
\text { estão fora de ordem recebe o valor } 1 \text {. }\end{array}$ \\
\hline TTh & Armazena as horas do Tempo Total. \\
\hline TTm & Armazena os minutos do Tempo Total. \\
\hline TTs & Armazena os segundos do Tempo Total. \\
\hline Ultimo Item & Armazena o código do último item coletado pelo funcionário. \\
\hline Valor da Velocidade & $\begin{array}{l}\text { Quando o usuário define na interface VBA que a velocidade } \\
\text { de deslocamento do funcionário será fixa esta variável recebe } \\
\text { o valor definido. }\end{array}$ \\
\hline Valor do Desbalanceamento & $\begin{array}{l}\text { Quando o usuário define na interface VBA que a divisão de } \\
\text { itens por funcionário será desbalanceada esta variáve } \\
\text { recebe o valor do desbalanceamento. }\end{array}$ \\
\hline ValorMaximo & $\begin{array}{l}\text { Utilizada na geração dos códigos dos itens. Recebe um valor } \\
\text { diferente para cada uma das três etapas. Apresenta o maior } \\
\text { valor do código a ser gerado em cada etapa. }\end{array}$ \\
\hline ValorMinimo & $\begin{array}{l}\text { Utilizada na geração dos códigos dos itens. Recebe um valor } \\
\text { diferente para cada uma das três etapas. Apresenta o menor } \\
\text { valor do código a ser gerado em cada etapa. }\end{array}$ \\
\hline Velocidade & Recebe o valor da velocidade de deslocamento. Esse valor \\
\hline
\end{tabular}




\begin{tabular}{|l|l|}
\hline Velocidade Variável & $\begin{array}{l}\text { pode ser proveniente de uma distribuição triangular (se o } \\
\text { usuário definir que a velocidade não é fixa) ou de um valor } \\
\text { escolhido pelo usuário na interface VBA. }\end{array}$ \\
\hline Vetor1 $(4,1)$ & $\begin{array}{l}\text { Indica o desejo do usuário em relação à velocidade de } \\
\text { deslocamento do funcionário. Seu valor é definido na } \\
\text { interface VBA. Se o usuário define que a velocidade é } \\
\text { constante esta variável receberá o valor 0. No caso contrário } \\
\text { receberá o valor 1. }\end{array}$ \\
\hline Vetor2(4, 1) & $\begin{array}{l}\text { Contém os quatro valores básicos que permitirão calcular o } \\
\text { espaço percorrido entre o uma prateleira de origem e o setor } \\
\text { de empacotamento. }\end{array}$ \\
\hline & $\begin{array}{l}\text { Contém os quatro valores básicos que permitirão calcular o } \\
\text { espaço percorrido entre o setor de empacotamento e uma } \\
\text { prateleira destino. }\end{array}$ \\
\hline
\end{tabular}




\section{APÊNDICE 2 - IMPLEMENTAÇÃO NO ARENA ${ }^{\circledR}$}

O software de simulação Arena ${ }^{\circledR}$, produzido pela Rockwell Software, permite a modelagem de sistemas de eventos discretos por meio de fluxogramas. Além disso, também é possível usar os recursos de programação de sua linguagem nativa (SIMAN) e Visual Basic for Applications (VBA). Para inserir dados ou até mesmo executar o modelo de simulação, é necessário que o usuário tenha conhecimento do software e, por isso, usando o visual basic, a interface do usuário com o software se torna mais simples. Porém não será comentado o uso do VBA porque não será o enfoque do trabalho.

A versão 5.0, disponível no Laboratório de Simulação e Controle de Sistemas Discretos da EESC, foi utilizada para a modelagem do SPP.

\section{- Gerador de pesos}

Como citado no capítulo anterior, o modelo proposto deve ser capaz de ler os pesos dos itens em estoque a partir de um arquivo. Como os dados reais não estão disponíveis foi criado um modelo no Arena para gerar estes pesos. A figura 45 apresenta o modelo "Gerador_de_Pesos".

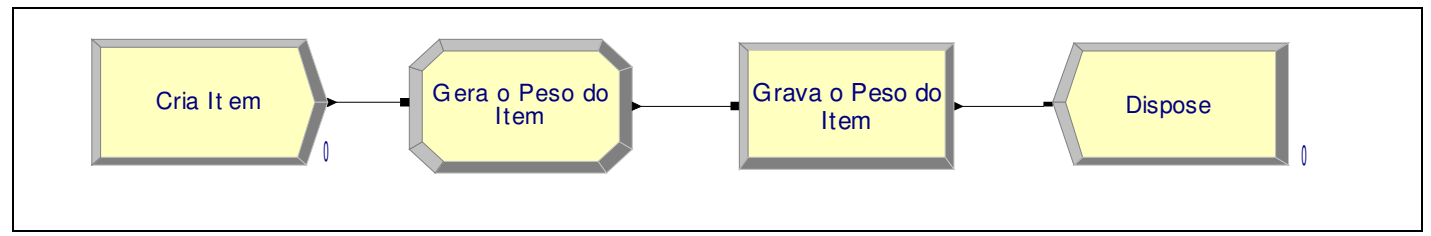

FIGURA 45 - MODELO GERADOR DE PESOS.

A entidade Create gera 30.000 entidades e representa todos os códigos dos itens. A figura 46 apresenta a configuração do Create.

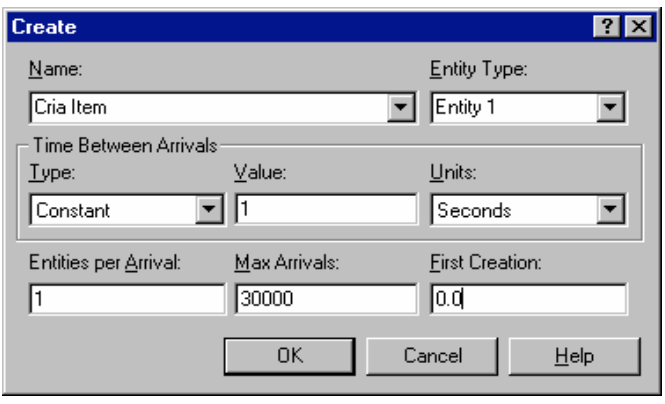

FIGURA 46 - CONFIGURAÇÕES DO CREATE.

Assim que uma entidade é criada, ela passa para o módulo Assign cuja responsabilidade é gerar um número aleatório e armazená-lo em uma variável. A distribuição uniforme foi adotada para criar os pesos dos itens e gera valores entre 0,1 e 20 . A figura 47 apresenta a configuração do Assign. A variável utilizada no modelo está apresentada na figura 48.

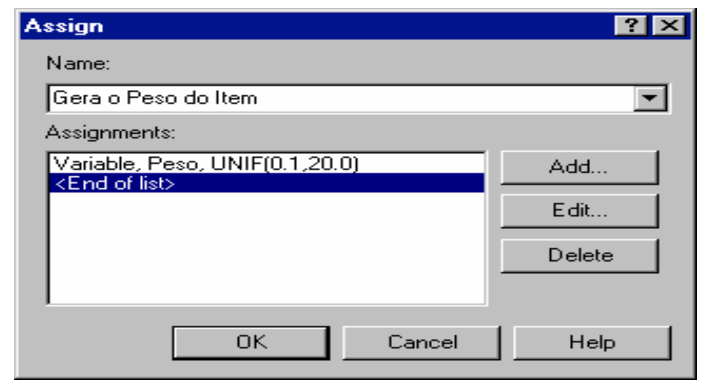

FIGURA 47 - CONFIGURAÇÕES DO ASSIGN. 


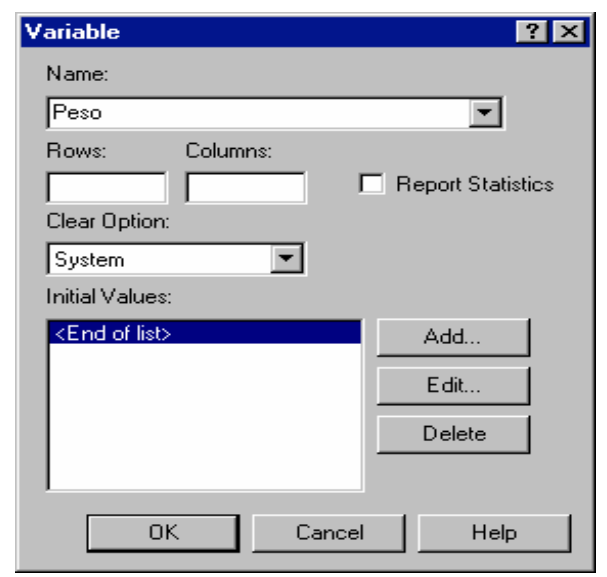

FIGURA 48 - VARIÁVEL UTILIZADA NO MODELO.

O módulo após o Assign é denominado ReadWrite e faz parte do template Advanced Process. Seu objetivo é ler dados (do teclado ou arquivo) ou enviar dados (para o vídeo ou para arquivo). Quando trabalha com arquivo, é necessário definir o nome do arquivo no módulo File, que também é encontrado no template Advanced Process.

A figura 49 apresenta a configuração do módulo File. Quando não é especificado um caminho (path) para o arquivo, ele é gerado (ou lido) no diretório a partir de onde o modelo foi aberto.

A figura 50 apresenta a configuração do módulo ReadWrite. O comando "(F4.2)" permite que o valor gerado receba até 6 algarismos, sendo 2 destes decimais. É possível observar que o módulo está configurado para gravar em um arquivo (write to file) e que a variável a ser gravada é Peso. A figura 51 ilustra os primeiros números gerados, os quais representam os pesos de 30.000 itens. Em um Athlon XP 2.000 , esta geração levou cerca de 6 segundos.

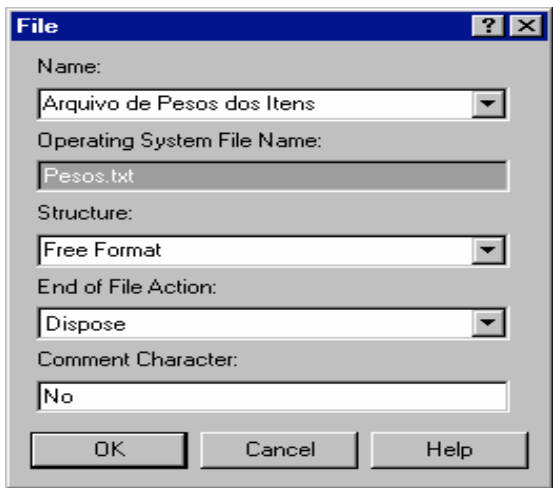

FIGURA 49 - CONFIGURAÇÕES DE FILE.

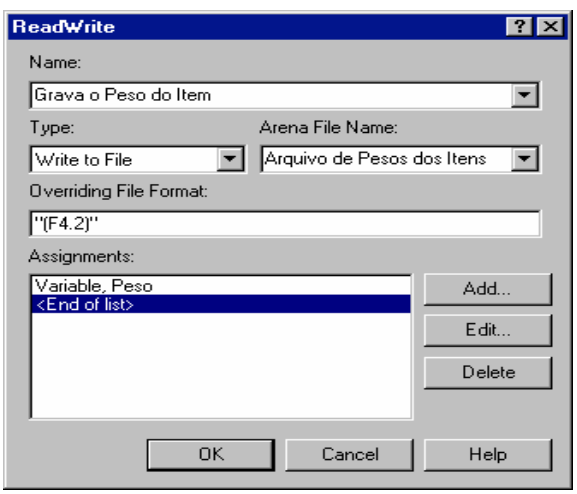

FIGURA 50 - CONFIGURAÇÕES DE READWRITE. 


\begin{tabular}{|c|c|c|c|c|c|}
\hline 5,92 & 4,65 & 12,98 & 7,93 & 6,61 & 8,68 \\
\hline 7,25 & 15,51 & 12,76 & 18,48 & 15,34 & 5,46 \\
\hline 4,81 & 8,31 & 18,00 & 4,39 & 9,60 & 15,88 \\
\hline 1,26 & 14,49 & 18,74 & 11,34 & 8,48 & 9,39 \\
\hline 2,71 & 13,20 & 12,51 & 17,91 & 2,57 & 12,50 \\
\hline 2,44 & 3,34 & 18,58 & 5,53 & 19,80 & 16,64 \\
\hline 18,86 & 17,09 & 0,38 & 7,02 & 7,95 & 2,46 \\
\hline 10,98 & 15,24 & 6,04 & 14,53 & 9,24 & 2,22 \\
\hline 17,08 & 2,72 & 5,33 & 5,76 & 12,81 & 11,82 \\
\hline 16,85 & 19,50 & 9,27 & 19,97 & 17,20 & 15,06 \\
\hline 2,72 & 15,94 & 10,68 & 16,34 & 18,28 & 4,09 \\
\hline 16,42 & 13,41 & 12,00 & 12,16 & 8,44 & 3,82 \\
\hline 19,11 & 9,04 & 7,21 & 13,28 & 7,46 & 7,98 \\
\hline 2,37 & 6,88 & 4,88 & 0,30 & 16,68 & 4,00 \\
\hline 9,41 & 1,78 & 6,25 & 19,88 & 18,92 & 7,27 \\
\hline 10,78 & 6,48 & 3,04 & 1,92 & 9,22 & 4,65 \\
\hline 6,01 & 19,08 & 0,17 & 5,63 & 4,10 & 2,13 \\
\hline 3,85 & 17,53 & 8,47 & 3,55 & 11,05 & 18,34 \\
\hline 3,70 & 6,17 & 7,59 & 12,06 & 4,37 & 8,60 \\
\hline 19,48 & 11,03 & 1,41 & 5,68 & 18,72 & 3,72 \\
\hline 17,46 & 18,03 & 18,64 & 8,99 & 15,65 & 5,99 \\
\hline 17,78 & 8,94 & 11,28 & 7,56 & 0,35 & 1,09 \\
\hline 19,95 & 5,68 & 11,88 & 15,03 & 14,74 & 17,61 \\
\hline 16,84 & 14,38 & 19,16 & 18,79 & 18,49 & 12,87 \\
\hline 14,91 & 18,81 & 3,30 & 0,16 & 3,00 & 10,09 \\
\hline 14,91 & 11,98 & 13,90 & 6,06 & 19,56 & 5,57 \\
\hline 4,99 & 11,11 & 4,74 & 7,41 & 18,78 & 16,23 \\
\hline 9,27 & 10,33 & 19,12 & 8,97 & 0,69 & 1,15 \\
\hline 0,46 & 6,50 & 19,80 & 13,91 & 14,47 & 4,75 \\
\hline
\end{tabular}

FIGURA 51 - EXEMPLO DOS PESOS GERADOS PELO MODELO PARA O ARQUIVO PESOS.TXT.

\section{- O modelo do SPP}

A figura 52 apresenta o modelo desenvolvido para simular o SPP. O modelo pode ser dividido em três partes distintas. A primeira parte cria o pedido e vai até o submodelo Relatório do Pedido Ordenado. A segunda parte simula o tempo de recolhimento das peças pelos funcionários. A parte final gera o relatório estatístico da simulação e é composta apenas pelo submodelo Estatísticas. 


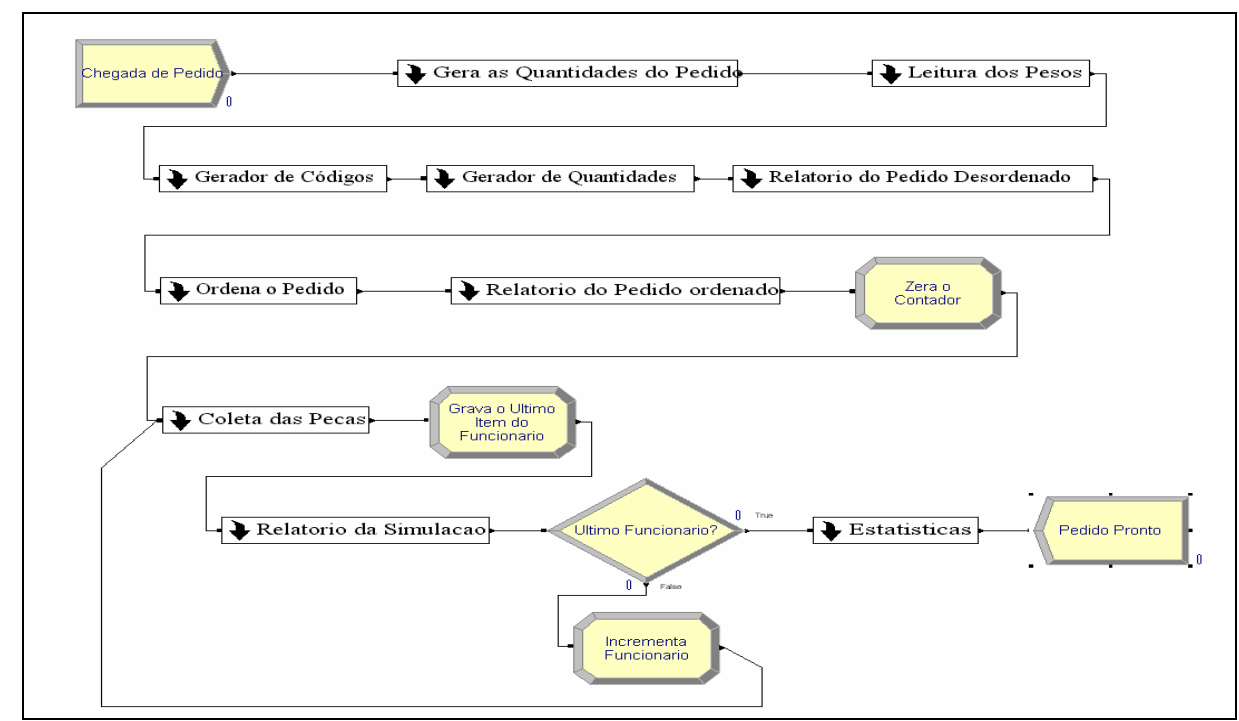

FIGURA 52 - MODELO DO SPP.

As diferentes experimentações (alteração dos parâmetros de entrada) foram desenvolvidas em uma interface VBA, como apresentada pela figura 53. A interface é acionada apenas no início da simulação, permitindo ao usuário configurar os seguintes parâmetros:

- Número de replicações;

- Quantidade de itens do pedido aleatória ou fixa. Sendo fixa o usuário escolhe a quantidade desejada;

- Carga máxima do transportador;

- Velocidade do transportador variável ou constante. No caso de velocidade constante o usuário define o valor desejado;

- Número de funcionários por pedido;

- Divisão de itens por funcionário balanceada ou desbalanceada. No caso da divisão desbalanceada o usuário define o percentual de desbalanceamento.

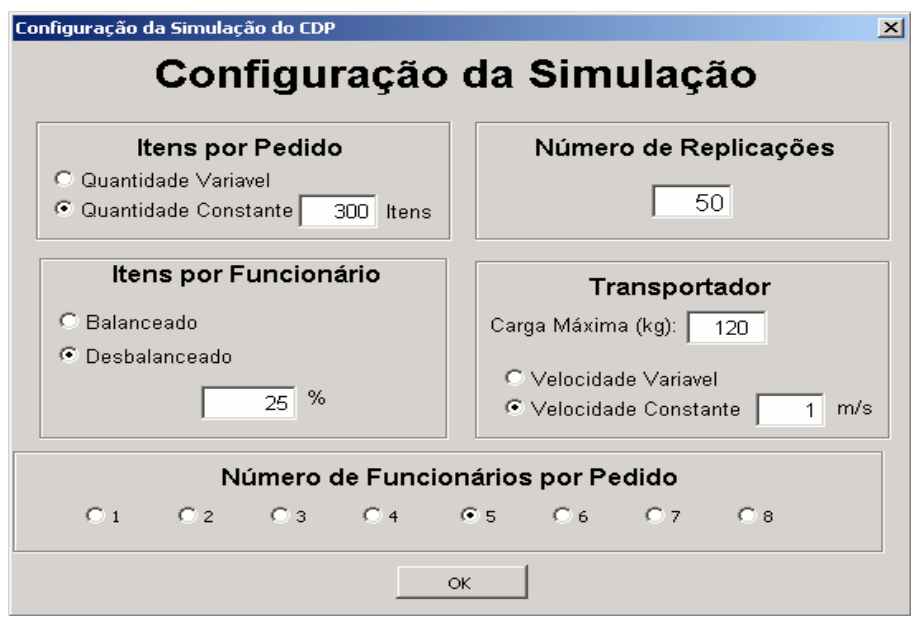

FIGURA 53 - INTERFACE VBA PARA CONFIGURAÇÃO DA SIMULAÇÃO.

\section{- Gerando o pedido}

Para simular um pedido de um cliente e seu processamento pelo computador, que gera as etiquetas de coleta de forma ordenada, foram realizadas as seguintes etapas:

- Gerar aleatoriamente o número de itens do pedido;

- Dividir o pedido em itens A, B e C;

- Leitura dos pesos dos itens; 
- Gerar aleatoriamente o código de cada item e sem repetições porque dois itens não podem ter o mesmo código. Às vezes o cliente pode até pedir o mesmo item em momentos diferentes, mas o computador irá somar as unidades e dessa forma, em um mesmo pedido, não há repetição de itens;

- Gerar aleatoriamente a quantidade de peças de cada item;

- Ordenar o pedido pelo código do item (para que fique na seqüência de recolhimento).

\section{- Gerando o número de itens do pedido}

A figura 54 mostra o submodelo que gera a quantidade de itens do pedido e a sua divisão em A, B e C. Neste caso, esta quantidade refere-se ao número de itens.

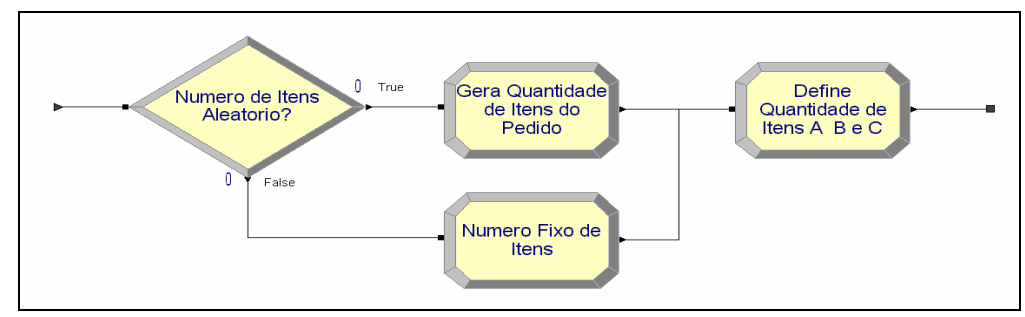

FIGURA 54 - SUBMODELO GERA AS QUANTIDADES DO PEDIDO.

Quando o usuário decide, na interface VBA, se o número de itens do pedido é aleatório ou fixo, ele estará definindo o valor de uma variável denominada Quantidade Variável. Para número aleatório de itens, essa variável recebe o valor 1 e para número fixo de itens, valor 0 (zero), porque é uma maneira do Arena reconhecer o pedido de ser aleatório ou fixo. No caso de definir um número fixo de itens, a variável Numero de Itens recebe o valor definido pelo usuário.

Na figura 55 é apresentada a configuração do Decide. A figura 56 mostra a configuração dos Assign's Gera Quantidade de Itens do Pedido e Número Fixo de Itens. A figura 57 apresenta as configurações do Assign Define Quantidade dos Itens A, B e C.

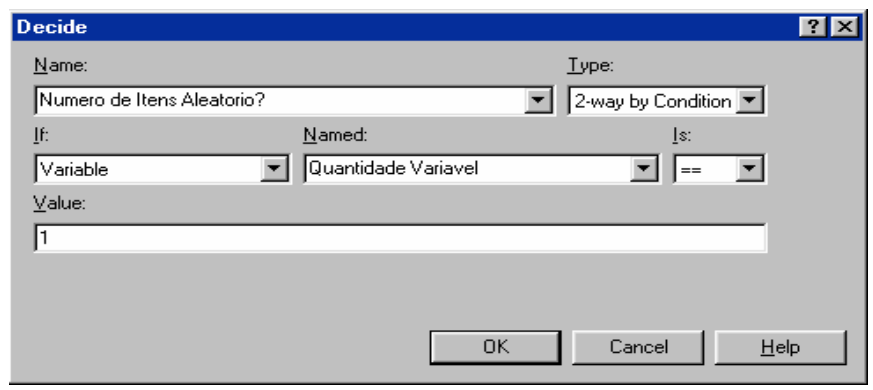

FIGURA 55 - CONFIGURAÇÃO DO DECIDE NÚMERO DE ITENS ALEATÓRIO?
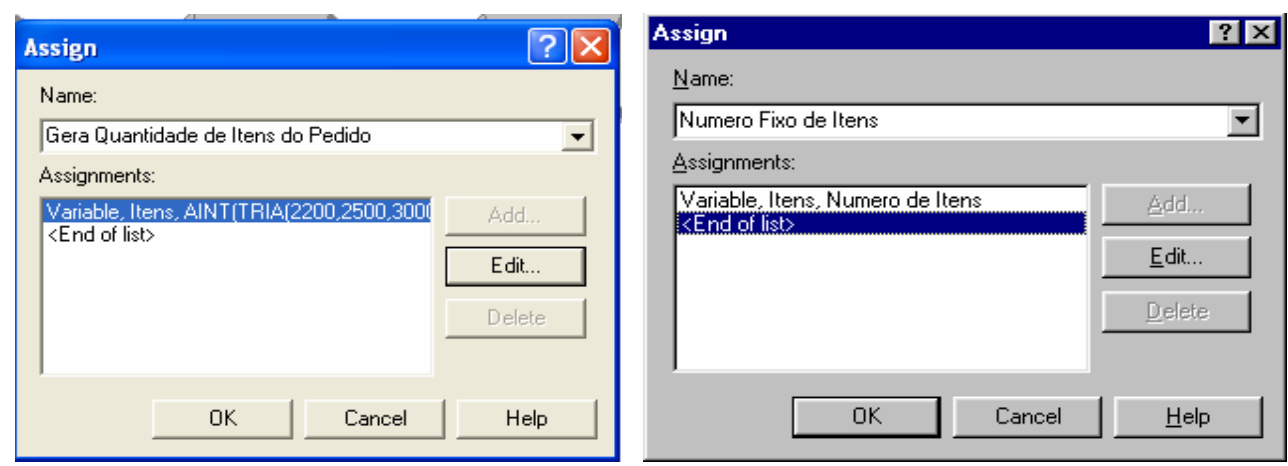

FIGURA 56 - CONFIG DO GERA QUANTIDADE DE ITENS DO PEDIDO E NÚM FIXO DE ITENS. 


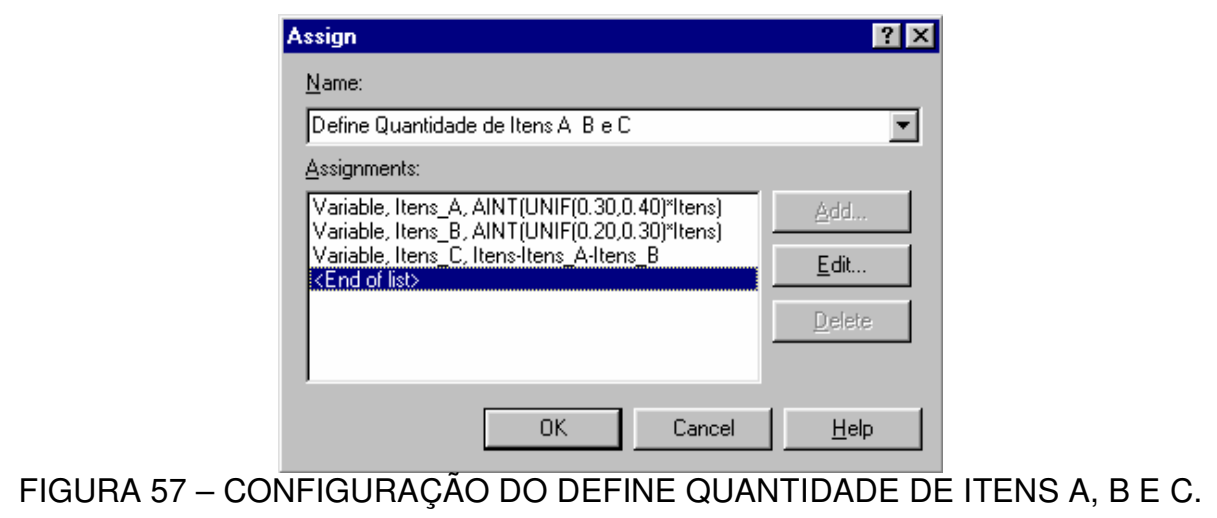

\section{- Leitura dos pesos}

A figura 58 mostra o submodelo Leitura dos Pesos. Seu objetivo é colocar os valores do arquivo Pesos. TXT no vetor chamado Pesos. É com este submodelo que o programa irá reconhecer os valores dos pesos dos itens.

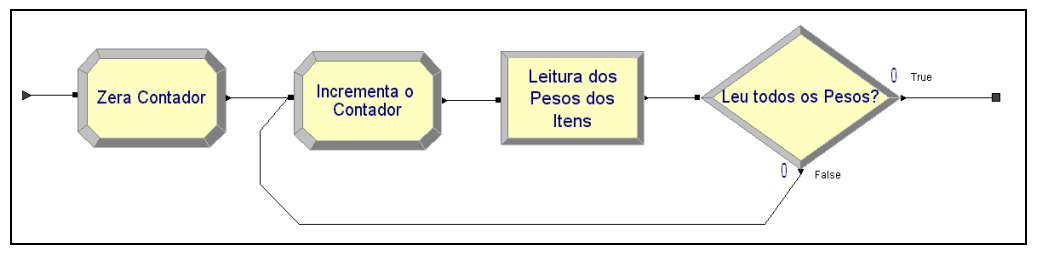

FIGURA 58 - SUBMODELO LEITURA DOS PESOS.

O Assign Zera Contador faz o que o próprio nome diz, ou seja, faz a variável Contador ter valor nulo. O Assign Incrementa ao contador um valor unitário. Assim, o novo valor da variável Contador será o antigo valor mais uma unidade, que é representada por Contador=Contador+1. O bloco de nome Leitura dos Pesos dos Itens é do tipo ReadWrite, e sua configuração é mostrada na figura 59. O Decide permite que o Contador conte até 30.000 e com isso, o bloco Leitura dos Pesos dos Itens realiza a leitura de todos os pesos e após isso, a função do submodelo se encerra. Este bloco funciona como se fosse um vetor.
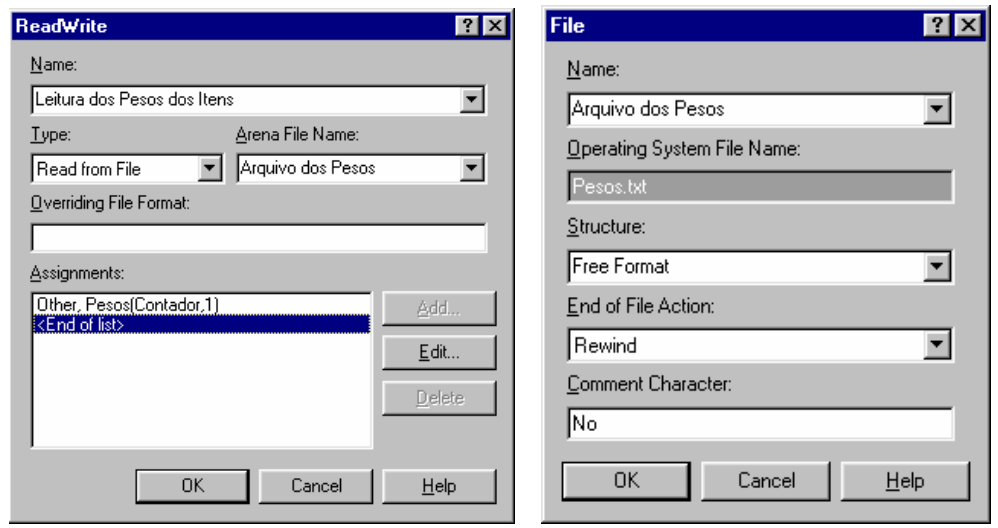

FIGURA 59 - CONFIGURAÇÃO DO BLOCO READWRITE E DO BLOCO FILE.

Para configurar o ReadWrite é necessário, antes, configurar o File. Um detalhe importante deve ser observado na maneira como o Arena manipula vetores e matrizes. Em se tratando vetores ou matrizes, o Arena só os reconhece se for como sendo tipo Other. A figura 60 mostra a configuração do vetor Pesos. 


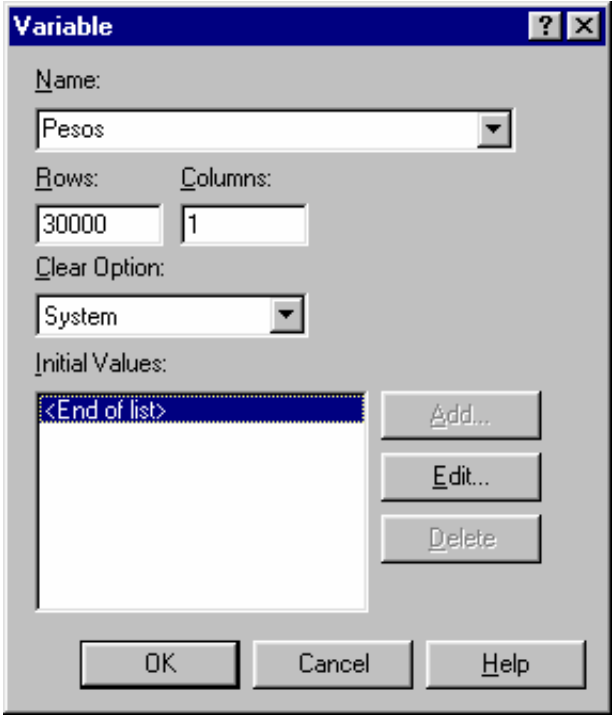

FIGURA 60 - CONFIGURAÇÃO DO VETOR PESOS.

\section{- Gerador de códigos}

A figura 61 mostra o submodelo responsável por gerar os códigos. Esta função é realizada em três etapas. Na primeira etapa gera-se os códigos das peças tipo A (de 1 até 2.000). A segunda etapa gera os códigos para as peças B (de 2.001 até 4.000). A terceira etapa gera os códigos das peças tipo C (de 4.001 até 30.000).

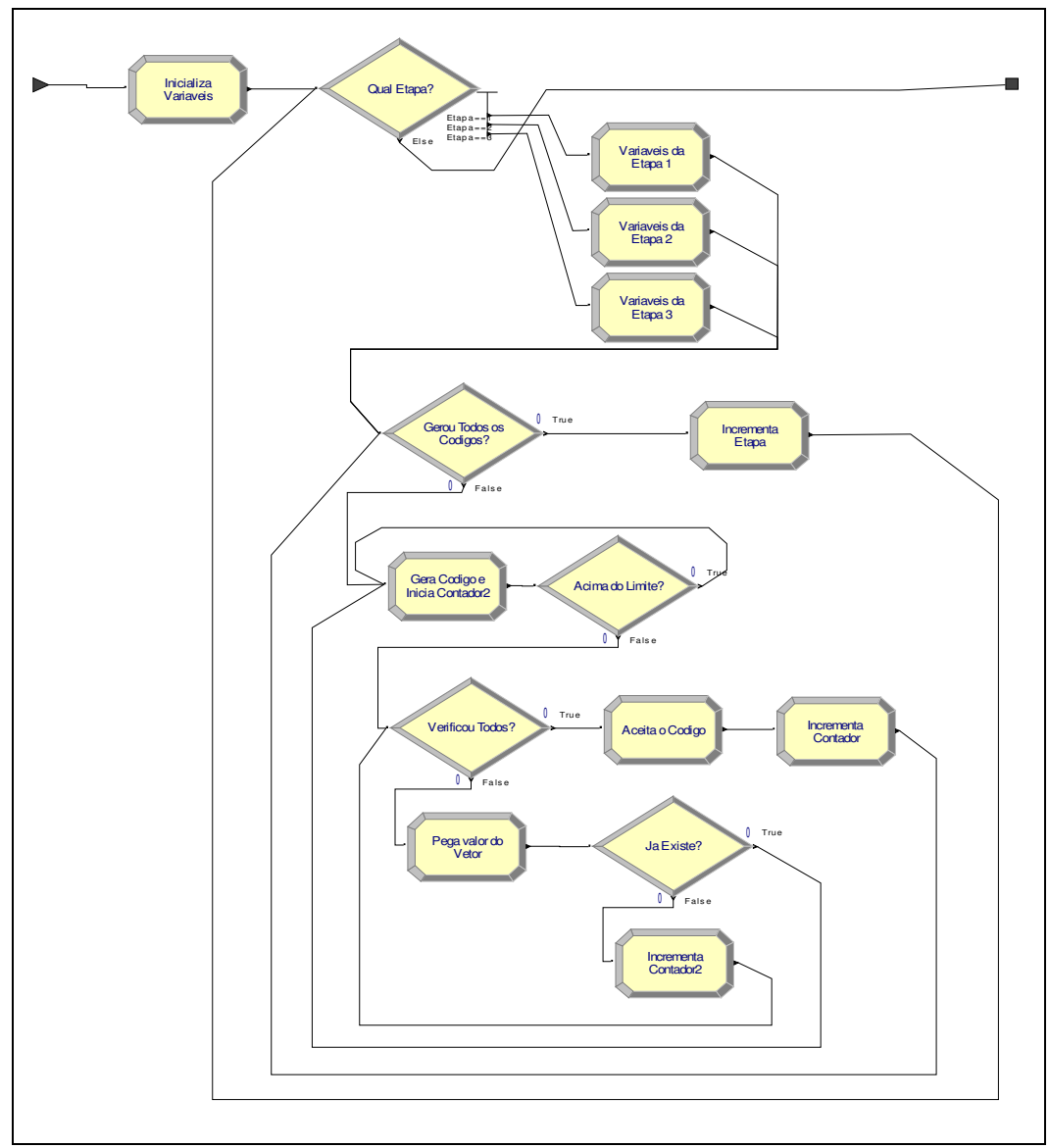

FIGURA 61 - SUBMODELO GERADOR DE CÓDIGOS.

O pedido será armazenado em um vetor chamado Pedido que possui 2 colunas e 3.000 linhas (número máximo de itens por pedido). Na primeira coluna serão colocados os códigos dos itens solicitados e na segunda coluna a quantidade de cada item. 
Como já citado, em um mesmo pedido, não há repetição de itens. Sendo assim, após gerar aleatoriamente um código, deve-se verificar se o mesmo já não foi usado. Além disso, deve-se gerar os códigos na proporção de itens A, B e C estipulada.

A figura 62 mostra que duas variáveis são inicializadas pelo bloco Assign que está no início do submodelo. A variável Etapa é incrementada após o último código de cada tipo de item ser gerado.

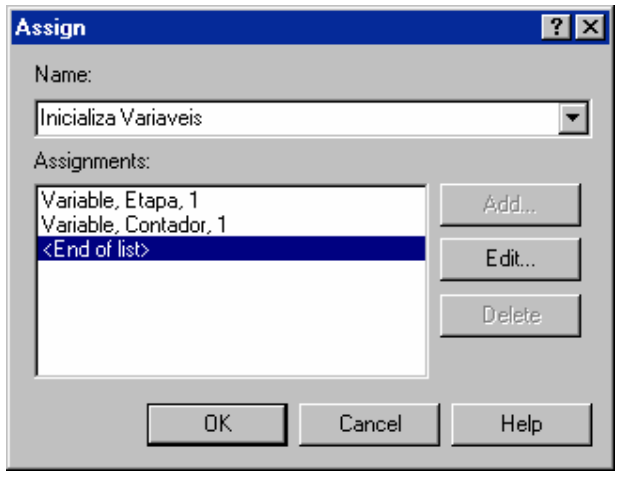

\section{FIGURA 62 - CONFIGURAÇÕES DO ASSIGN - INICIALIZA VARIÁVEIS.}

As configurações do Decide - Qual Etapa? estão na figura 63. Sua função é desviar o fluxo da entidade em função da etapa em andamento. Quando a variável Etapa tiver valor 4 o bloco encaminhará o fluxo para a saída do submodelo.

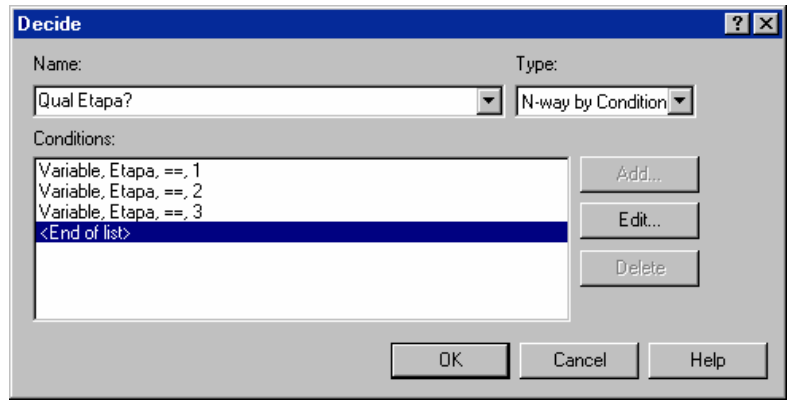

FIGURA 63 - CONFIGURAÇÕES DO ASSIGN - INICIALIZA VARIÁVEIS.

Para cada uma das três etapas são definidos valores para que o código seja gerado dentro dos valores que cada item possui. As variáveis são Minimo, Maximo, Limite e Fim e estão apresentadas na figura 64. Pode-se observar que em todos os três casos o valor máximo está acima do limite de cada item. Optou-se por isto para garantir que os últimos códigos de cada tipo de item tenham a oportunidade de serem gerados. A variável Fim será a responsável por passar de uma etapa para outra.

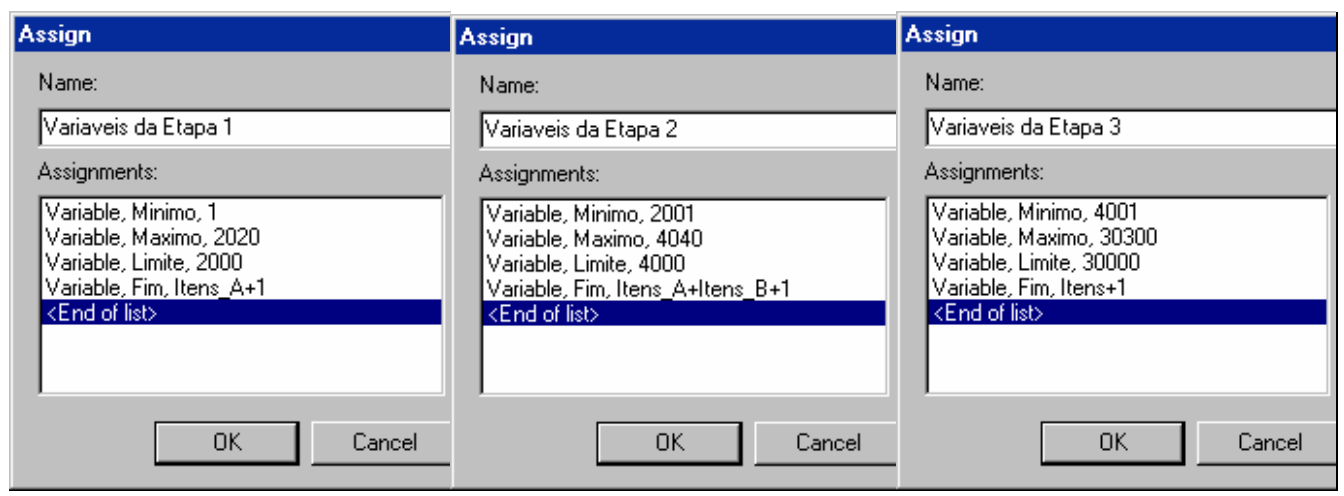

FIGURA 64 - CONFIGURAÇÃO DOS ASSIGN'S PARA CADA ETAPA.

O bloco Decide - Gerou Todos os Códigos $?$ verifica a condição Contador = Fim . Este fim refere-se ao fim de cada etapa. O bloco Assign - Incrementa Etapa realiza a seguinte função: Etapa = Etapa +1 .

O bloco Assign - Gera Código e Inicia Contador 2 tem suas configurações mostradas pela figura 65. Pode-se notar que a variável Codigo receberá um valor inteiro que vem de uma distribuição uniforme 
definida pelas variáveis Minimo e Maximo. A Variável Contador2 será utilizada para verificar se o código gerado não é repetido.

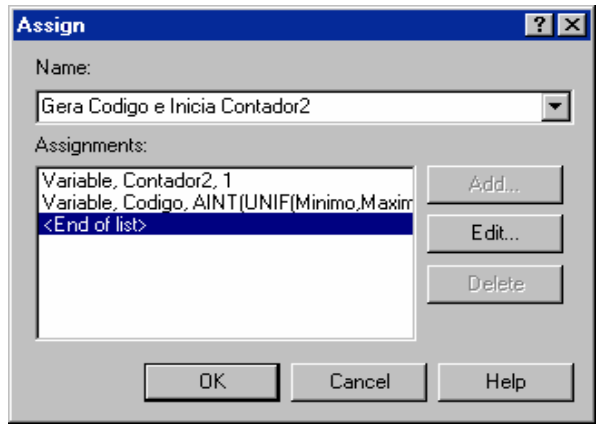

FIGURA 65 - CONFIGURAÇÃO DO ASSIGN - GERA CÓDIGO.

O bloco Decide - Acima do Limite? tem por função garantir que o código gerado está dentro da faixa especificada para cada item. Sua condição verdade é Codigo > Limite. Caso isto ocorra, o fluxo da entidade faz com que um novo código seja gerado.

Após gerar um código dentro da faixa válida, é necessário verificar se já não foi gerado anteriormente. Para isso varia-se Contador2 e compara-se o código gerado com os códigos armazenados. Se Contador2 $=$ Contador significa que o código não foi encontrado e pode ser armazenado, como mostra a figura 66.

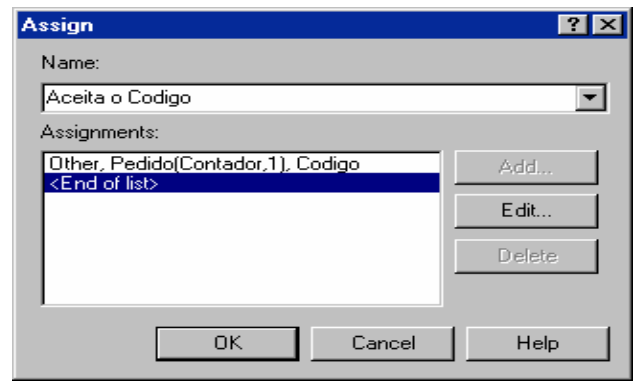

FIGURA 66 - ARMAZENAMENTO DE UM CÓDIGO VÁLIDO.

Cria-se um bloco Assign - Pega valor do Vetor, como mostra a figura 67 para armazenar o conteúdo do vetor na variável Aux1 e esta variável é comparada pelo Decide - Já Existe? (Aux1 = Codigo?).

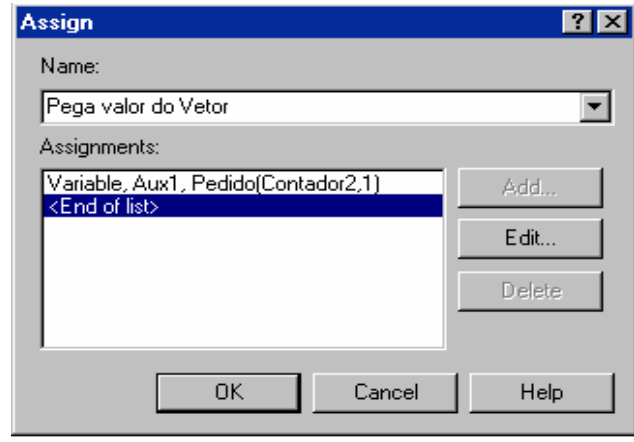

FIGURA 67 - USO DA VARIÁVEL AUX1.

\section{- Gerador de quantidades}

Na figura 68 é possível observar o submodelo Gerador de Quantidades. É possível notar que novamente tem-se um loop baseado na variável Contador. O bloco Assign - Inicializa Contador faz com que a variável receba o valor 1 . O Decide - Gerou Todos? compara Contador=Itens+1 (como o contador é inicializado com 1, a geração das quantidades só se encerra quando o Contador for maior que a variável Itens, e portanto a estabeleceu-se que o Contador deve ser o número total de itens do pedido somado a 1). 


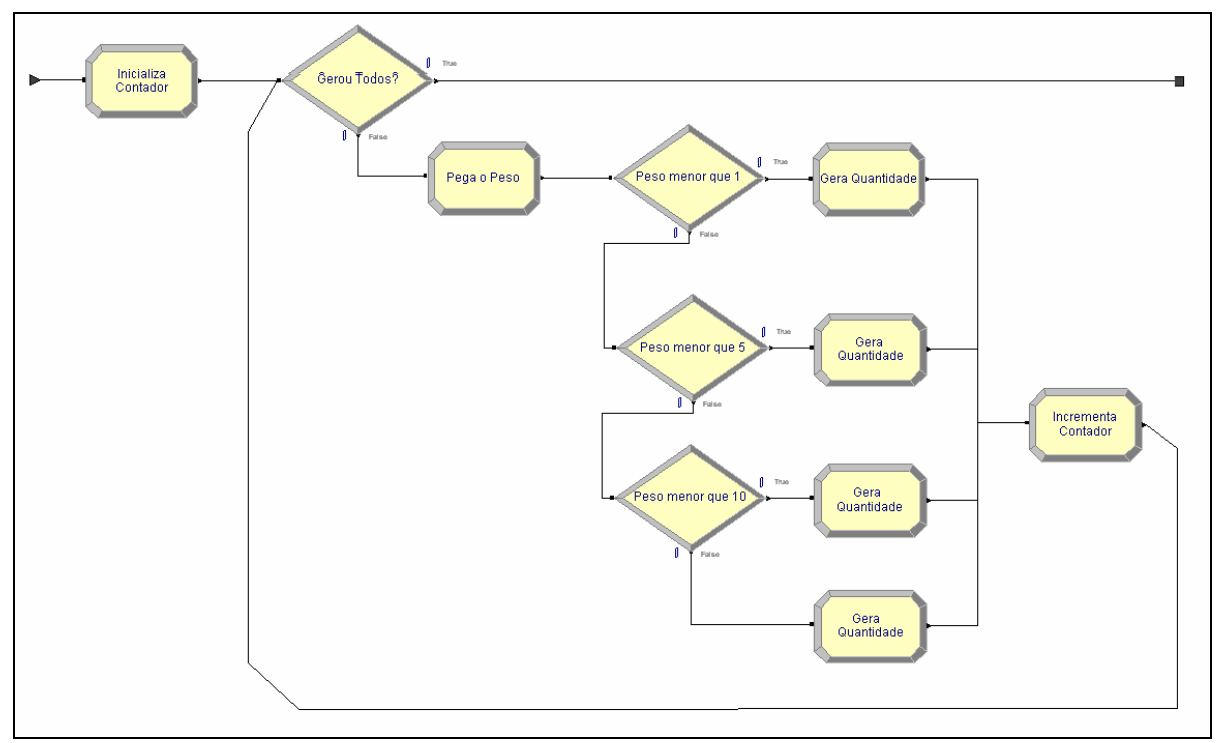

FIGURA 68 - SUBMODELO GERADOR DE QUANTIDADES.

Foi dito que a quantidade de peças de cada item em um pedido é muito variável. Para resolver este problema e aproximar a simulação da realidade adotou-se quatro distribuições diferentes, de acordo com a faixa de peso do item solicitado, ver tabela 08.

Como mostra a figura 69 o Assign - Pega o Peso coloca o peso do item na variável Aux1. Este Aux1 irá armazenar as informações dos pesos dos itens. Tendo estas informações, o programa irá comparar com as informações da tabela 08 para identificar qual das faixas de quantidade de peças usar e depois disso, armazenar estas quantidades em um vetor denominado Pedido (Contador, 2).

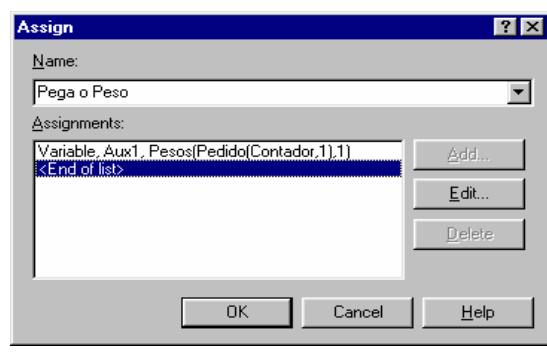

FIGURA 69 - CONFIGURAÇÃO DO ASSIGN - PEGA O PESO.

$\mathrm{Na}$ figura 70 é possível verificar que o vetor Pedido possui 3.000 linhas e 2 colunas. Como não é possível definir o número de linhas por meio de uma variável durante a execução do modelo foi necessário criá-la com base na maior quantidade possível de itens em um pedido. A primeira coluna receberá o código do item e a segunda coluna a quantidade.

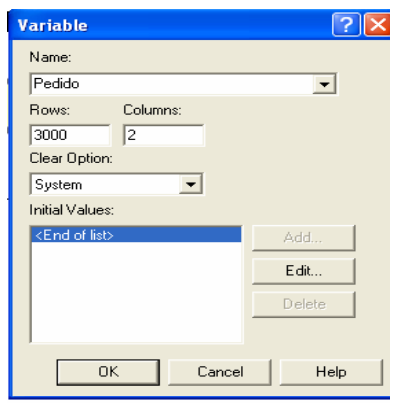

FIGURA 70 - CONFIGURAÇÃO DO VETOR PEDIDO.

\section{- Relatório do pedido desordenado}

Este submodelo teve sua importância durante a fase de depuração. Apesar disso foi mantido no modelo final, pois mostra como gerar um arquivo de texto com uma formatação básica. 
Este relatório é, basicamente, o conteúdo do vetor Pedido. Quando o vetor é gerado os códigos ficam fora de ordem. Um submodelo será responsável por ordenar esse vetor e outro irá gerar o relatório ordenado. A comparação dos dois relatórios permitiu corrigir problemas na ordenação do pedido.

A figura 71 exibe o submodelo Relatório do Pedido Desordenado. Analisando sua lógica é possível perceber que o relatório é gerado apenas na primeira replicação.

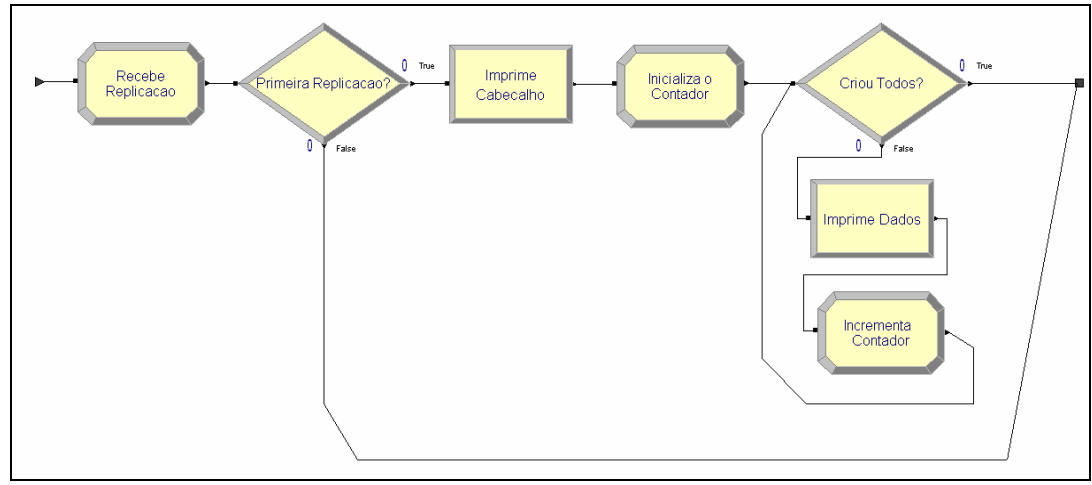

FIGURA 71 - SUBMODELO RELATÓRIO DO PEDIDO DESORDENADO.

O Assign - Recebe Replicação define duas variáveis que serão utilizadas no restante do modelo: Replicação, que contém o número da replicação atual e Replicações, que contém o número total de replicações. Os comandos em Arena são NREP e MREP respectivamente. A figura 72 ilustra suas configurações.

Novamente é realizado um looping para gravar no arquivo Pedido (desordenado).txt todos os valores. Mas, antes de se iniciar o looping é gravado um cabeçalho. Essa tarefa é realizada pelo bloco ReadWrite - Imprime Cabeçalho. A sua configuração está na figura 73.

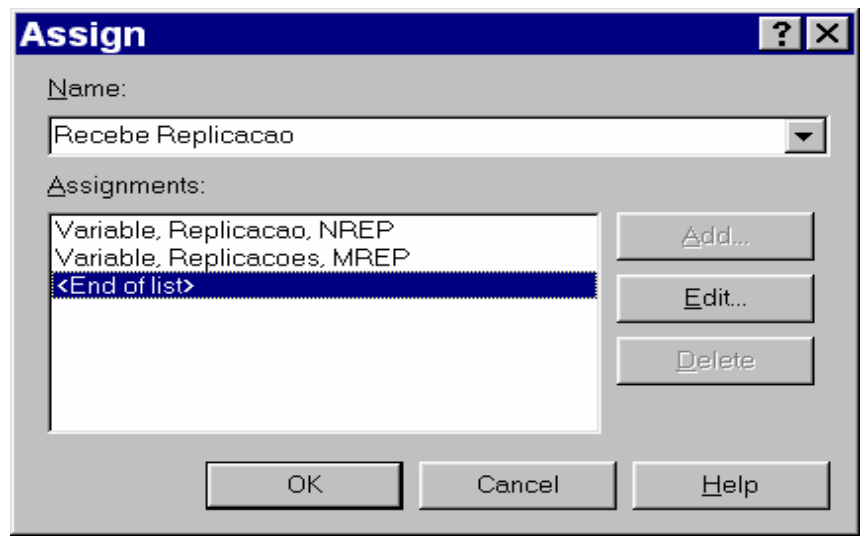

FIGURA 72 - CONFIGURAÇÃO DO ASSIGN - RECEBE REPLICAÇÃO.

A forma de se inserir algum texto no arquivo é bastante semelhante ao da linguagem Fortran. $O$ conteúdo a ser enviado deve estar entre parênteses, que por sua vez devem estar dentro de aspas duplas.

Os itens a serem gravados devem estar separados por vírgula. Estes itens podem ser textos, que deverão estar entre aspas simples, ou comandos. Na figura 73 pode-se observar o uso do comando barra (/). Cada barra indica a criação de uma linha (carriage return). Uma observação: o bloco ReadWrite sempre inicia o envio de dados em uma nova linha.

A figura 74 mostra um relatório com apenas 25 itens. Nota-se que os códigos estão fora de ordem e que na etapa de ordenação cada código deve ser movido juntamente com sua respectiva quantidade. 


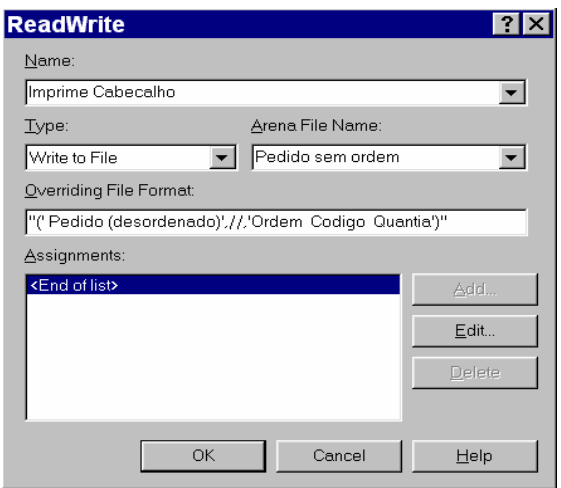

FIGURA 73 - CONFIGURAÇÃO DO READWRITE - IMPRIME CABEÇALHO.

\begin{tabular}{|c|c|c|}
\hline Pedido & \multicolumn{2}{|c|}{ (desordenado) } \\
\hline Ordem & Codigo & Quantia \\
\hline 1 & 726 & 1 \\
\hline 2 & 479 & 2 \\
\hline 3 & 118 & 2 \\
\hline 4 & 265 & 2 \\
\hline 5 & 238 & 1 \\
\hline 6 & 1.903 & 1 \\
\hline 7 & 1.105 & 1 \\
\hline 8 & 1.723 & 1 \\
\hline 9 & 3.717 & 3 \\
\hline 10 & 2.269 & 2 \\
\hline 11 & 3.673 & 1 \\
\hline 12 & 3.948 & 2 \\
\hline 13 & 2.233 & 2 \\
\hline 14 & 2.955 & 1 \\
\hline 15 & 18.114 & 2 \\
\hline 16 & 11.808 & 1 \\
\hline 17 & 8.955 & 2 \\
\hline 18 & 8.760 & 3 \\
\hline 19 & 29.618 & 2 \\
\hline 20 & 26.945 & 1 \\
\hline 21 & 27.359 & 1 \\
\hline 22 & 26.124 & 2 \\
\hline 23 & 23.572 & 1 \\
\hline 24 & 23.575 & 2 \\
\hline 25 & 10.466 & 2 \\
\hline
\end{tabular}

FIGURA 74 - EXEMPLO DO RELATÓRIO DE PEDIDO DESORDENADO. 
Dentro do looping está o bloco ReadWrite - Imprime Dados que, como o próprio nome diz, envia os dados do vetor para o arquivo. A figura 75 mostra sua configuração.

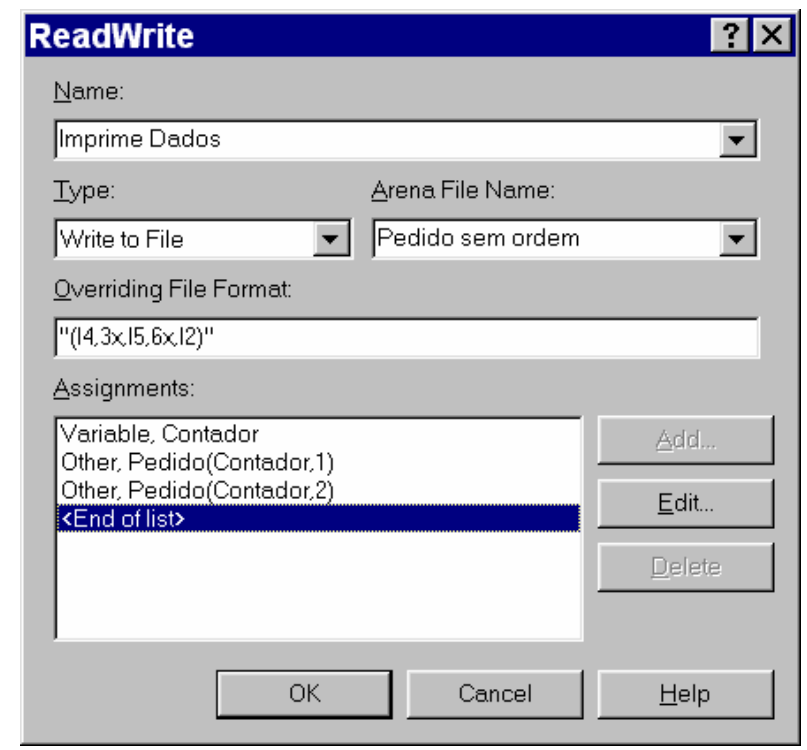

FIGURA 75 - CONFIGURAÇÃO DO READWRITE - IMPRIME DADOS.

Pela figura 75 pode-se conhecer mais detalhes da formatação Fortran. São mostrados cinco comandos separados por quatro vírgulas. Os comandos que iniciam-se com a letra I informam que será enviado um número inteiro e o número que o segue define o número de algarismos inteiros. Os números seguidos da letra $\mathbf{x}$ informam o número de espaços a serem enviados para separar os conteúdos.

Note que existem três comandos na caixa de configuração. Estes comandos permitem que os dados sejam escritos ou impressos no arquivo. A ordem com que são impressos é sequencial, ou seja, o dado relacionado ao primeiro comando será impresso primeiro e assim por diante.

\section{- Ordena o pedido}

O submodelo Ordena o Pedido está na figura 76. Como citado anteriormente, sua função é ordenar os dados do vetor Pedido em ordem crescente pelo código (coluna 1). O algoritmo implementado é conhecido com Bubble Sort.

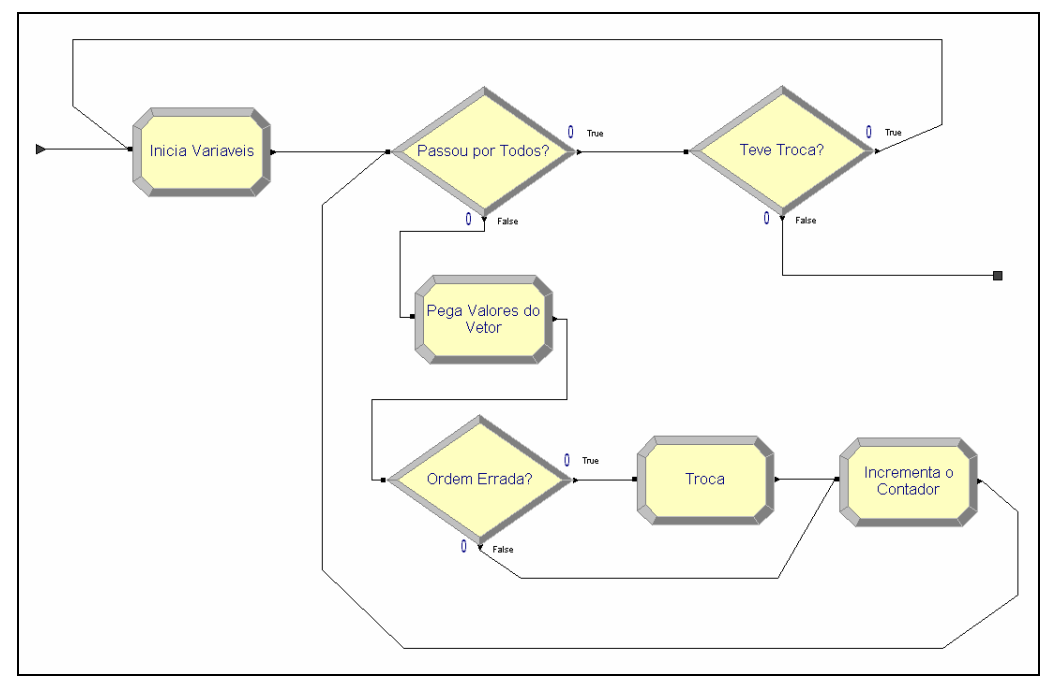

FIGURA 76 - SUBMODELO ORDENA O PEDIDO.

A ordenação utiliza a variável Contador para passar por todo o vetor e uma variável denominada Trocou, que é iniciada com valor zero. Quando ocorre alguma troca de posição no vetor esta variável recebe o valor 1. A ordenação se encerra quando todo o vetor é verificado e nenhuma troca ocorreu (ver figura 77). 


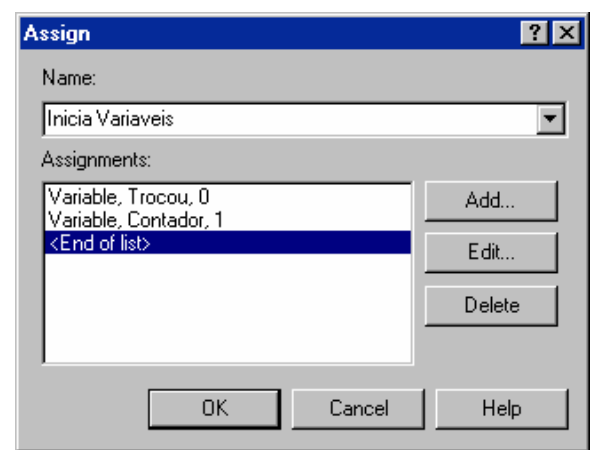

FIGURA 77 - CONFIGURAÇÃO DO ASSIGN - INICIA VARIÁVEIS.

Um looping percorre todo o vetor. É necessário neste momento a criação de um bloco Assign para lidar com vetor. A variável do vetor armazena os valores que serão analisados e os coloca em variáveis auxiliares, como mostra a figura 78.

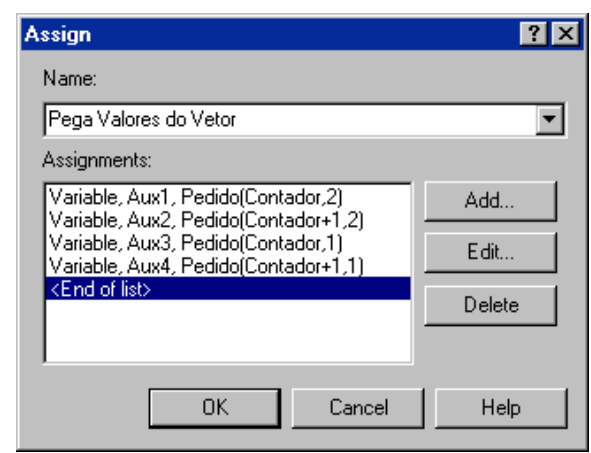

FIGURA 78 - CONFIGURAÇÃO DO ASSIGN - PEGA VALORES DO VETOR.

O módulo Decide - Ordem Errada? compara Aux1 e Aux2 (figura 79). Caso estejam fora de ordem então o módulo Assign - Troca realiza a tarefa de mudar tanto os códigos quanto seus respectivos pesos de ordem (figura 80).

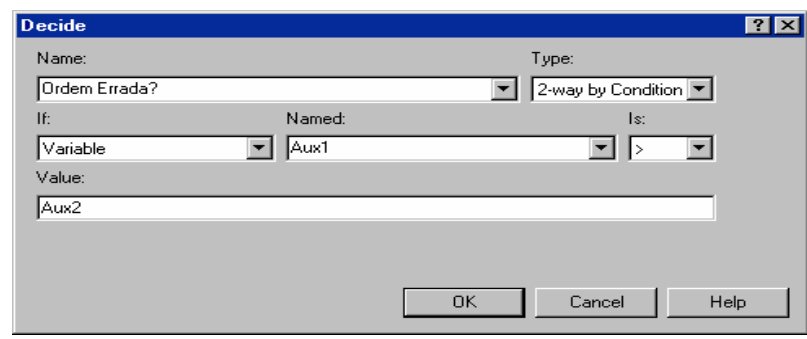

FIGURA 79 - CONFIGURAÇÃO DO DECIDE - ORDEM ERRADA?

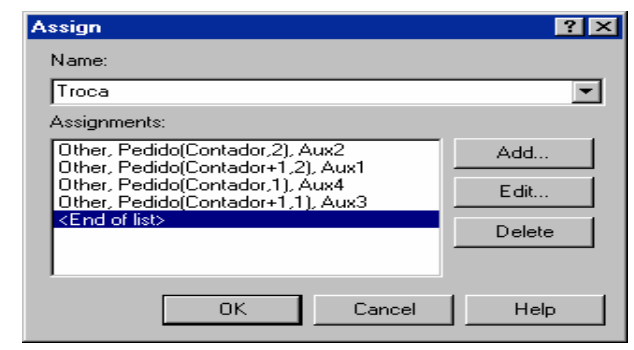

FIGURA 80 - CONFIGURAÇÃO DO ASSIGN - TROCA.

\section{- Relatório do pedido ordenado}

Como citado anteriormente, este submodelo teve sua importância durante a fase de depuração e foi mantido no modelo final. Este relatório é o conteúdo do vetor Pedido após sua ordenação e também é gerado apenas na primeira replicação. 
A figura 81 exibe o submodelo Relatório do Pedido Ordenado. Nota-se que é exatamente igual ao Relatório do Pedido Desordenado. Mas existe uma diferença. O bloco ReadWrite - Imprime Dados envia mais duas informações: peso unitário do item e o peso total (peso unitário multiplicado pela quantidade solicitada do item). Essas informações adicionais permitiram verificar se os pesos corretos estavam sendo buscados no vetor Pesos. A figura 82 apresenta o relatório com os 30 itens ordenados. Comparando com a figura 81 nota-se que os códigos estão em ordem e que os seus respectivos pesos os acompanharam.

È de se notar também que foi usada uma função nova no bloco ReadWrite da figura 83. Há agora o comando $\mathrm{F}$ seguido de um número decimal. Este é o comando para enviar valores numéricos decimais para o arquivo. Por exemplo, o comando F6.2 indica que será um número com 6 dígitos, dos quais 2 são decimais.

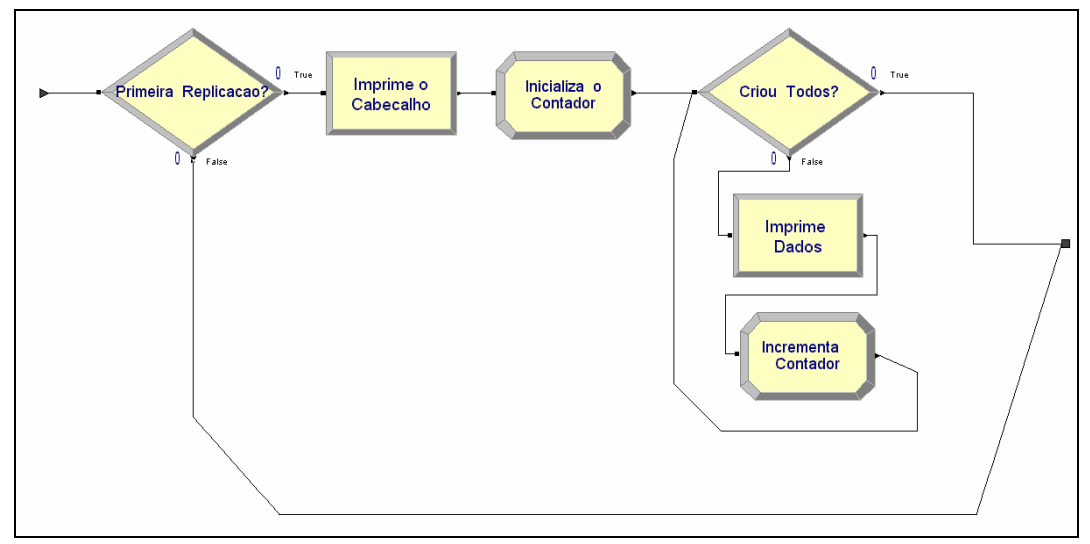

FIGURA 81 - SUBMODELO RELATÓRIO DO PEDIDO ORDENADO.

\begin{tabular}{|c|c|c|c|c|}
\hline Pedido & (ordenac & & & \\
\hline Ordem & Codigo & Quantia & Peso Unit & Peso Total \\
\hline 1 & 118 & 2 & 15,34 & 30,68 \\
\hline 2 & 238 & 1 & 16,78 & 16,78 \\
\hline 3 & 265 & 2 & 7,60 & 15,20 \\
\hline 4 & 479 & 2 & 11,27 & 22,54 \\
\hline 5 & 726 & 1 & 6,71 & 6,71 \\
\hline 6 & 1.105 & 1 & 19,66 & 19,66 \\
\hline 7 & 1.723 & 1 & 12,57 & 12,57 \\
\hline 8 & 1.903 & 1 & 6,01 & 6,01 \\
\hline 9 & 2.233 & 2 & 13,51 & 27,02 \\
\hline 10 & 2.269 & 2 & 17,80 & 35,60 \\
\hline 11 & 2.955 & 1 & 15,40 & 15,40 \\
\hline 12 & 3.673 & 1 & 11,46 & 11,46 \\
\hline 13 & 3.717 & 3 & 0,53 & 1,59 \\
\hline 14 & 3.948 & 2 & 14,35 & 28,70 \\
\hline 15 & 8.760 & 3 & 9,05 & 27,15 \\
\hline 16 & 8.955 & 2 & 18,16 & 36,32 \\
\hline 17 & 10.466 & 2 & 12,93 & 25,86 \\
\hline 18 & 11.808 & 1 & 13,21 & 13,21 \\
\hline 19 & 18.114 & 2 & 17,19 & 34,38 \\
\hline
\end{tabular}




\begin{tabular}{|rrrrr|}
\hline 20 & 23.572 & 1 & 8,17 & 8,17 \\
21 & 23.575 & 2 & 1,55 & 3,10 \\
22 & 26.124 & 2 & 12,45 & 24,90 \\
23 & 26.945 & 1 & 6,16 & 6,16 \\
24 & 27.359 & 1 & 18,09 & 18,09 \\
25 & 29.618 & 2 & 11,83 & 23,66 \\
\hline
\end{tabular}

FIGURA 82 - EXEMPLO DO RELATÓRIO DE PEDIDO ORDENADO.

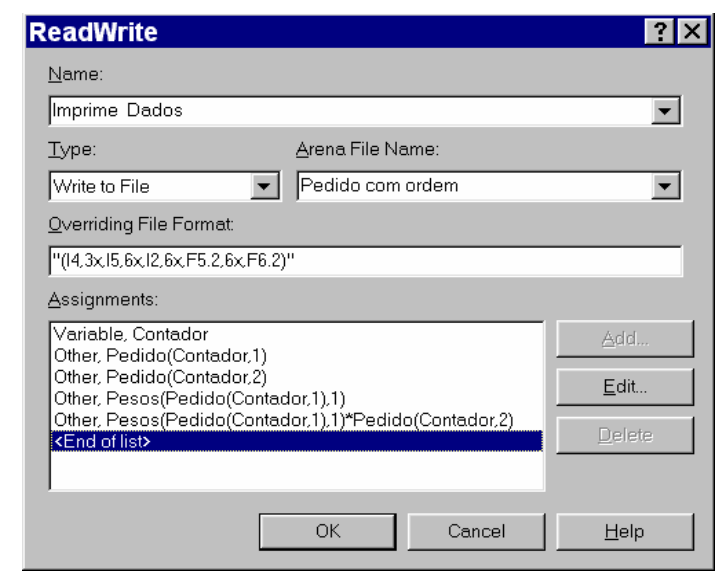

FIGURA 83 - CONFIGURAÇÃO DO READWRITE - IMPRIME DADOS.

\section{- Coletando as peças}

A coleta das peças inicia-se com a definição de algumas variáveis, conforme mostra a figura 84 . As variáveis Somatório de Fator $B$ e Fator $B$ Anterior permitem o cálculo do desbalanceamento do número de itens entre os funcionários.

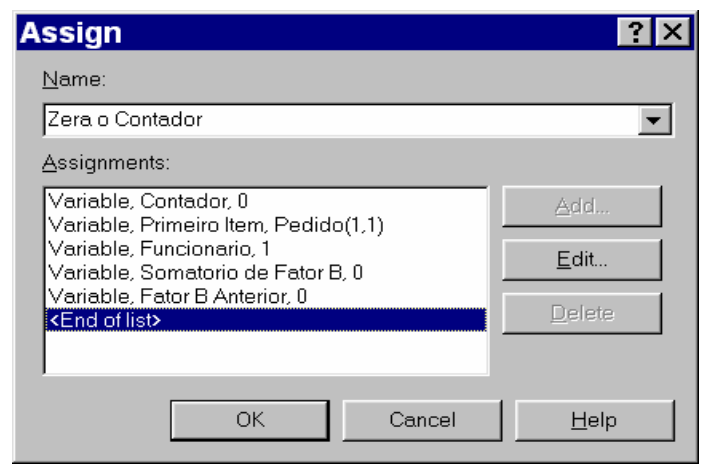

FIGURA 84 - CONFIGURAÇÃO DO ASSIGN - ZERA O CONTADOR.

A figura 85 apresenta o submodelo Coleta das Peças que é o responsável por computar todo o tempo gasto por cada funcionário para coletar suas peças. 


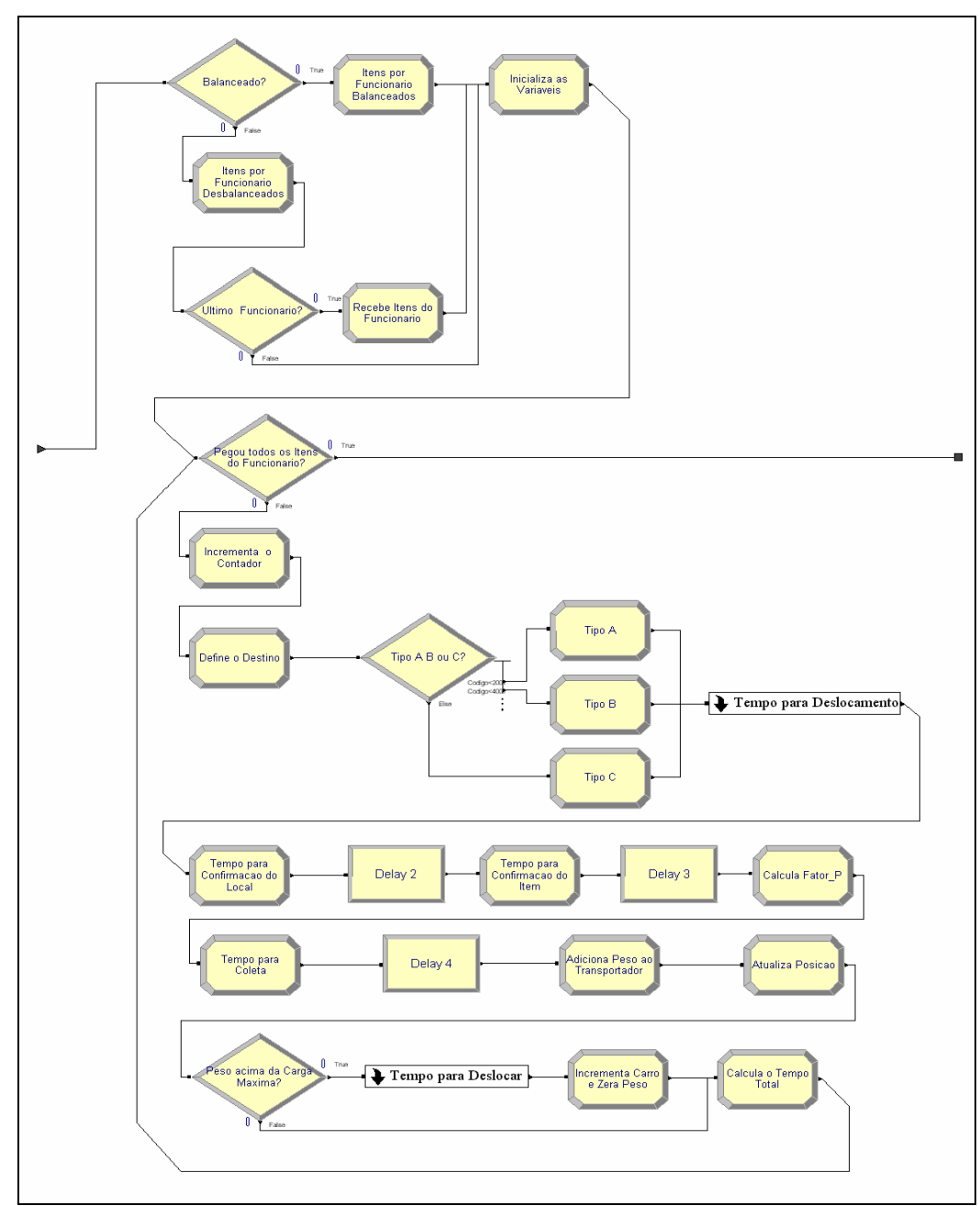

FIGURA 85 - SUBMODELO COLETA DAS PEÇAS.

A variável Itens Balanceados que tem seu valor originado na interface VBA irá receber valor 0 (zero) se deseja-se que a divisão do número de itens seja desbalanceado e valor 1 para divisão balanceada. Em seguida, irá verificar esta variável e direcionar o fluxo da entidade no submodelo.

Quando a divisão é balanceada, por exemplo, o Decide - Balanceado? direciona a entidade a passar e ativar a função de um Assign de nome Itens por Funcionário Balanceados, como mostra a figura 86.

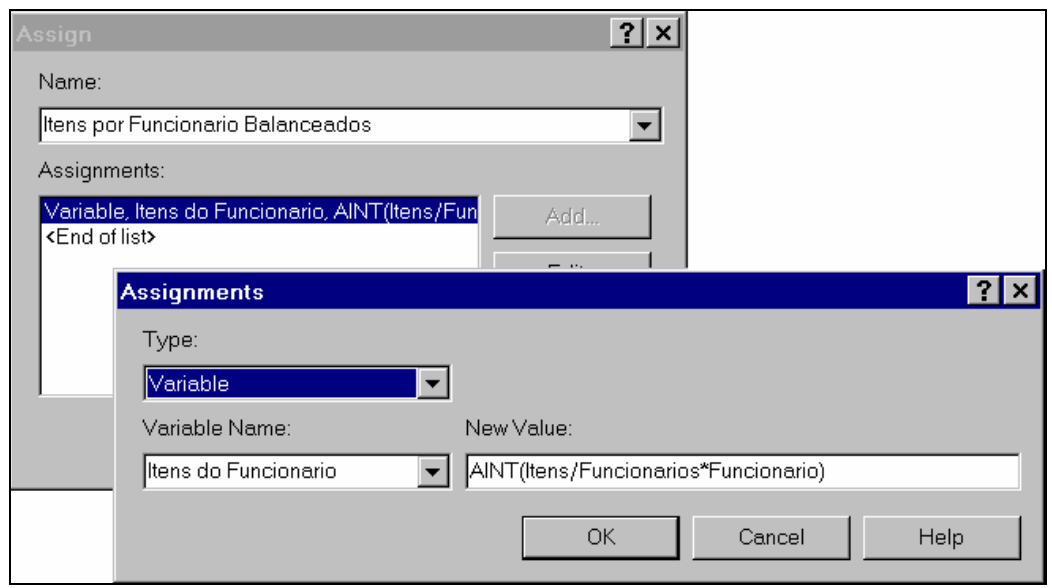

FIGURA 86 - CONFIGURAÇÃO DO ASSIGN - ITENS POR FUNCIONÁRIO BALANCEADOS.

Quando a divisão é desbalanceada, é necessário realizar a lógica discutida no final do capítulo anterior. A figura 87 apresenta a configuração do Assign - Itens por Funcionário Desbalanceados. 


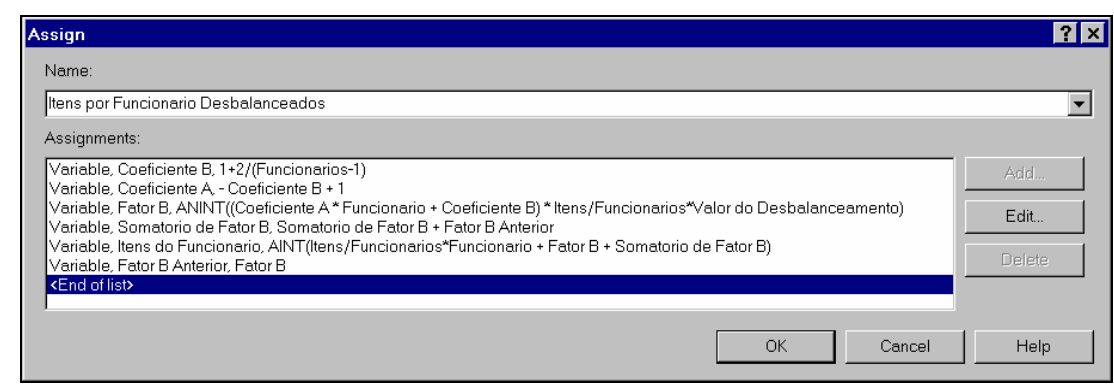

FIGURA 87 - CONFIGURAÇÃO DO ASSIGN - ITENS POR FUNCIONÁRIO DESBALANCEADOS.

Definido o número de itens, tanto balanceado quanto desbalanceado, o passo seguinte é definir variáveis que são responsáveis pela coleta de dados da coleta. Este inicia-se com o Assign - Inicializa as Variáveis que, como o próprio nome diz, coloca valores iniciais nas variáveis necessárias para movimentar e realizar as estatísticas relacionadas ao tempo gasto pelo funcionário. As variáveis são:

$$
\begin{aligned}
& \text { Seção }=0 \\
& \text { Seção Destino }=0 \\
& \text { Prateleira }=0 \\
& \text { Prateleira Destino }=0 \\
& \text { Carro }=0 \\
& \text { Peso no Carro }=0 \\
& \text { Tempo de Deslocamento }=0 \\
& \text { Tempo de Confirmação do Local }=0 \\
& \text { Tempo de Confirmação Item }=0 \\
& \text { Tempo de Coleta }=0 \\
& \text { Tempo Total }=0 \\
& \text { Fator_P }=1 \\
& \text { Peso Total }=0 \\
& \text { Peças }=0 \\
& \text { Percurso Total }=0 \\
& \text { Itens_A do Funcionário }=0 \\
& \text { Itens_B do Funcionário }=0 \\
& \text { Itens_C do Funcionário }=0 \\
& \text { Total de Itens do Funcionário }=0
\end{aligned}
$$

Após a definição destes valores inicia-se um looping que só será encerrado quando o último item do último funcionário (responsável pela coleta de itens de códigos elevados) for coletado. Dentro deste looping ocorre basicamente a seguinte seqüência de eventos:

- Define a prateleira e a seção destino em função do código do item;

- Verifica se o item é A, B ou C e incrementa as variáveis relacionadas;

- Calcula o tempo para se deslocar até o destino;

- Calcula o tempo de confirmação do local;

- Calcula o tempo de identificação do item;

- Calcula o tempo de coleta (em função do número de peças, tempo de coleta unitária e o fator-peso);

- Adiciona o peso das peças ao transportador e calcula o Fator_V;

- Verifica se o transportador já está com a carga máxima. Se ainda não atingiu a carga máxima, então vai para a seção onde se encontra o próximo item. Se atingiu a carga máxima vai para o setor de empacotamento (e calcula o tempo de deslocamento). 
Devido à grande quantidade de módulos que compõem este submodelo, elas não serão mostradas em detalhes. Suas configurações podem ser observadas no modelo que acompanha este relatório.

O cálculo do tempo gasto pelos funcionários pode ser dividido em duas etapas. A primeira é quando o funcionário se desloca do SPP para o setor de empacotamento. Este é realizado pelo submodelo Tempo para Deslocar, e este cálculo é exibido pela figura 88.

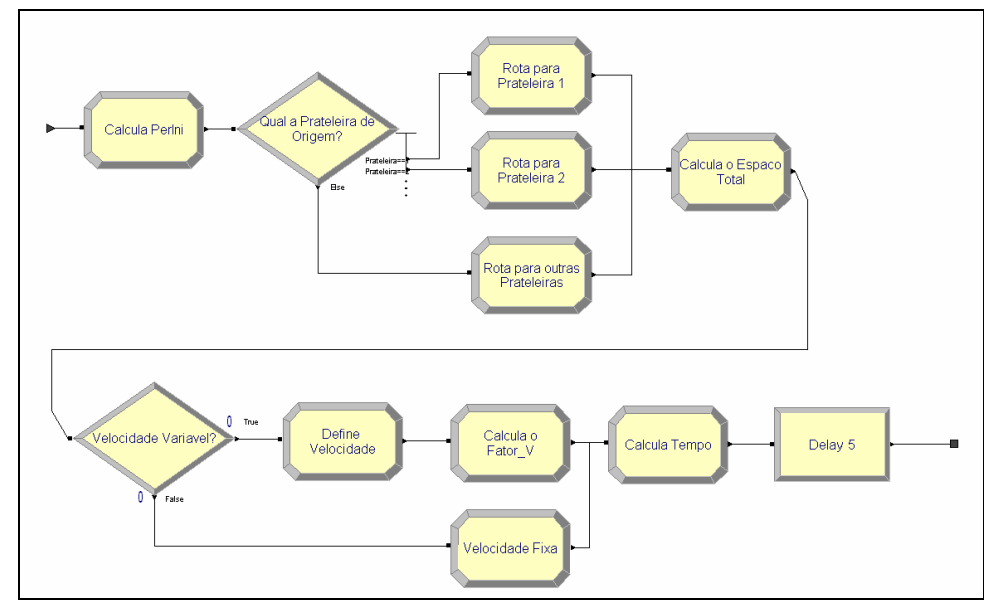

FIGURA 88 - SUBMODELO TEMPO PARA DESLOCAR.

Para se calcular o tempo de deslocamento, é necessário conhecer o valor de Perlni e também a velocidade do transportador (ou funcionário), que pode ser variável ou fixa, dependendo da seleção feita pelo usuário na interface VBA.

A segunda etapa é responsável por calcular o tempo gasto pelo funcionário quando desloca-se para um item. Esta situação indica mais outras duas possibilidades. A primeira é quando o funcionário está no setor de empacotamento e irá se deslocar até o S51 com o transportador vazio. A outra situação ocorre quando o funcionário desloca-se de um item para o item seguinte.O submodelo Tempo para Deslocamento, apresentado pela figura 89 .

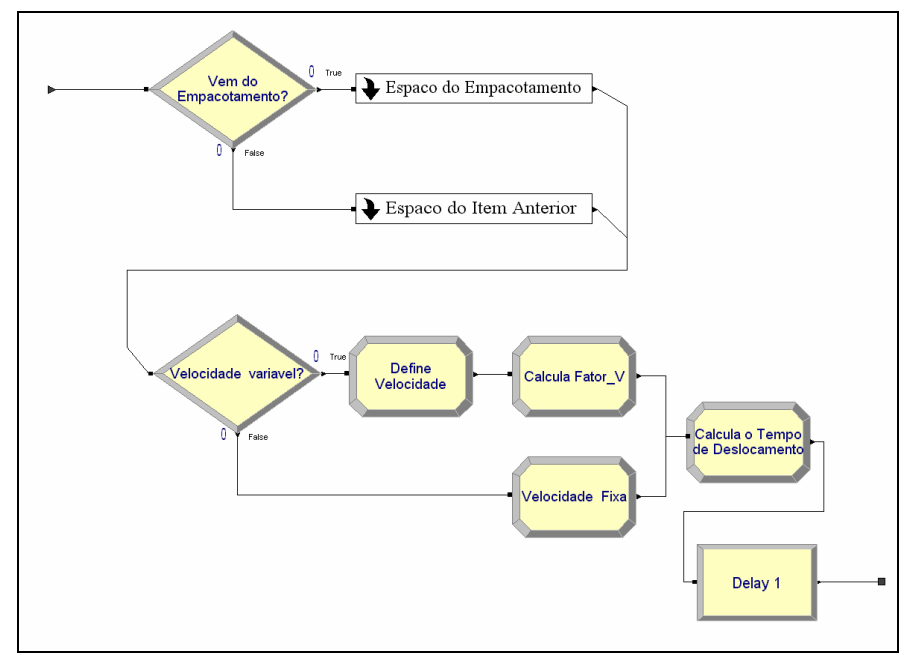

FIGURA 89 - SUBMODELO TEMPO PARA DESLOCAMENTO.

Em qualquer um dos casos das etapas, após o cálculo da distância a ser percorrida, define-se a velocidade de deslocamento (fixa ou variável) para em seguida calcular o tempo.

$\mathrm{Na}$ figura 90 pode-se observar o submodelo Espaço do Empacotamento da figura 89.

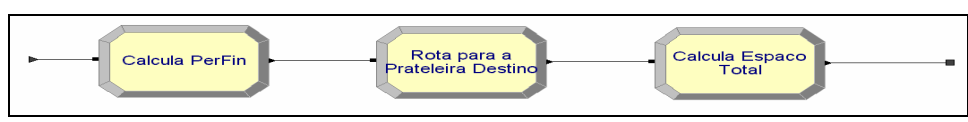

FIGURA 90 - SUBMODELO ESPAÇO DO EMPACOTAMENTO.

A figura 91 apresenta as configurações dos três blocos Assign da figura 90 que compõem o submodelo Espaço do Empacotamento. 


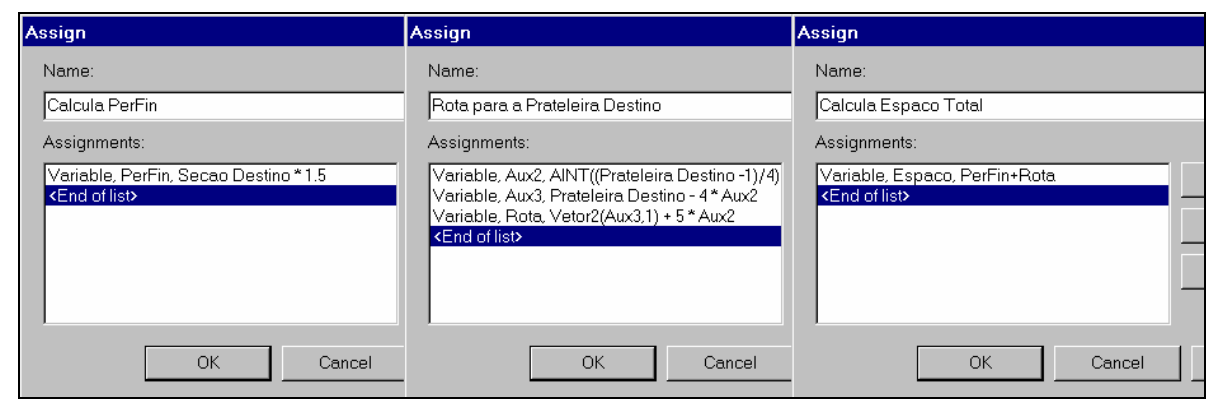

\section{FIGURA 91 - CONFIGURAÇÃO DOS BLOCOS ASSIGN DO SUBMODELO ESPAÇO DO EMPACOTAMENTO.}

O submodelo Espaço do Item Anterior da figura 89 está ilustrado com detalhes na figura 92. Como discutido no capítulo anterior, se os itens estão na mesma prateleira, a distância será (Seção Destino-Seção Atual) ${ }^{\star} 1,5$, e é calculada pelo Assign -Distância entre Seções. Quando o próximo item está em uma prateleira diferente do item atual, deve-se calcular conforme a lógica descrita pela figura 26.

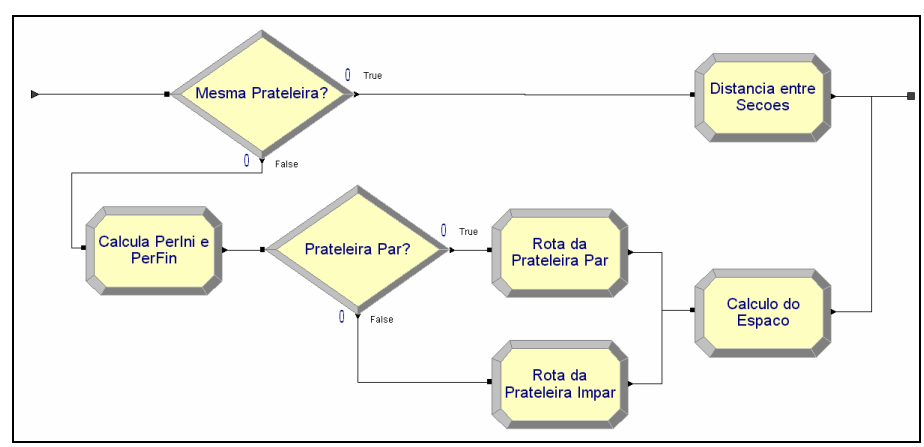

FIGURA 92 - SUBMODELO ESPAÇO DO ITEM ANTERIOR.

A variável Aux1, mostrada pela figura 93, será utilizada no Decide - Prateleira Par?. Se seu valor for 0 (zero), então o módulo Decide direciona a entidade do programa a percorrer para a prateleira de destino par, caso contrário, direciona-a à uma prateleira impar.

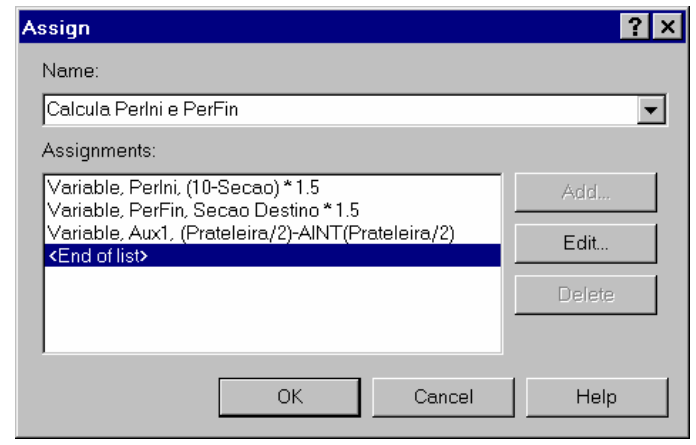

FIGURA 93 - CONFIGURAÇÃO DO ASSIGN - CALCULA Perini e PerFin.

A figura 94 apresenta as configurações dos blocos que calculam a distância entre prateleiras, conforme a lógica descrita no capítulo anterior.

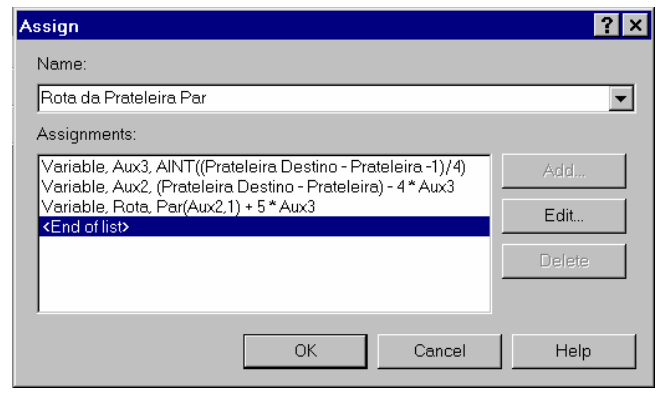




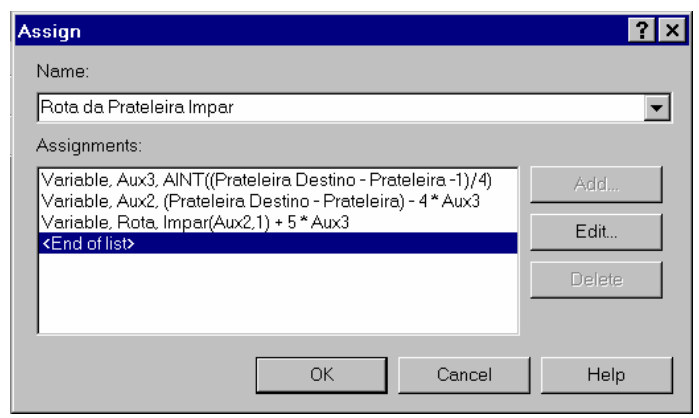

FIGURA 94 - CONFIGURAÇÃO DOS ASSIGN'S PARA PRATELEIRA PAR E IMPAR.

O Assign - Cálculo do Espaço faz o cálculo do espaço percorrido entre itens em diferentes prateleiras, pela equação. Para que isso aconteça, este Assign recebe a variável Espaço, cujo valor é Perlni + Rota + PerFin.

\section{- Relatório da simulação}

O relatório da simulação é dividido em duas partes. A primeira apresenta os valores das variáveis de cada funcionário em cada replicação. A segunda parte apresenta uma estatística destes valores, em termos de: mínimo, máximo, média e desvio padrão.

\section{- Coletando as informações}

A primeira parte é gerada durante o looping de coleta de peças do funcionário. O submodelo Relatório da Simulação está na figura 95. Como pode ser observado, um cabeçalho é criado apenas na primeira replicação. Este submodelo trabalha com diversos blocos ReadWrite. Quase todos enviam dados para o arquivo Relatório.txt (File Relatório Final). Apenas os blocos denominados Grava Dados Iniciais Para Estatística e Grava Dados Para Estatística trabalham com o arquivo Dados.txt (File Dados para Estatística). $\mathrm{O}$ arquivo Dados.txt é lido após a última replicação para os cálculos estatísticos no submodelo Estatísticas.

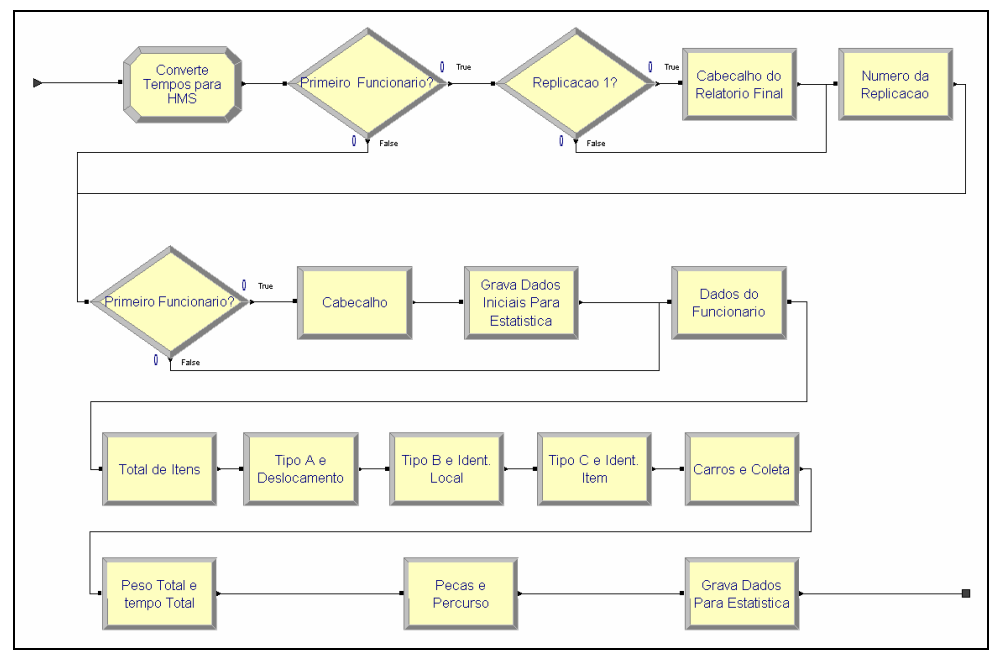

FIGURA 95 - SUBMODELO RELATÓRIO DA SIMULAÇÃO.

O modelo trabalha com todos os tempos em segundos. Para que no relatório fosse possível ter os valores de tempo no formato hh:mm:ss, foi necessária a utilização de diversas variáveis definidas no Assign - Converte Tempo para HMS. A figura 96 mostra uma parte do relatório. 


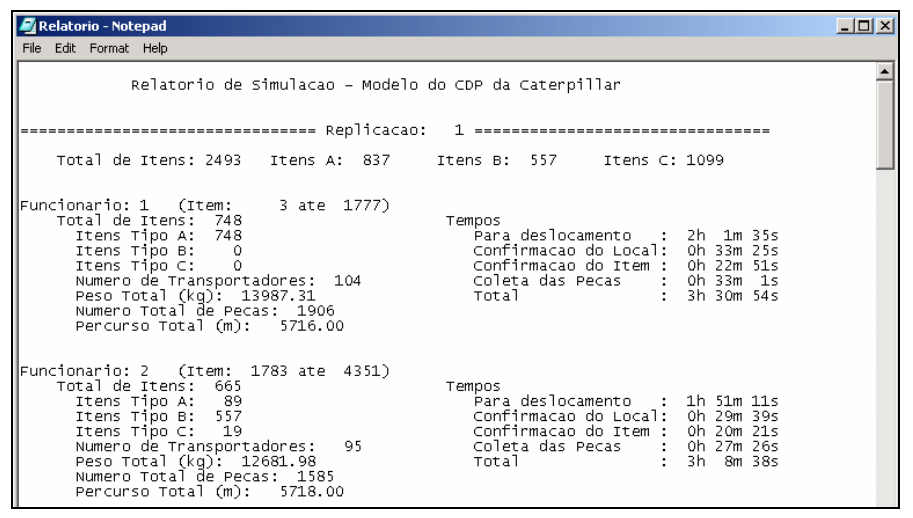

FIGURA 96 - EXEMPLO DO RELATÓRIO FINAL.

Após o último funcionário executar sua tarefa na última replicação, inicia-se os cálculos estatísticos dos dados que constam no final do relatório. Esta tarefa é realizada pelo submodelo Estatísticas. A figura 97 apresenta o conteúdo deste submodelo.

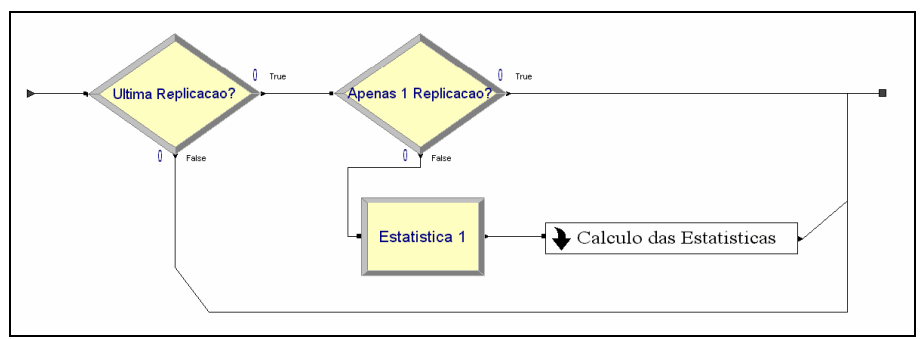

FIGURA 97 - SUBMODELO ESTATÍSTICAS.

O submodelo deve fazer duas verificações. A primeira é se está sendo realizada a última replicação. Se não for a última então não se realiza o cálculo das estatísticas. Caso seja a última replicação é necessário verificar se não se trata de apenas uma única replicação. Nesta situação não é possível (e nem necessário) realizar os cálculos estatísticos.

O submodelo Cálculo das Estatísticas está na figura 98. Para facilitar o seu entendimento ele foi dividido em quatro outros submodelos, cada um responsável por uma parte da tarefa.

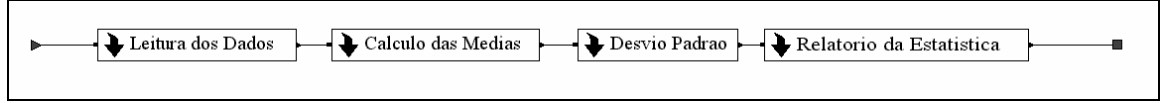

FIGURA 98 - SUBMODELO CÁLCULO DAS ESTATÍSTICAS.

\section{- Leitura dos dados}

A primeira parte, denominada Leitura dos Dados, pode ser vista na figura 99. Nota-se, logo no início, a existência de um bloco diferente. Trata-se do bloco Close, que faz parte do template Blocks. Sua função é fechar o arquivo Dados.txt (File Dados para Estatísticas), que estava no modo escrita (Write) para que possa ser reaberto e lido (modo Read). A razão disso é que não é possível executar as duas tarefas simultaneamente. Ou abre-se o arquivo para adicionar dados (Write) ou para ler dados (Read).

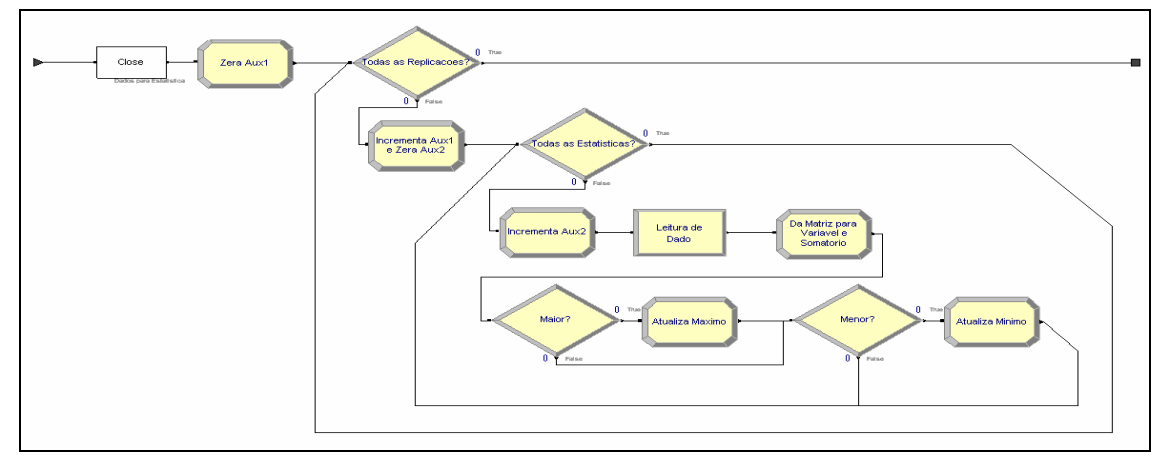

FIGURA 99 - SUBMODELO LEITURA DOS DADOS. 
A função do submodelo não é apenas ler os valores do arquivo Dados.txt para a matriz Dados. Durante a leitura, envia-se o maior valor de cada variável para o vetor Máximo, bem como o menor para o vetor Mínimo. É realizado o somatório de cada variável para posteriormente realizar o cálculo do desvio padrão.

É importante entender sobre o número de estatísticas calculadas. Em cada replicação são gerados 4 valores gerais e 13 valores para cada funcionário. Então o número de total de estatísticas a serem calculadas é $4+13^{*}$ Funcionários, que varia de um mínimo de 17 (quando apenas 1 funcionário faz a coleta) até 108 (quando 8 funcionários trabalham simultaneamente no pedido). A figura 100 apresenta a configuração do Decide - Todas as Estatísticas? que utiliza este cálculo.

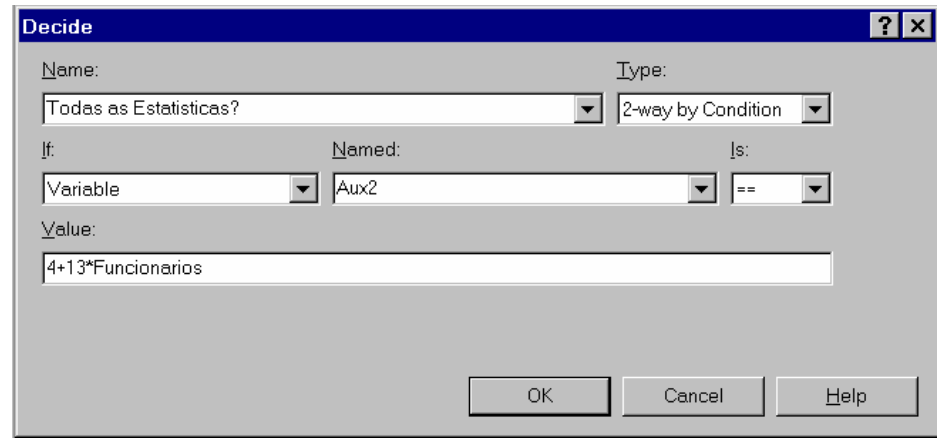

FIGURA 100 - CONFIGURAÇÃO DO DECIDE - TODAS AS ESTATÍSTICAS?

Dessa forma a matriz $\operatorname{Dados}(200,108)$ e os vetores Mínimo(1, 108), Máximo(1, 108), Média(1, 108), Somatório(1, 108), SomatorioQuadrado(1, 108) e Desvio $(1,108)$ foram dimensionadas para a situação extrema. A seqüência em que os dados são processados é descrita pela tabela 24.

TABELA 24 - DADOS PROCESSADOS PARA O CÁLCULO DAS ESTATÍSTICAS.

\begin{tabular}{|c|c|}
\hline Variável & Descrição \\
\hline Itens & Número total de itens do pedido \\
\hline Itens_A & Número total de itens $A$ no pedido \\
\hline Itens_B & Número total de itens $B$ no pedido \\
\hline Itens_C & Número total de itens $\mathrm{C}$ no pedido \\
\hline Total de Itens do Funcionário & Número de total itens do funcionário \\
\hline Itens_A do Funcionário & Número total de itens $A$ do funcionário \\
\hline Itens_B do Funcionário & Número total de itens $\mathrm{B}$ do funcionário \\
\hline Itens_C do Funcionário & Número total de itens $\mathrm{C}$ do funcionário \\
\hline Carro & Número de transportadores usados \\
\hline Peso Total & Peso total de todas as peças coletadas \\
\hline Peças & Número total de peças coletadas \\
\hline Percurso Total & Distância total percorrida \\
\hline Tempo de Deslocamento & Somatória dos tempos de deslocamento \\
\hline Tempo de Identificação do Local & Somatória dos tempos de identificação do local \\
\hline Tempo de Identificação do Item & Somatória dos tempos de identificação do local \\
\hline Tempo de Coleta & Somatória dos tempos de coleta \\
\hline Tempo Total & Tempo total consumido \\
\hline
\end{tabular}

\section{- Cálculo das médias}

Após a leitura de todos os dados, tem-se o vetor Somatório preenchido. É o momento do submodelo Cálculo das Médias executar sua tarefa. Sua estrutura é muito simples, como pode ser notado pela figura 101. 


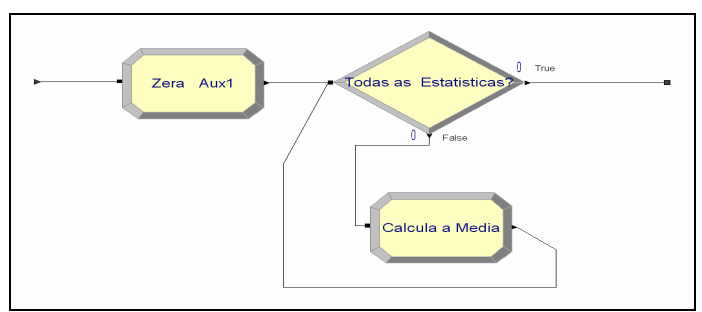

\section{FIGURA 101 - SUBMODELO CÁLCULO DAS MÉDIAS.}

Na figura 102 pode-se verificar a simplicidade do cálculo do valor médio de cada variável. Nesta parte do modelo utilizou-se a variável Aux1 como contador. A configuração do Decide - Todas as Estatísticas? é exatamente igual à mostrada pela figura 100, com exceção da variável que, neste caso é Aux1 e não Aux2.

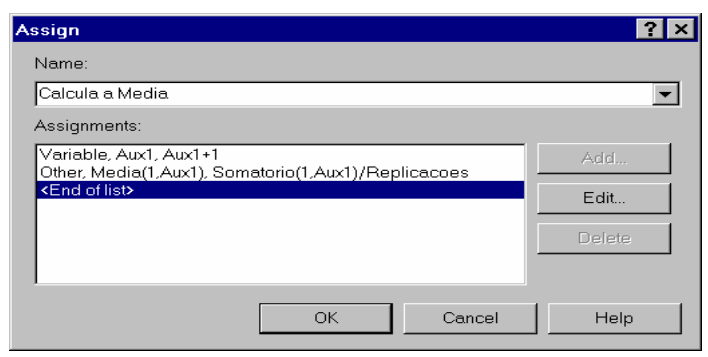

FIGURA 102 - CONFIGURAÇÃO DO ASSIGN - CALCULA A MÉDIA.

É provável que o leitor faça um questionamento: como blocos podem ter o mesmo nome? $\mathrm{Na}$ realidade os nomes são muito parecidos. Em cada bloco de nome similar há número de espaços diferentes entre as palavras, fazendo com que o Arena considere-os como sendo diferentes.

\section{- Cálculo do desvio padrão}

De posse da matriz Dados e do vetor Média é possível agora calcular o desvio padrão. A primeira etapa, como mostra a figura 103 é calcular o somatório dos quadrados das diferenças.

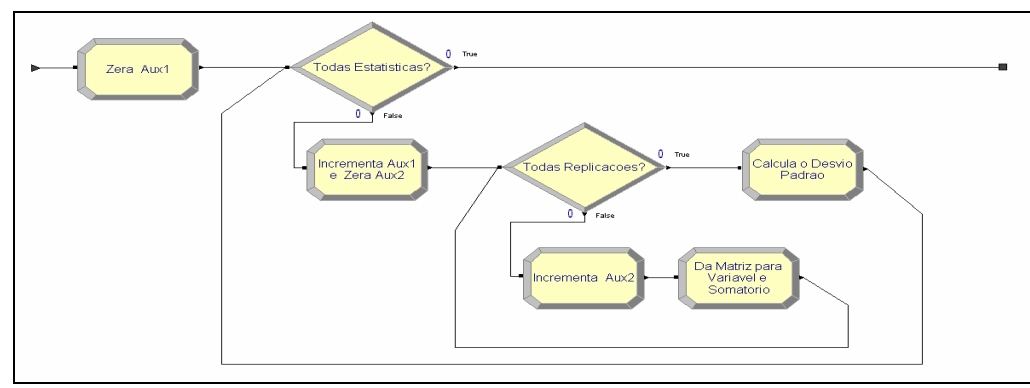

FIGURA 103 - SUBMODELO DESVIO PADRÃO.

O Assign - Da Matriz para Variável e Somatório, disponível na figura 104, realiza o cálculo do somatório dos quadrados das diferenças, ou seja, $\Sigma$ (Dado-Média) ${ }^{2}$.

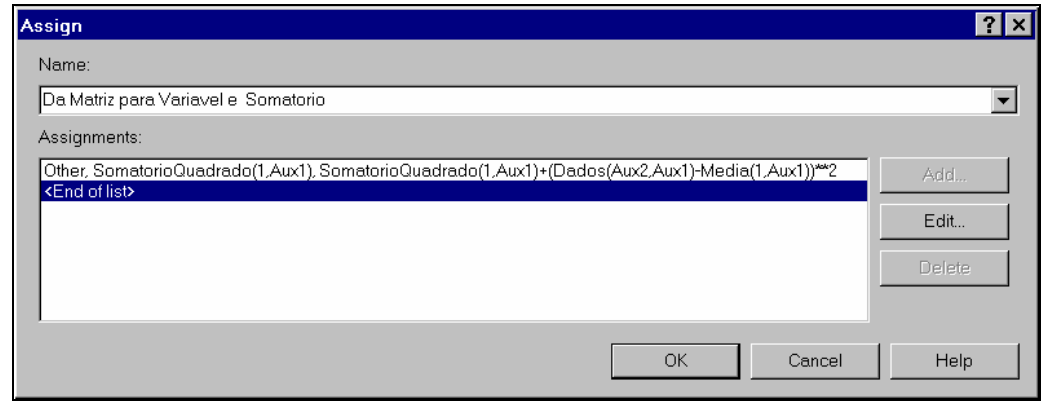

FIGURA 104 - CONFIGURAÇÃO DO ASSIGN - DA MATRIZ PARA VARIÁVEL E SOMATÓRIO.

Somente após obter este somatório é que se realiza o cálculo do desvio padrão, como mostra o Assign - Calcula o Desvio Padrão na figura 105. 


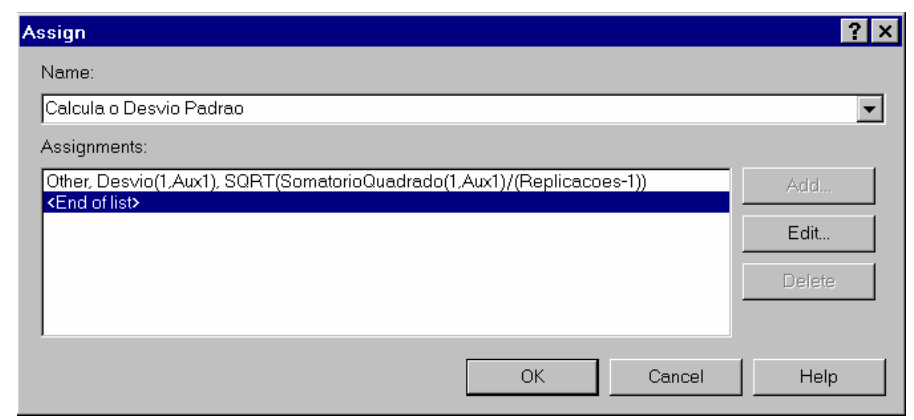

FIGURA 105 - CONFIGURAÇÃO DO ASSIGN - CALCULA O DESVIO PADRÃO.

\section{- Finalizando o relatório}

Após terem sido realizados todos os cálculos chega o momento de enviá-los para o Relatório.txt, finalizando-o. Esta etapa é feita pelo submodelo Relatório da Estatística, que está apresentado na figura 106.

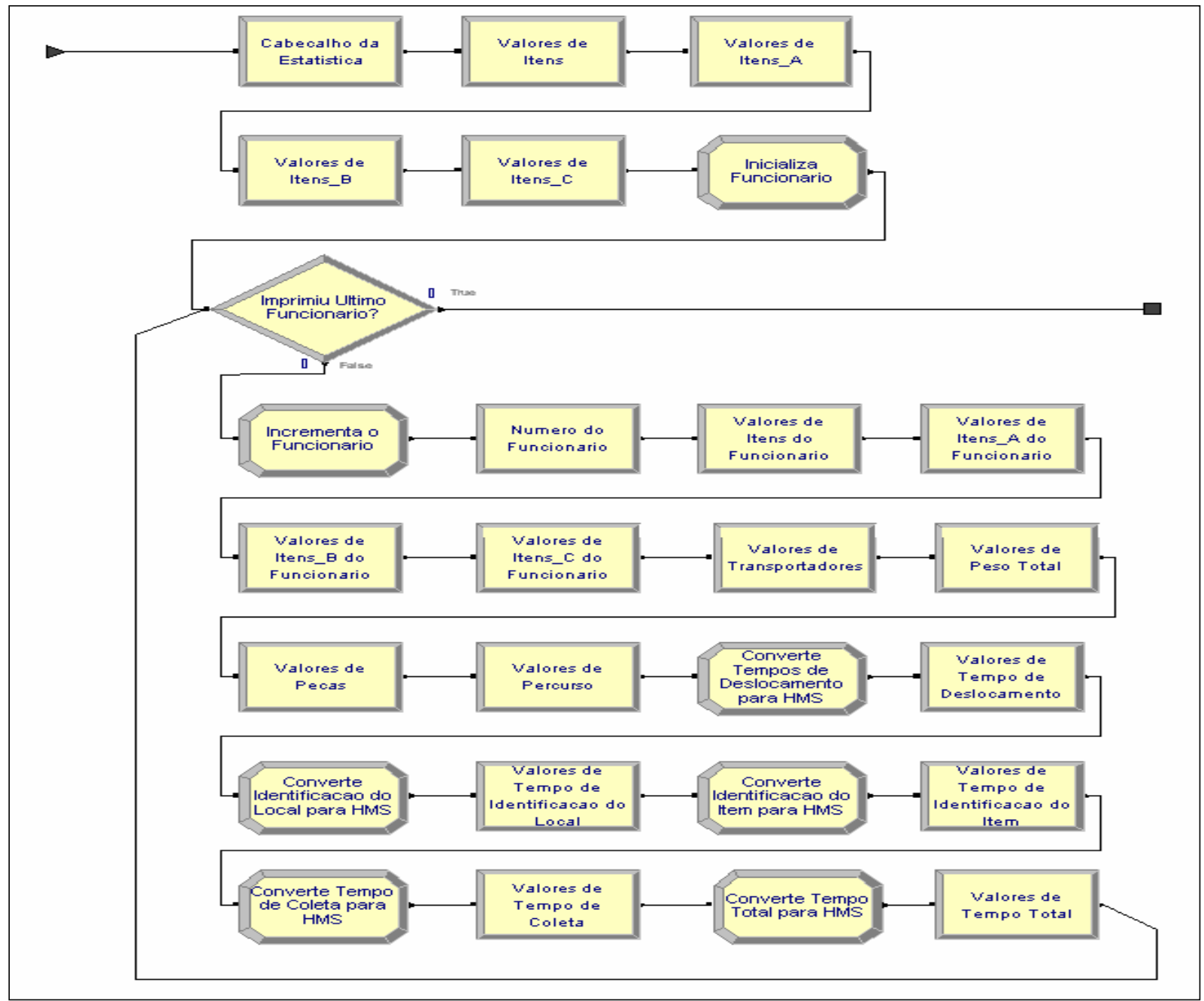

FIGURA 106 - SUBMODELO RELATÓRIO DA ESTATÍSTICA.

Cada bloco ReadWrite envia seus respectivos dados na seqüência Mínimo - Máximo - Média Desvio Padrão. A figura 107 apresenta a parte estatística de um relatório com apenas 2 funcionários. 


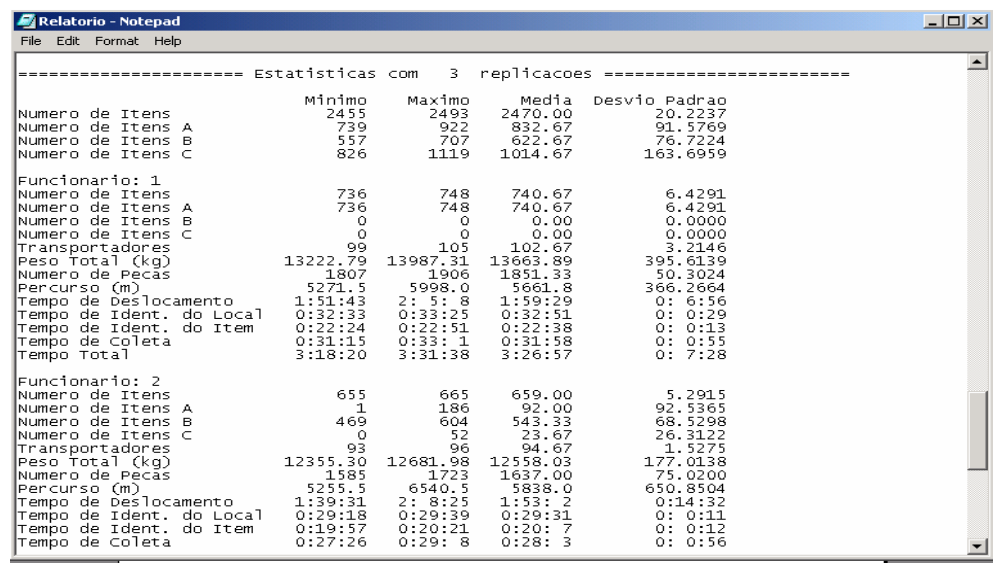

FIGURA 107 - EXEMPLO DAS ESTATÍSTICAS DO RELATÓRIO.

Nota-se as quatro primeiras variáveis no início (referindo-se ao número de itens) e em seguida por blocos com 13 variáveis para cada funcionário. No cabeçalho há a identificação do número de replicações executadas.

\section{ANEXO 1 - INFORMAÇÕES DO SPP}

\section{Confidential Green \\ Retain Until: 13/11/2003 \\ Retention Category: G90 - Information and Reports}

Seguem abaixo os dados:

1. Dimensões externas do setor: 39 Largura x 37 comprimento (metros)

2. Número de itens: 77.212

3. Distribuição entre a, b e c:

$$
\begin{aligned}
& A=1.522 \\
& B=3.120 \\
& C=25.413 \\
& D=21.846 \\
& E=25.311 \\
& \text { TOTAL }=77.212
\end{aligned}
$$

4. Estrutura de pedidos diários: Emergência

$$
\begin{aligned}
& \text { Estoque } \\
& \text { Exportação }
\end{aligned}
$$

5. Número de pedidos: 3 pedidos

6. Número de itens por pedido (em média): Emergência 700 itens/diário

$$
\text { Estoque } 1.705 \text { itens/diário }
$$

Exportação 114 itens/diário

7. Tipo de item por pedido a,b e c: $\mathrm{A}=1.033$

$\mathrm{B}=733$

$\mathrm{C}=1.141$

$\mathrm{D}=199$

$\mathrm{E}=99$

8. Identificação do cliente: Sotreq

Paraná

Marcosa

Macrosa

Petersen

Gencosa

Morton 
ANEXO 2 - METHODS-TIME MEASUREMENT (MTM)

TABELA 25 - DADOS DO TEMPO DE "ALCANÇAR" (FONTE: MAYNARD, 1970).

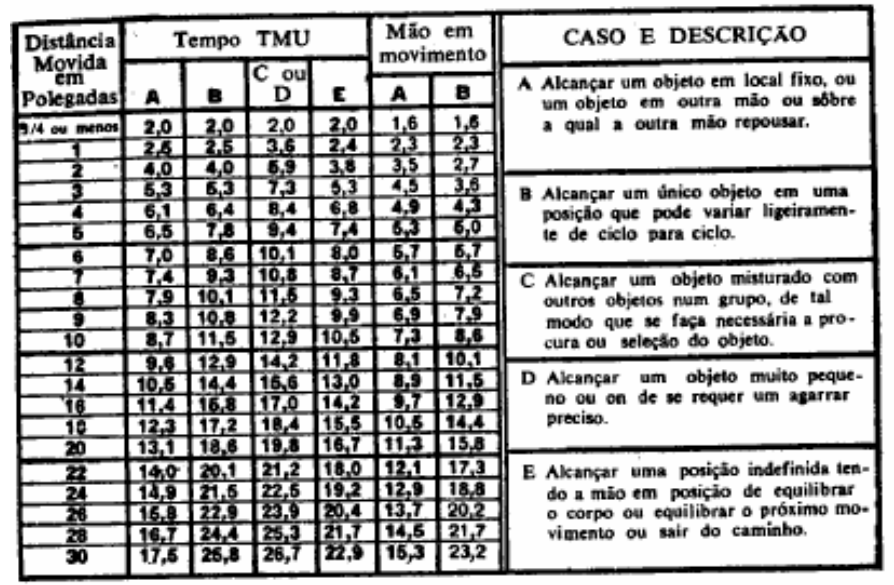

TABELA 26 - DADOS DO TEMPO DE "MOVER" (FONTE: MAYNARD, 1970).

\begin{tabular}{|c|c|c|c|c|c|c|c|c|}
\hline \multirow[b]{2}{*}{$\begin{array}{c}\text { Distâncial } \\
\text { Movida } \\
\text { em } \\
\text { Polegadas }\end{array}$} & \multicolumn{4}{|c|}{ Tempo TMU } & \multicolumn{3}{|c|}{ Péso permitido } & \multirow{2}{*}{$\begin{array}{c}\text { CASO E } \\
\text { DESCRICÁO }\end{array}$} \\
\hline & A & B & c & $\begin{array}{l}\text { Mho } \\
\text { én } \\
\text { Mori- } \\
\text { memie } \\
\text { B }\end{array}$ & \begin{tabular}{|c|} 
Péso \\
libras \\
acima \\
de
\end{tabular} & Fator & $\begin{array}{l}\text { Cons- } \\
\text { tante } \\
\text { TMU }\end{array}$ & \\
\hline 3/4 so menoch & 20 & 2.0 & 2.0 & 1,7 & 2,5 & 1,00 & 0 & \\
\hline & 2.5 & $\frac{15}{25}$ & $\frac{3.4}{5,2}$ & $\frac{2,3}{39}$ & & & & A Mover objeto para ou- \\
\hline 3 & 4,9 & & 6 & $\frac{5,3}{3,6}$ & $7, \mathbf{6}$ & 1,0 & $\mathbf{2 , 2}$ & tra mão ou contra ante- \\
\hline$\frac{4}{5}$ & 6 & 6,5 & 80 & 4,3 & & & & \\
\hline$\frac{6}{6}$ & 7,3 & 8,0 & 0 & 6,0 & 12,6 & 1,11 & 3,0 & \\
\hline & E.1 & 8,9 & 10,3 & $\frac{5,7}{18}$ & 17,6 & 1.17 & 5.6 & \\
\hline & $\frac{6}{9.7}$ & 50.6 & $\frac{112}{119}$ & $\frac{9.8}{7.2}$ & & & & \\
\hline$\frac{6}{10}$ & 10.5 & T11.5 & 12,7 & 7,8 & 22,6 & 1,22 & 7,4 & \\
\hline$\frac{10}{12}$ & 11,3 & 12,2 & 13,5 & 8,6 & & & & $\begin{array}{l}\text { Mover ob j t to para lo: } \\
\text { calizacáo aproximada ou }\end{array}$ \\
\hline$\frac{12}{14}$ & $\frac{12.9}{12 .}$ & 13,4 & 15,2 & 10,0 & 27,6 & 1,20 & 0,1 & indefinida \\
\hline 18 & $\frac{10}{18.0}$ & 15,8 & 18,7 & 128 & & & & \\
\hline 18 & 17.8 & 17,0 & 20.4 & 16,2 & $\mathbf{3 2 , 6}$ & 1,33 & 10,8 & \\
\hline 20 & 19,2 & 18.2 & 22,1 & 15,5 & & & & \\
\hline 22 & 20,8 & 19,4 & 23,8 & 170 & 37,6 & 1,39 & 12,6 & \\
\hline 24 & 22,4 & & & 16,4 & 48 & 14 & 143 & C Mover objeto pars lo- \\
\hline$\frac{28}{28}$ & $\frac{24,0}{x, 8}$ & 21,8 & 27,3 & $\frac{19,8}{212}$ & & & & \\
\hline$\frac{50}{30}$ & $\frac{25,5}{27,1}$ & $\frac{23,1}{24,3}$ & $\frac{29,0}{30,7}$ & 22,7 & 47,5 & $1, \infty 0$ & 16,0 & \\
\hline
\end{tabular}

TABELA 27 - DADOS DO TEMPO DE "GIRAR E APLICAR PRESSÃO” (FONTE: MAYNARD, 1970).

\begin{tabular}{|c|c|c|c|c|c|c|c|c|c|c|c|}
\hline \multirow{2}{*}{ Pèso } & \multicolumn{11}{|c|}{ Tempo TMU para Ãngulos em graus } \\
\hline & $30^{\circ}$ & $45^{\circ}$ & $60^{\circ}$ & $75^{\circ}$ & $90^{\circ}$ & $105^{\circ}$ & 1200 & $135^{\circ}$ & 1900 & $165^{\circ}$ & 71800 \\
\hline Pequeno - 0 a 2 libras & 2,8 & 3,5 & 4,1 & 4,8 & 5,4 & 6,1 & 6,8 & 7,4 & 8,1 & $\mathbf{e , 7}$ & 9,4 \\
\hline Medio $-2,1$ a 10 libras & 4,4 & 5,5 & 6,5 & 7,5 & 8,5 & 9,6 & 10,6 & 11,6 & 12,7 & 13,7 & 14,8 \\
\hline Grande $-10,1$ a 35 libras & 8.4 & 10,5 & 12,3 & 14,4 & 16,2 & 18,3 & 20,4 & 22,2 & 24,3 & 26,1 & 128,2 \\
\hline APLICAR PRESSAO CASO & & & & & APLIC & & RESSiAC & 10 CAS & so $2: 10$, & $0,6 \mathrm{TM}$ & \\
\hline
\end{tabular}


TABELA 28 - DADOS DO TEMPO DE "AGARRAR” (FONTE: MAYNARD, 1970).

\begin{tabular}{|c|c|c|}
\hline Caso & $\begin{array}{c}\text { Tempo } \\
\text { TMU }\end{array}$ & DESCRICXOO \\
\hline IA & 2,0 & 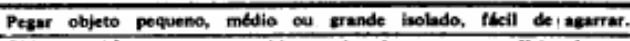 \\
\hline 18 & 3,5 & Objeto muitó pequeno ou objeto colocado sums superficieiplanan. \\
\hline ICI & 7,3 & $\begin{array}{l}\text { Agarrar com interferéncia no fundo e num lado de um obleto } \\
\text { Aproximadamente cilindrico. Dilmetro malior que } 1 / 2^{\prime \prime} \text {. }\end{array}$ \\
\hline 1C2 & 8,7 & 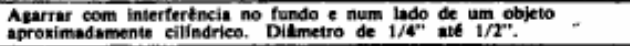 \\
\hline IG & 10,8 & 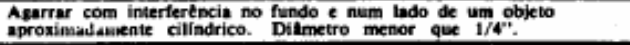 \\
\hline$\overline{2}$ & $\overline{6,5}$ & Reagarrat \\
\hline$\overline{3}$ & 6,5 & Transterit o Agarrar \\
\hline 44 & 7,3 & 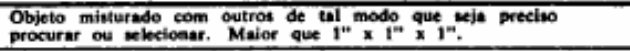 \\
\hline 48 & 9,1 & 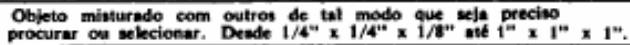 \\
\hline 4C & 12,9 & 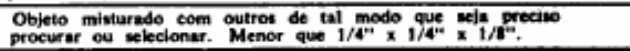 \\
\hline $\bar{E}$ & $\overline{0}$ & Afarriar por Contalo, Enganchamento e Excorregamento. \\
\hline
\end{tabular}

TABELA 29 - DADOS DO TEMPO DE "POSICIONAR" (FONTE: MAYNARD, 1970).

\begin{tabular}{|c|c|c|c|c|}
\hline \multicolumn{2}{|c|}{ CLASSE DE AJUSTE } & Simetria & $\begin{array}{l}\text { Fácil de } \\
\text { manejar }\end{array}$ & $\begin{array}{c}\text { Dificil de } \\
\text { manejar }\end{array}$ \\
\hline \multirow{3}{*}{ 1 - Folendo } & \multirow{3}{*}{ Nlo t necesuldio presulio } & $\mathbf{s}$ & 5,6 & 11,2 \\
\hline & & $8 s$ & 2,1 & 14,7 \\
\hline & & NS & 10,4 & 16,0 \\
\hline \multirow{3}{*}{2 -Apertesd } & \multirow{3}{*}{ - necestairio poves meato } & $\mathbf{3}$ & 16,2 & 21,8 \\
\hline & & $\mathbf{8 8}$ & 19,7 & 25,3 \\
\hline & & NS & 21,0 & 28,6 \\
\hline \multirow{3}{*}{3 - Exato } & \multirow{3}{*}{ 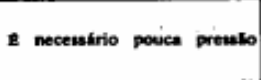 } & 8 & 430 & 48,6 \\
\hline & & SS & 46,5 & $\$ 2,1$ \\
\hline & & NS & 47,8 & $\mathbf{3 3 , 4}$ \\
\hline
\end{tabular}

-Distincia percorrida para aiustar $-\mathrm{I}^{\text {+* }}$ ou menos

TABELA 30 - DADOS PARA O CÁLCULO DO TEMPO DE "SOLTAR” (FONTE: MAYNARD, 1970).

\begin{tabular}{|c|c|c|}
\hline Caso & $\begin{array}{c}\text { Tempo } \\
\text { TMU }\end{array}$ & \multicolumn{1}{|c|}{ DESCRIÇXO } \\
\hline 1 & 2.0 & $\begin{array}{l}\text { Soltur normalmente, } \\
\text { abrindo or dedos como } \\
\text { movimento independen- } \\
\text { ies. }\end{array}$ \\
\hline 2 & 0 & Soltar o contati \\
\hline
\end{tabular}

TABELA 31 - DADOS PARA O CÁLCULO DO TEMPO DE "DESENGATAR" (FONTE: MAYNARD, 1970).

\begin{tabular}{|c|c|c|}
\hline CLASSE DE ANUSTE & $\begin{array}{c}\text { Fidil } \\
\text { de } \\
\text { mantejes }\end{array}$ & $\begin{array}{c}\text { Difieil } \\
\text { de } \\
\text { manejar }\end{array}$ \\
\hline 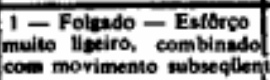 & 40 & 8,7 \\
\hline $\begin{array}{l}2 \\
\text { Iorso normal, pequeno }\end{array}$ & 7,5 & 11,8 \\
\hline $\begin{array}{l}3 \text { - Firme - Estidrso } \\
\text { convidertvei, notidamente } \\
\text { recuor de mlo. }\end{array}$ & 22,9 & 34,7 \\
\hline
\end{tabular}

TABELA 32 - TEMPO PARA MOVER E FOCALIZAR OS OLHOS (FONTE: MAYNARD, 1970).

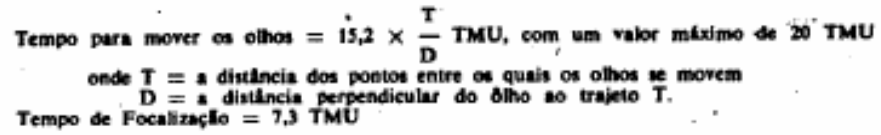

